\title{
ARCHITECTURE WITHOUT EXPECTATION: DESIGNING A THIRD PLACE FOR MENTAL WELLBEING IN THE COMMUNITY
}

BY

\author{
KEZIA FAIRBROTHER
}

A thesis submitted to the Victoria University of Wellington

in fulfilment of the requirements for the degree of

Master of Architecture (Professional)

Victoria University of Wellington

(2020) 



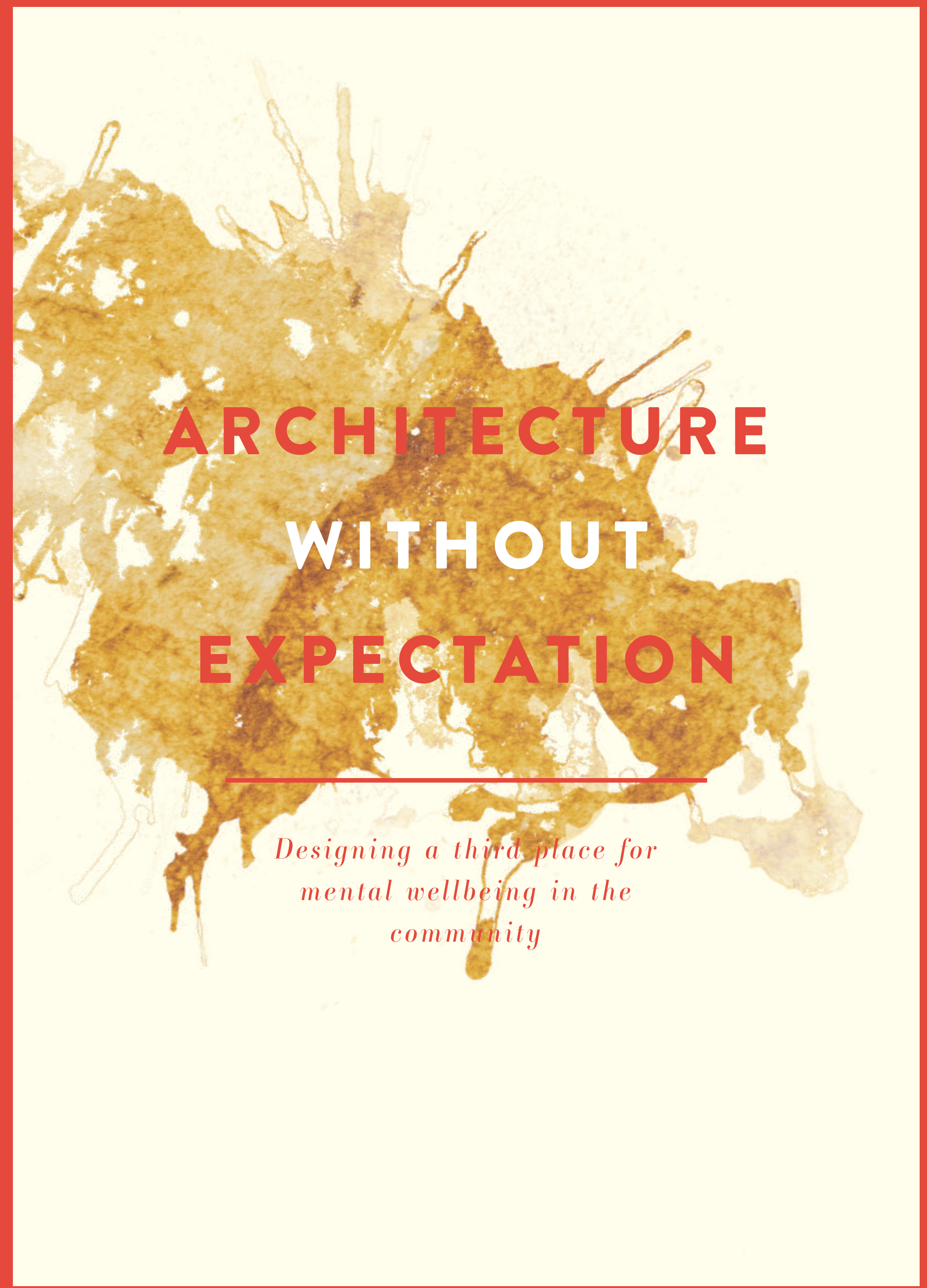


This thesis is dedicated to

$$
\text { Polly }
$$

$1971-2018$

A sister who encouraged me

to see the world differently 


\section{ACKNOWLEDGEMENTS}

It takes a village to raise a thesis. I would like to acknowledge the contributions of the following people and organisations to the completion of this one in particular:

My supervisors: Rosie Scott, for her ideas and enthusiasm in the beginning; Emina Petrovic and Nan O'Sullivan for their compassionate support and guidance through the end.

David Comiskey, and Pathways, for the amazing work they do every day, and for talking to me and letting me tour their facility.

My friends and classmates in the 2019 MArch cohort, especially the ones to had to share a desk with me.

My family, friends and boyfriend for their unwavering nutritional, emotional and mental support - special shoutout to my sister Gretel for the daily meals delivered to campus in the last month. Not all heroes wear capes.

The academic, cleaning, admin and technical staff of Te Aro Campus who have helped to create a safe and positive learning environment.

Lastly, thanks to the scientists and researchers who developed citalopram. I couldn't have done it without you. 


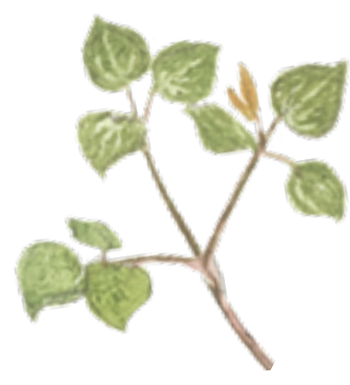

CONTENTS

ABSTRACT

INTRODUCTION

1. HISTORY

Architecture and mental care in Wellington, NZ

\section{THEORETICAL CONTEXT}

Contributing theories and positioning

\subsection{DEFINING WELLBEING}

2.1.1 Māori Mental Health

2.1.2 Māori and Pasifika Models of Wellness

2.1.3 Building Connections

2.2 KEY THEORETICAL FRAMEWORKS

2.2.1 Therapeutic Landscapes

2.2.2 Evidence-Based Design

2.2.3 Non-Representational Therapeutic Landscapes

2.2.4 Third Places

2.2.5 Shopping Centres As Emergent Third Places

3 KEY PRECEDENTS

A reference index

3.1 Madlove: A Designer Asylum

3.2 Maggie's Centre, Edinburgh

3.3 Our Future Foyle

52

3.4 Residential Care Facility 
Taita Shopping Centre
4.1 Site Selection
4.2 Site overview
4.3 Site Analysis
62
4.4 Experience of Site
64
4.5 Reflection + Opportunities

5 REFLEXIVE DESIGN EXERCISES

Explorations in therapeutic materials and processes

\section{REFLEXIVE DESIGN RESEARCH}

5.1 Ochre

5.2 Harakeke - Muka

5.3 Yellow Clay

5.4 Combining Materials/ Methods

5.6 Clay - Ochre - Timber

5.7 Water Tower / Ochre - Muka - Water (Gravity)

5.8 Ochre - Drawing

5.9 Materials As Process; Materials As Therapy?

6 SPATIAL DRAWINGS

From materials to atmosphere
6.1 Therapeutic atmospheres
110
6.2 Moments
6.3 Reflection

7 SITED DESIGN

Designing for mental wellbeing in suburban public space

7.1 Approach To Site

7.2 Sited spatial drawings

7.3 Reflection 
8 THERAPEUTIC JOURNEY

Designing for a range of therapeutic space preferences

8.1 WAYS TO JOURNEY 133

8.1.1 Accessiblity 136

8.1.2 Ramp Development 137

8.2 DESIGN PROPOSAL 147

ADDENDUM 151

Examination Renders and Images

9 CONCLUSION 161

Towards new ways of thinking about mental health and architecture

$\begin{array}{ll}\text { SUMMARY } & 162\end{array}$

DISCUSSION 163

$\begin{array}{ll}\text { IMAGE LIST } & 168\end{array}$

REFERENCES 170 



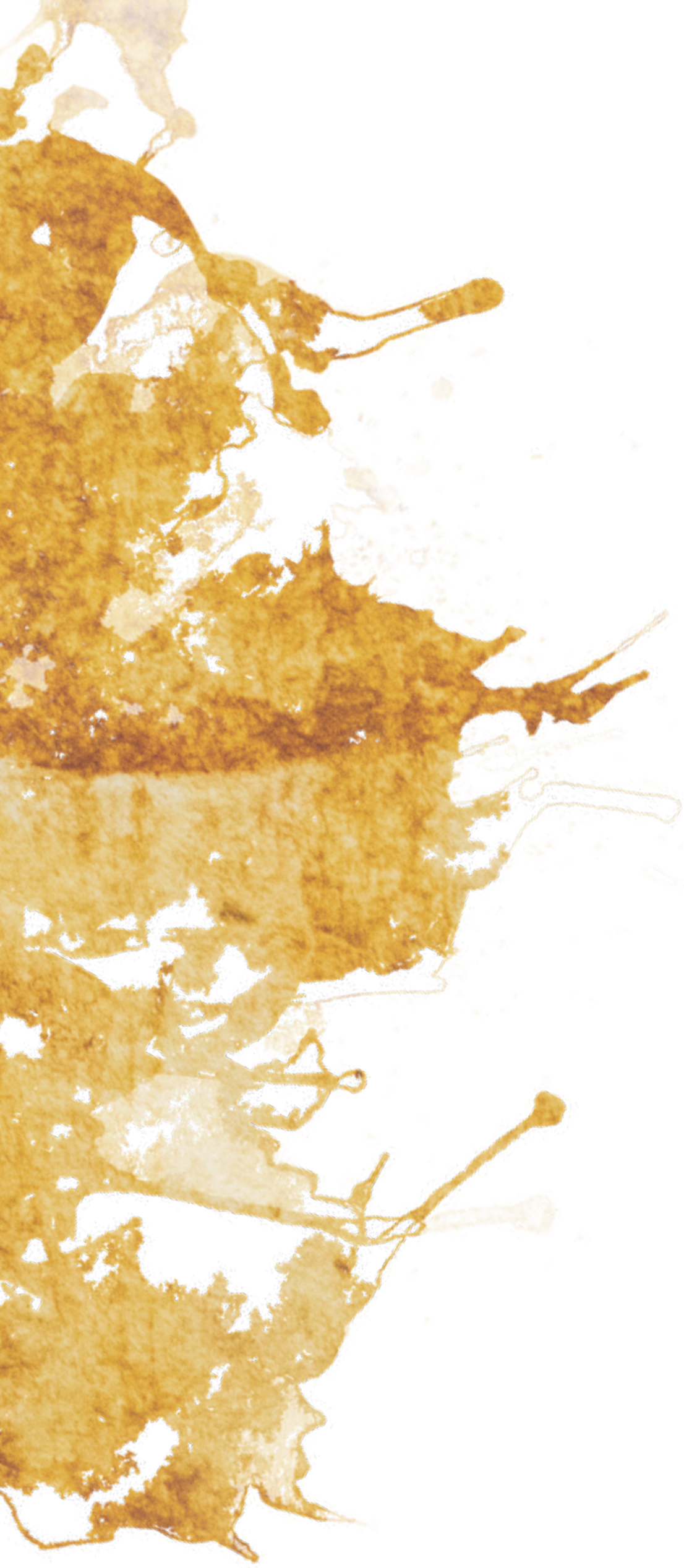




\section{ABSTRACT}

In 2018, the government published the report of its inquiry into mental health and addiction in Aotearoa New Zealand, which called for a 'paradigm shift' in the country's approach to mental wellbeing. This research portfolio explores the role architecture has to play in this shift, acknowledging the problematic historical associations of architecture and mental health. In doing so, the work aims to establish principles for a new architectural typology of mental health care, outside of conventional institutions. It explores contemporary approaches to wellness, and integrates research from several bodies of theoretical and evidence-based research into a new creative practice within architecture. Specifically, the research draws on theory around nonrepresentational therapeutic landscapes, third place and evidence based design. These inform creative explorations of the therapeutically affective qualities of naturally-sourced materials. The findings of this explorations are transferred to spatial design using a 'multiplicity' approach based on nonrepresentational theory and Māori health models, which is then applied to a specific site in Wellington, New Zealand. Finally, architectural applications for this research are proposed in the form of a community-based third place to support mental health and wellbeing. 


\section{INTRODUCTION}

In the period from June 2017 to July 2018, more people died from suicide in New Zealand than in any other year since the Ministry of Justice began keeping records ten years earlier (Chief Coroner Releases Provisional Annual Suicide Figures, 2018). In December of 2018, the government released He Ara Oranga: Report of the Government Inquiry into Mental Health and Addiction (New Zealand Government, 2018), the findings of a year-long inquiry into the mental health system. In that report, the panel noted an overwhelming consensus from respondents and submissions of a much-needed "paradigm shift" (p.7) in the country's overall approach to mental health.

This research portfolio responds primarily to one of the main themes outlined in the call for change detailed in He Ara Oranga, a need for:

\footnotetext{
"wellbeing and community solutions - for help through the storms of life, to be seen as a whole person, not a diagnosis, and to be encouraged and supported to heal and restore one's sense of self." (New Zealand Government, 2018, p. 8)
}

This view is echoed by mental health researchers, who have over the last decade argued for a more holistic, community and culturally focused approach to wellbeing (Durie, 2011; Foliaki et al., 2001; Williams et al., 2017).

Historically, political and cultural changes in approaches to mental health have been accompanied by a corresponding architectural typology; such as asylums, mental hospitals and psychiatric clinics. New Zealand has a specific history regarding this in which, like many colonial societies, these architectural typologies were formed on the basis that mental illness, and the people afflicted by it, were considered primarily as a problem to be contained, rather than as fully-formed people with autonomy and agency. This has produced a cultural stigma against mental health architecture which has seen institutions minimised and buildings and spaces for care and treatment which are designed to be largely invisible to the general public. While this is an intentional approach to mitigating that stigma, it has meant that most access points to mental health services are found only in crisis; through emergency rooms, hotlines, GPs offices, or even the justice system. If architecture is to respond to the need for a 'paradigm shift,' new typologies and design strategies will need to be considered, in order to avoid invoking the stigma of the past while supporting visible wellbeing and community solutions. 

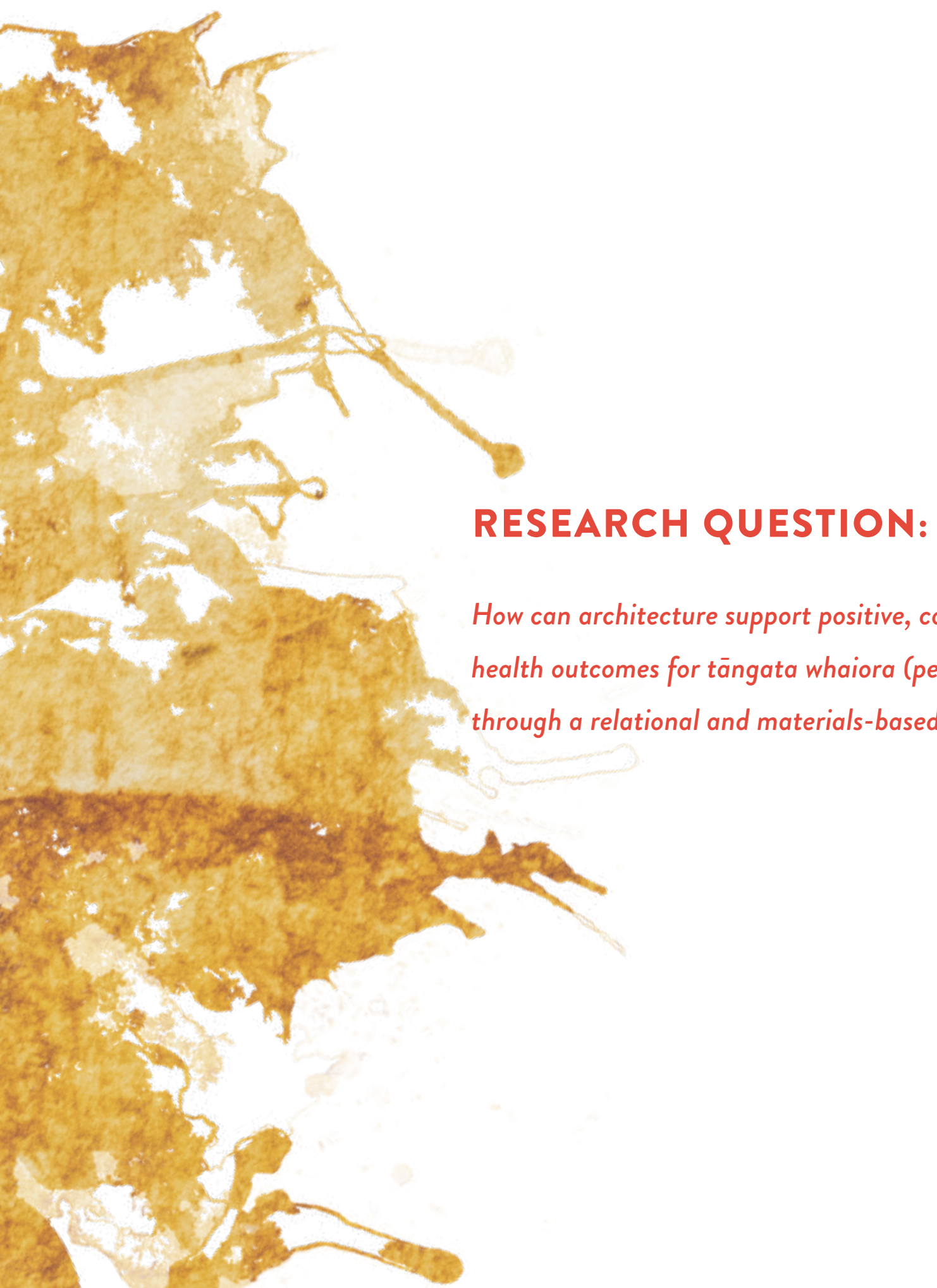

How can architecture support positive, community-based mental health outcomes for tāngata whaiora (people seeking wellness) through a relational and materials-based design strategy? 


\section{AIMS AND OBJECTIVES}

\section{Aims:}

1. To establish principles for a new "third place" typology of community-based mental health architecture

2. To transfer research from several bodies of theoretical and evidence-based research into creative practice

3. To explore the therapeutic possibilities of natural materials as more than tectonic objects in architecture

\section{Objectives:}

1. To use the history of mental health and architecture in Wellington, New Zealand as a basis for understanding how architecture has contributed to stigmatising mental health

2. To draw relevant principles and concepts from research into wellbeing, culture and place, and transfer this into creative practice

3. To experiment with natural materials in a reflexive and open way, allowing for new discoveries and ways of engaging with these materials architecturally.

4. To develop a design approach for building relational therapeutic third places in the community 


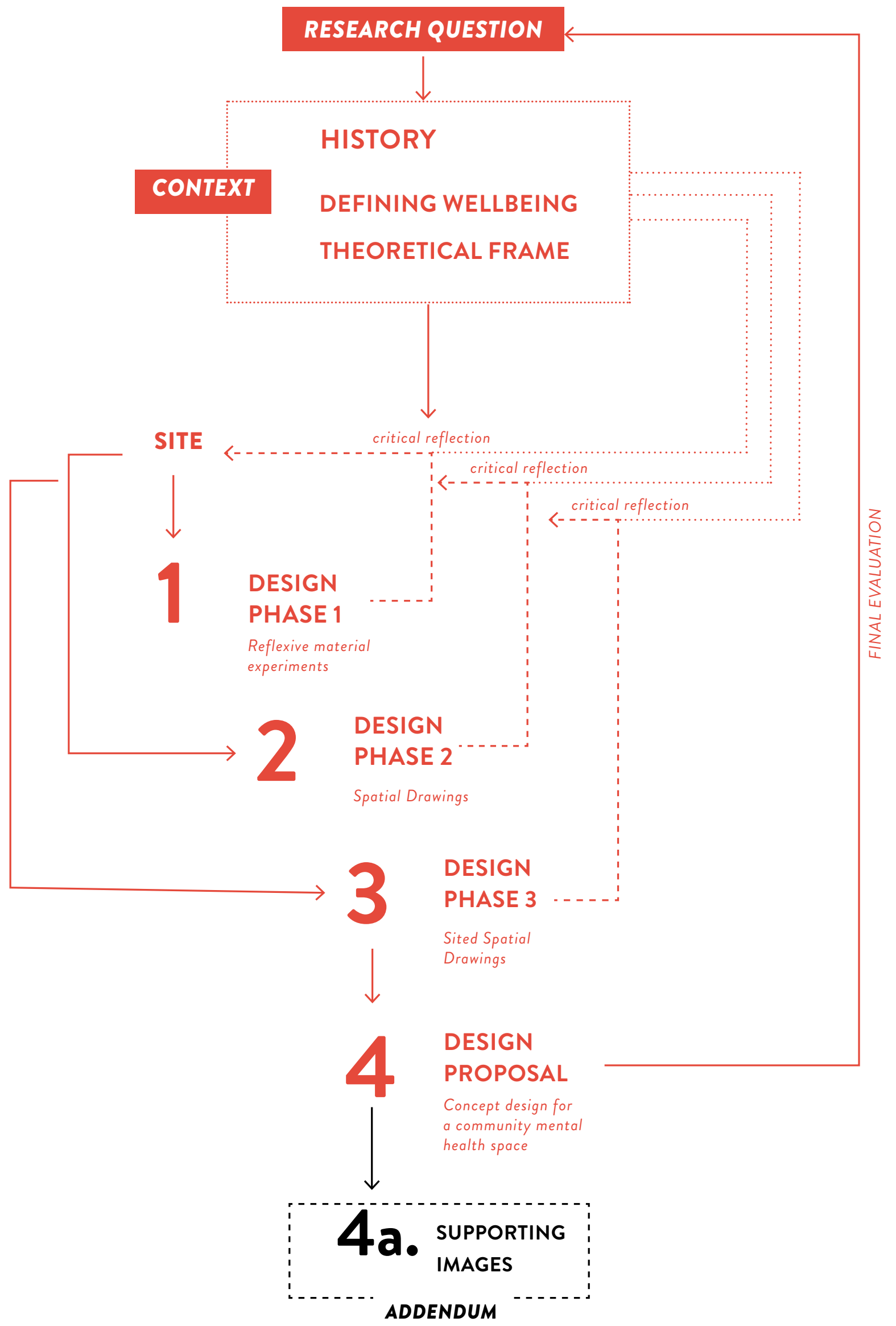




\section{ROLE OF DESIGN:}

While context and history in the topic of mental health architecture is hugely important for understanding the political and social implications of the subject, exploring new design approaches is necessary to help avoid the traps of the past, and align architecture and design in general with current thinking on wellbeing. Most of the current research into mental health and architecture is still based around improving institutional spaces. In order to move further away from this, we need to test ways of designing, using materials and approaching the design process in a more relational and experiential way. 
A locked door prevents me from waltzing

into dinner, so I crave it all the more

Another lock and key traps the garden

outside, I stare more longingly

A card swiped on the wall leads me

to the big out there, I flinch

for where I live is within an impediment

a series of enclosures not meant to be

in the sense, secure, as a cocoon,

but as a cage for an animal,

for the wild and untamed, to be

led by the function of these

enclosures to feel the loss of freedom anew

over and over, as our daily rituals

of capture and release, one day soon,

becomes stunned by the immediate, endless world

-Poem by Gillian Taylor, printed in (Coleborne, 2012)

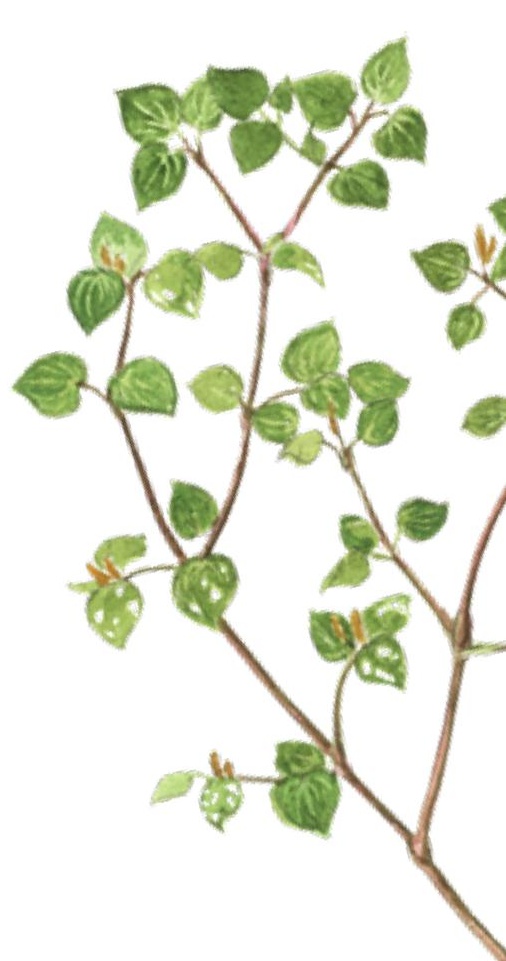




\section{HISTORY}

Architecture and mental care in Wellington, NZ

1.1 Introduction

1.2 The Terrace Gaol

1.3 Karori Asylum

1.4 Mount View Asylum

1.5 Porirua Lunatic Asylum / Porirua Mental Hospital

1.6 Deinstitutionalisation and

Community Care

1.7 Conclusion 


\subsection{INTRODUCTION}

Architecture and mental health have a uniquely intertwined history. At various points throughout history, architecture has been a container (Adlam et al., 2013) and a curative agent for the mentally unwell (Chrysikou, 214), and even today, the impact of architecture and the environment is acknowledged to play at least a supporting role in positive mental health outcomes (Gesler, 1992). The conceptual needle behind mental health architecture in Western society has always swung between the carceral and the therapeutic, and the legacy of this is still apparent today, even in a deinstitutionalised setting. This section will take a brief look at the history of mental health and architecture in Pōneke Wellington, from the country's first dedicated space for the mentally unwell, on the side of the Terrace Gaol, to the long-running asylum at Kenepuru in Porirua, in order to generally establish how treatment models, philosophies of care and contemporary biases were expressed through the design and function of these spaces. Finally, it will turn to the contemporary period, in order to better understand the kinds of architecture that exist in a deinstitutionalised world.

Colonisation bought the Western (primarily English) conception of mental health to Aotearoa via the Lunatics Ordinance of 1846. With no dedicated places for the mentally unwell, and with no goal toward treatment or recovery, the primary function of this ordinance was the containment of the mentally unwell for public safety (O'Brien \& Kydd, 2013). While this first piece of legislation primarily governed the confinement of lunatics considered dangerous, a more comprehensive second piece of legislation followed in 1882, the Lunatics Act, which defined lunatics as "any insane person, idiot, lunatic, or person of unsound mind, incapable of managing himself or his affairs" (Lunatics Act 1882). This Act set out the approach of the colonial government toward the mentally ill, drawing on the latest English approach to care (Brunton, 2005).

At that time in Europe, the theory of 'moral treatment' was in full swing, setting the basis for modern psychology and psychiatry. Promoted separately by reformers William Tuke and Phillipe Pinel, the aim was to liberate the insane from incarceration in prisons and 'madhouses' by establishing a separate, therapeutic space - the asylum (Chrysikou, 2014, p. 12). Moral management was a system of care that encouraged moving away from patient restraint, utilising instead a combination of environmental factors, routines and activities to alter patient behaviour. The aim was not intended to "cure" so-called lunatics, but to manage their symptoms in a more humane ("moral") way. Under this system, the environment itself was seen as being a feature of treatment, with Tuke describing gardens and fields as "therapeutic tools" (Tuke, 1813, in Markus, 1993). Architecturally, the plan was also considered as a part of treatment, with a 
segregated geometric layout, the provision of day rooms, access to fresh air and the outdoors, adequate ventilation and sufficient heating being requirements of ideal moral care (McLaughlan, 2014).

\subsection{THE TERRACE GAOL}

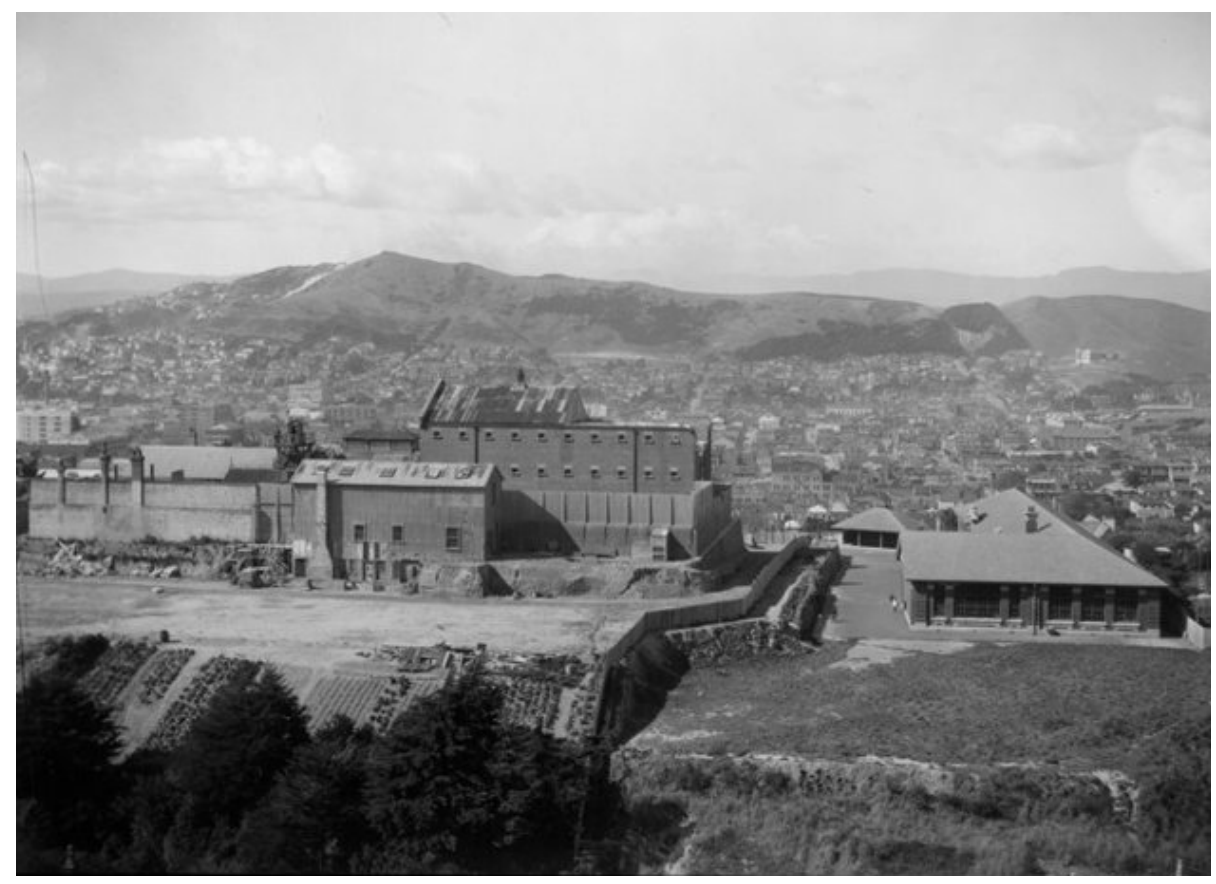

Fig 1.1 The Terrace Gaol, 1927

(Crown Studios Ltd: Negatives and prints, 1927)

In mid-19th century New Zealand, where colonial infrastructure was just beginning to take shape, people who were experiencing mental distress were either confined at home, general hospital, or, if particularly disruptive, in a gaol. One of the first specifically-denoted spaces for those experiencing mental distress in the country was a wooden building attached to the side of the Terrace Gaol (1844) on what is now the site of Te Aro School in Wellington (Brunton, n.d.). There is little information available regarding the specific circumstances of care under which lunatics were imprisoned at the gaol, but a royal commission of enquiry into conditions at the gaol in 1902 noted that there was a lack of separation between prisoners and lunatics, and a general overcrowding of cells (Methven, 2011, p. 84). In 1908, an otherwise glowing review of the prison's new bathing facilities was accompanied by the following description of the grounds:

"The walls, lofty as two-storey buildings, are of strong corrugated iron, surmounted with huge 
spikes, long enough for bayonets. The sunshine, save when it is overhead, is excluded. Flowers are forbidden; not a blade of grass is allowed to grow. Everything save the atmosphere seems petrified, rigid, hard, unimpressionable, like the scowls on some of the faces." ("The Terrace Gaol.," 1908)

The gaol was, in other words, in no way a therapeutic environment, nor does it seem to have discriminated between general prisoners and those imprisoned on grounds of insanity. The lack of a designated facility for people classed as "chronically" insane was a cause of frequent criticism, based on these conditions and the prevailing movement toward more humane care internationally (“INEBRIATE ASYLUMS," 1899) (“UNFIT CASE FOR THE GAOL.," 1913). Asylums were first established in New Zealand between 1854 and 1876 under a provincial governance system, before the administration of these institutions became the purview of a central government (Brunton, 2003).

\subsection{KARORI ASYLUM}

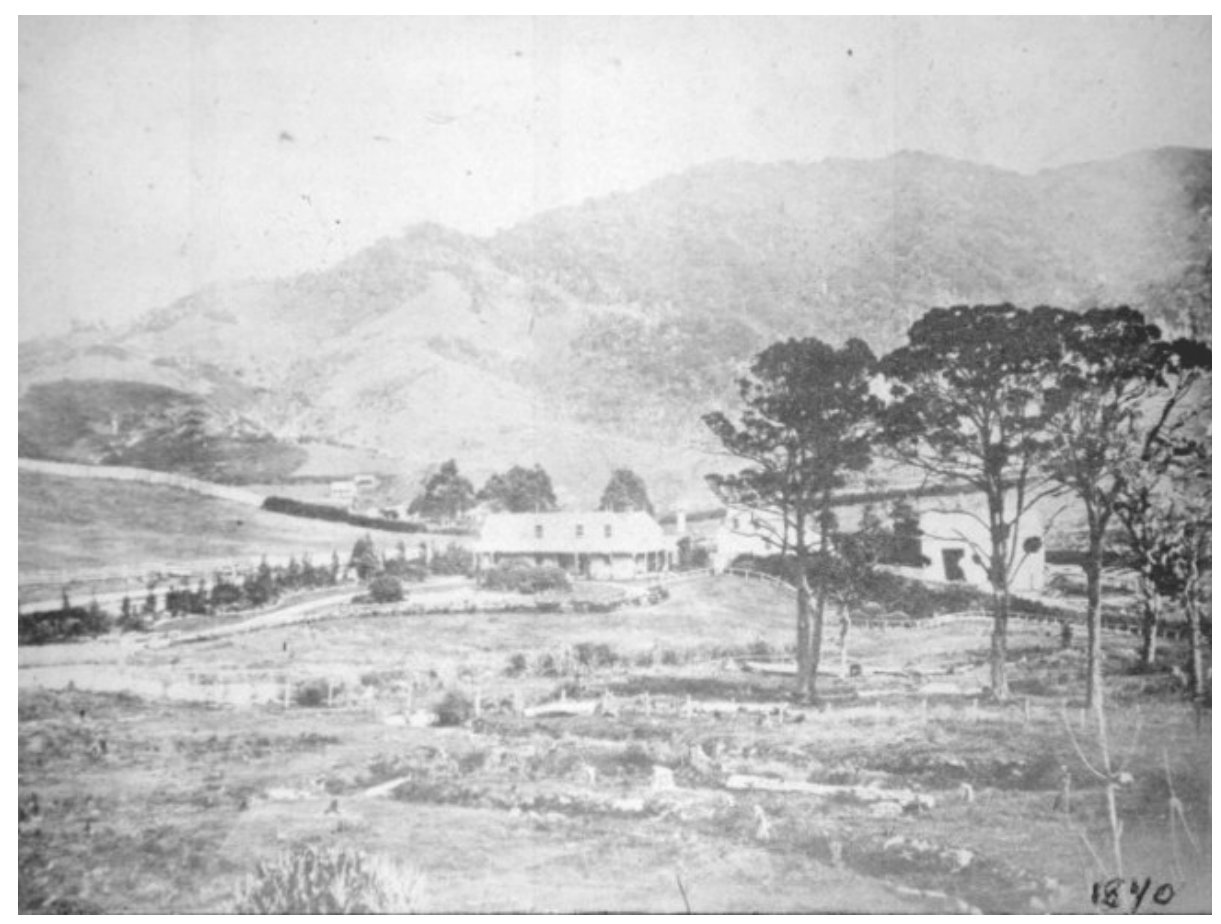

Fig 1.2 Karori c. 1870

(Karori Historical Society: Photographs, 1870)

Pōneke/Wellington established the country's first asylum, the Karori Lunatic Asylum, soon after the implementation of the Lunatics Ordinance in 1846. In 1862, the following description of Karori Asylum was recorded by the newlyinstated medical officer, Dr. France:

\footnotetext{
"The buildings are of wood, being weatherboards externally and matchlined within. They
} 


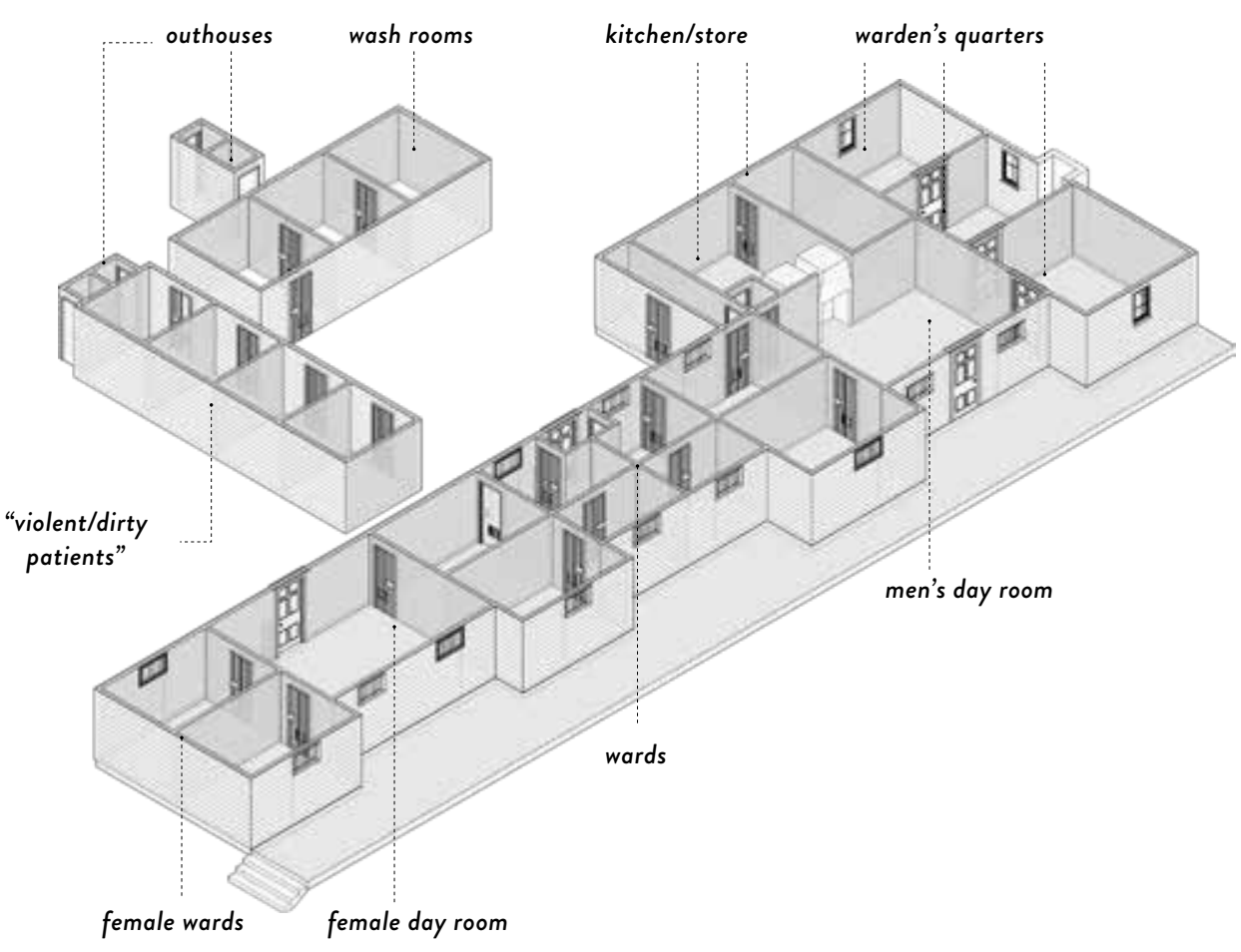

consist of one long building containing 8 sleeping rooms and one sitting-room common to both sexes, with a kitchen, and also two rooms and a kitchen for the resident officers. There is also a detached storehouse and wash-house." (The Karori Lunatic Asylum, 1862)

This 1862 assessment provided a relatively positive view of the state of the asylum, which then housed 10 "inmates," most of whom were classed as nonviolent. The asylum was the first step away from the imprisonment of the insane in gaols in the country, and though significantly under-resourced and badly managed, it reflected many of the principles of moral management at the time. The plan of the building (recreated above) loosely reflects some of the principles of planning espoused by moral theorists and architects in Europe, with segregated areas for men and women, day rooms for each, ventilation through openings in the ceiling, and an attached residence for the keeper and matron (emphasising the promotion of family which was seen as beneficial). Patients were kept occupied - male patients in the garden and female patients with needlework or other less rigorous activities. Routines were strictly adhered to, and provision for care was expected to be given by the keeper and matron (The Karori Lunatic Asylum, 1862). As in Europe, the asylum was located in the sparsely occupied countryside, far from the stressors of urban life, with access to picturesque views. This isolation may also have arisen from the stigma associated with lunacy; in 1896, much objection was raised at the prospect of converting the Terrace Gaol into an asylum, with one letter writer to the Evening Post ("An Active Voter") expressing a preference for a female prison, or boys' reformatory
Fig 1.3 Karori Lunatic Asylum Author's depiction based on floor plan in (Williams, 1987) 
over the proposed plan - "but a lunatic asylum! Ugh! it makes me creep [sic]." ("Citizens of Wellington, Awake! Awake! To the Editor.," 1896) The isolation of the asylum probably contributed to the neglect of its facilities and a lack of management oversight which came to light in later years.

The Karori Asylum was a far cry from Tuke's York Retreat. In 1873, a letter from J. Woodward, the Commissioner of Crown Lands and the General Government, to the Superintendent, reported the buildings to be in terrible condition, with a kitchen so small that "the plates containing the patient's food can only be set on the floor" and a general deterioration of the structure so that a "more unsuitable or uncomfortable place, can scarcely be imagined" (Correspondence from The Karori Lunatic Asylum, 1862). At that time, the asylum's inmate population had nearly doubled, and concerns had been raised about their treatment on a number of fronts. None of the keepers, matrons or other attending staff ever held any direct experience with asylums. Mr Seager, appointed to the position of keeper in 1872, was noted to be the brother of a man who was head of a Christchurch asylum, and this was deemed to be experience enough (Williams, 1987, p.

15). Overcrowding meant that the keeper and matron were often tasked with supervising the daily routines of around 20 patients with limited assistance, and accusations of cruelty began to surface. Faced with such material degradation, concerns over management and growing overcrowding, the asylum was closed and its inmates moved to the new Mount View asylum in 1873 (Burch \& Hughes, 1998). While the Karori Asylum was obviously not fit for purpose, even by the standards of the day, it remains an important touchstone in the progression of colonial mental health care, an example of the provincial asylums which were little more than custodial arrangements for those without resources or family.

\subsection{MOUNT VIEW ASYLUM}

The much larger Mount View Asylum opened in 1873, and was overseen by the same matron, keeper and medical officer as at Karori Asylum. Designed by architect Christian Julias Toxward, the new asylum was much larger and its floor plan reflects and attention to international asylum norms. Toxward was born in Copenhagen and studied at the Kunstakademiet (Academy of Fine Arts). He was responsible for many of Wellington's early public buildings, mostly designed in timber. Mount View's structure was similarly based in timber, with exterior weatherboards, though the cells were lined with concrete. It was a large, two storey structure on what is now the site of Government House in Newtown. In 1880 it was enlarged by the addition of two extra wings. The symmetrical layout was intended to support the policy of moral treatment more effectively than at Karori. The entire plan was neatly symmetrical, with each half of the building 
divided by gender around a distinctive entrance and large gallery space. Each gendered section had a yard, day rooms, and separate wards for patients of different classes: the "moderately tranquil," the "aged and infirm," the "dirty and violent." This orderly layout more closely aligned the Wellington Asylum with European asylums of the era; it was thought that the disordered minds of the patients could be influenced by the order and stability of classical architecture.

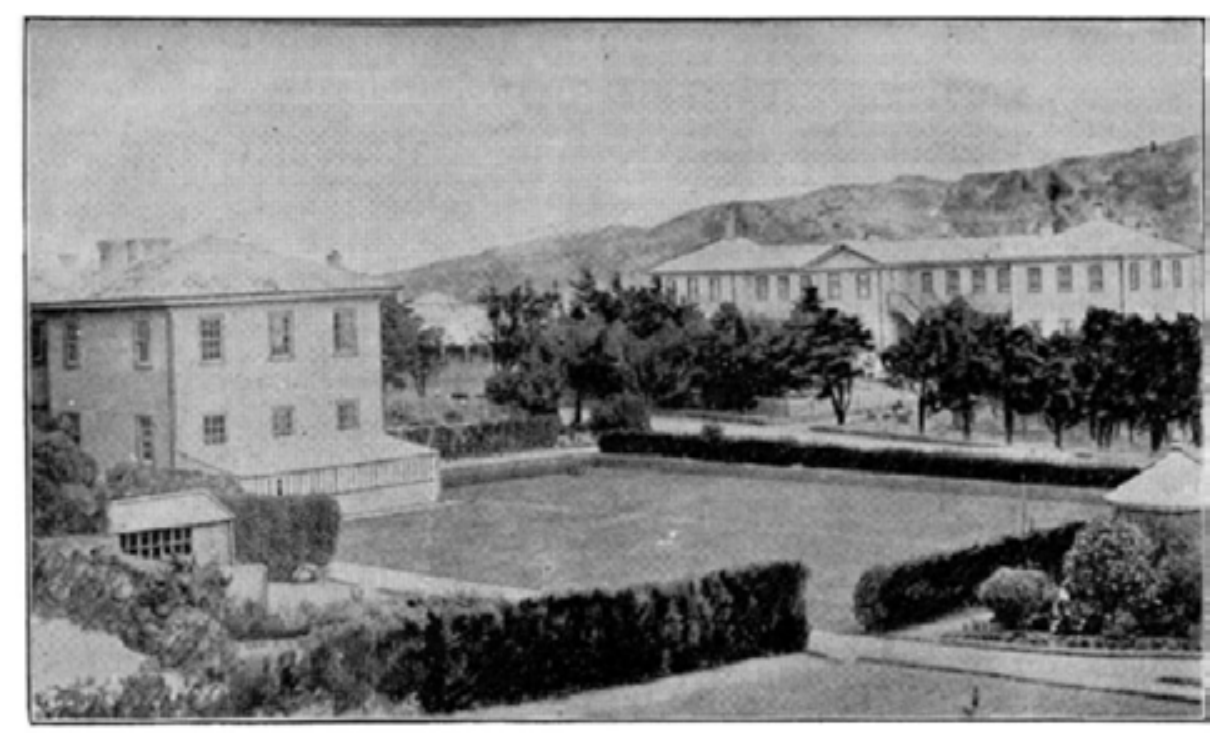

TuE Asrues,

Despite the in investment in the new facilities at Mount View, it was apparent from the year of its opening that the asylum had its faults - many similar in nature to the problems faced at Karori, but there were also several issues with the very architecture which was intended to provide a curative environment. A visit by the Governor and Superintendent was made in 1873, and both raised concerns about the new asylum. Along with issues of patient mismanagement, including the overuse of restraint (which was supposed to be prohibited, or least a last resort according to moral theory) and seclusion, the superintendent called the cells "gloomy" and "damp." The governor went further in his criticism, saying that the interior court was "destitute of view or cheerfulness," and that:

"...the construction of many of the sleeping apartments is totally unsuited to the cure of lunatic patients, being in fact prison cells."(Correspondence from The Karori Lunatic Asylum, 1862)

In 1881, a damning enquiry into practices and conditions at the asylum reported many cases of staff abuse of patients and found issues with the architecture which were used as justification of excessive use of restraint, such as the location of a carpenters' shed in the area reserved for "violent females," which brought them into unsupervised contact with male patients, and a lack of secure fencing in the yards, and a lack of heating in some cells - which led to patients being

Figure 1.4 Mount View Asylum, c. 1897

(Cyclopedia Company Limited, 1897) 
restrained in straightjackets when they tore off their clothes("Wellington Lunatic Asylum.," 1881). It also noted a distinct contrast in the treatment and conditions of patients in the front cells versus patients in the secure cells to the back of the asylum:

"From 6 p.m. until 9 a.m. patients are shut up in solitary cells without artificial light or heat, winter and summer alike. It is difficult to imagine a worse fate for any human being than an incarceration in this part of the asylum - overcrowded, surrounded by the most repulsive and degrading spectacle of idiotic and demented men."

The report makes clear a fundamental misalignment with the stated architectural goals of the asylum and the realities of often under-resourced and mismanaged care that was found not only in Mount View, but in many asylums around the world (Markus, 1993). Mount View was officially closed in 1910, and the main space for the care and treatment of the mentally ill in the Wellington region became the Porirua Lunatic Asylum.

\subsection{PORIRUA LUNATIC ASYLUM / PORIRUA MENTAL HOSPITAL}

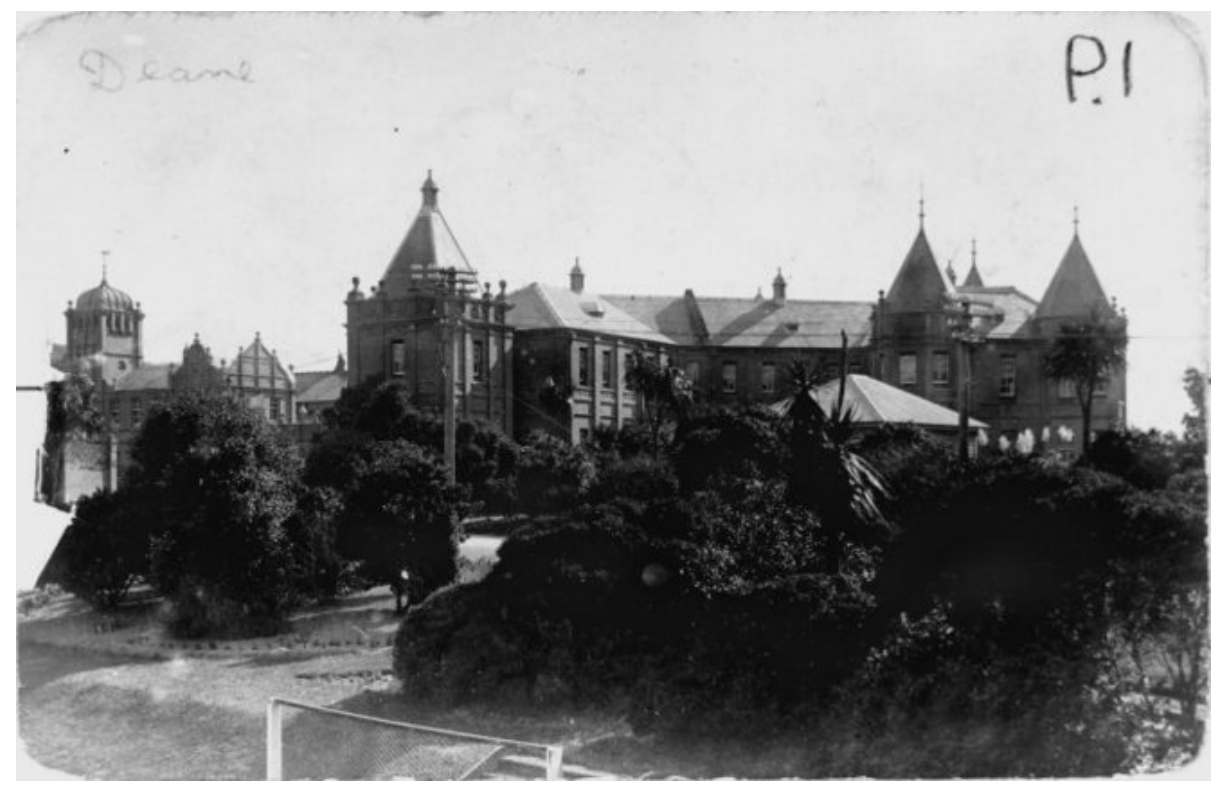

Figure 1.5 Porira Lunatic Asylum c. 1910 (Alexander Turnbull Library, 1910)

Porirua is home to the longest lasting asylum in Wellington's history. It began as a "farm asylum" in 1887, and was expanded over many years in response to overcrowding at Mount View, from the period of 1891 until 1910 (Williams, 1987, p.45). From an original one storey timber building, the asylum at the start of the twentieth century consisted of a large, multi-storey central brick 
building, symmetrically laid out with a female and male wing. The strategy of moral treatment was continued in the asylum's early days, with patients working (unpaid) in the hospital grounds and gardens as a key part of their therapy.

In 1911, The Mental Defectives Act marked a key change in terminology and therapeutic approaches. Porirua Asylum became Poirura Mental Hospital, and instead of housing "lunatics" looked after by "attendants," "inmates" were cared for by "nurses." Williams (1987) attributes this official shift in designation to a desire to shift the associations of the mental hospital away from prisons and toward hospitals. Architecturally, this was echoed in the adoption of the "villa system," where patients were grouped together in smaller, contained accommodations. This was thought to try and promote self-sufficiency and undo some of the more detrimental effects of institutionalisation (Mclaughlan, 2012). The new legislation meant that patients could voluntarily admit themselves into hospital care, in an attempt to provide early intervention for those at risk. When Truby King became the Inspector General in 1924, he established psychiatric outpatient clinics at mental and general hospitals as a way of trying to undo the stigma of insanity and address mental illness early. These clinics allowed people to receive care and advice for "nervous affections" without the embarrassment of a court order. Despite a period of reform during the 1920s, mental hospitals remained the basis of psychiatric treatment.

\subsection{DEINSTITUTIONALISATION AND COMMUNITY CARE}

The 1940s and 50s were a time of crisis for mental institutions (Coleborne, 2003, p.107). Staff shortages and high demand for these services were accompanied by increasing awareness of patient mistreatment, and the rise of social psychiatry. New drug treatments meant that institutional treatment was no longer expected to be a life sentence, as people could manage their mental health in their own communities. Mental hospitals began "opening up," and allowing more patient freedoms (Brunton, 2003, p. 95). The purpose of asylums as both places of refuge and places of incarceration was beginning to be questioned (Coleborne, 2012). An international movement toward deinstitutionalisation began in the 1960s, and was the basis for Erving Goffman's seminal text on psychiatric institutions, Asylums, in which he argued that mental hospitals were "total institutions," through which the foundation of the individual is systematically eroded through isolation and control (Goffman, 1961). In New Zealand, the mass closure of institutions was prompted by a 1988 government inquiry into practices and institutions (Mason, 1988), and a later 1996 inquiry 
which came to be known as the Mason Report.

Brunton (2003) argues that "deinstitutionalisation" can be seen as a process of reform, as well as a movement towards closure. He argues that from the very early days of institutions in New Zealand, the problems with institutional care (stigma, loss of autonomy, loss of liberty, and low material standards) were understood, and that much of the subsequent political reforms to institutional care were attempts to counteract these negative effects. The process of deinstitutionalisation once institutions began to close was often uneven, and confusing for members of the public (Kritsotaki et al., 2016), who were concerned about the dislocation of services and relocation of patients (Burge, 2016). The last major mental health institution closed its doors in 1992 (Donald Beasley Institute Inc., 2008). In a study of former residents of that institution, most reported positive effects from their transition into community care, such as increased autonomy and better relationships with their care workers (Donald Beasley Institute Inc., 2008, p. 44). Today, in New Zealand, most mental health services are based in the community, and people are treated on an outpatient basis. Only a small amount of people are treated in institutional settings (largely forensic, and short stay hospital wards) (Coleborne, 2012).

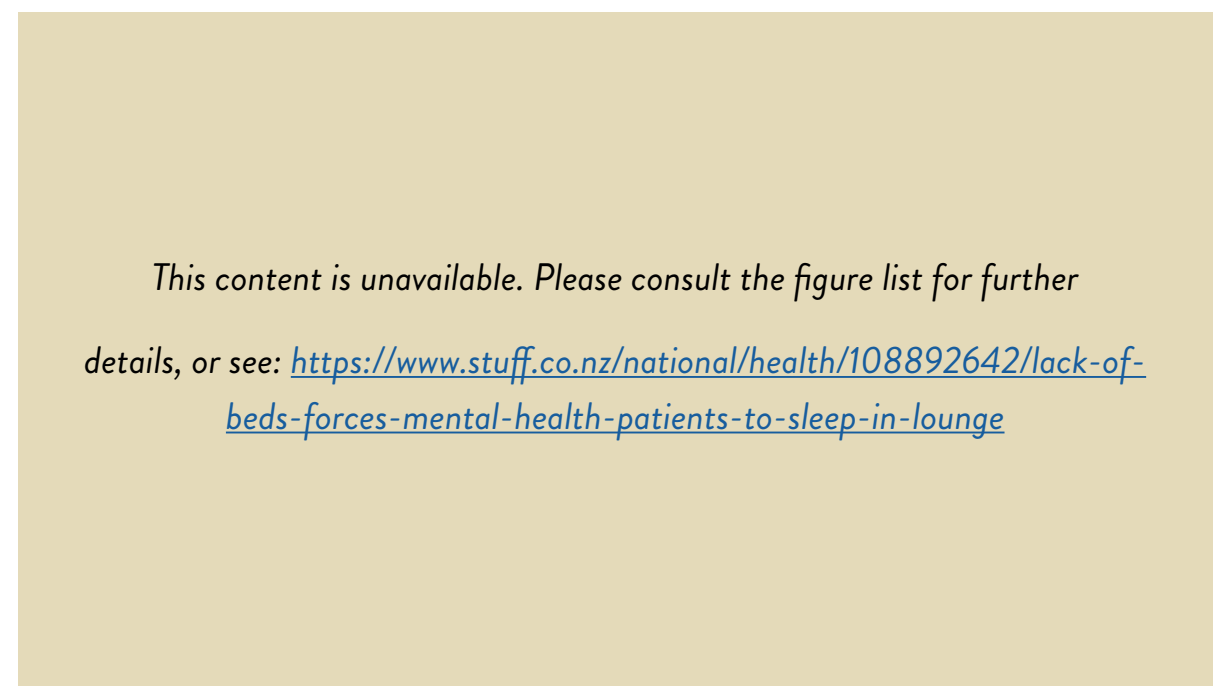

Figure 1.6 Inpatient rooms at Te Whare o Matairangi, Wellington Hospital.

(Tso \& Holl, 2018)

Apart from these remaining institutional spaces, the main architectural typology that defines community care is small scale, residential facilities, run largely by non-government organisations (Coleborne, 2020; New Zealand Mental Health Commission, 2007). The rationale behind this is largely in response to the problem of stigma outlined in the Mason Report, and follows the normalisation theory, which suggests that architectural environments for mental health treatment should avoid invoking the hospital, and resemble a home-like setting (Chrysikou, 2014, p.2). This normalised architecture has meant that people using 
these services can live amongst the community with relatively normal routines, avoiding stigma and isolation (see section 3.1.4).

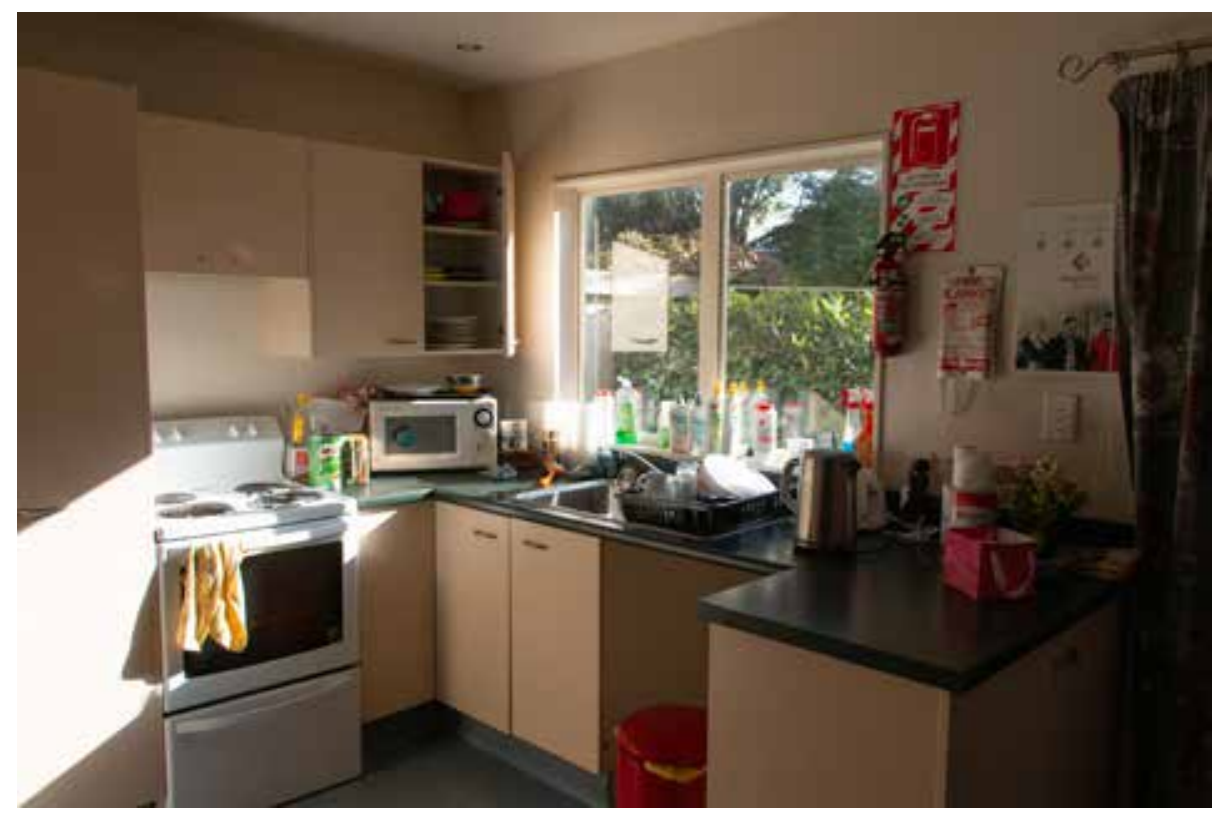

Figure 1.7 Kitchen area in a residential care facility run by a non-government organisation

(Author, 2019)

In many ways however, this lack of visibility is a double-edged sword. Access to mental health services is seen as crucial, but has been an ongoing problem in New Zealand, as outlined in successive reports, including He Ara Oranga (New Zealand Government, 2018; New Zealand Mental Health Commission, 2007). Te Rau Hinengaro (Oakley Browne et al., 2006), a survey of mental health in New Zealand undertaken in 2006, roughly 20 per cent of New Zealanders have at some point in their lives experienced mental distress or addiction issues, while New Zealand has a current access target of only 3.7 per cent of the population, aimed almost exclusively at people with the highest needs. The official point of access through referrals to community health providers by primary health providers (GPs) and acute inpatient crisis services (hospitals) (New Zealand Mental Health Commission, 2007). In Wellington, people can also call the community assessment team in case of a mental health emergency (Te Haika, n.d.). In reality, however, the police are becoming an increasing point of contact for people in crisis (MacDonald, 2018). What this translates to, for most people coming into contact with mental health services, is that the primary architecture they will engage with is their GP's office, the hospital - or sometimes, police cells (Cook, 2017).

\subsection{CONCLUSION}

From a design standpoint, understanding the problematic history of mental health and architecture is incredibly important when looking for new ways to 
design spaces which support and encourage mental wellness. The history of mental health and architecture in Aotearoa New Zealand, like many colonial societies, is loaded with stigmatised conceptions of mental illness, which understandably led to a movement away from architectural solutions for mental health during the period of deinstitutionalisation. Though not as obvious as previous eras, the period of community care that has followed the closure of institutions has its own kind of architecture. From typologies centred around the control and management of people experiencing mental illness, the architecture of treatment has primarily shifted to a more domestic scale and a residential typology, which allows tāngata whaiora (people seeking wellness) more autonomy and increased community connection. This shift has intentionally reduced the visibility of architecture for treatment, but with only a small percent of the population eligible to access these services, it has conversely rendered the architecture of mental health invisible for people suffering from distress that don't meet that criteria.

As outlined in the final section of this chapter, the main points of access to mental health care are through the medical system, or the justice system - two systems which have dominated the history of mental health in New Zealand and abroad, and which most researchers and activists are encouraging a move away from (see 2.1). In order for architecture to positively support cultural changes in the ways we deal with and view mental wellbeing, we need to look to new typologies and ways of supporting people that avoids the dehumanising mistakes of the past. This thesis proposes moving toward the creation of a visible "third place" for mental wellbeing, set in the community, which can both enhance the maintenance of mental wellbeing, and provide a possible alternative access point for people with experiencing serious, but not severe, forms of mental distress. 


\section{7) THEORETICAL CONTEXT}

Contributing theories and positioning

\subsection{DEFNING WELLBEING}

\subsubsection{Māori Mental Health}

2.1.2 Māori and Pasifika Models of Wellness

2.1.3 Building Connections: opportunities in therapeutic environments

\subsection{KEY THEORETICAL FRAMEWORKS}

2.2.1 Therapeutic Landscapes

2.2.2 Evidence-Based Design

2.2.3 Non-Representational Theory

2.2.4 Third Place

2.2.5 The Suburban Shopping Centre as an Emergent Third Place 


\subsection{DEFINING WELLBEING}

A brief overview of current models of mental health care

Definitions of mental illness and wellness have changed dramatically throughout Western history. The primary clinical method for categorising mental illness today is according to the DSM-5, and there exist many ways of defining severity, from level of impairment, frequency and persistance, ability to function, quality of life, risk of mortality or disability and number of symptoms; though there are still many issues with how this is applied and the clinical implications for patients (Zimmerman, Morgan, \& Stanton, 2018). In year from July 2017 to July 2018 recorded the highest deaths from suicide in New Zealand in ten years, and the broad-ranging Government Inquiry into Mental Health and Addiction 2018 highlighted a comprehensive list of issues including lack of access and cultural responsiveness which may have contributed to this.

Mental health researchers and campaigners have for a long time been arguing that a more holistic approach to mental health is needed, with many strategies being developed to emphasise the multidimensional nature of mental wellbeing. These strategies help to inform the work of health pracitioners and organistions dealing with mental illness, as well as government policy. Much of this work draws on efforts to better incorporate Māori perspectives on mental health and wellness into the health system, which has highlighted many of the deficiencies in the current system. This section takes a brief look at the key issues that these models of care seek to address, with reference to He Ara Oranga, in order to illustrate the values and beliefs which are desirable in an improved New Zealand mental health system. 


\subsubsection{MĀORI MENTAL HEALTH}

Both historically and today, Māori have been largely underserved by the New Zealand mental health system (Bryder \& Dow, 2001). Māori populations in mental health facilitities up until the 1970s were significantly lower than Pākehā populations, and Māori and Pasifika people are dispropportionately affected by mental distress, while being less likely to seek treatment for mental illness. Though the Mason Report called for a change of attitudes toward mental illness in 1993, from a justice issue to a health issue, Māori are still most likely to access inpatient services through the justice system (likely as a result of inadequate provision in primary care) (Wratten-Stone, 2016, p. 7). An intertwined range of causes for this have been suggested, all of them stemming from the marginalising effects of colonisation and the perception of the mental health system as being exclusively for Pākehā. Many have pointed to systemic causes, such as undermining of traditional Māori healing through the Tōhunga Suppression Act 1909 (M. Durie, 2011; Jones, 2000), as well as the relative social and cultural isolation of Māori and Pākehā prior to Māori urbanisation (Sweetman (2017). Kingi et. al. (2018) broadly categorise these issues as a lack of recognition and prioritisation of Māori cultural needs, as the mental health system was imported from Britain and designed for British users. This cultural misalignment has been a feature of other colonial societies around the world, where indigenous people are rightly wary of colonial institutions and frameworks which do not serve their needs (Gone, 2008).

Multiple studies have established that mental illness has a significant cultural element in how it is both understood and treated (Fenton, Liz \& Te Koutua, Te Wera, 2000; Russell, 2006; Sanders, Kydd, Morunga, \& Broadbent, 2011). Schizophrenia is a commonly quoted example; in traditional Māori culture, the same symptoms which Western biomedical practitioners would diagnose as schizophrenia were/are seen as a form of mate Māori with special spiritual connotations, traditionally celebrated rather stigmatised ( NiaNia, Bush, \& Epston, 2019; Taitimu, Read, \& Mclntosh, 2018). It is also important to note the collectivist nature of treatment and support in Māori culture - where Western culture has traditionally viewed mental illness as a dangerous aberration to be treated on the fringes of society, Māori suffering from distress were included and sheltered within whanau, hapu and iwi (R. Baker, 1988, in Kingi et al., 2018). The benefits of the Māori view of health and its implications, not only for Māori, but the health system in general, was the focus of many researchers seeking to improve not only the mental health system, but the wider health system as well (M. H. Durie, 1985). 


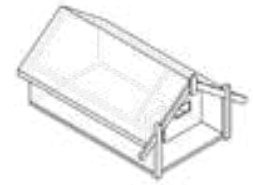

Te Taha Tinana

Te Taha Hinengaro

Te Taha Wairua

Te Taha Whānau

*Foundation

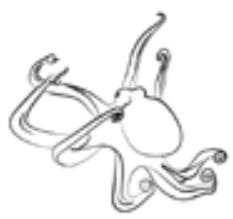

Tinana

Whatumanawa

Hinengaro

Wairuatanga

Mauri

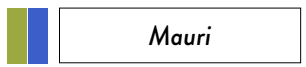

Mana ake

Whānaungatanga

Hā a koro ma, kuia ma

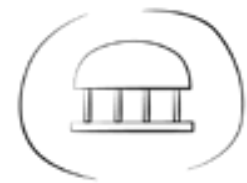

Pou - Physical

Pou - Spiritual

Pou - Mental

Pou - Other

Foundation - family

Roof - Culture \& beliefs

Cocoon - Time,

Environment, Context

\subsubsection{MĀORI AND PASIFIKA MODELS OF WELLNESS}

The campaign to bring Te Ao Māori into psychiatric treatment began to gain momentum around the 1980s. Many models of health have been proposed as an alternative or complement to the Western biomedical model which aim to better integrate Māori philosophies of care into the mental health system (and health system generally). This section will briefly outline some of the fundamental concepts highlighted by key kaupapa Māori models, as well as their resonance with Pacific models and strategies highlighted in the 2018 Mental Health Inquiry.

Te Whare Tapa Whā was first proposed by Mason Durie in 1985 (M. H. Durie, 1985) after extensive consultation with Māori at marae around the country. It has been a widely acknowledged model in both mental health and wider health practice. The model is deceptively simple, and boils Māori philosophies of health down to four categories. These concepts are represented as the four walls of the whare: te taha tinana (physical), te taha wairua (spiritual), te taha hinengaro (emotional/psychological) and te taha whānau (family). In a 2011 article, Mason reflects on the holistic strategy of care that the model was advocating for: 


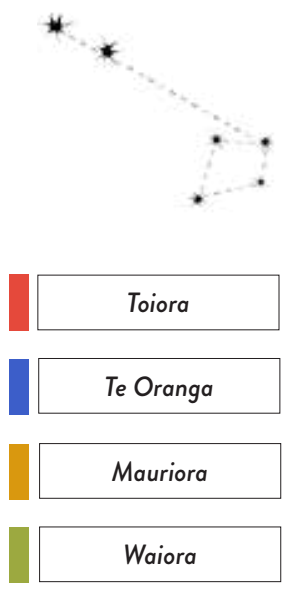

Te Mana Whakahaere

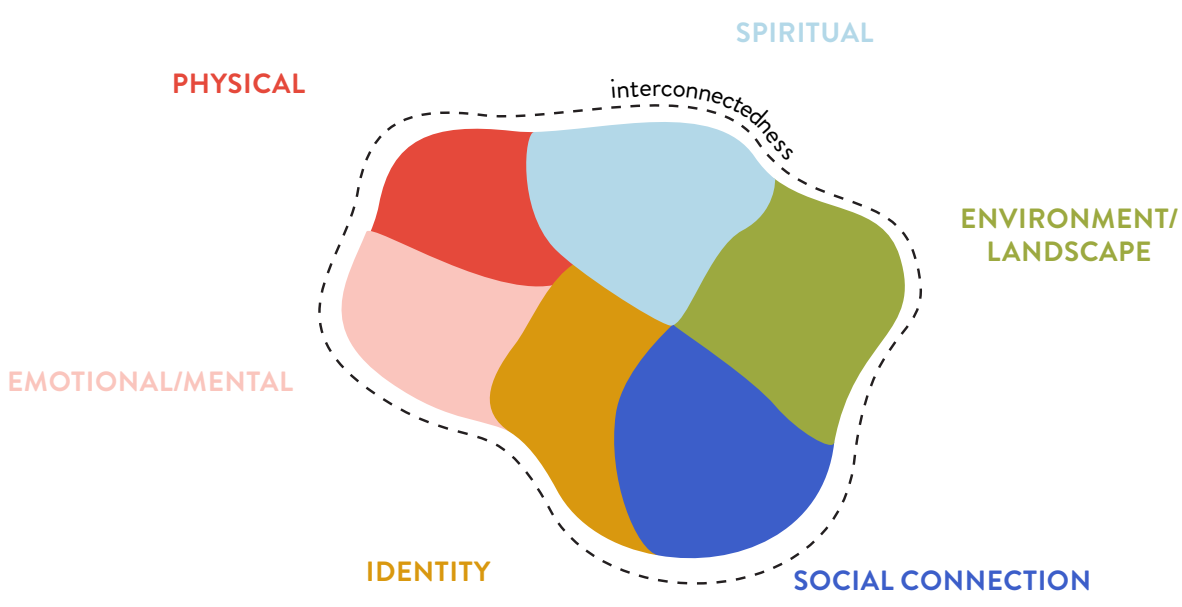

Ngā Manukura

"Mental health services, for example, should not be so narrowly focused on the psyche that health, spiritual dimensions, or social relationships [are] ignored." In his words, it was a "whole-person" approach to wellness. The model reached beyond cultural boundaries by offering a more personalised approach to health care that was welcomed by the wider New Zealand community (M. Durie, 2011).

Alternative models to Te Whare Tapa Whā include Te Wheke and Te Pae Mahutonga. Te Wheke (the octopus) was raised by Rose Pere around the same time as Te Whare Tapa Whā and is used widely in mental health, general health and education contexts. It shares many similarities with the Tapa Whà model, but focuses around the whānau, hāpu and iwi (the body of the octopus), with many intertwined conceptual tentacles extending from there. Many of these concepts are shared with Durie's model, but also distinguishes additional concepts of individual and group identity, or uniqueness (mana ake), the power of place, landscape and living things (mauri), kinship and connection (whānaungatanga), and knowledge of tupuna (hā à koro mā à kuia mā) (Love, 2004).

Te Pae Mahutonga is another model by Durie, which visualises a taskscape in the form of the Southern Cross, with each of the Cross' four stars representing Waiora (physical environment), Toiora (healthy lifestyles), Te Oranga (participation in society) and Mauriora (cultural identity). The pointer stars which guide us to these concepts are Ngā Manakura (community leadership) and Te
Fig 2.1 Diagram showing connected themes accross multiple models of wellness 
Mana Whakahaere (autonomy). The Fonofale model, designed by and for Pacific populations in New Zealand, echoes the Tapa Whā model in structure, drawing on the imagery of the fale to express the interconnectedness of similar concepts (Foliaki, 2001).

The common thread between all these kaupapa Māori and Pacific models is a focus on spirituality, cultural identity, relationships between the self, the community and the landscape and an overall interconnectedness. These models have informed not only service delivery strategies, but campaigns to change the mental health system. A submission to the Mental Health Inquiry 2018 from the Wellbeing Manifesto, led by patients-rights activist Mary O'Hagan, drew heavily on Te Whare Tapa Whā and Te Wheke in proposing an interconnected wheel of service delivery. This was presented as a counter to so-called "Big Psychiatry," shifting the focus instead to "Big Community" ("Wellbeing Manifesto,"2018). In all of these models, the biomedical aspect is treated as an important but not dominant part of care. The overarching theme is to recognise the multifaceted nature of wellness and address it on cultural, social and relational levels as well.

\subsubsection{BUILDING CONNECTIONS: OPPORTUNITIES IN THERAPEUTIC ENVIRONMENTS}

The $2018 \mathrm{He}$ Ara Oranga report noted that mental distress and illness exists along a continuum, and that an individual's needs can fluctuate over their lifetime. A key takeaway from the report was that more opportunities for early intervention are neccesary - the last year recorded the highest suicide rate in this country in a decade, and nearly half of those people had been in recent contact with mental health services(New Zealand Government, 2018). Mason Durie (2018) has drawn a distinction between mental illness and mental distress, and notes that even in cases of suicide and other forms of extremely diminished mental health, a mental illness that meets DSM- 5 criteria is not always the cause. This is important because it leaves the door open to other kinds of interventions that are not the sole province of health services, such as environmental and social interventions. One way of doing this is through primary and secondary prevention - elimination of causative factors and mitigating mental distress through the provision of adequate housing and other life essentials; but Durie also notes that there is opportunity for tertiary prevention that allow people with longer-term issues to participate in society. He notes: "Creating an environment that is user friendly can significantly alter the mental health of anyone with mental or physical disabilities." (M. Durie, 2018).

Essentially, Māori models of health emphasise the connectedness of the 
individual to their whanau and community as well as their physical and spiritual environment. It is a relational way of seeing the world that would be familiar to space, place and architectural theorists who analyse networks and assemblages, where the hierarchy of agencies and relationships between people, place, landscape and activities are flattened and viewed as an interconnected, dynamic whole. The kind of user-friendly environment described by Durie could essentially be anywhere - it could mean paying attention to existing spaces which are frequented by tāngata whaiora, such as hospitals, schools, daycares, shopping centres, workplaces, social services and supported housing. It could also mean spaces which provide and strengthen the social connectedness and opportunities offered by community, such as a community centre, library, wellness hub or other publicly-accessible space. Many of these spaces can be described as functional "third places"; accessible public spaces away from the home and work (or hospital), where the primary goal is socialising, rather than meeting tasks or expectations. The next section outlines some of this theory in more detail, and looks at case studies which provide insight into the kinds of spaces which support wellness in the community outside of the biomedical model. 


\subsection{KEY THEORETICAL FRAMEWORKS}

Therapeutic Lansdscapes, Evidence-Based Design, Non-Representational Theory, and Third Place

\section{INTRODUCTION}

In order to better understand the relationship between space, place and mental wellness, the following chapter draws on four key theoretical frames: therapeutic landscapes, evidence-based design, non-representational theory and Oldenberg's third place.

\subsubsection{THERAPEUTIC LANDSCAPES}

The concept of therapeutic landscapes emerged from the discipline of cultural geography in the 1980s. Early studies sought to confirm the long-assumed link between contact with the natural environment and positive health effects (Bohnen et al., 1990; Kaplan, 1995; R. S. Ulrich, 1984). The term "therapeutic landscapes" was first coined by Gesler to distinguish a kind of landscape which could be identified as having healing of therapeutic properties (Gesler, 1992), be they "traditional" (mineral springs and mountain retreats), or "non-traditional" (healer's huts, physician's offices, hospitals). The concept has developed into a large field of scholarship and is now considered one of the core principles of health geography (Gesler, 2009). Much of this research has focused on the positive health effects associated with green spaces (grass, fields, parks) (Bell, Westley, et al., 2018; Burls, 2007; Finlay et al., 2015) and blue spaces (water, streams, oceans) (Foley, 2015; Foley \& Kistemann, 2015; Satariano, 2019), but is broadening in scope to include different "palettes of place" (Bell, Foley, et al., 2018), such as urban environments and streetscapes (Kang \& Kim, 2019; Saitelbach, 2016).

Therapeutic landscapes have always been understood as being shaped by "physical, human and social influences" (Gesler, 1992, p.736), but in earlier theory, the therapeutic value of these landscapes tended to be viewed as instrinsic, and studies took a biomedical approach to understanding how particular mechanisms of these places positively impacted individual health and 


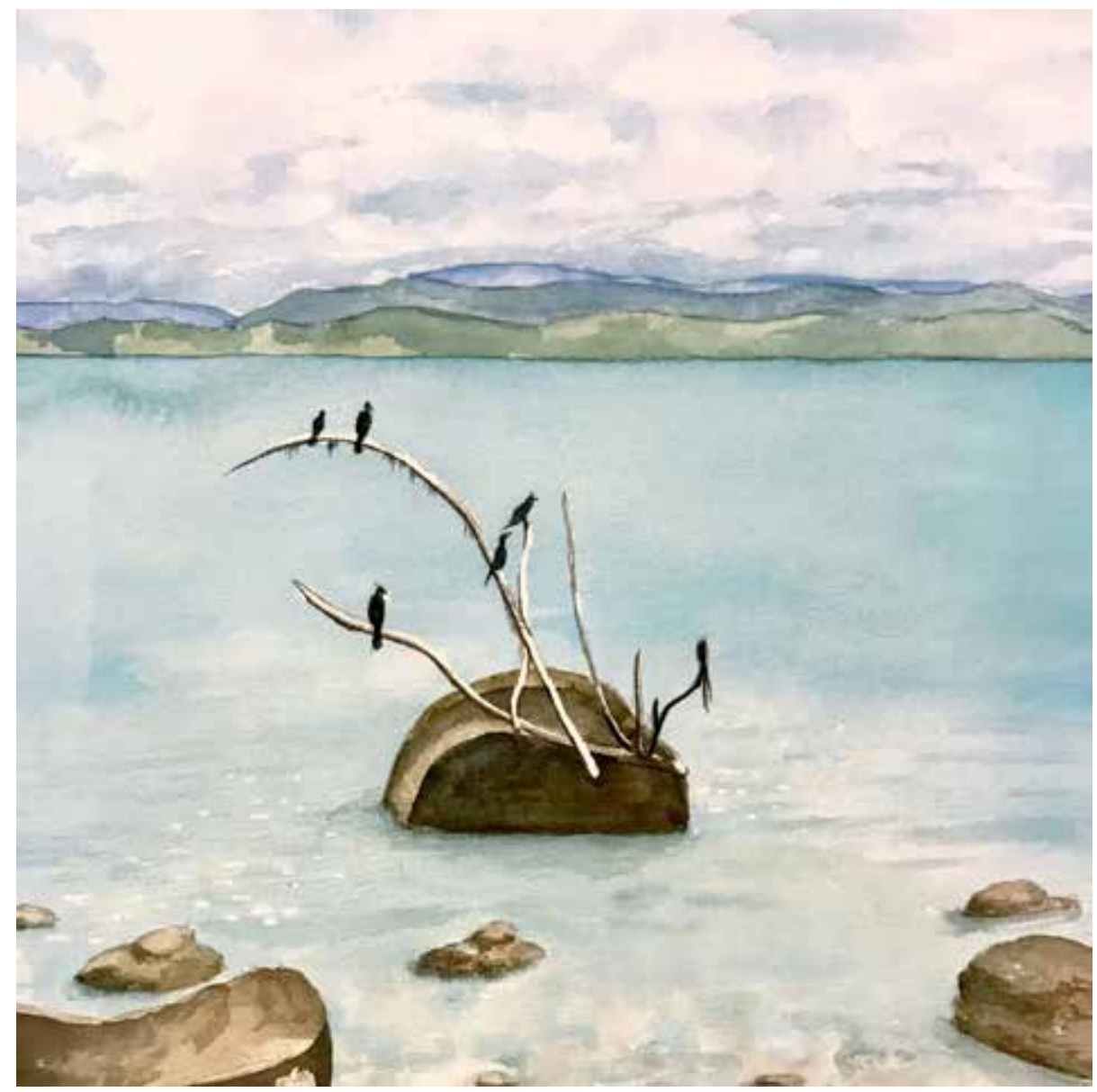

Fig 2.2 A traditional therapeutic landscape (Author, 2019) healing. Smyth (2005) recognises a significant shift away from the biomedical tradition that began in the 1990s, prompted by the work of Robin Kearns (1993). Kearns argued that the field needed to more directly address social and public health theory, moving toward a broader field of health geography (Williams, 2007). Smyth outlined one of these broader perspectives as "therapeutic networks," where therapy and healing support can be given and received outside of the biomedical tradition, consisting of a level of community or social interaction which adds to the therapeutic environment. Such networks have also been presented as "taskscapes" (Dunkley, 2009) and "assemblages" (Butterfield \& Martin, 2016). This more contextual way of thinking about place and space is particularly relevant to the field of mental health, where there are increasing calls for a more holistic and multi-faceted approach (see 2.1), and is discussed next more in section 2.2.3.

\subsubsection{EVIDENCE-BASED DESIGN}

While research on therapeutic landscapes tends to take an analytic approach to understanding space and health, it is closely related to more a quantitative strand of research which seeks to prove scientifically the link between specific environmental elements and their correlated health effects. Gesler's early work 
was influenced by this kind of research (Ulrich et al., 1991), a field which has come to be known as "evidence-based design." This research has helped to improve the design and construction of therapeutic environments (Eisen et al., 2008; Peters \& Verderber, 2017; Sherman-Bien et al., 2011; Verderber, 2014), providing quantifiable evidence to support the design of more humane spaces. In the mental health field, much of this research is focused on the design of institutional spaces (Connellan et al., 2013; Long et al., 2011; Rich et al., 2011), examining design elements such as colour, internal organisation and pattern in relation to the symptoms of specific mental illnesses (Chrysikou, 2014). Evidence-based design is beginning to be incorporated into studies of more general and alternative therapeutic contexts as well, such as open urban spaces (Pleasant et al., 2013) and housing (Kylén et al., 2019; Rollings et al., 2017).

A recent literature review on the subject of therapeutic landscapes (Bell, Foley, et al., 2018) noted a tension in the different approaches of analytic and scientific studies, between "something that is valuable (in its own right) as an emotionally framed experiential finding, or value-able as a measureable and potentially commodifiable result" (p.125). While there is certainly value in the evidence-based approach, it has been critiqued for its tendency to generalise the patient experience, creating what has been described as a "moving target" (Sherman-Bien et al., 2011). A part of this might be in the way the evidencebased approach conceptualises wellbeing. It has been argued that evidence-based models often foreground Western conceptions of landscape and wellness at the expense of other conceptions which may be more relevant in Indigenous and other cultural settings (Gone, 2008). Atkinson (2013) presents the dominant framing of wellbeing in research and policy as component-based and individualfocused at the expense of global and subjective factors. She argues that this component-based approach is too reductive and suggests an alternative framing for wellbeing as a process that is both situated and relational.

\subsubsection{NON-REPRESENTATIONAL THERAPEUTIC LANDSCAPES}

Non-representational theory is a philosophical approach in human cultural geography attributed to Nigel Thrift, which he summarises as a view which tries to capture the "onflow of everyday life;" in which "actions presuppose practices, and not vice versa" (Thrift, 2008, pp. 5-8). It emphasises actions rather than products, and focuses on affect and sensation over signs and signification. NRT is a way of seeing the world not as fixed, but as an ever-changing flow in which the human and nonhuman coexist in an interrelated field of affect. Affect, in Thrift's words, is neither "irrational nor sublime," but "a different kind of intelligence" 
(Thrift, 2004). It is an awareness of the world which privileges materiality, sensation and emotion.

In therapeutic landscapes, the nonrepresentational approach views the therapeutic benefit of place as a relational, subjective, active quality, dependant on many different factors in flux. Where traditional therapeutic landscape literature has studied places for their intrinsic health benefits, this relational view takes a more qualitative approach. It looks particularly at the psychosocial rather than the biomedical; at the complex whole of an individual, and the social context that surrounds that individual (Conradson, 2005). Foley (2015) unpacks this more in a qualitative analysis of selected coastal swimming spots in Ireland. The traditional therapeutic value of swimming is recognised in the responses to this study, but it is shown to be produced in these places through a range of factors, including the camaraderie and social engagement associated with each particular place, the personal histories associated with that place, and the particular sensory engagement with the natural environment that the activity encourages. Andrews et al. (2014) frame this nonrepresentational approach to therapeutic landscapes as seeking to understand the "taking place" of health and place. They tested the approach through their own qualitative study of places and situations in which the researchers themselves experienced "wellbeing:" taking field notes describing the situations, their response, thought process and emotions. Among their conclusions was that 'wellbeing' can be seen as an emergent quality, produced through affective experience. The role of place, then, is that it provides "opportunities for, and actual, unique affective moments of wellbeing set within general structural parameters and limits" (Andrews et al., 2014, p. 218). While these places were often 'natural,' they could just as likely include some element of design or engineering.

\subsubsection{THIRD PLACES}

In a recent literature review on the subject, (Bell, et al., 2018) the authors trace the broad trends that have emerged in the therapeutic landscapes field over the last ten years. One of the topics they address is the concept of the "third place." It is not a new term at all, it was first coined by sociologist Ramon Oldenburg in 1982 as a way of describing particular places, separate from home and work, which enable otherwise impossible social opportunities and behaviours seen as essential for individual wellbeing (Oldenburg \& Brissett, 1982). His writing was primarily concerned with the experiences of middle class American suburbanites in the early 80 s, and emphasised that the value of a third place in the life of an individual was not based on escapism from everyday life, but on a need to supplement everyday routines with access to a less regulated, lively social environment (such as the coffee house, or local pub). The benefits to a person's 
mental health were addressed as providing 'perspective' through socialising with those outside of one's normal sphere. The third place, in Oldenburg's view, is a place where status is set aside and diversity is welcomed - the basis for true community connection.

In terms of mental health and architecture, the idea of the third place has been utilised in the concept behind Maggie's Centres and Gilda's Centres, specially-designed places for restoration which allow people living with cancer a place of respite from the pressures of home and hospital (Butterfield \& Martin, 2016; Glover \& Parry, 2009). More broadly, it has been suggested that the process of deinstitutionalisation has meant that people with mental illness have lost access to a "place to be" (Collins et al., 2016), away from the pressures of broader society. Parr (1997) notes that under the community care model, those experiencing mental distress often seek out makeshift places of respite. In this framing, places such as cafes, parks, homeless shelters and pavements may become de facto therapeutic landscapes - created not through healthcare providers but by people themselves, carving out spaces to 'be themselves' within the public sphere. The difference between the "places to be insane" referred to by Parr and "third spaces" for restoration (Glover and Parry, 2009) is that one is informal, de facto, and self-sought, while the other is formalised and designed for the purpose of "third place" activities.

Laws (2009) analyses one kind of defacto space, where a group of ex-psychiatric inpatients meet to support each other in healing from unhappy experiences within institutional care. Due to a lack of resources, this group meets primarily a public park described as "a bit dodgy" (p.1829) by one of the participants. Though the park setting provides an element of green space connection, it is far from Gesler's conception of a desirable therapeutic landscape (though it provides an element of natural connectedness). Despite this, its participants attach a sense of identity and subversive power to their location due to its perception as being oppositional to the typical spaces of treatment they had experienced previously. Notably, some members reported 'escaping' institutional environments temporarily to attend meetings, before returning afterward to their wards. This study highlights that what might be considered a pleasant aesthetic environment for one group of people may be a source of tension and alienation for another, and vice versa.

In the context of mental health in Aotearoa, where people's experience of space has historically been so intertwined with their treatment, it is worth asking what kind of third places currently exist. Today, tanngata whaiora who have gained access to our mental health system currently move through a variety of spaces. Those that are in supported residential situations often make these places 'home' (although there is a lack of permanancy which inhibits place attachment and belonging). The second place, inevitably, becomes the hospital, or the complex 


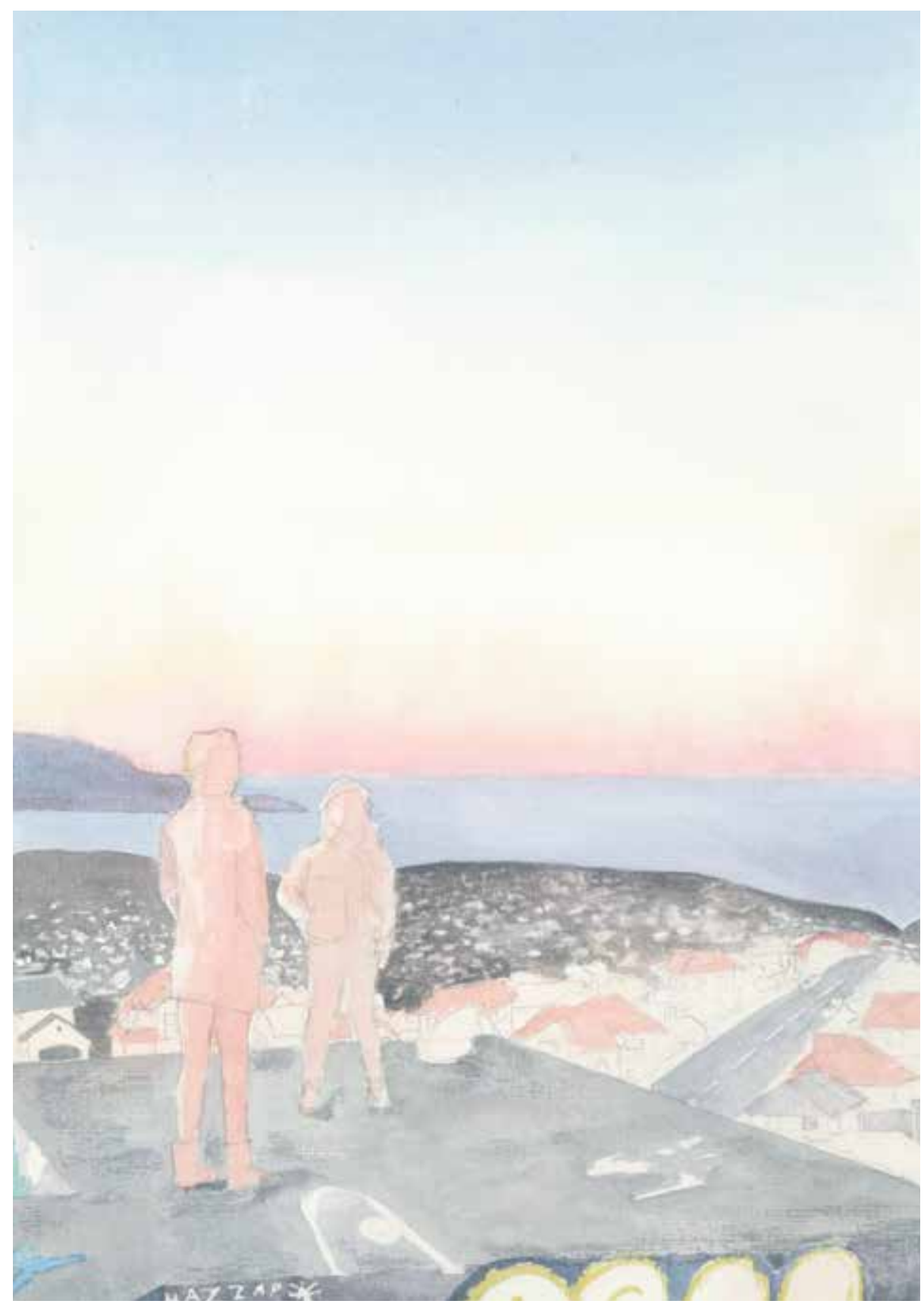

Fig 2.3 An alternative therapeutic landscape (Author, 2019)

web of the contemporary mental health system more generally. The third place remains harder to determine.

It has been suggested that the library is a new kind of third place; a place which is free to access, is accessible (within walking distance), provides food and drink, a place where you can find friends and have the option of partaking in different groups or activities (Montgomery \& Miller, 2011). This is true of many of our public libraries in Aotearoa today, whether they be large urban libraries or small community ones. The public response to Tūranga, Chrischurch's rebuilt public library, designed by Architectus in association with the Matapopore Trust, reflects this. The architects paid special attention to the idea of a third place when designing, an idea which is described as: "a place anyone can go to 
for whatever reason, be it to study, to research or to seek haven and rest as a parent, traveller or homeless person" (Khouri, 2019)(Mawer, 2018, p. 50). Other kinds of third places, however, remain scarce. A recent news article suggested that the outdoors is New Zealand's traditional third place - but asserted that there is nowhere in our cities and towns for our communities to access (White, 2018).

\subsubsection{SHOPPING CENTRES AS EMERGENT THIRD PLACES}

Aside from being centres of commercial activity, suburban shopping centres and malls have long played an important social role in bringing community members together and providing access to support. A 2018 thesis by Chantal Mawer took a close look at the role of suburban shopping centres in the Wellington region, focusing on two in particular - the Wainuiomata Mall and the Johnsonville Shopping Centre. Mawer interviewed community members that frequented these two centres and found that participants had a strong emotional attachment to these places, and felt that their recent commercial decline had resulted in less socialisation and opportunities for interaction. Where previously people could walk down to the shops and run into friends and make new acquaintances, now most socialising takes place in private homes, significantly reducing the opportunities for forming new social bonds and maintaining old ones. One participant noted: "there is still no other facility other than maybe the marae that does that, that you know people don't feel they're going down there just to buy something, they are going down there to catch up, they're going down there to watch you know their children, a concert all of that, I think, is what's been lost" (Mawer, 2018, p. 50). The decline of the shopping mall means the loss of retail outlets, but more importantly, the loss of the incidental social interactions that were associated with these outlets.

While Oldenburg dismissed the community and third place function of suburban shopping malls (Lasch, 1996, p. 124), it is clear from research like Mawer's that they do have (or once had) a strong role to play in promoting socialisation and a sense of community; two important characteristics in maintaining mental wellbeing. The idea of the third place and the nonrepresentational therapeutic landscape shares several core values - they are activity based, non-prescriptive spaces which encourage affective relationships between an individual, their environment and the social context. With the loss of commercial activity as a core attractor for communities into shopping centre space, there is an opportunity to reimagine these places as emergent third places for community wellbeing. 
KEY PRECEDENTS

A reference index

3.1 Madlove: a designer asylum

3.2 Maggie's Centre Edinburgh

3.3 Our Future Foyle

3.4 Residential Care Facility 


\subsection{MADLOVE: A DESIGNER ASYLUM}

This content is unavailable. Please consult the figure list for further

details, or see: http://www.madlove.org.uk/

Category: Art

Artists: $\quad$ the vacuum cleaner (Jason Leadbitter) and Hannah Hull

Architectural: James Christian, Benjamin Koslowski,

Date: 2014 - ongoing

Location: Various workshops and galleries around England

Materials: $\quad$ Mixed media: pen and paper, scale models, small-scale architectural installations

Details: Madlove is an ongoing participatory art project that asks: "Is it possible to go mad in a positive way? How would you create a safe place in which to do so? If you designed your own asylum, what would it be like?" "What is Madlove?," n.d.). Working from a sensory and experience-based perspective, the project involves an ongoing set of community workshops, where people are asked to decribe a utopian vision of the asylum (Zagorska, 2019). The responses from these workshops were then interpreted by the artists into installations, exhibitions and "take-overs" ("A Madlove Take Over," n.d.). Madlove seeks to restore the spatial agency of those at the heart of the mental health system, and destigmatise the symptoms and frustrations of those who have been in care.

Fig 3.1 Installaion produced for Madlove exhibition ("What is Madlove?," n.d.) 
This content is unavailable. Please consult the figure list for further

details, or see: https://slate.com/human-interest/2015/03/madlove-adesigner-asylum-from-james-leadbitter-the-vacuum-cleaner-is-a-mentalhealth-space-designed-by-patients-in-the-u-k.html

Fig 3.2 A sketch produced at a Madlove community workshop (Hohenadel, 2015)

Relevance: This project is of primary relevance to the following research objectives:

\section{Objective 2:}

To draw relevant principles and concepts from research into wellbeing, culture and place, and transfer this into creative practice

\section{Objective 4:}

To develop a design approach for building relational therapeutic third places in the community

The methodology developed in the project is unique in that it aligns with quantitative social science methods, while retaining an element of creative interpretation and free expression. Vacuum Cleaner, the primary artist, extends his own experiential knowledge of institutional psychiatric spaces (of which he has spent significant time in) by creating workshops in the community and seeking participatory input. The data gleaned from these workshops is made freely available, and could be used to inform a design approach for building a relational third place in the community, as far as broad sensory preferences are concerned. As it is primarily an art project, the outcomes are not restricted by the same architectural pragmatics that are often considered in evidencebased studies, which allows for a free creative and imaginative response. The installations developed from this are examples of evidence-based knowledge applied to creative space (Hohenadel, 2015). 


\subsection{MAGGIE'S CENTRE, EDINBURGH}

This content is unavailable. Please consult the figure list for further details, or see: http://www.richardmurphyarchitects.com/viewltem.php?id=2452

Category: Architecture

Client: Maggie and Charles Jencks

Architect: Richard Murphy

Completion date: 1996

Extension completion date: 2001

Location: Edinburgh, Scotland

Materials: Stone, timber, steel (adapted from existing stone building)

Details: Maggie's Centres are significant architectural third places in the UK.

The first building, originally conceived of as a Caring Cancer Centre, began as a singular building in Edinburgh. Its conception was prompted by the experiences of Maggie Jencks (nee Keswick) and her husband Charles Jencks as she battled with a terminal cancer diagnosis. In the midst of trying to understand her diagnosis and find hope for new treatments, the pair found hundreds of informal support groups around Britain which shared information and supported one another in processing and understanding their disease. The only thing lacking,
Fig 3.3 Maggie's Centre, Edinburgh

(Richard Murphy Architects:

Maggie's Cancer Caring

Centre, Edinburgh, n.d.) 
they imagined, was a formal place to meet and access to professional guidance. Richard Murphy was commissioned to redesign an existing stable next to a hospital into a welcoming, non-institutional environment where people could come to find information, support and hope. The brief, Murphy recalls in a 2010 retrospective book on the centres, was extremely open:

"What exactly was the building for? We knew it wasn't going to be a clinical building but Maggie was going on about all kinds of things, relaxation, a library, meetings, yoga, beauty care. How would we fit this all in?" (Jencks \& Heathcote, 2010, p. 94)

As a result of this desire for a multitude of different potential activities and purposes, the architect sought to create space which were multi-functional. Instead of focusing on the programme of the space, he focused on generating an atmosphere which was domestic rather than institutional, and in doing so created a key point of the resulting programme, one which was recreated in all subsequent Maggie's Centres: the kitchen. There are other programmatic elements which are a result of this somewhat ambivalent brief: a lack of corridors, a proliferation of nooks and sitting spaces, a connection to the outdoor courtyard. Though this prototype design is more modest than some later versions by big-name architects, all of these elements are now considered part of the general brief of a Maggie's Centre.

Relevance: This project is of primary relevance to the following research objectives:
Aim 1:
To establish principles for a new "third place" typology of community-based mental health architecture

\section{Objective 4:}

To develop a design approach for building relational therapeutic third places in the community

The Maggie's Centre project is an example of the successful establishment of a third place architecture (Glover \& Parry, 2009) for what is, essentially, the purpose of mental wellbeing. The problem with this kind of project, a vague brief, quickly became its strength, as the architect drew on the experience of the client to design a flexible, welcoming space that could support a variety of programmes. The success of the approach has been proven through the many other Maggie's Centres which have flourished since this initial space was built. The challenge that this raises for this thesis is: how can the principles of the Maggie's Centre (flexible programme, open, welcoming atmosphere) be transferred into a more general, community public space? 


\subsection{OUR FUTURE FOYLE}

This content is unavailable. Please consult the figure list for further details, or see http://www.futurefoyle.org/bio

Category: Urban design

Client: Public Health Agency

Collaboration: Hamlyn Centre for Design, Royal College of London

Architect/Designers: Our Future Foyle, Urban Scale Interventions

Date: 2016-2018, ongoing

Location: Derry/Londonderry, Northern Ireland

Details: "Our Future Foyle" is a collaboration between the Public Health Agency (PHA) and the Hamlyn Centre for Design, in response to a review by the PHA of health and wellbeing, which identified a need to change perceptions and behaviours around the River Foyle. The city of Derry/Londonderry has one of the highest suicide rates in the country, and unfortunately, bridges over the River Foyle have become a site for many of these deaths. The stigma associated with the area is to such an extent that locals have developed a phrase: "I'm ready for the Foyle," used to communicate stress or hardship ("A case study of architectural interventions in Derry/Londonderry," 2019). The planning and research phases of the project occurred over two years, and in 2019, the organisation formed out of this is working with local authorities to implement it at different stages. Some of the interventions proposed by this project include an interactive railing along the bridge to improve prevention and deter suicidal behaviour, and positive community installations such as the "Foyle Bubbles." The Bubbles are 40 portable spaces along the riverfront, which will be made available to individuals, organisations and small businesses to increase social activity in
Fig 3.4 Our Future Foyle concept drawing.

(Our Future Foyle, 2018) 
the area. The idea is that the people and organisations occupying these bubbles will receive mental health training and be able to act as first responders in the community in the event of incidents along the river (Our Future Foyle, 2018).

\section{Relevance:}

The primary relevance to the following research aims and objectives:

\section{Aim 1:}

To establish principles for a new "third place" typology of communitybased mental health architecture

\section{Objective 4:}

To develop a design approach for building relational therapeutic third places in the community

The stated aim of the project was:

"to use Inclusive Design to create social and cultural interventions around the banks and bridges of the River Foyle that improve wellbeing, reduce suicide and create more positive associations with the waterfront" " $A$ case study of architectural interventions in Derry/Londonderry," 2019).

The research behind the project was based on a participatory methodology, working with a range of key stakeholders and members of the community. The success of the primary stated aim has yet to be measured, but the strength of the participatory approach is evident in the momentum the project has carried from its design phase into the beginning stages of implementation. While the scope of this thesis does not include participatory design, it is an important factor in considering the real-world applications and "next steps" of the results of this design research. Additionally, the ideas and concepts generated through community consultation provide a good point of reference for what an urban intervention based around mental health needs to consider. 


\subsection{RESIDENTIAL CARE FACILITY}

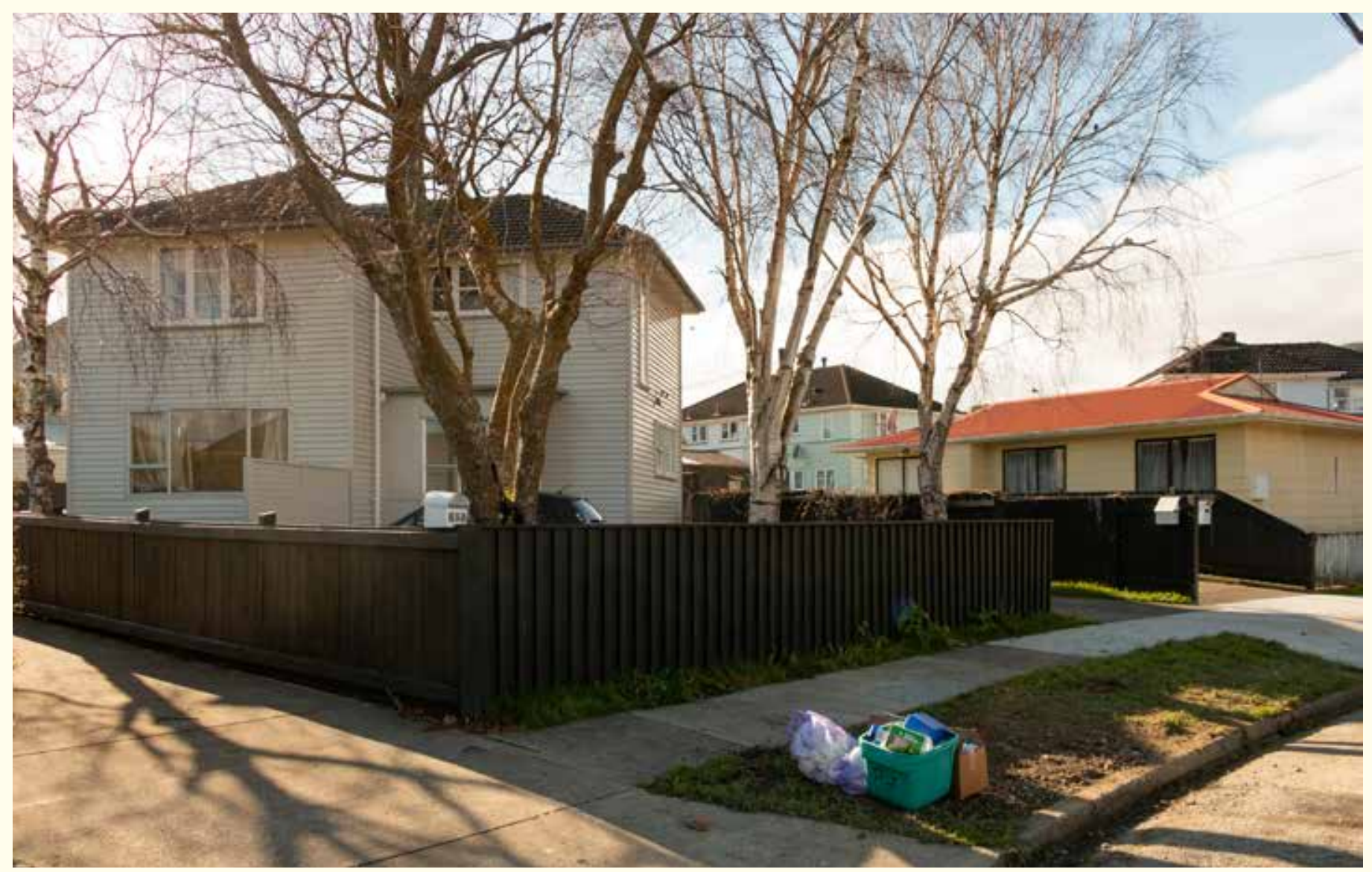

Category: Architecture

Client: Housing NZ

Architect: Unknown

Completion date: Approx 1997

Location: Lower Hutt

Materials: Timber frame construction, gib interior, weatherboard exterior

Details: As outlined in the History section of this thesis (1.6), the main typology for supporting people with the highest needs in the mental health system today is residential-scale buildings with a domestic atmosphere, set within the wider community. This facility is a residential care facility run by a non-government mental health organisation (NGO), which also runs a range of other services throughout Wellington and New Zealand. The organisation, Pathways, allowed me to tour the facility and take photographs of some of the amenities, which provided insight into the "everyday flow" of current architectural spaces supporting mental wellbeing. The facility has two primary functions: to offer long-term care and support to residents with severe mental health issues, from several months up to several years; and to provide short term respite care for people in need of a break from the stress of their everyday living situations.

The facility was clean and well-constructed, with longer-term residents living in
Fig 3.5 The architecture of the facility blends into the suburban area

(Author, 2019) 

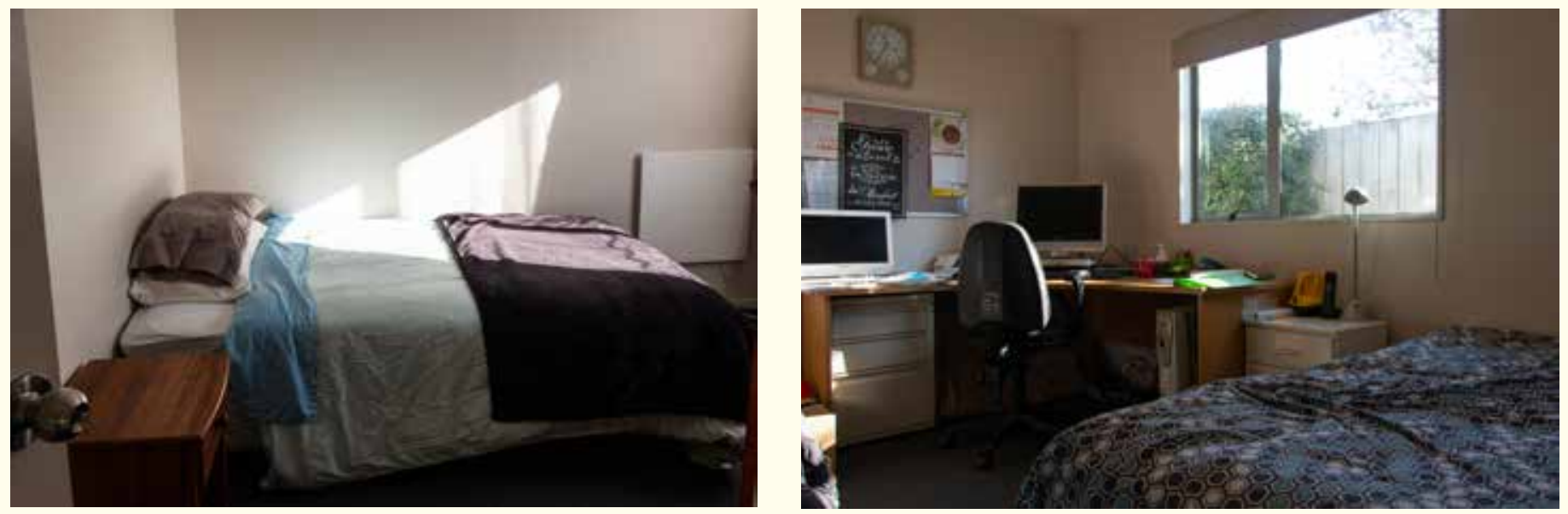

shared "flatting" situations, which are designed in a manner no different from residences outside of the facility (bedrooms, bathroom, kitchen, lounge, back yard). The respite centre is attached to the main office, where a staff member is always present. The main office has a small private office for staff only, where a bed, desk and bookshelf are crammed into the same space.

Relevance: This building is of primary relevance to the following research objectives:

\section{Aim 1:}

To establish principles for a new "third place" typology of community-based mental health architecture

\section{Objective 1:}

To use the history of mental health and architecture in Wellington, New Zealand as a basis for understanding how architecture has contributed to stigmatising mental health

In order to establish a new kind of community-based mental health architecture, it is important to understand what is already there and serving the community. Through visiting the facility and talking to staff and tāngata whaiora, a fuller understanding of the concept of community care was developed. People talked about existing community day programmes at nearby facilities that tāngata whaiora could attend, which provide therapeutic activities such as singing, art, sensory activities and life skills education. Staff noted that there were a lot of community-based services, but that there was sometimes a disconnection between them because of the fact that most of them are provided by different NGOs. As well as this, it was noted that there was a huge demand for these services which there are not enough resources to meet, sentiments similarly expressed in the He Ara Oranga report (New Zealand Government, 2018).

Fig 3.6 (Left) A bedroom in the respite area of the facility Fig 3.7 (Right) Staff often have to stay the night, sleeping in cramped quarters in their ofice

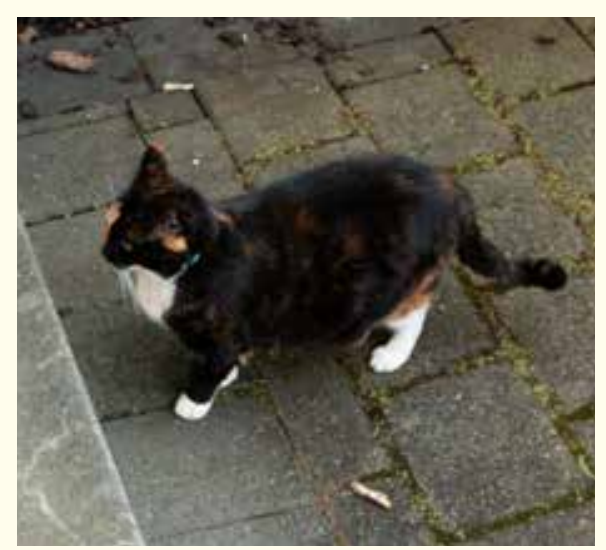

Fig 3.8 The community approach to care means long-term residents are able to keep pets

All images: (Author, 2019) 


\section{SITE}

Taita Shopping Centre

4.1 Site Selection

4.2 Site Overview

4.3 Site Analysis

4.4 Experience of Site

4.5 Reflection + Opportunities 


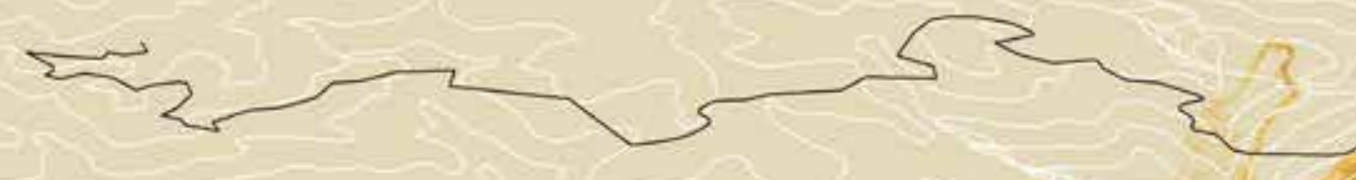




\subsection{SITE SELECTION}

The site for my research was chosen for its locality and for the fact that it holds many of the features of a typical New Zealand suburban centre. The Taita Shopping Centre, like many in Aotearoa, is one that was built in the 1950s, and originally was a hub of community interaction for its provision of groceries, essential services, and local produce. As outlined in the Mawer thesis (2018) referenced earlier (2.2.5), the nature of retail has changed significantly in the last 70 years, and these once vibrant suburban hubs are struggling to redefine their purpose in an increasingly online and centralised world. The Taita Shopping Centre reflects this change in the many vacancies it holds, and the nature of the remaining tenancies - dollar shops, dairies, a liquor store, a Samoan grocery store, an MP's office and a bakery. Significant work has already been done in the area to revitalise the shopping centre, with the new Walter Nash Centre and Library upgraded from the old Walter Nash Stadium and community library in 2015 (designed by Warren and Mahoney). This development has been wellreceived by the public, and provides many of the third space qualities seen as desirable for community mental health outlined in the previous chapter. That said, there is a clear distinction between the atmosphere of the new complex, and that of the old shopping centre. Where the new area is well utilised, especially by families during the day and on weekends, the shopping centre often remains a ghost town.

Taita itself is located in upper Lower Hutt City, in the eastern region of the Hutt Valley. It is bounded in the West by the Hutt River, by hills in the east, the Taita Gorge in the north, and the suburbs of Avalon and Naenae in the south. It is a socially, culturally and economically diverse community. The European population of the suburb, while still the majority, makes up a smaller percentage of the demographic than in Wellington or Hutt City generally. According to the latest census (Statistics NZ, 2013), Māori residents constitute 27 per cent of the population, while Pacific people make up about 30 per cent of the population overall (with a higher concentration in Taita North). It skews younger, with 15 per cent of its population aged 15 years and under. Poverty is an issue in the area (Viggers et al., 2008), and it is classified as between 9 and 10 (most deprived) on the Social Deprivation Index. Poverty is seen as a key contributor to poor mental health (New Zealand Government, 2018). That said, Taita is home to an engaged community, with many initiatives aimed at improving safety, support and opportunities in the area (Viggers et al., 2008, p.106-108). 


\subsection{SITE OVERVIEW}

\section{TAITA SHOPPING CENTRE}

1. Walter Nash Centre (and Library)

2. Taita Fish Supply

3. Four Square

4. Indian Takeaways

5. Liquor Store

6. Fast Food Store

7. Dairy

8. MP's Office

9. Youth Centre

10. Dairy/Laundromat

11. Taita Pharmacy / Medical Centre

Fig . 2.1 Overview of Taita

Shopping Centre and

surrounding area

\section{(13)}

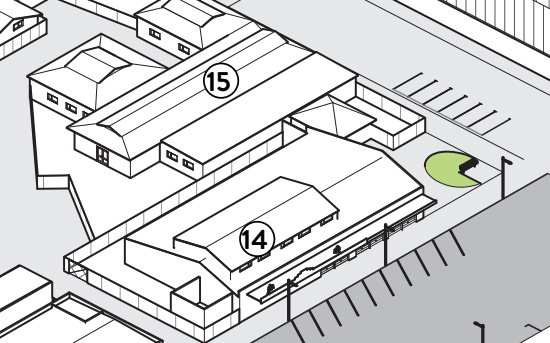

(1)
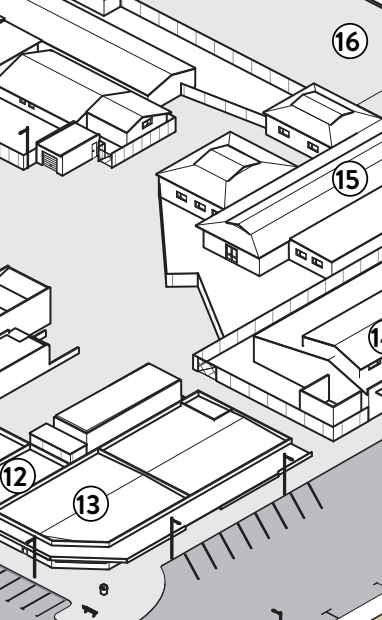


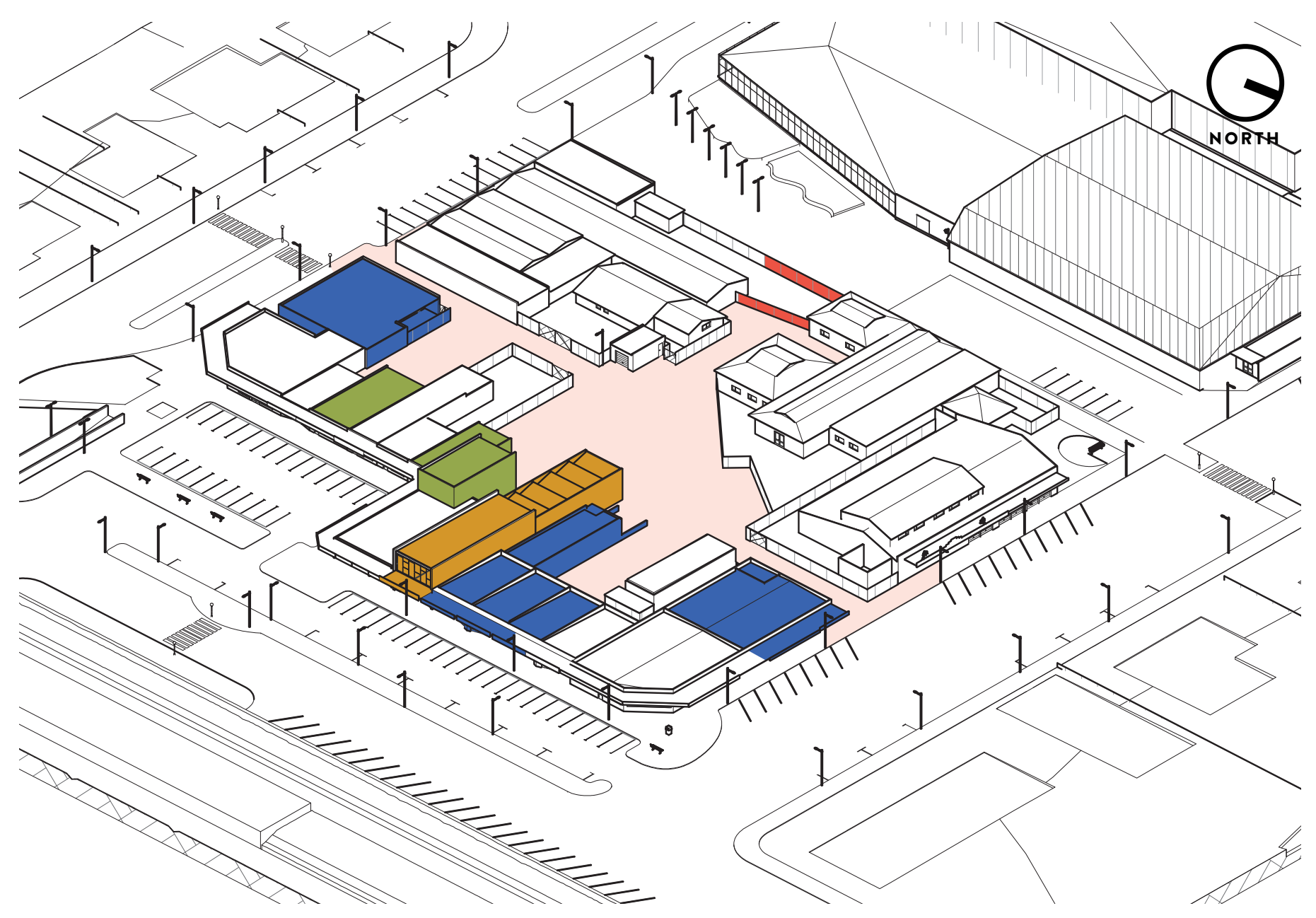

\subsection{SITE ANALYSIS}

There are several interesting elements to the shopping centre itself highlighted above and explored more in the next section (Site Experience). There are several vacant tenancies (in line with the decline outlined in Mawer's thesis). These create a featureless wall of roller doors along big stretches of the street front which make it unwelcoming. From my observation, very few pedestrians actually utilise this part of the shopping centre, and when they do, they tend to drive there and not linger. Interestingly, from the perspective of this thesis, there is an existing medical centre attached to the pharmacy (yellow). While the pharmacy is clearly signposted, the medical centre remains very mysterious. I was only able to find an entrance after spending a long time walking through the site (see next section). The centre also houses a youth centre and an MP's office (green).

With the high number of vacancies in the centre creating an off-putting street front in many areas, it seemed on first appraisal that people might utilise the pathway that runs through the centre as a way of navigating across the site. On site, this was found to be necessarily be true, though the nearby public walkway developed alongside the Walter Nash Centre seems to perform this function. Additionally, that pathway is separated from the shopping centre's interior public space by a small, fenced-off area of one store. There really is no direct connection from the vibrant atmosphere of the Walter Nash Centre to the shopping centre itself.
Fig - 2.2 Key features of current site: vacancies (blue), community services (green), medical centre (yellow), blocked access to WNC (red) 


\section{SUN}

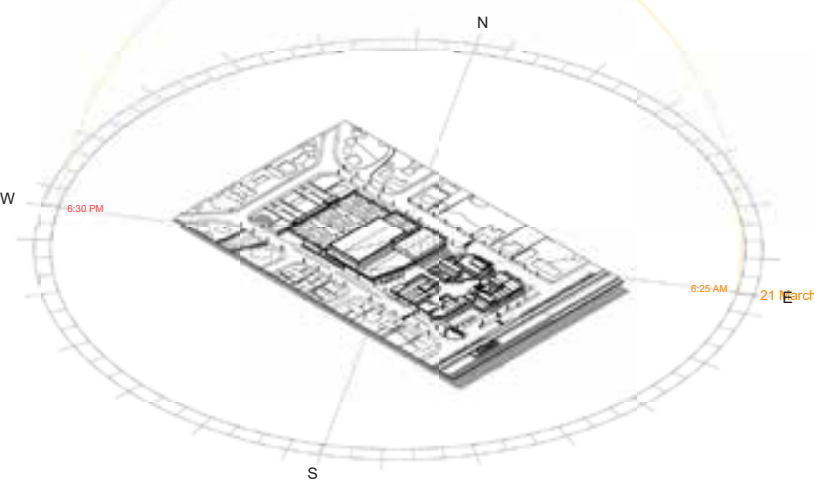

$21 \mathrm{MARCH}$

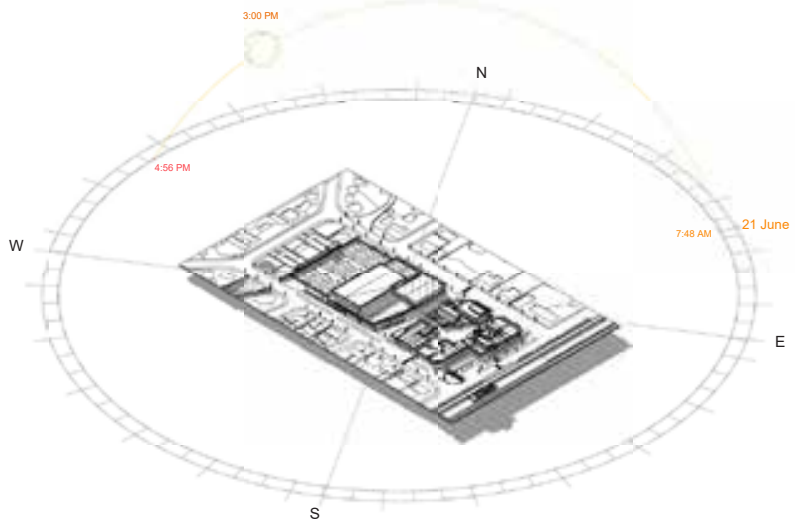

21 JUNE

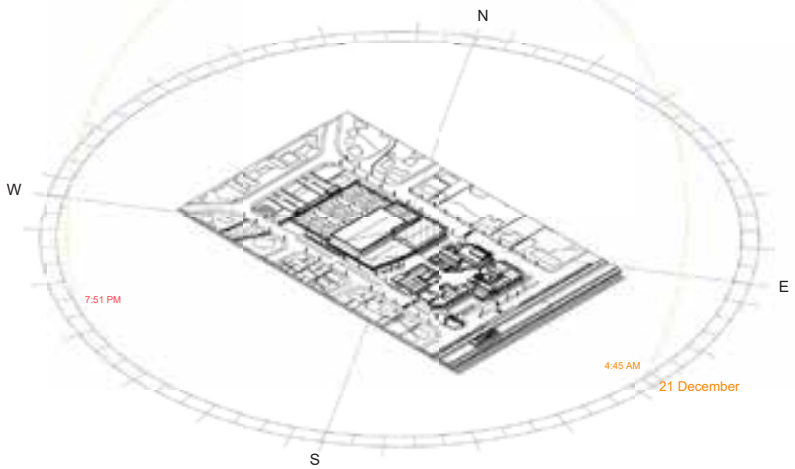

21 DECEMBER

WIND

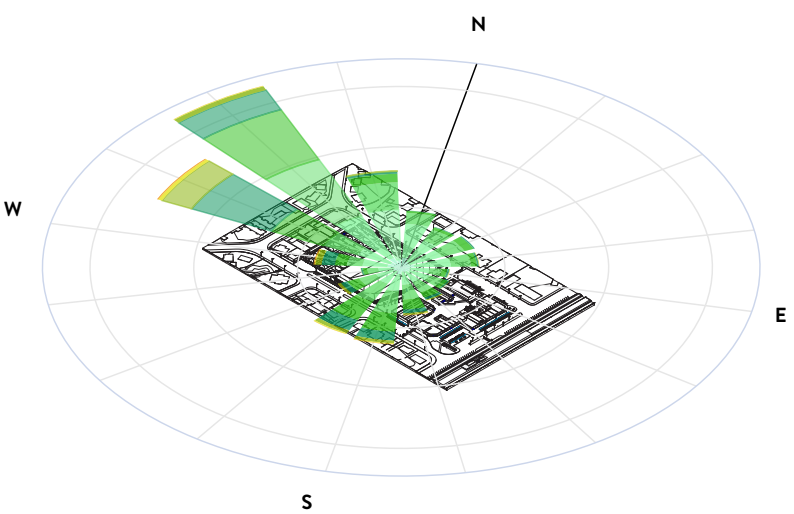




\subsection{EXPERIENCE OF SITE}

"The first time I encountered the site, I was captivated by its innate expression: a series of rooms, overrun by a chaos of vines, moldering and crumbling in the tropical humidity. Palm trees stood here and there amid the thick odour of vegetation - ornamental plants left behind from the previous century's agricultural theme park; the rampant weeds had a festive smell about them."

- (Hu, 2016, p. 15)

This short paragraph is taken from Hu Fang's essays on the design of Sou Fujimoto's Mirrored Gardens. Sited in a "micro-village" in rural China, the project aimed at bringing together art and agriculture. Hu's collection of essays frames the design process and experience of site as a journey, and his writing is expressive: the site is not a series of geographical orientation points which define the architectural object, but instead it is a sensorial experience which provokes memory and emotion. Hu's approach to the site as a 'dialogue' resonated with my experience of site photography. Photography offers a unique way of conversing with and responding to a place, a method which requires the photographer to spend a certain amount of time on site, moving with the natural flows and patterns that emerge there. The taking (or making) of a photograph "closely resembles the way we experience reality, recording sensory perceptions in a slow process of expression - an interpretation of transitions, a fluid, gradual unfolding of the world" (Pearce, 2015, p. 137). Photography was therefore employed as a primary tool for site analysis, in an attempt to approach the place as an assemblage, rather than a situated, static concept.

The site was visited on several occasions, at different times of the day and week. Naturally, different parts of the site were activated according to the different activities taking place on site and in the wider world at each time. On a Monday morning, for example, the site was mostly quiet. I found myself wanting to dive further in, exploring the depths of the Walter Nash Centre. On Saturday morning, the weekend sports crowd were taking full advantage of the sports courts, and I found myself retreating to the quieter zone of the deserted shopping centre - where even here, a new kind of atmosphere had emerged. The following photographs are by no means a comprehensive portrait of the site, but do exemplify some of the unexpected discoveries that can happen in the conversation between place and photographer.

Images in this chapter are all author's own (2019). 


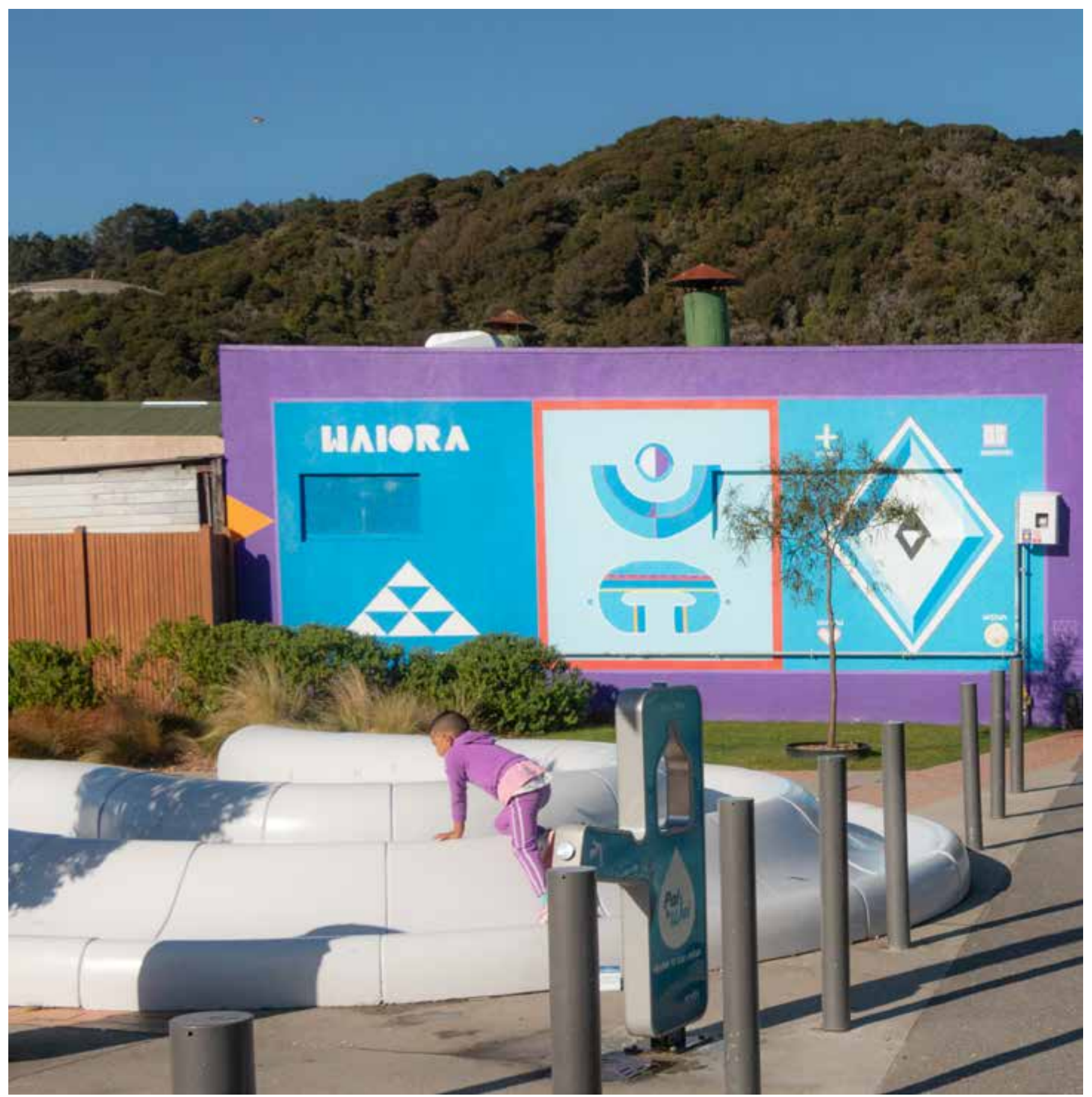

\section{Waiora}

A child plays the benches outside the Walter Nash Centre, with the eastern hills in the background 

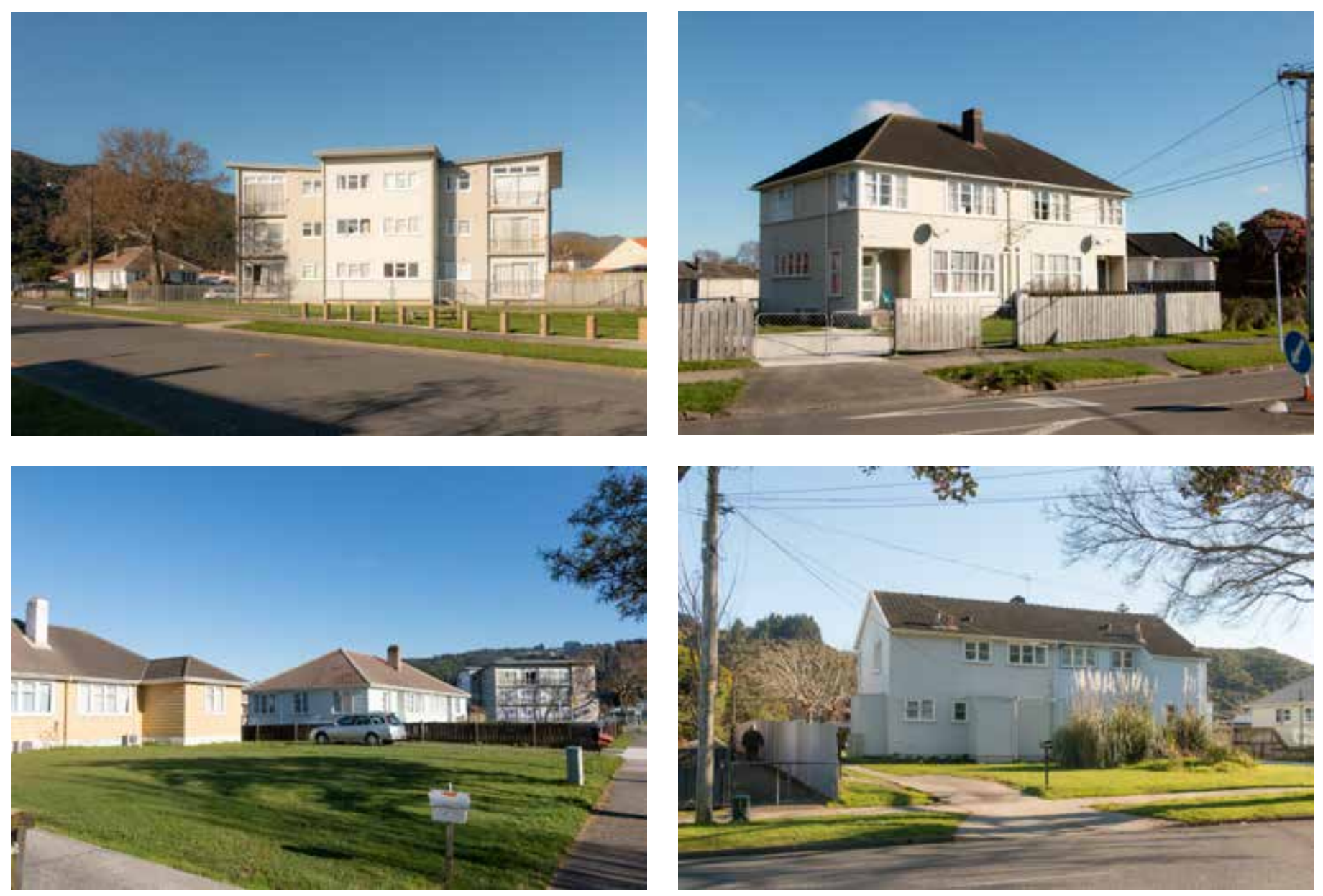

\section{Housing}

The area was built in the 1950s as one of the then-Labour Government's "designer suburbs;" with classic state housing, symmetrically laid-out streets and interconnecting alleyways. 

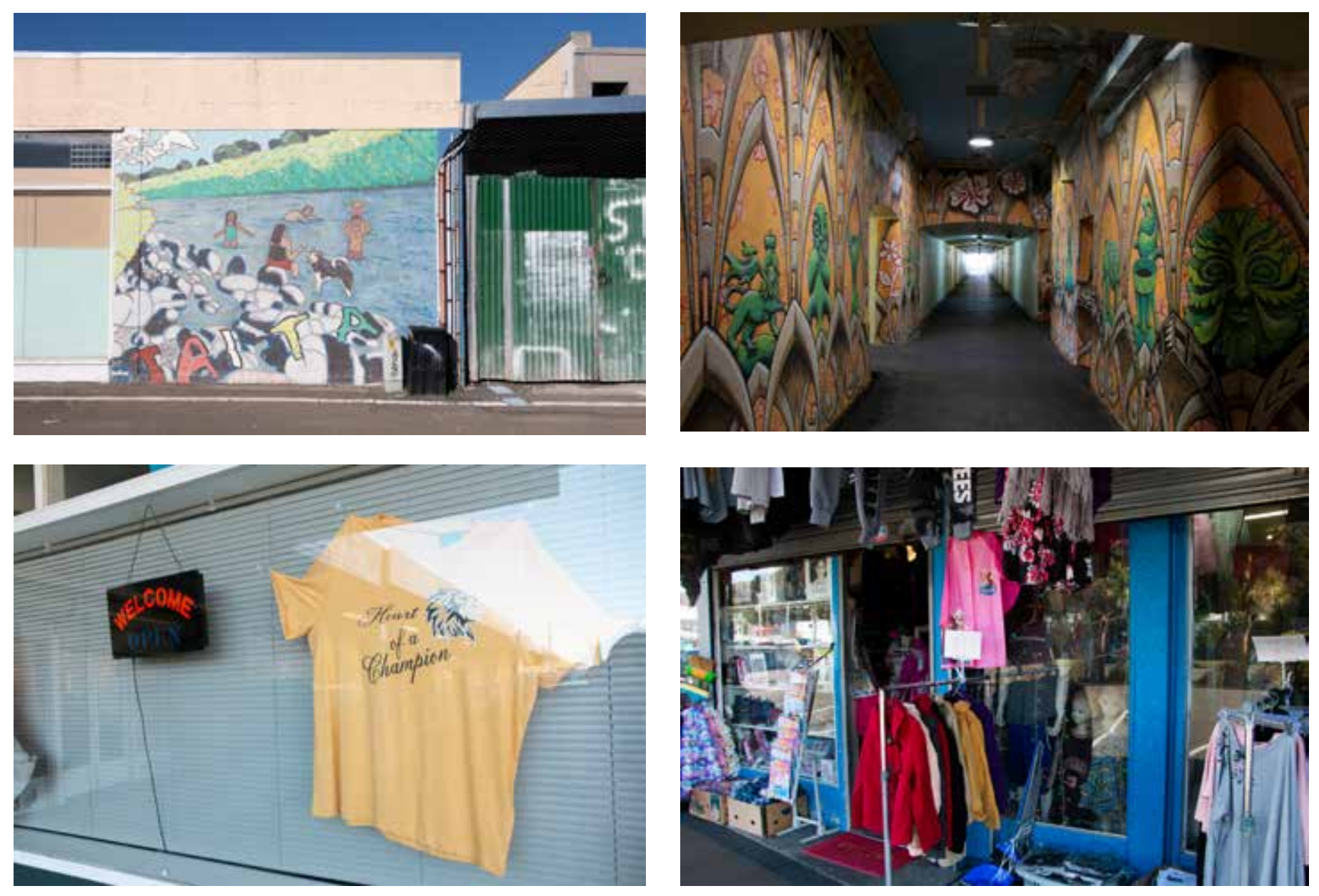

\section{Surface traces}

Murals and displays reflect a vibrant community 


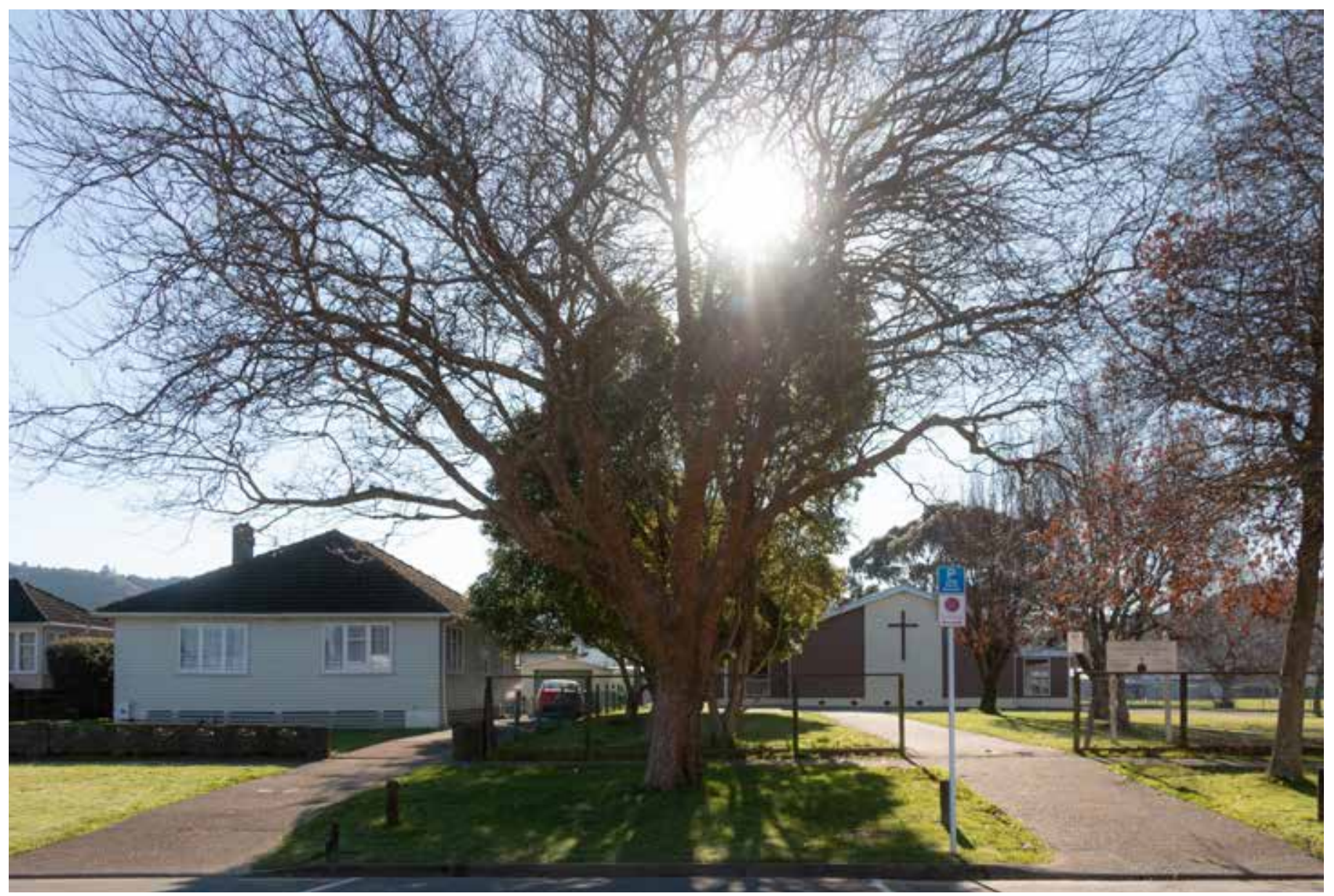

\section{Spiritual Places}

A variety of churches serve the area surrounding the shopping centre, and Taita is home to the Lower Hutt Islamic Centre 

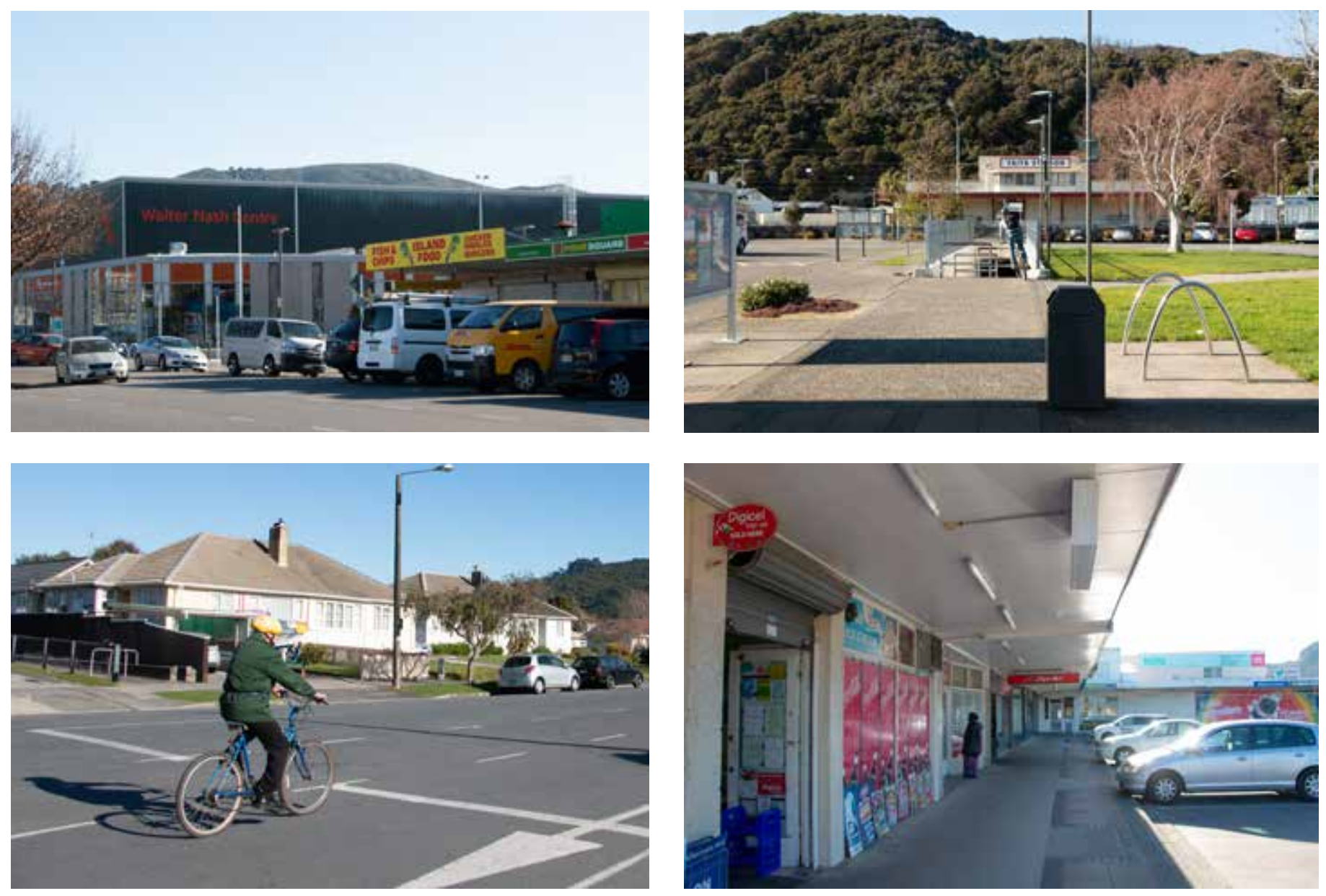

\section{Shopping Centre}

Adjacent to the Walter Nash Centre, and accessible via train, walking, driving and biking, the centre provides many key amenities, such as a local MP's office (bottom right) 

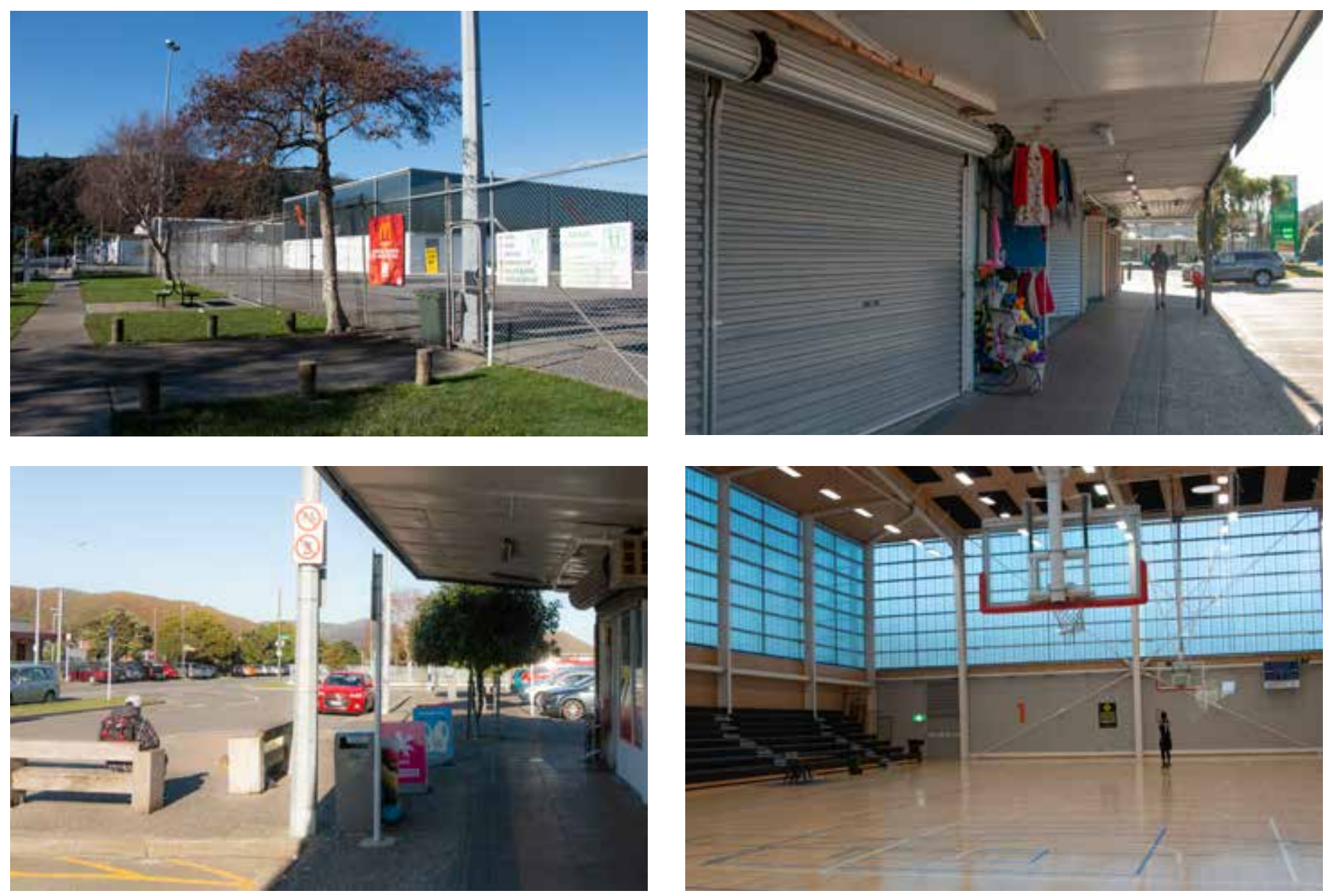

\section{Weekday}

While the interior of the Water Nash

Centre (especially the library) is utilised during the week, the exterior spaces remain quiet and unused. People in these spaces tend to be alone, or in small groups. 

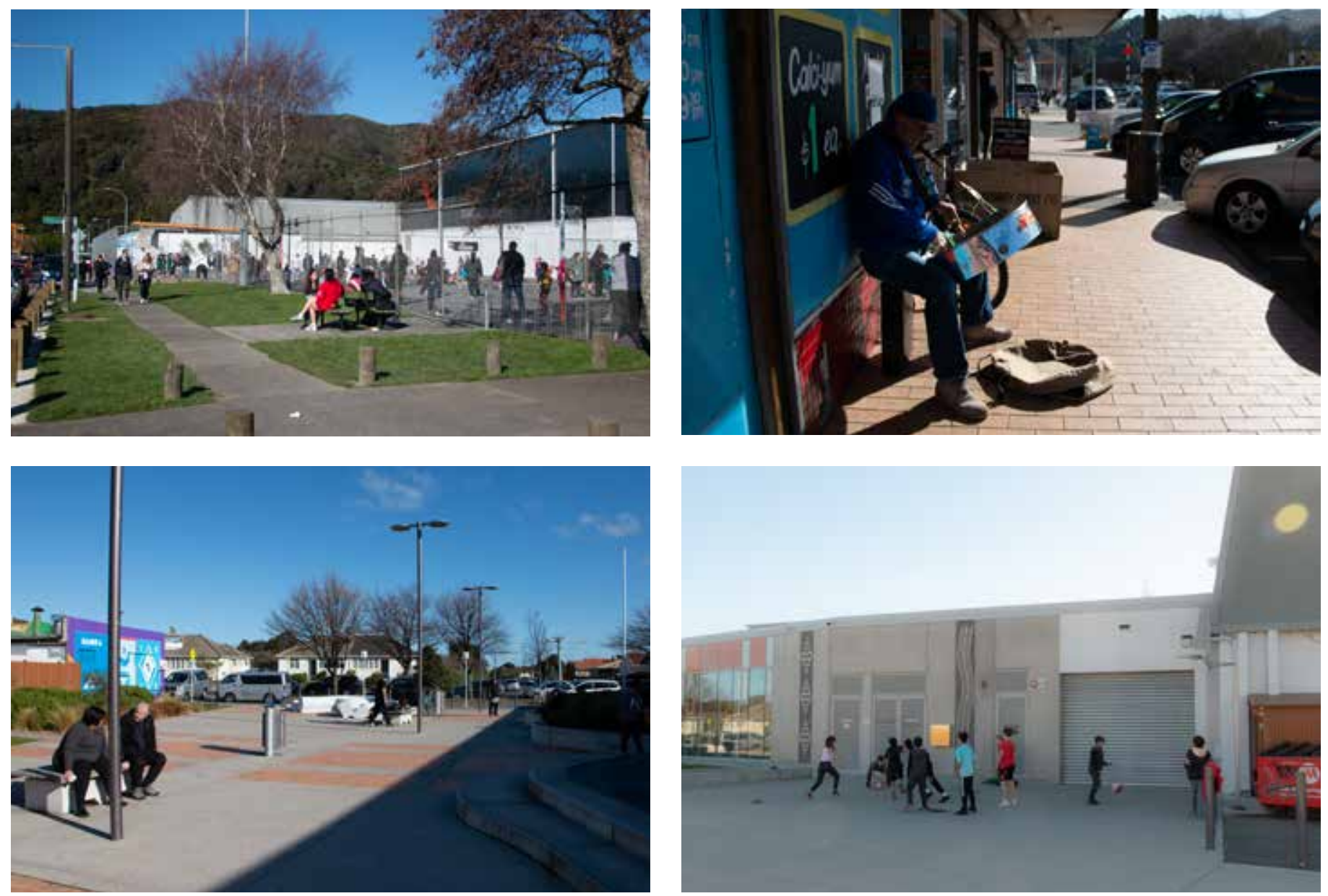

\section{Weekend}

Conversely, in the weekend, the exterior spaces of around the Walter Nash centre are full of lively activity and social interaction. This extends a small way into the shopping centre, but is largely centred around the sports courts. 

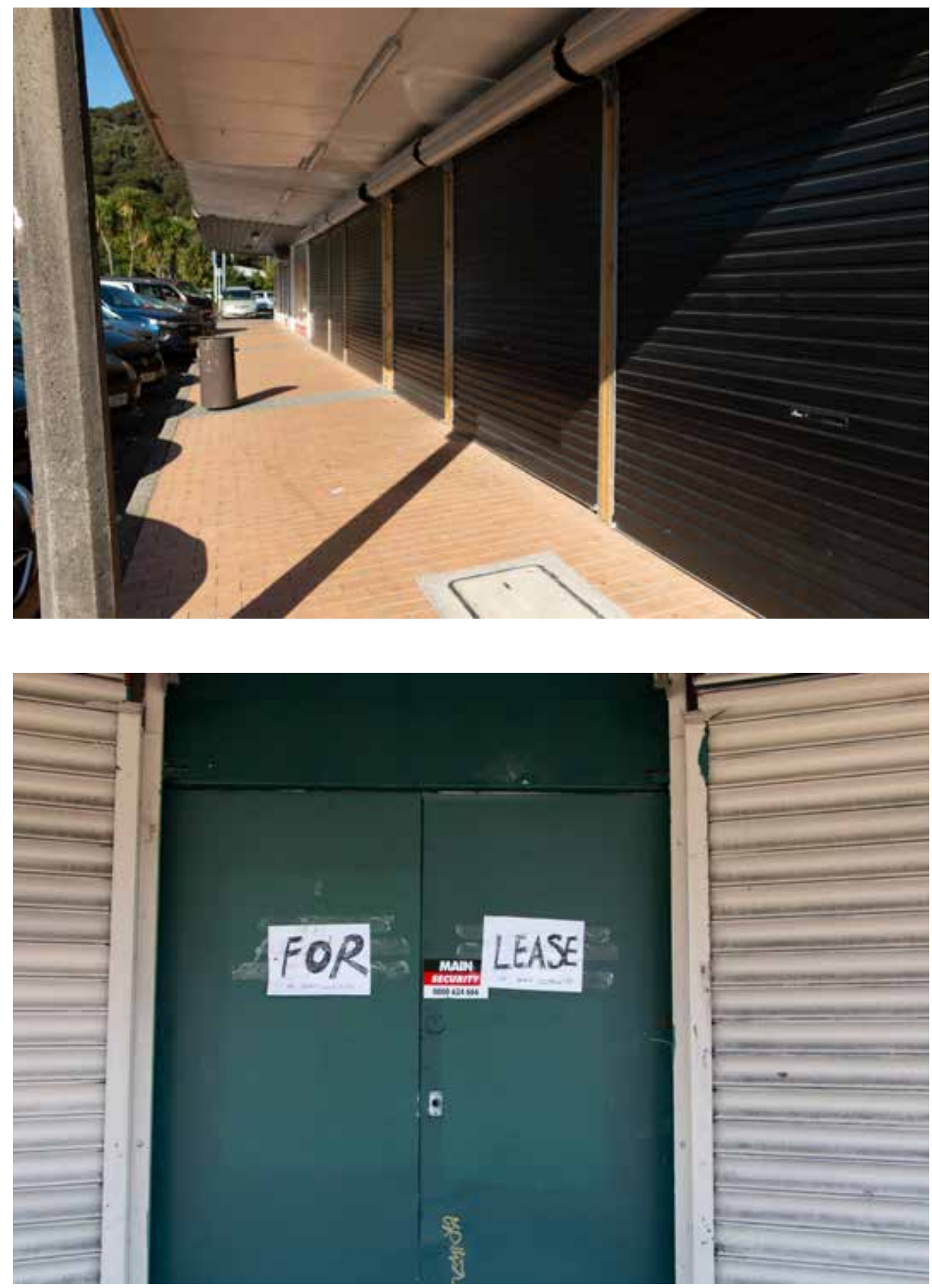

\section{Vacancies}

Even on the weekends, the eastern edges of the shopping centre remain quiet and the atmosphere does not encourage social interaction. A big part of this is due to the many vacancies along this stretch. 

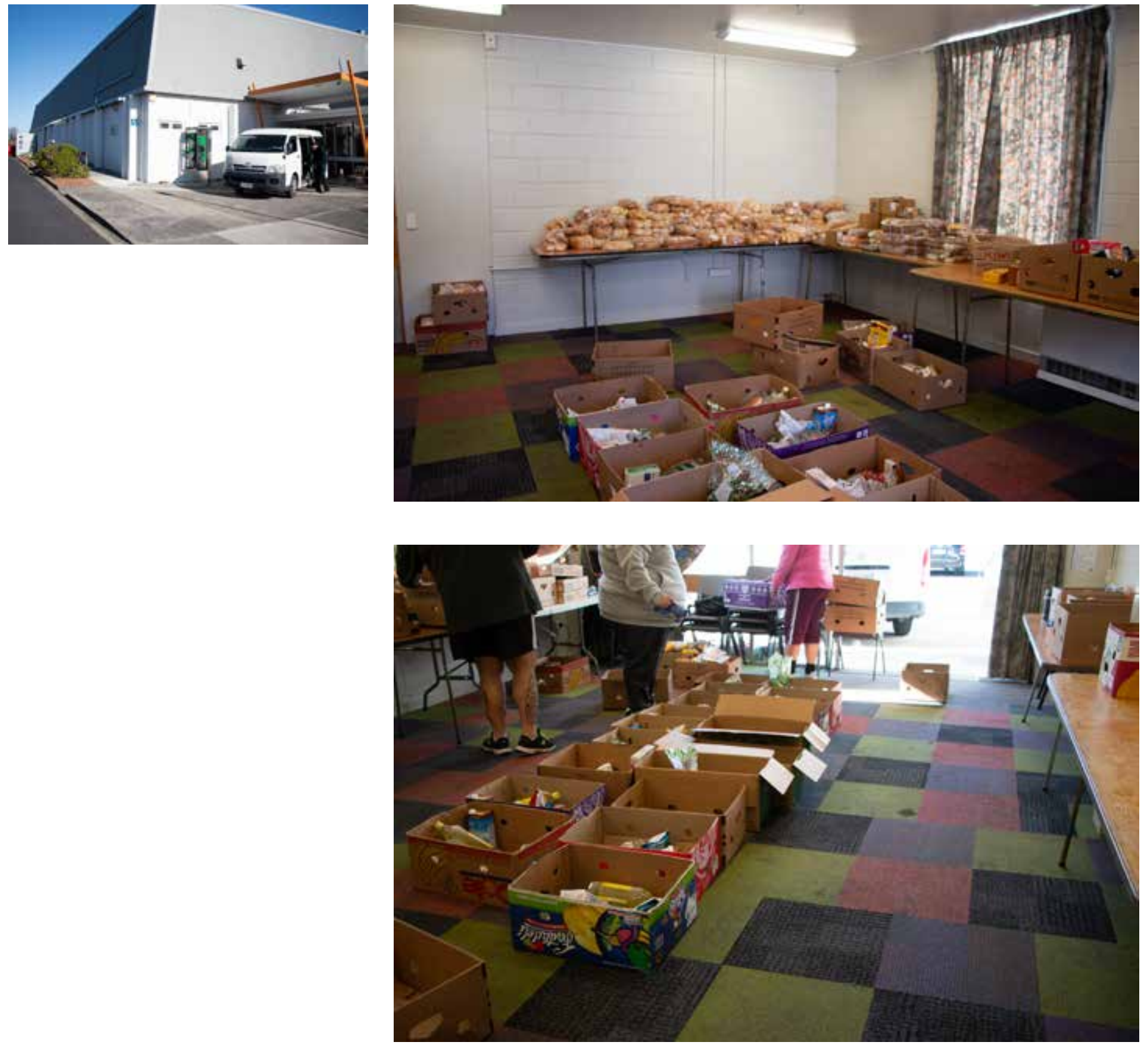

\section{Volunteering}

A volunteer group in the old

Walter Nash Centre organising the distribution of food to struggling families in the area 

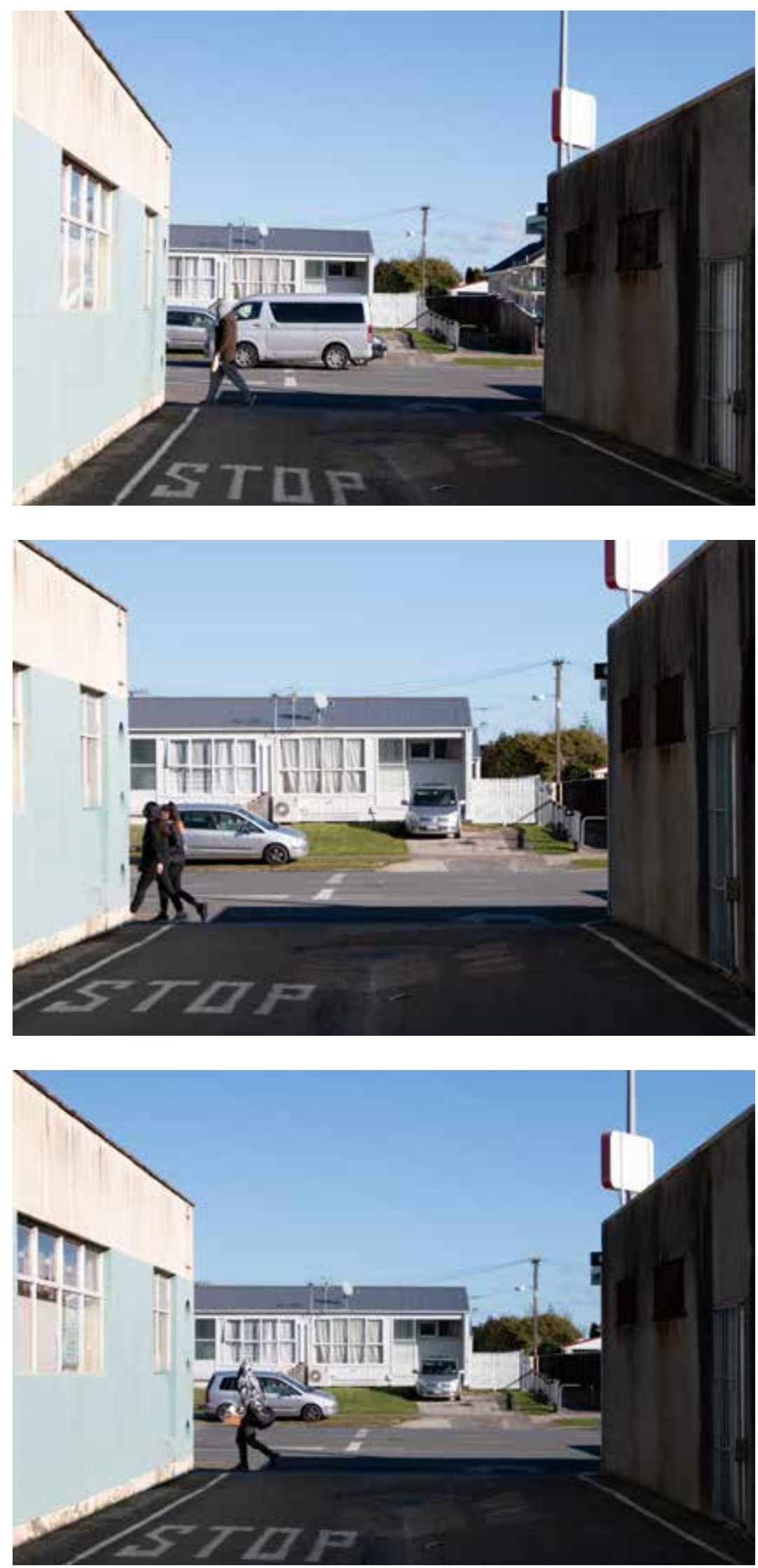

10. Pathway through Centre

It was expected the pathway that cuts through the Shopping Centre to be well used as a convenient access route, but it was found that it is avoided in favour of the Walter Nash pathway. 


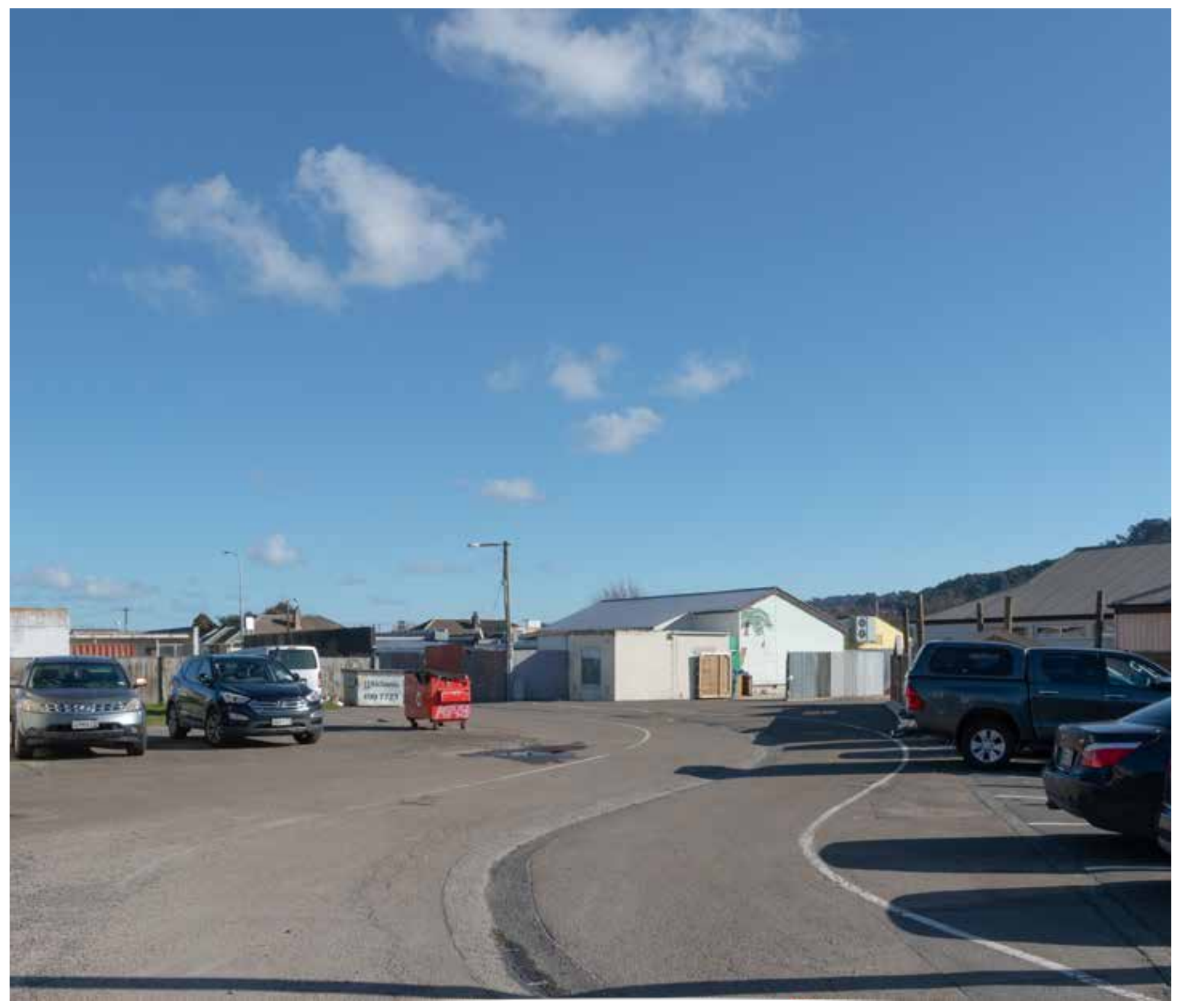

11. Interior Square of Shopping Centre

This path is primarily a service and parking zone, with plenty of underutilised space and no connection to the public space of the Walter Nash Centre. 


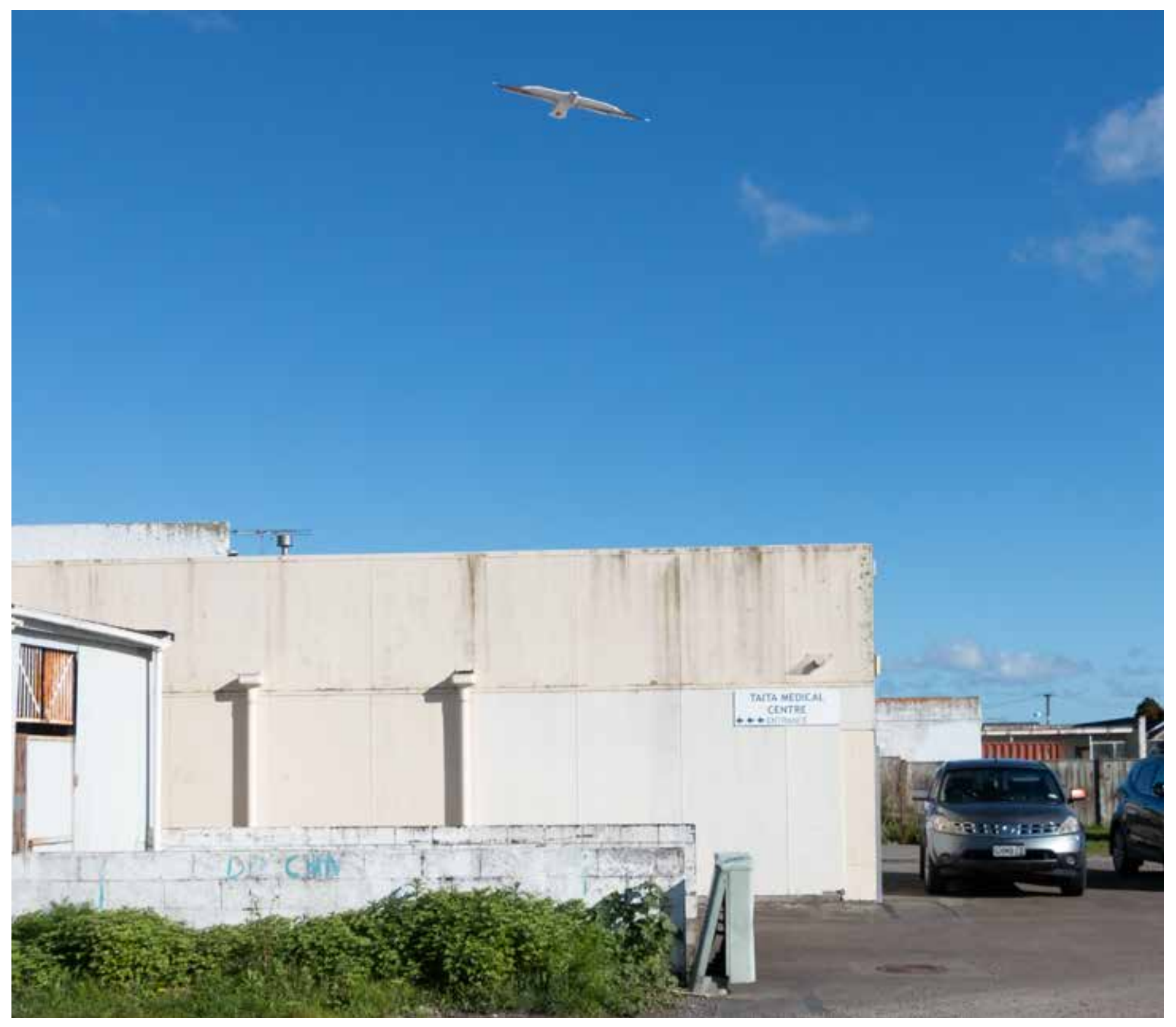

12. Taita Medical Centre Entrance

Strangely enough, this space is where the entrance to the Taita Medical Centre was finally found. 

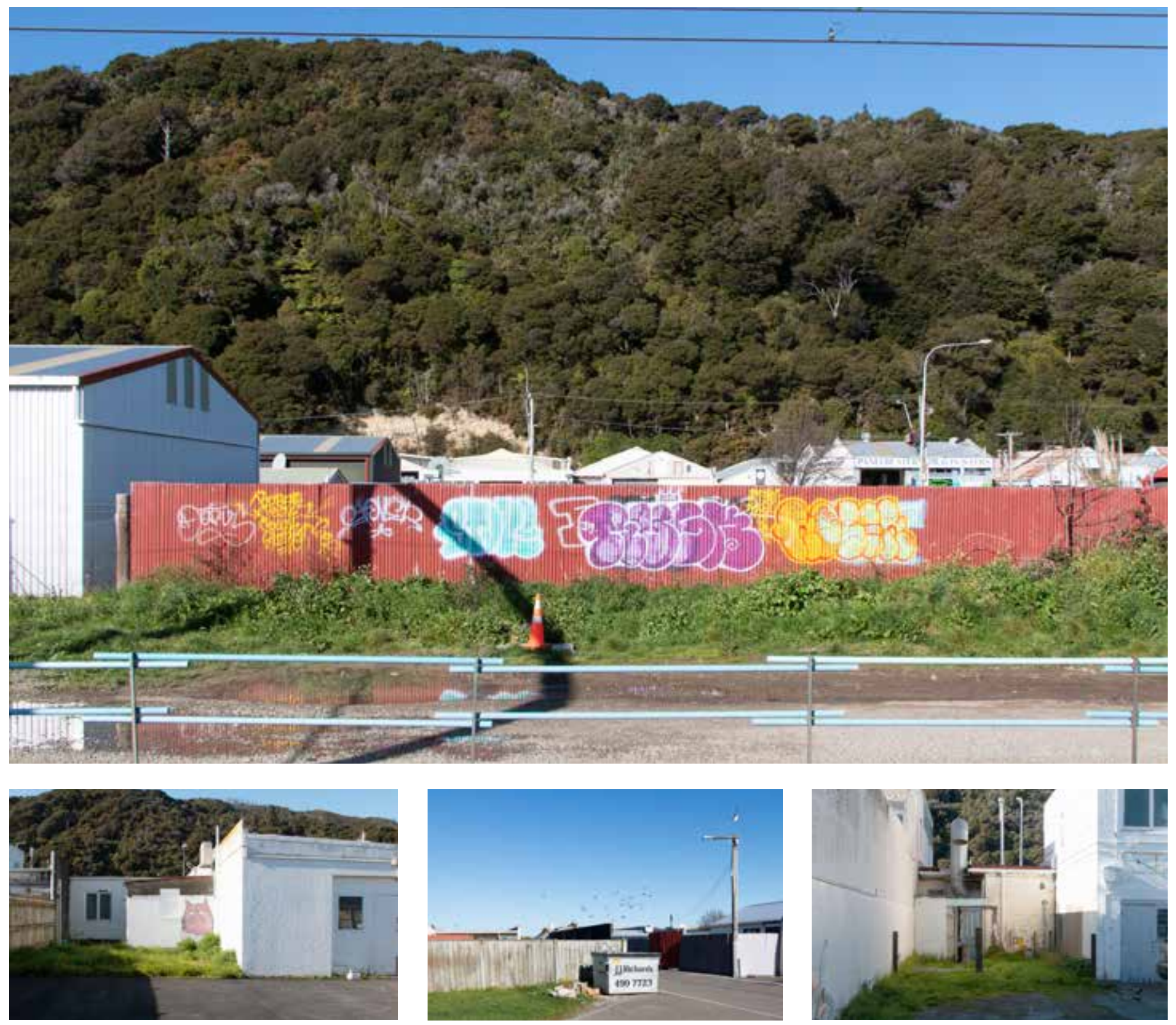

\section{Existing "green space"}

While two green space routes lead to the Western end of the block, the shopping centre is cut off from the native bush of the eastern hills by the train line. Remembering Laws' (2009) alternative therapeutic landscapes, I wanted to try and find what other kinds of "green space" might exist here. 


\subsection{REFLECTION + OPPORTUNITIES}

"The dialogue born out of encounter with the site has the potential to prompt the development of a kind of contemporary architecture, which relates to the imagination of the future but imagination should not be the exclusive doman of humanity: even a tree imagines the moment it encounters humanity, even an "abandoned site" imagines the moment it returns to the world's embrace. These perceptions, these fluctuations of desire, flood in from all directions, converging on this place."

- (Hu, 2016, p.23)

One of the strengths of approaching site as assemblage rather than static conceptual object, is the emphasis it places on the movement of time and changes in "everyday flow" that forms the site as a place. Discoveries were made about the use and atmosphere of the site by paying close attention to these changes in flow through photographic exploration. While some of these discoveries were to be expected, such as the lack of people lingering and social interaction around the main retail area, others were less so. On one quiet, sunny morning, where streets of the main shopping centre were largely deserted, the old building of the new Walter Nash Centre was filled with a variety of groups. Wandering the rabbit warren corridors, one could hear singing from behind closed doors, and observe the many posters and murals that adorned the walls. A volunteer group occupied a meeting room to organise food packages to be distributed to local families. The difference in atmosphere from the streetscape to this interior space was dramatic, and prompts the question of what architecture can do to make this sort of community-minded "coming together" more visible.

Another discovery was in the effect of the design of the shopping centre. At a time when retail was the main priority, the buildings that form the square of the centre were designed to face outward, oriented toward people on the perimeter streets. The path that cuts through the middle of the centre was likely designed solely as a service path, with no need for public amenity. Now that the retail atmosphere has faded, this path forms an interior square which is primarily used for parking, while the perimeter streets lie largely unused by pedestrians as well. The amount of open space in this area, which provides a direct path through the centre, and the fact that access to the Walter Nash Centre could be created without any real demolition, raises the question of whether this perimeter orientation could be reoriented to create a broader pedestrian public space, with 


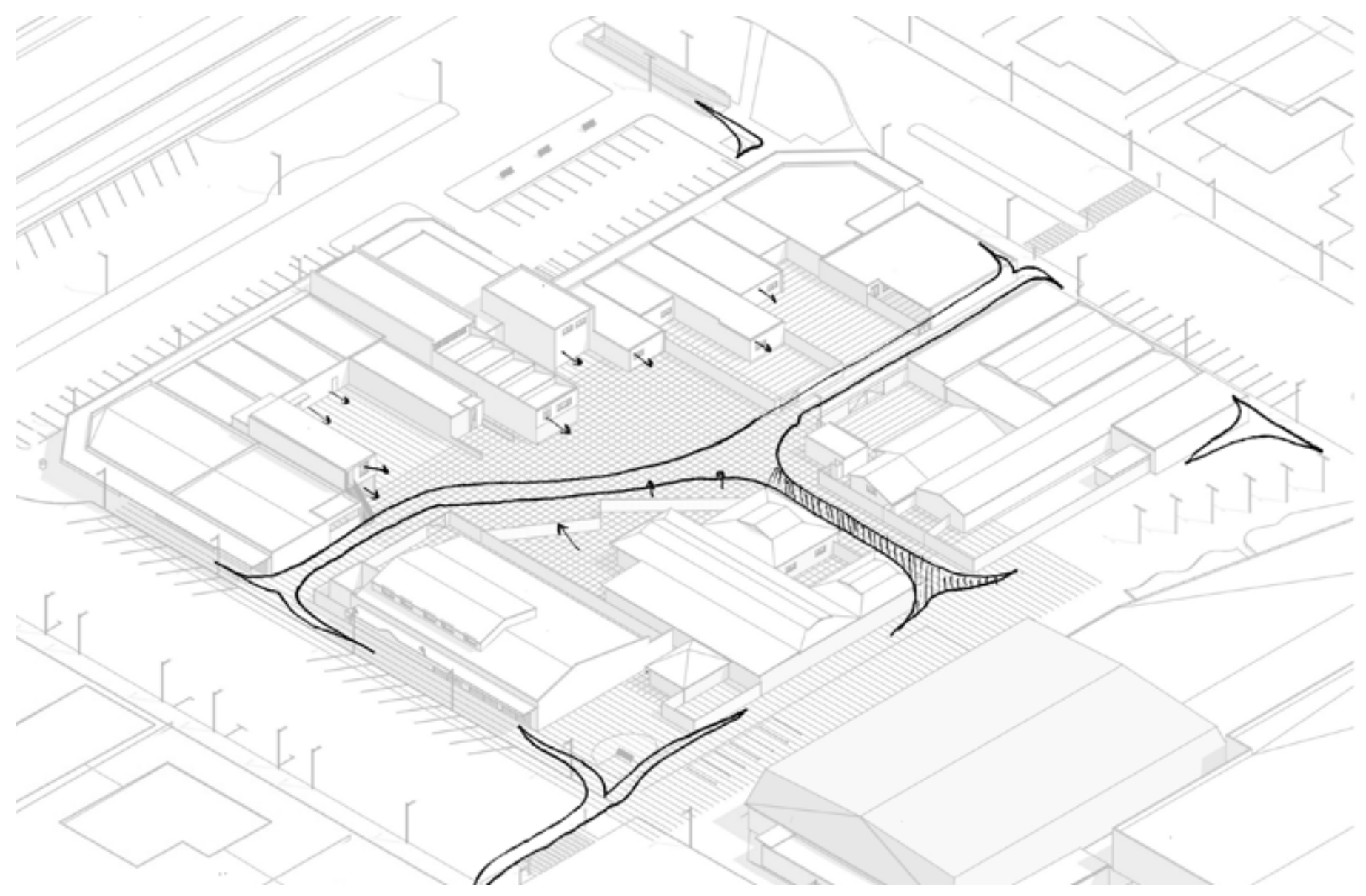

a new relationship to the surrounding shops, services and amenities.

The only current public access to these perimeter buildings is an unwelcoming,

Fig. 4.3 Site with shops re-oriented, and with existing and potential accessways (shaded). hard to spot entrance to the medical centre $(4.4-11$.). That centre sits next to three vacant tenancies, with a large amount of under-utilised space behind them, in the interior square. Given the holistic health and wellbeing positioning taken by this thesis, this appears to be a key opportunity for the development of a community-based third place. 


\section{REFLEXIVE DESIGN EXERCISES}

Explorations in therapeutic materials and processes

1. REFLEXIVE DESIGN RESEARCH

1.1 OCHRE

1.2 MUKA - HARAKEKE

1.3 YELLOW CLAY

2. COMBINATIONS

2.1 CLAY - OCHRE - TIMBER

2.2 OCHRE - MUKA - WATER (+GRAVITY)

2.3 OCHRE - DRAWING

3. REFLECTION 

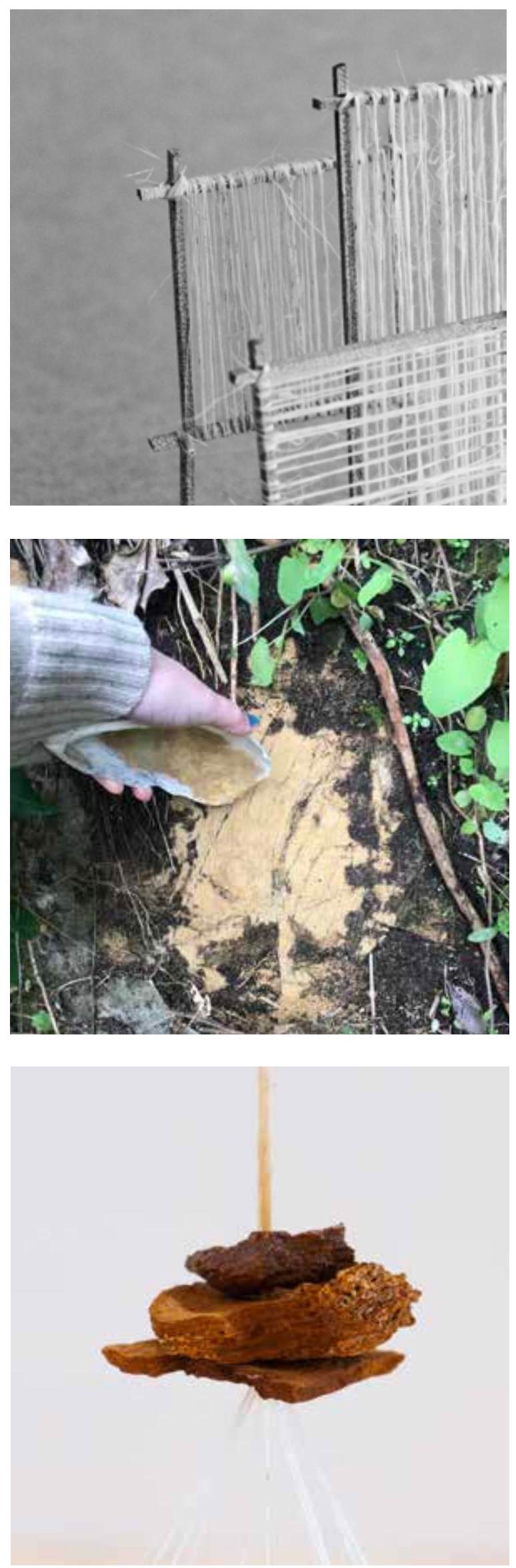


\section{REFLEXIVE DESIGN RESEARCH}

\section{INTRODUCTION}

The literature on therapeutic landscapes suggests that there is a strong correlation between interaction with the natural environment and improved mental health (Bell et al., 2014) (2.2.1). As outlined in Section 2.2.2, this connection has been explored through evidence-based design to produce better environments for people in hospital and other care settings. While this is important, the scientific nature of these studies are generally unable to capture the contextual complexity which surrounds a therapeutic encounter with the natural environment. Efforts to isolate positive aspects of the natural world for the creation of design recommendations involve a methodology which is necessarily reductive: "being outside in fresh air" gets translated into ventilation solutions, "sitting outside in the grass, under the sun" gets translated into window placement, interior planting and temperature regulation.

In reflecting on this, and introducing the following design exercises, I turn again to Nigel Thrift, on affect and emotion:

"Very often, the source of emotions seem to come from somewhere outside the body, from the setting itself, but this setting is cancelled out by such methods as questionnaires and other such instruments. In the second case, the problem is that emotions are largely non-representational: they are 'formal evidence of what, in one's relations with others, speech cannot conceal"'(Thrift, 2004, p. 60)

Here, Thrift highlights the strength of NRT, in that it seeks to understand the semi- or pre-conscious processes that provoke emotion and response in an individual from their setting. It also asks the question, how can we study this response, and design for this response, if it is cancelled out by traditional methods of data capture and analysis?

The following section takes an experimental approach to this problem, drawing on art and architectural design methods - particularly the "process art" of the 1960 s and 70s exemplified by the work of Richard Serra and Richard Morris (Butler, 1999). Originally a Minimalist artist, through his career, Morris began to advocate for the process of "making itself" (Morris, 1968); an emergent kind of practice which privileges material over form, where order is found (or allowed to be lost) rather than imposed. In architecture, where materials are primarily 
the means to support the built object, there is still room for this kind of material exploration. Instead of treating materials as static elements that give texture to the final form, the following exercises begin from a place of active engagement with natural, raw materials, exploring in an open and reflexive way.

On the basis of the positive connection between the natural world and human health (2.2.1), the selection of materials was drawn from the land: harakeke (growing in my garden); ochre (found in a geothermal river); and yellow clay (a common soil type in Wellington). None are typical building materials, though yellow clay is often a by-product of construction in excavation, but they offer a distinct material character. Each material was first researched to understand existing methods of utilisation, before a free, creative exercise was undertaken, manipulating and forming the materials and utilising natural forces such as air, water, and heat.

Images in this chapter are all author's own (2019). 

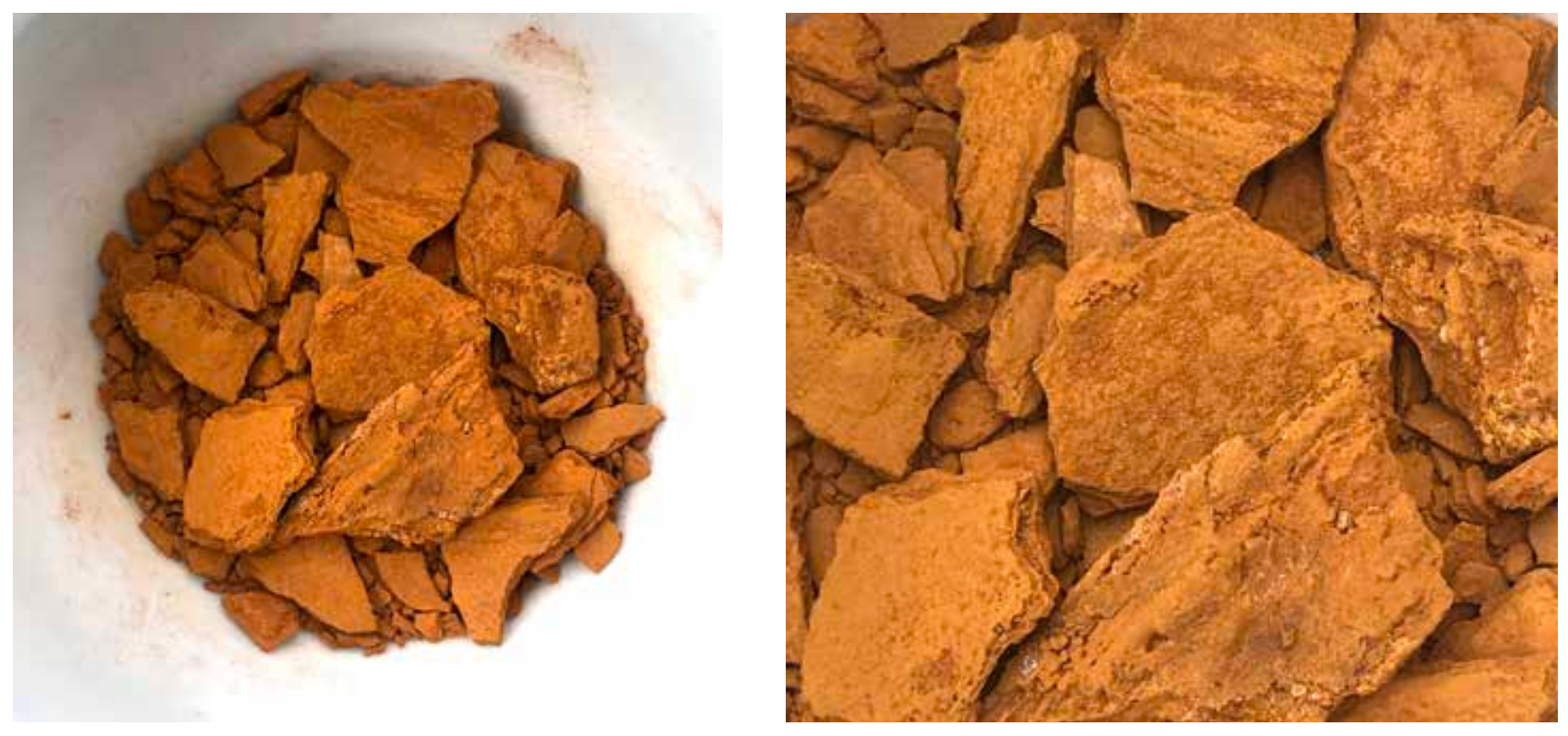

\subsection{OCHRE}

This yellow ochre was sourced from the Volcanic Plateau near Rotorua. A strongly pigmented, layered and crumbling stone, it would stain your fingers upon contact. Yellow or gold ochre such as this is generally composed of clay mixed with ferric oxide. While it was difficult to obtain studies on ochre deposits in the Volcanic Plateau, a study on deposits at Kokowai Springs in Mount Taranaki described it as "essentially siliceous ferrihydrite" (Childs et al., 1986). Ochre, especially red ochre, which occurs when yellow ochre is heated near 700 degrees Celsius, was and is a precious tāonga for Māori (an abundant source of this is Maunga Kākaramea, near Rotorua), used in ceremonies and for decorating whare and weaving. 

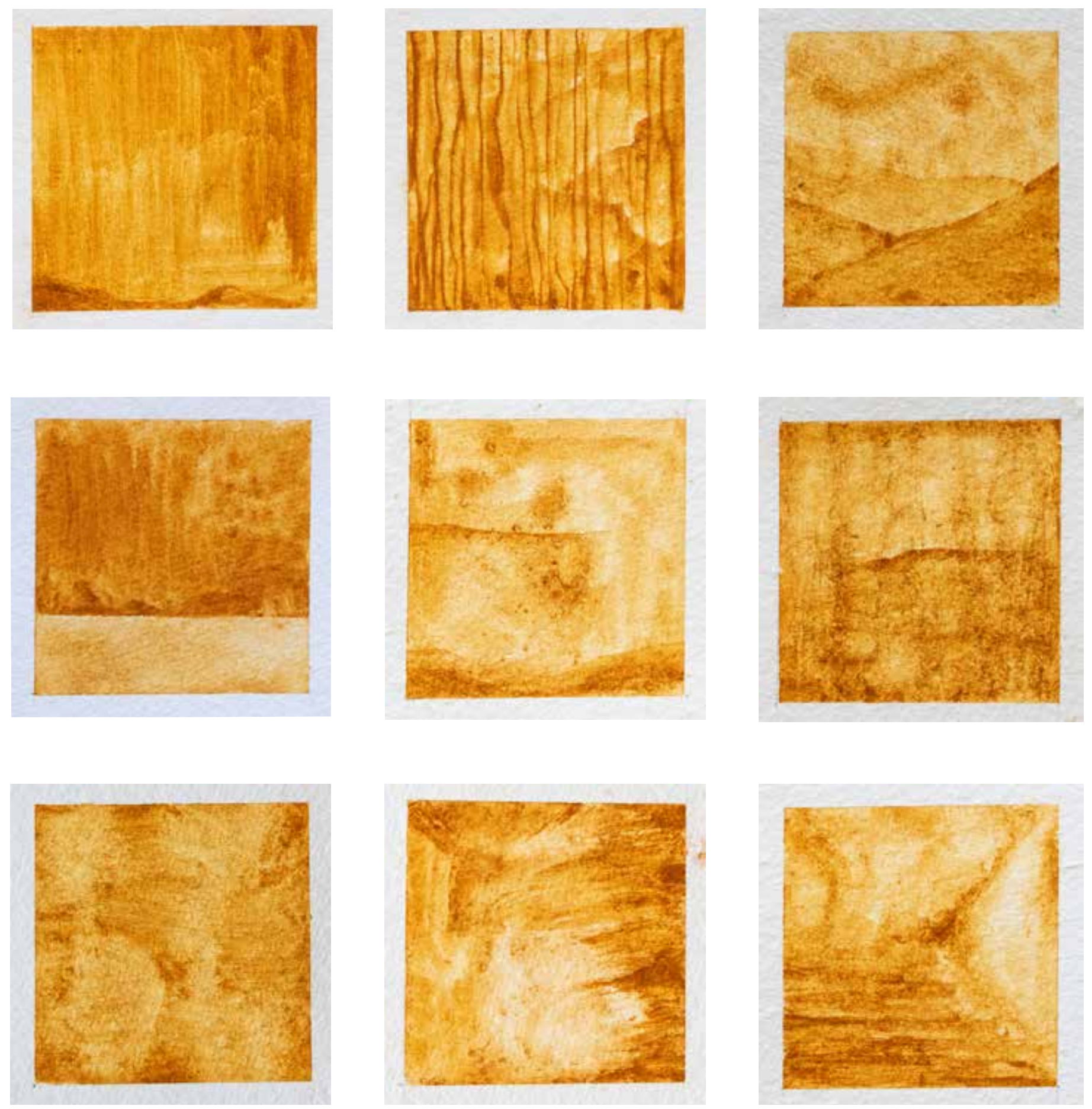
One of the primary sensory attractions of the ochre stone is its strong pigment. It is a highly interactive material: though the stone appears as hard as any other, it leaves imprints and marks when touched, scratched or immersed in water. Even simply holding it in one's hands can leave a stain. The first exercises played with the buildup of this pigment and how it could be moved around the page - how the density was not fixed until it dried, and even then, it could still be rehydrated and manipulated further. The more abstracted images are more successful at showing the accumulation of pigment on the thick paper, and the method of application (push, pull, brush, paint, smudge). Even while trying to resist depiction, the earthy colour and texture of the pigment and painterly approach to application resulted natural or organic looking forms. This unrefined ochre is an imprecise painting material, with a malleable and rough pigment. Knowing when an image was "finished" was instinctive and arbitrary - in many ways, these images can all be seen as the same image at different moments. 


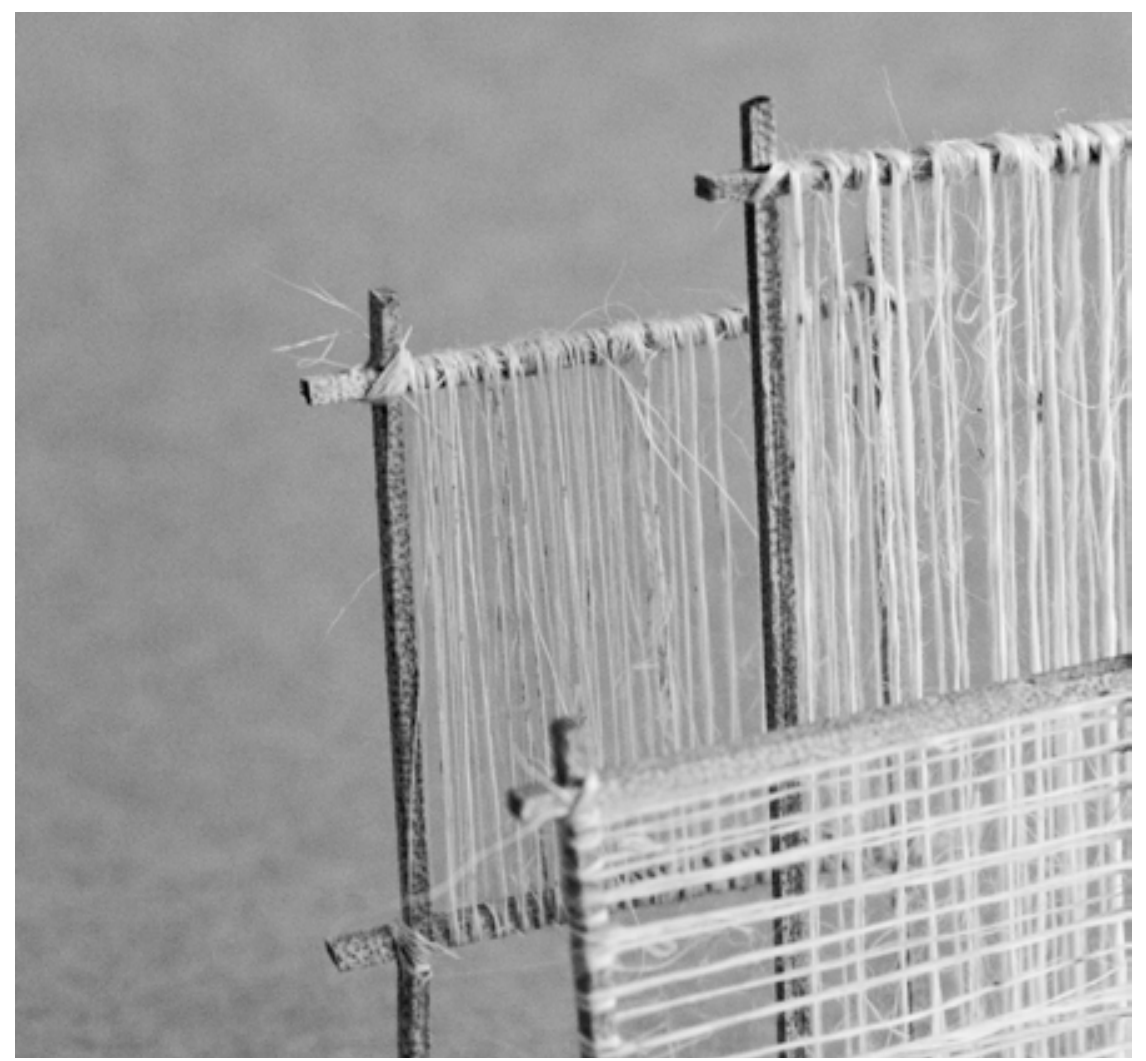

\subsection{HARAKEKE - MUKA}

Muka is the fibre extracted from harakeke (New Zealand flax) leaves and traditionally used for a variety of materials - from twining into nautical ropes, or finely weaving into korowai. Harakeke fibre has a powerful history in Māori art, storytelling and building, as well as in the history of early European settlement. The strength and versatility of the material was recognised by early colonists, and early trade with Māori evolved into a full industry in the late 1800s (Nancy Swarbrick, n.d.). Given that harakeke is considered a tāonga (object of cultural significance), and the author's own positioning as a Pākehā (NZ European) architecture student, research into tīkanga Māori (Māori cultural practices) around how to correctly harvest and produce muka from harakeke was necessary (Puketapu-Hetet, 1989; Taituha, 2014) (See illustration - . Refined muka is available for purchase in select places, and there are many Māori artists who expertly harvest and craft this material into subtle and beautiful korowai, kahu and kete. The aim of this exercise, however, was not to produce a perfect muka product, but to engage with the sensory and affective properties of harakeke, and to gain an experiential understanding of muka as a process.

Following a tīkanga Māori process as closely as possible involved: reciting a karakia, carefully harvesting selected leaves, sourcing a mussel shell with which to haro the harakeke, attempting to strip each leaf so that maximum fibre and length could be retained, using hand and leg to miro (twist) the fibres into 
1.

"Tenei matou i inoi atu ka koe

e Tane Mahuta; Nau enei

rawa kua poipoia; Nau enei

hua kua whakatipu; Tenei au

he piapono whare tohungatanga

raranga; Homai ngā rau o tenei

taonga te harakeke."

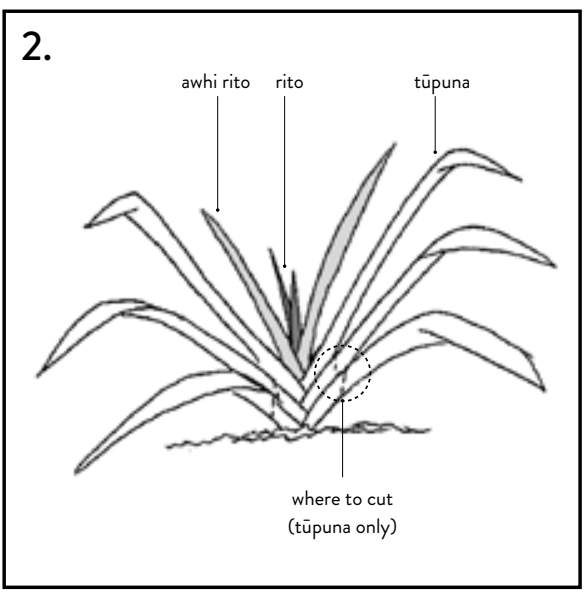

5.

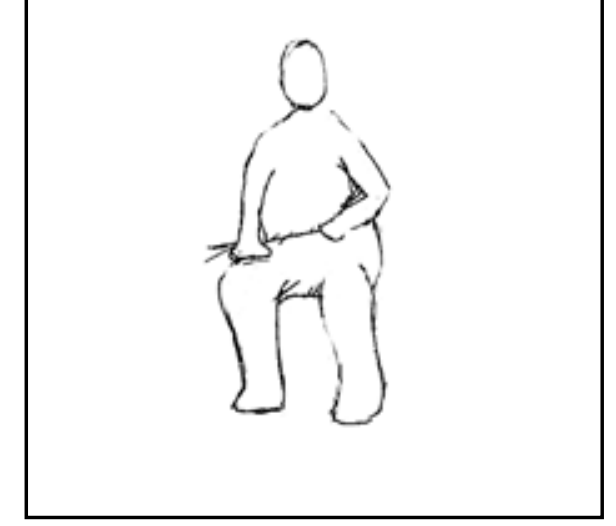

4.

Tīkanga Māori for harvesting harakeke

Harakeke, and the muka (fibre) that can be extracted from it, are an important tāonga in Te Āo Māori. The process illustrated above is more richly explored in a Masters thesis on the subject, carried out by Gloria Taihuta (2014), and outlined in a book by reknowned weaver Ererenoa Puketapu-Hetet (1986).
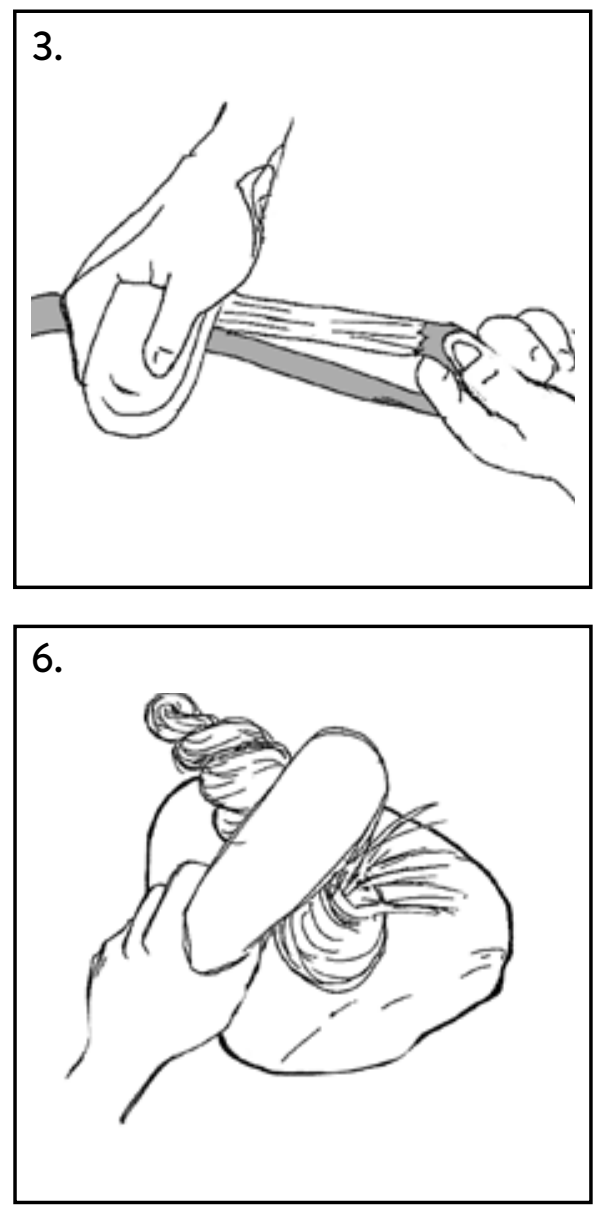

1. Karakia ō te harakeke

2. Harvesting harakeke

3. Whakapa \& haro

4. Miro

5. Whiri whenu

6. Patu whenu 


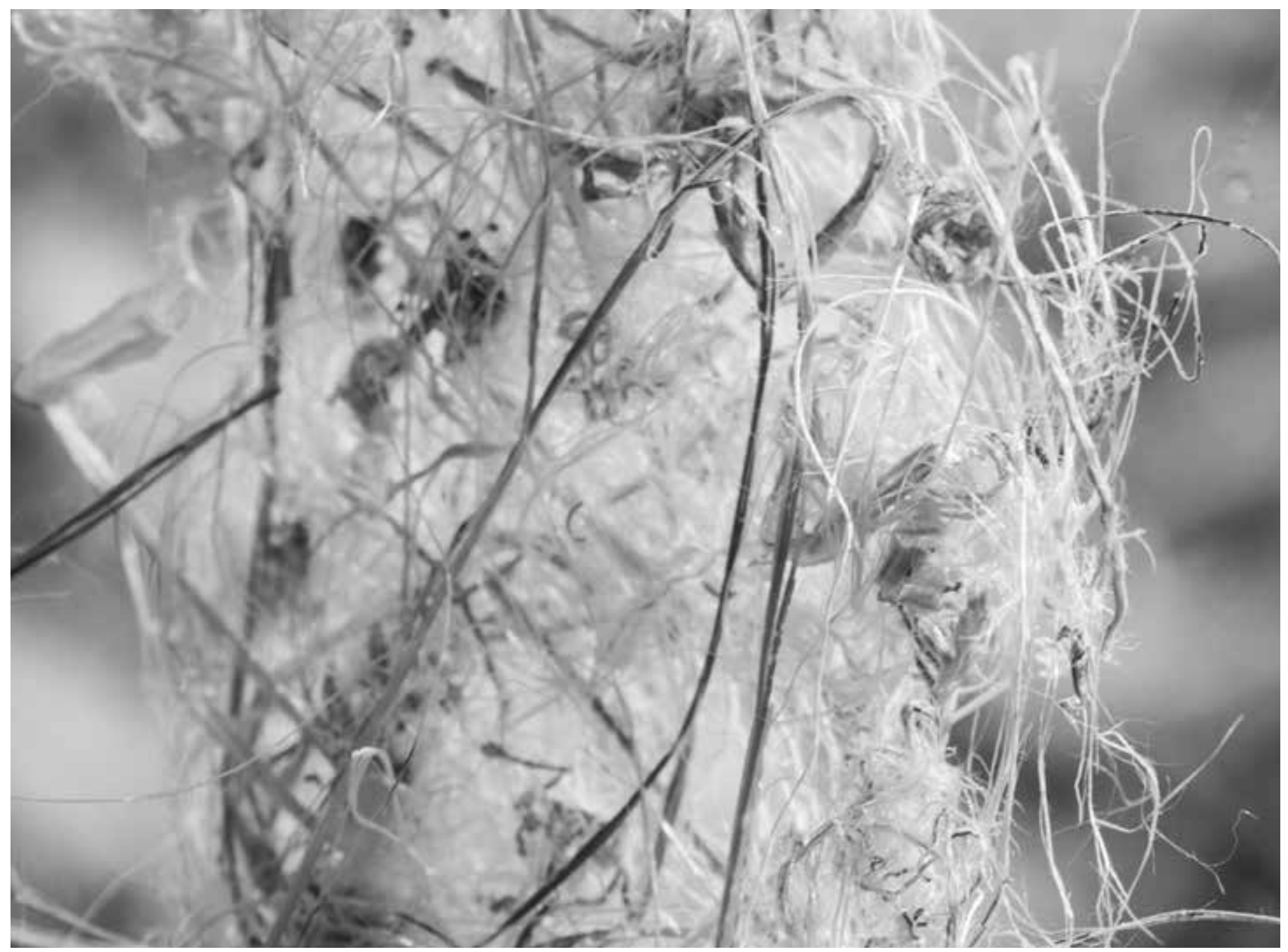

stronger threads, buying a new pot that had not been used for food to boil the threads, using a stone to patu (beat) the muka, and finally, hanging it to dry in the bright sun. All of these steps carried their own weight, as a series of activities which activate all of the senses of the person carrying out the process. In harvesting and producing muka by hand, the individual can see, smell, hear and feel the material transform. The sensory nature of this activity has potentially high therapeutic value for stress relief and elevation of mood (Sutton \& Nicholson, 2011; Wilson et al., 2016), as well as the benefits associated with nature interaction (Ulrich, 1984).
Above: Muka fibres mixed with para (top layer of harakeke leaf) have their own sensory qualities

Opposite: Harakeke threaded around wooden frames to illustrate texture and opacity 

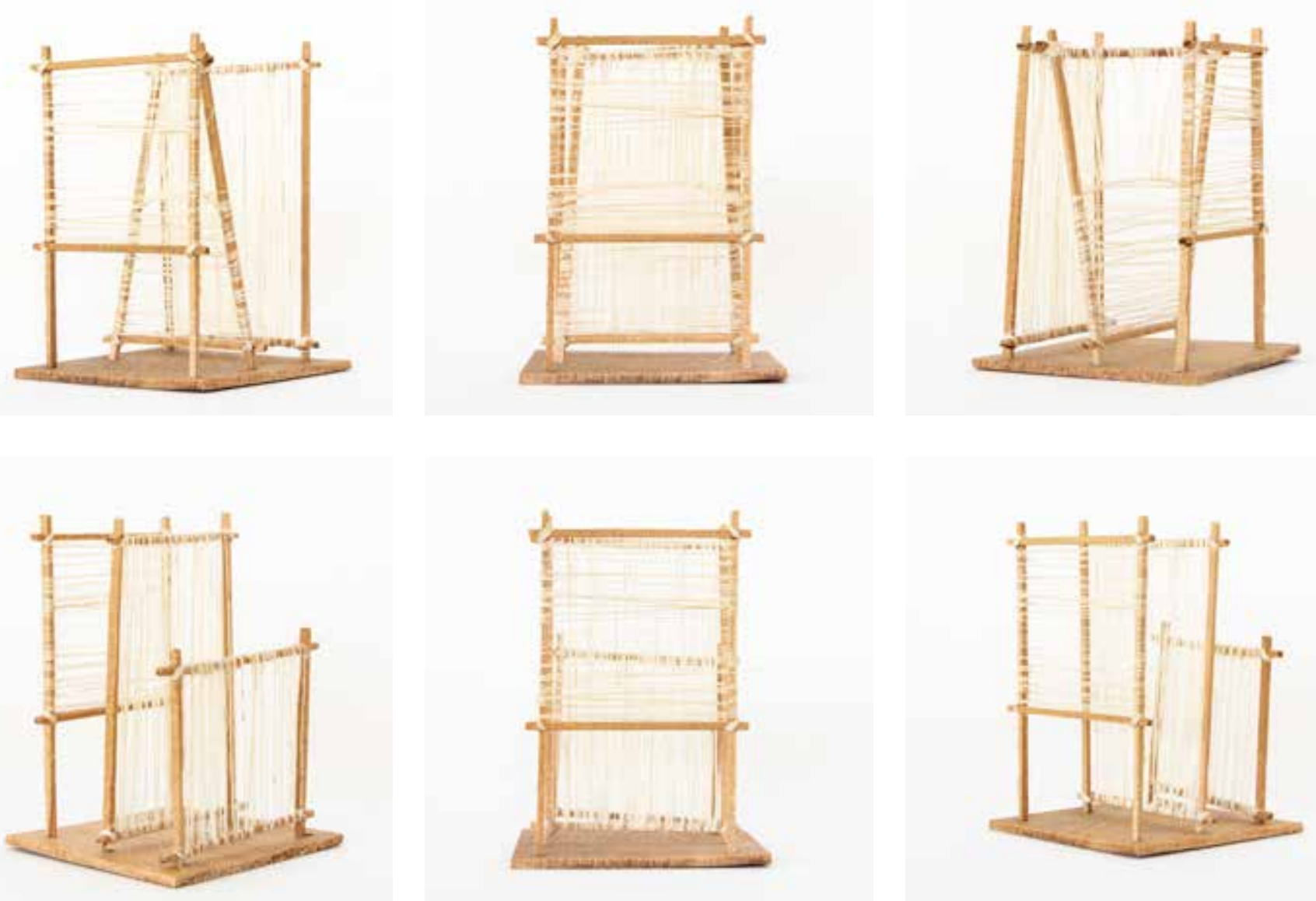

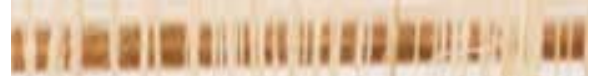
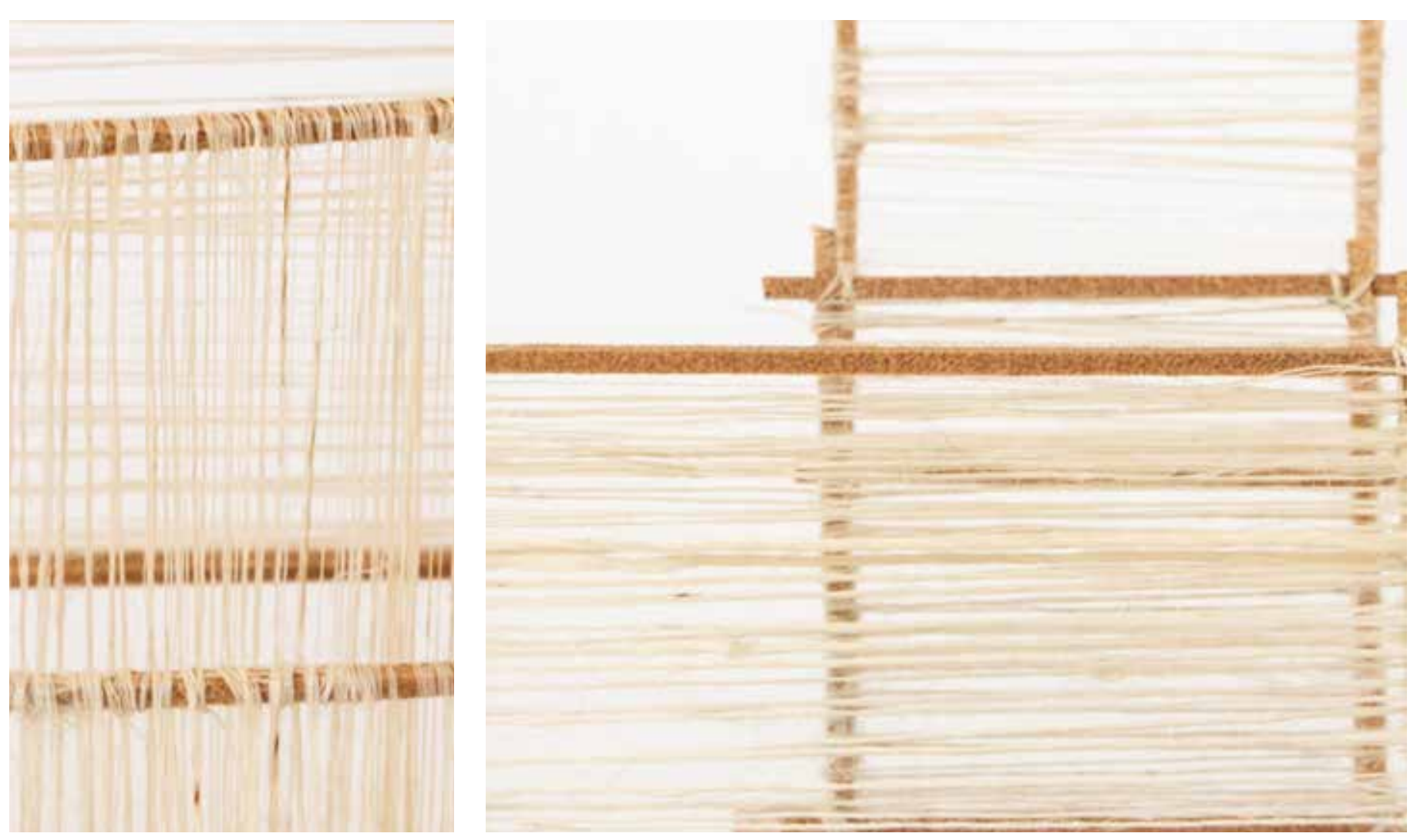


\subsection{YELLOW CLAY}

The yellow clay used in these exercises is extracted from a yellow clay loam present in the author's garden. These clay loams are found in abundance in layers beneath the subsoil of the Wellington region (Milne \& Northey, R. D., 1975) and are commonly extracted during the construction of roads and buildings. As former head of the NZ Soil Bureau, H. S. Gibbs, noted:

"soils are special bodies of materials with a particular relationship to the place where they occur. They "belong" to Wellington because the local climate, the plant and animal life, the drainage, the shaping of the land surface and other natural conditions all take part in making the soils out of the mineral and organic materials." (Gibbs, 1960)

Soil, as Gibbs says, both contributes to the formation of place, and is formed by both human and nonhuman elements of that place. It has its own agency, which is often overlooked during the construction process, or in the use of soilextracted materials such as clay as architectonic elements.

The composition of the unrefined clay, extracted from a clay bank using the same mussel shell used to haro harakeke, is coarse and sandy, with a unique way of packing and forming. By creating a slurry with water, and straining the clay several times (first with a sieve, then with a loose-weave linen bag), a more refined material was produced, reminiscent of potter's clay. What wet, this refined clay was sticky and malleable. When dry, it was sandy, delicate, and light yellow in colour. The exercise was undertaken in a very free, creative way in an attempt to disentangle the material from the architectural associations of bricks and concrete and other traditional building materials. Instead, the exercises focused on the natural qualities of sticky, brown clay versus hard, dry clay; two very different textures with a direct link to the humidity, saturation and temperature of the wider environment. 

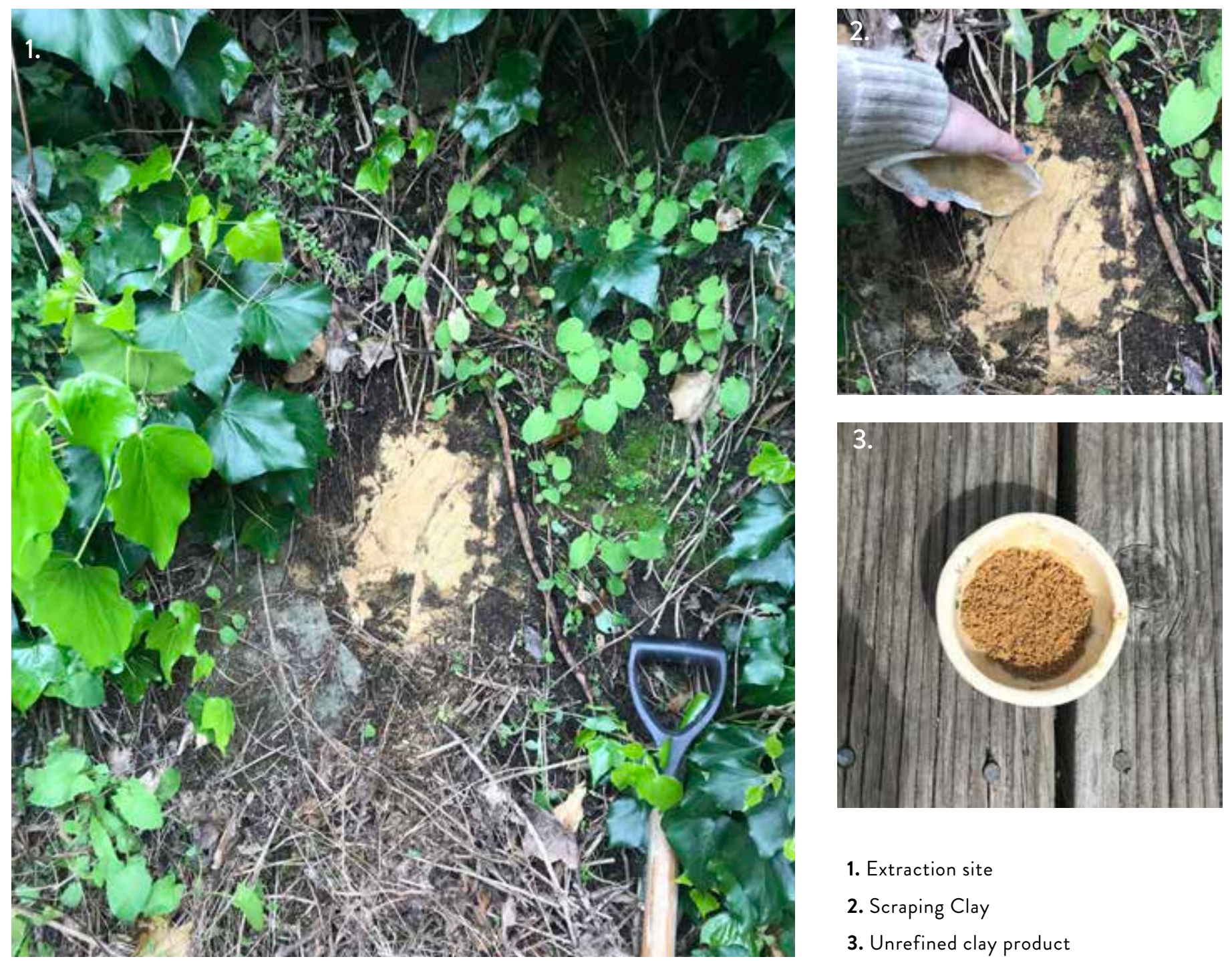

1. Extraction site

2. Scraping Clay

3. Unrefined clay product 

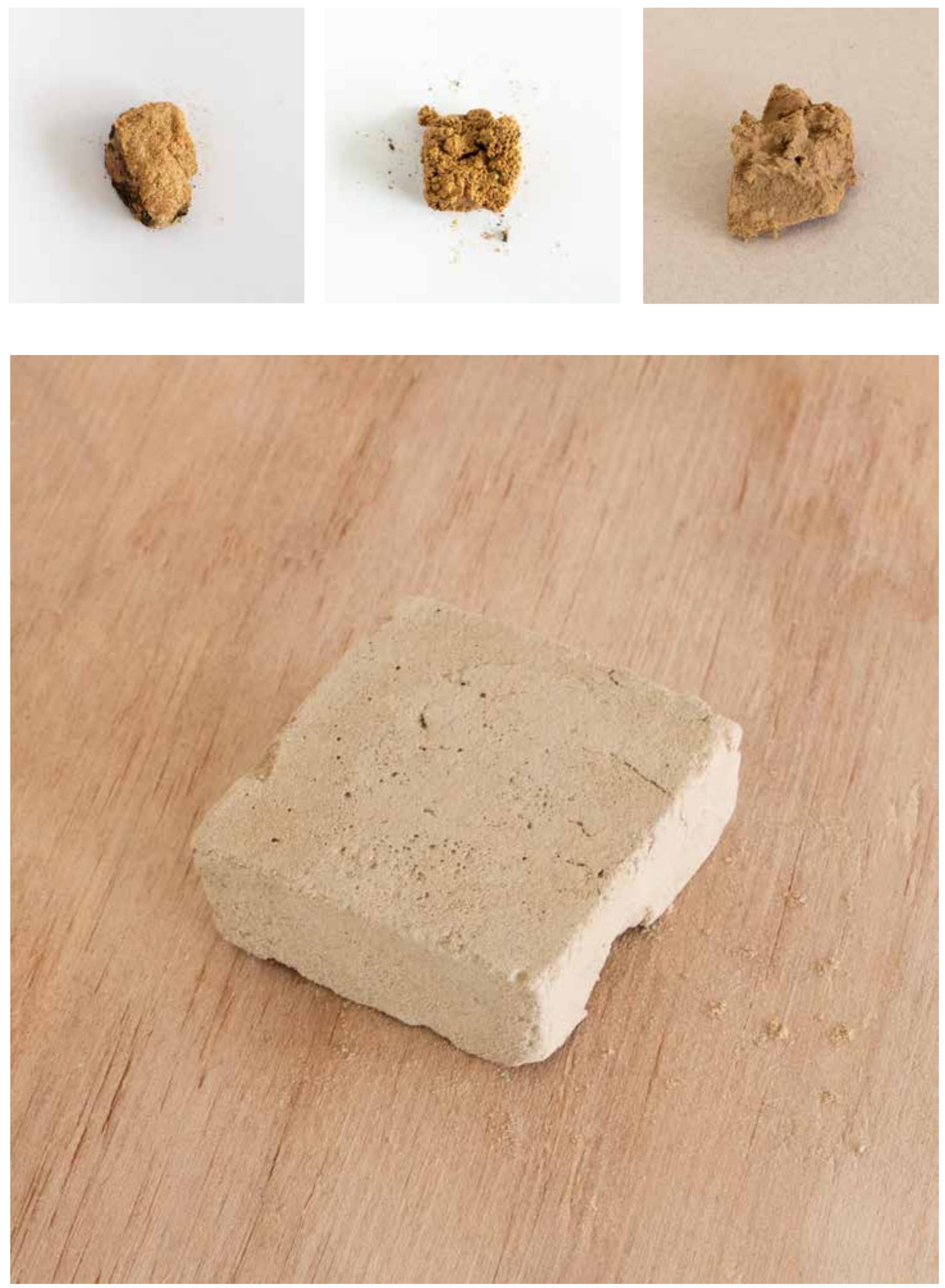

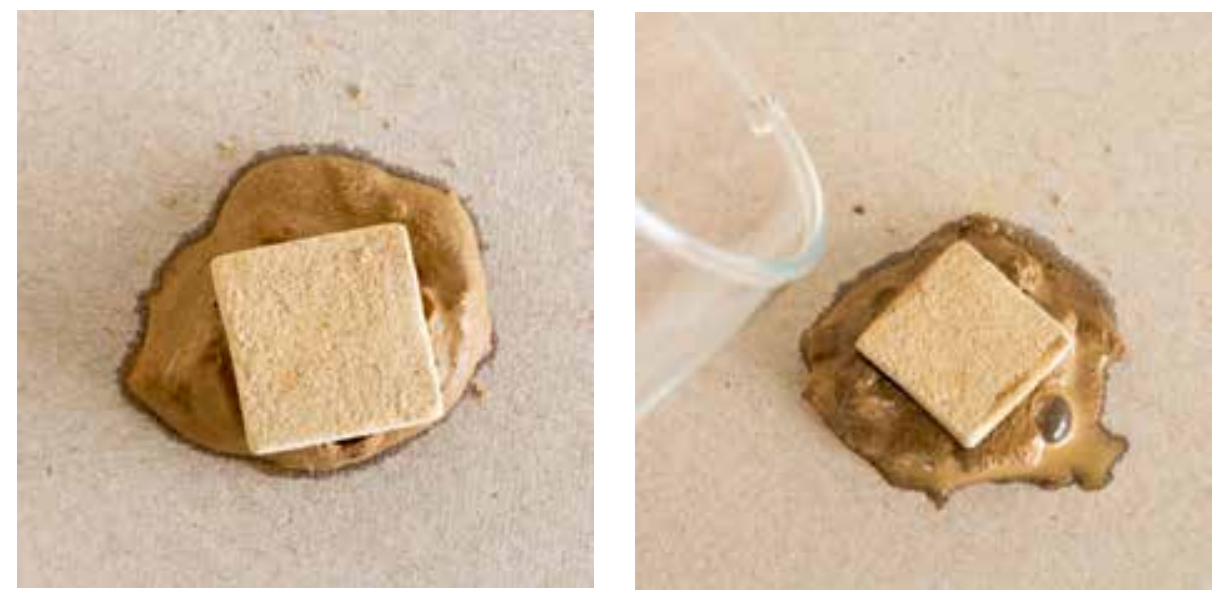

Left: Contrast of dry and wet clay disrupted by adding water

Below: Dry clay quickly loses form and reintegrates with wet clay
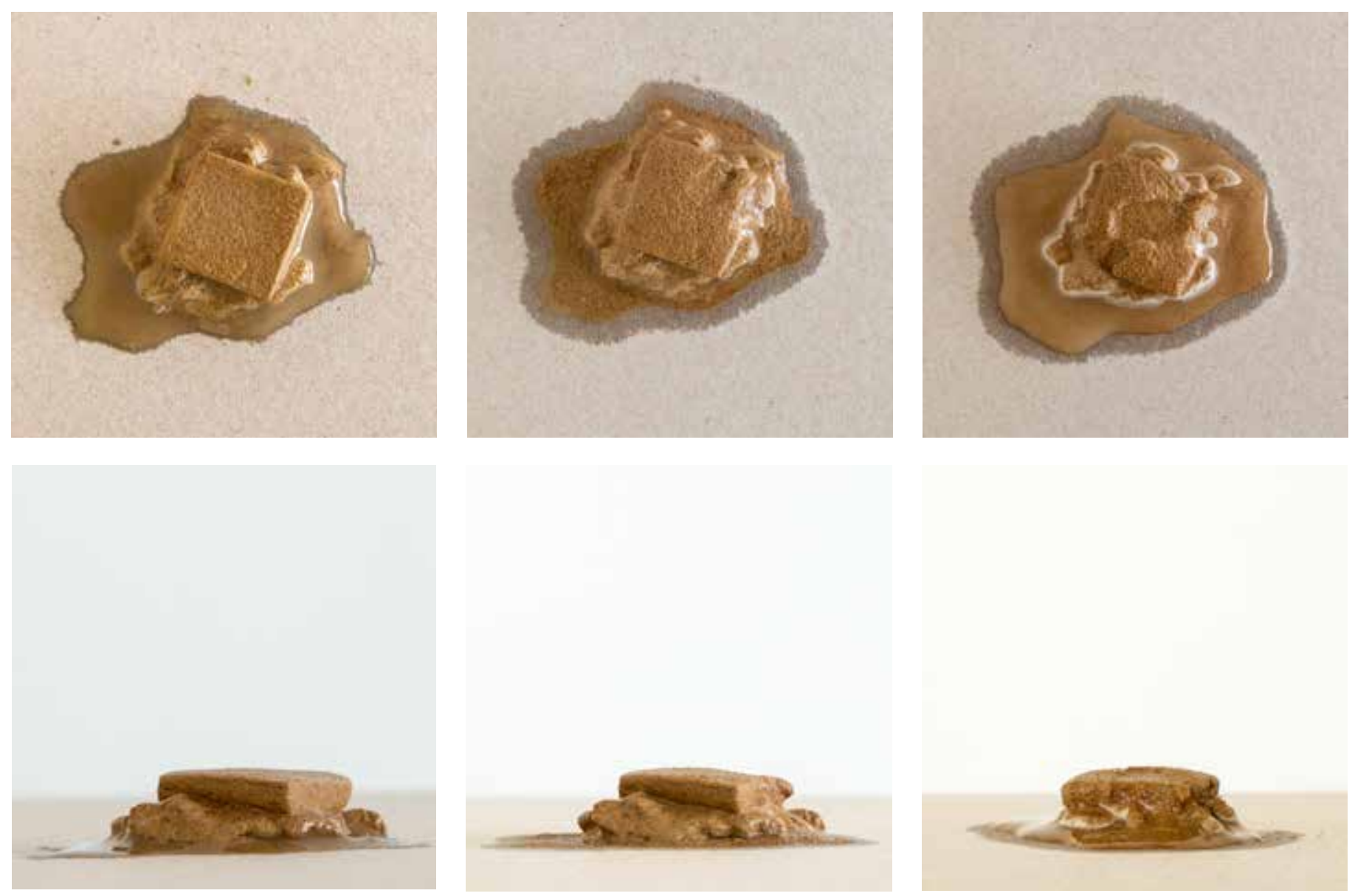

\section{Oopposite:}

1. Clay as extracted from ground

2. Clay after crushing + adding water

3. Clay after straining + refining

4. Dried refined clay 


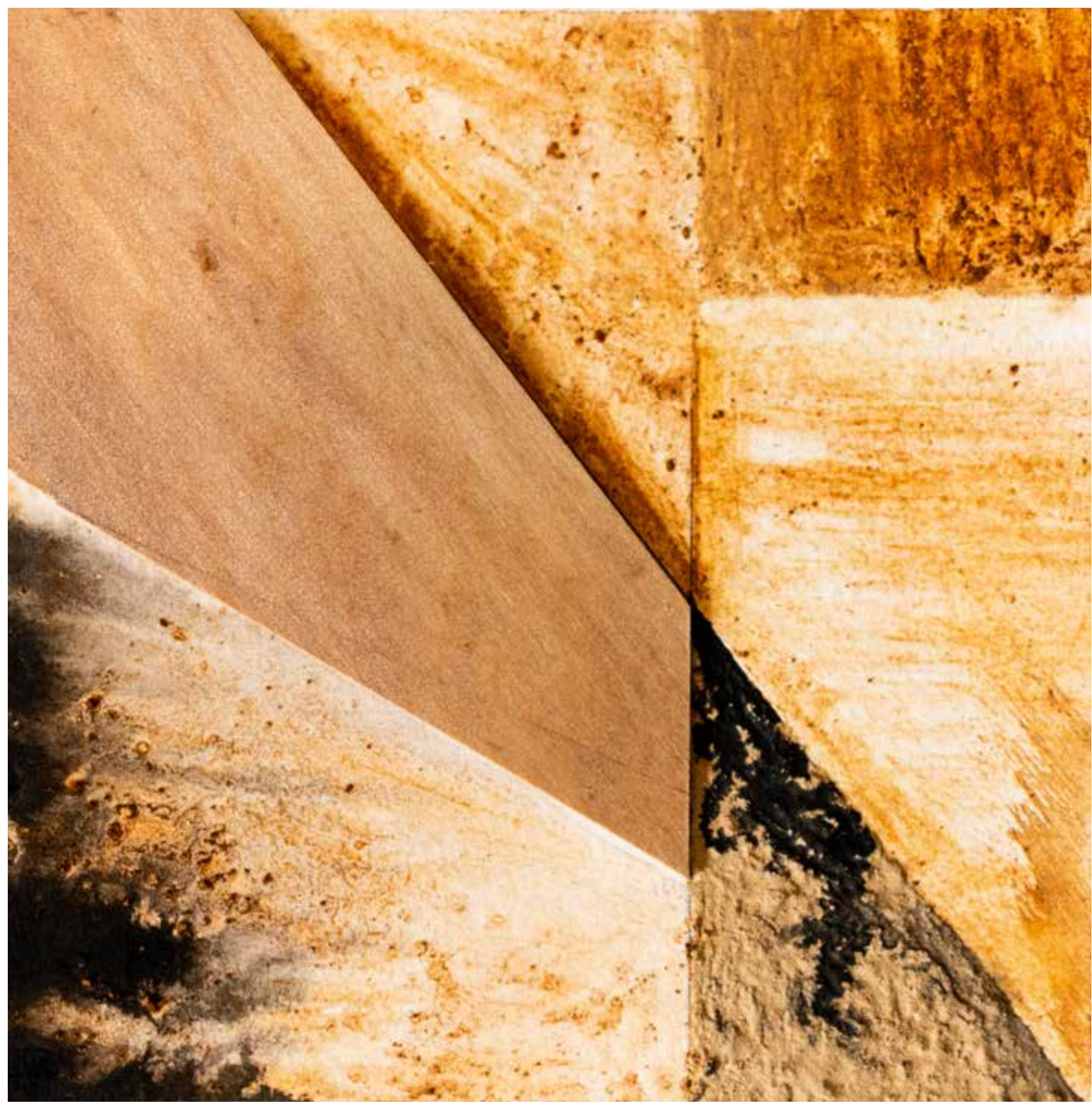

\subsection{COMBINING MATERIALS/ METHODS}

To push these initial explorations further, I began combining materials and methods to find new directions and possibilities. 


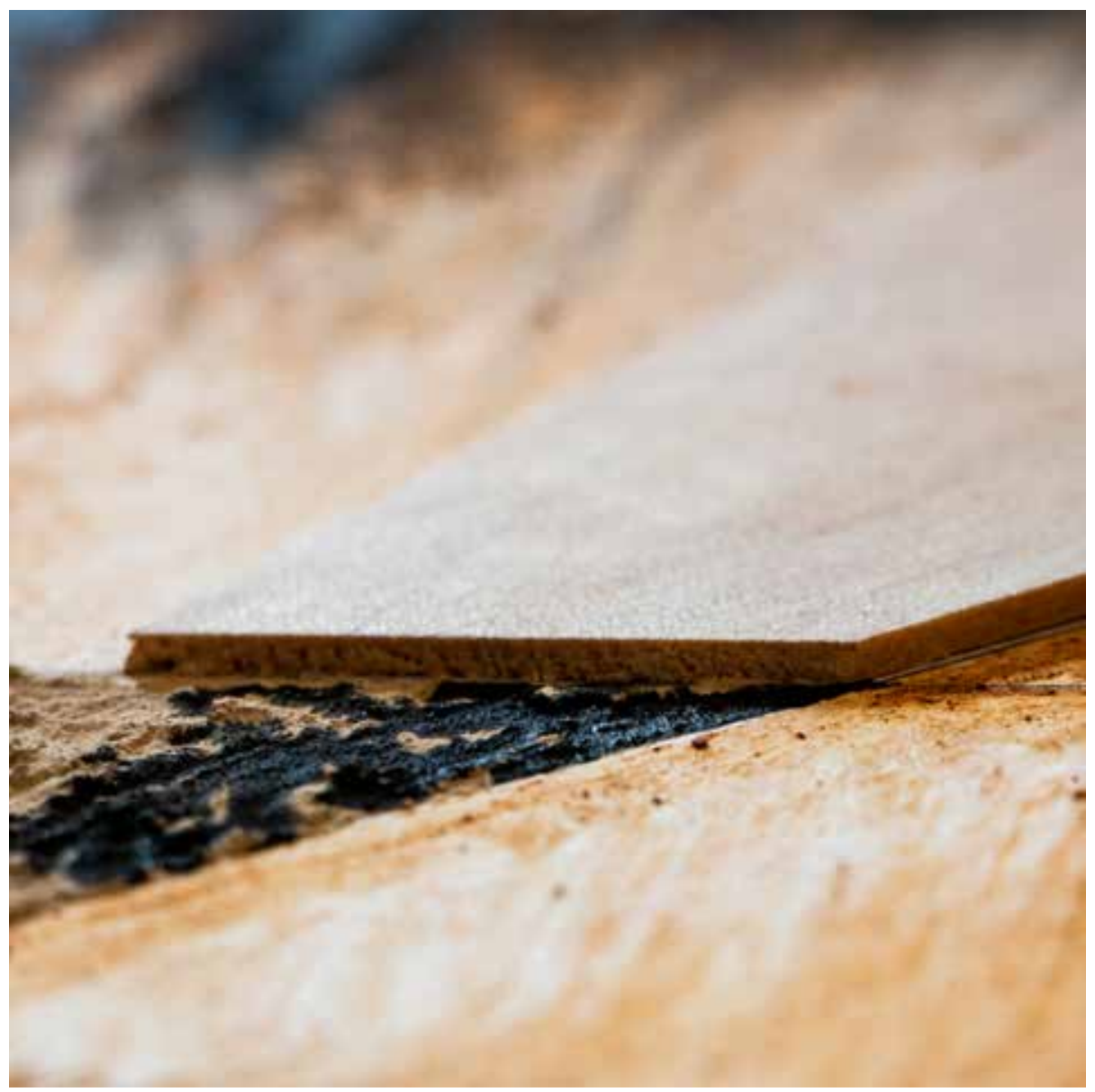

\subsection{CLAY - OCHRE - TIMBER}

The textures of clay and ochre were similar in many ways, yet distinct in their texture and reaction to water. Using a geometric frame, the materials were layered onto the page to find the contrasts, using ink and timber to highlight these differences. Ink was applied to record the wet texture of each material once it had dried. 


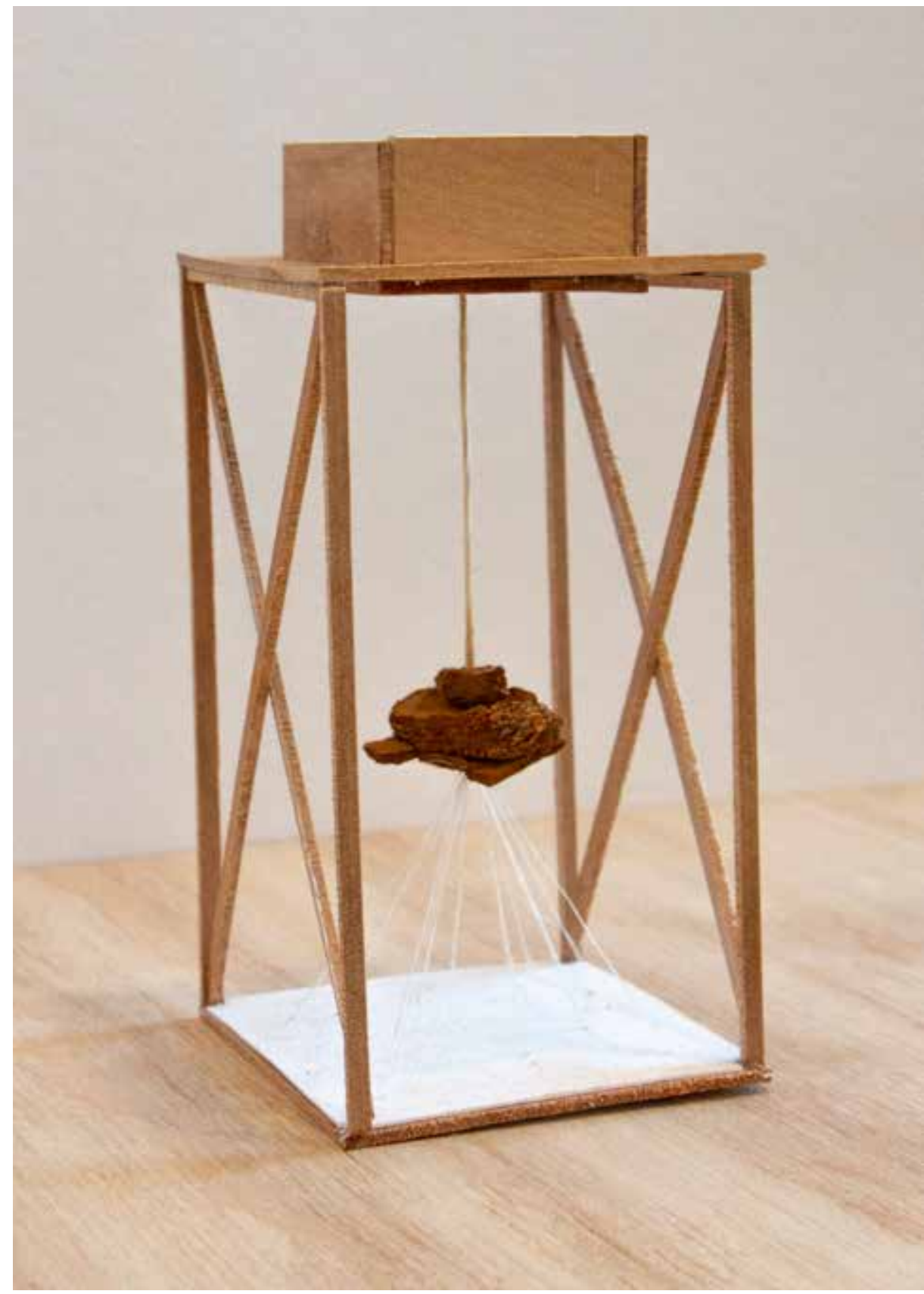

Left: Constructed water tower

Opposite: Water added to tank

\subsection{WATER TOWER / OCHRE - MUKA - WATER (GRAVITY)}

This exploration was intended to focus on the interactions of different materials, with as little human input as possible. A "water tower" was constructed, which allowed water to flow down the muka, over the ochre, and onto a pad of watercolour paper to record the results. 


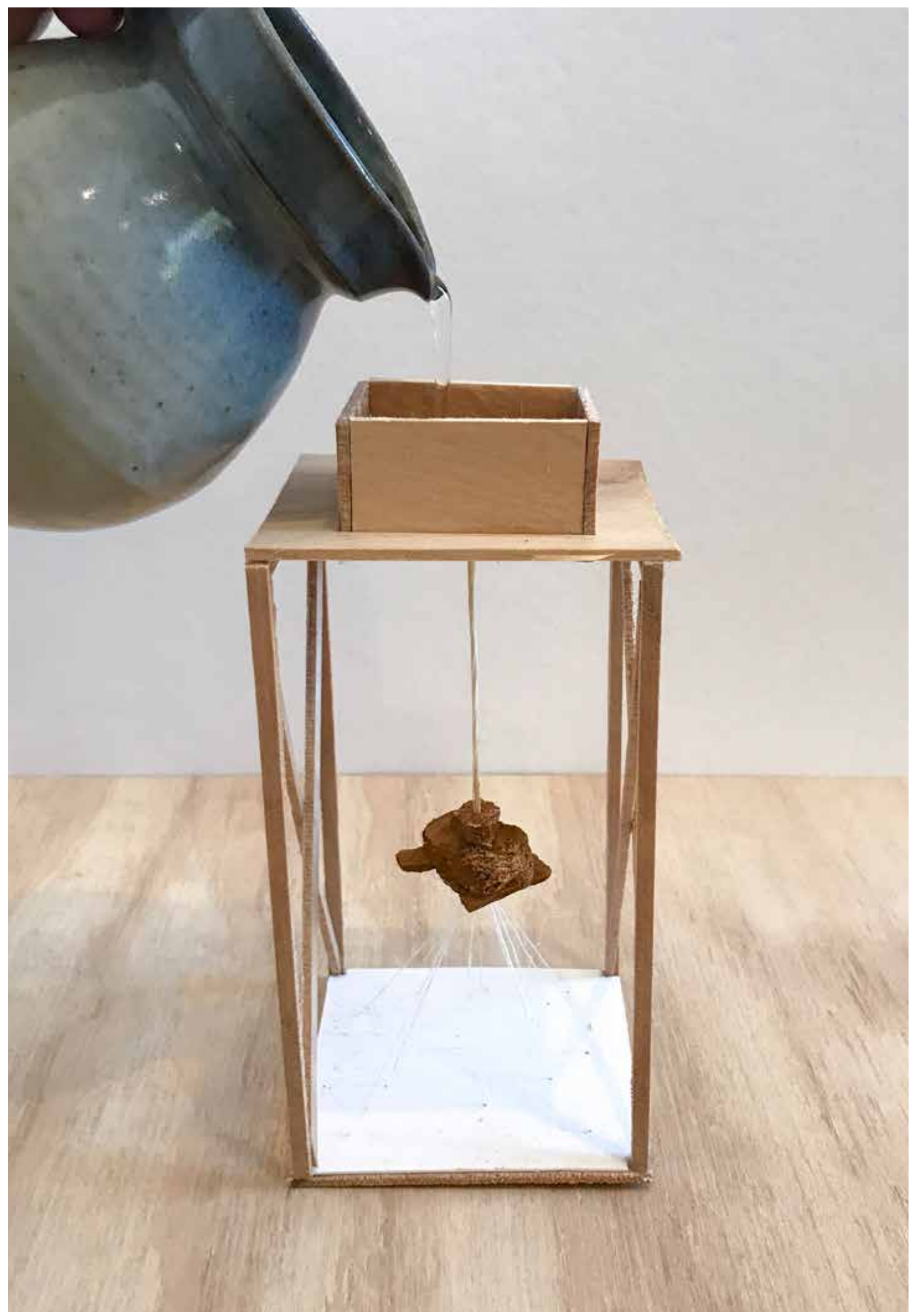



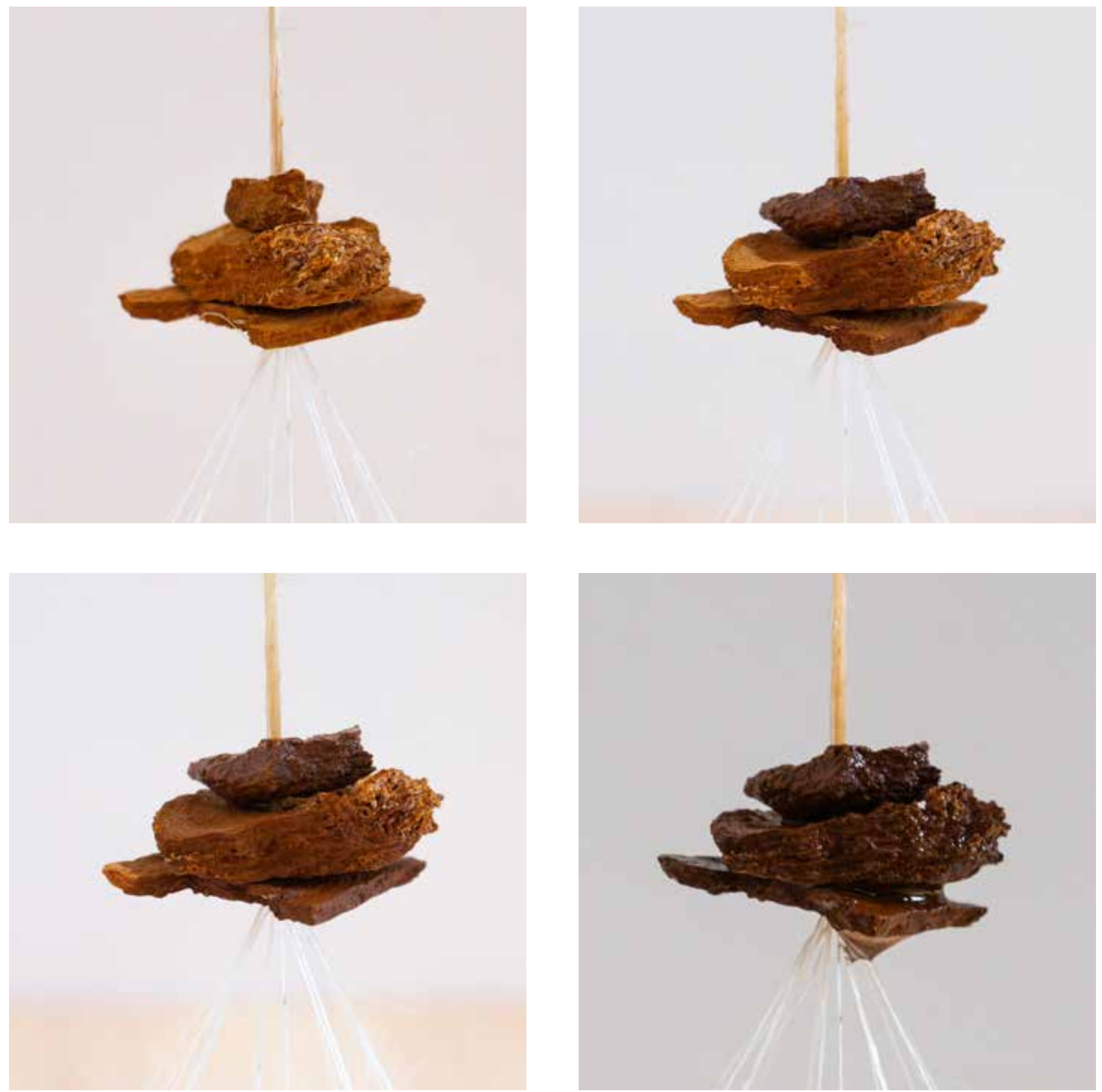

Above: Water slowly saturates the ochre 


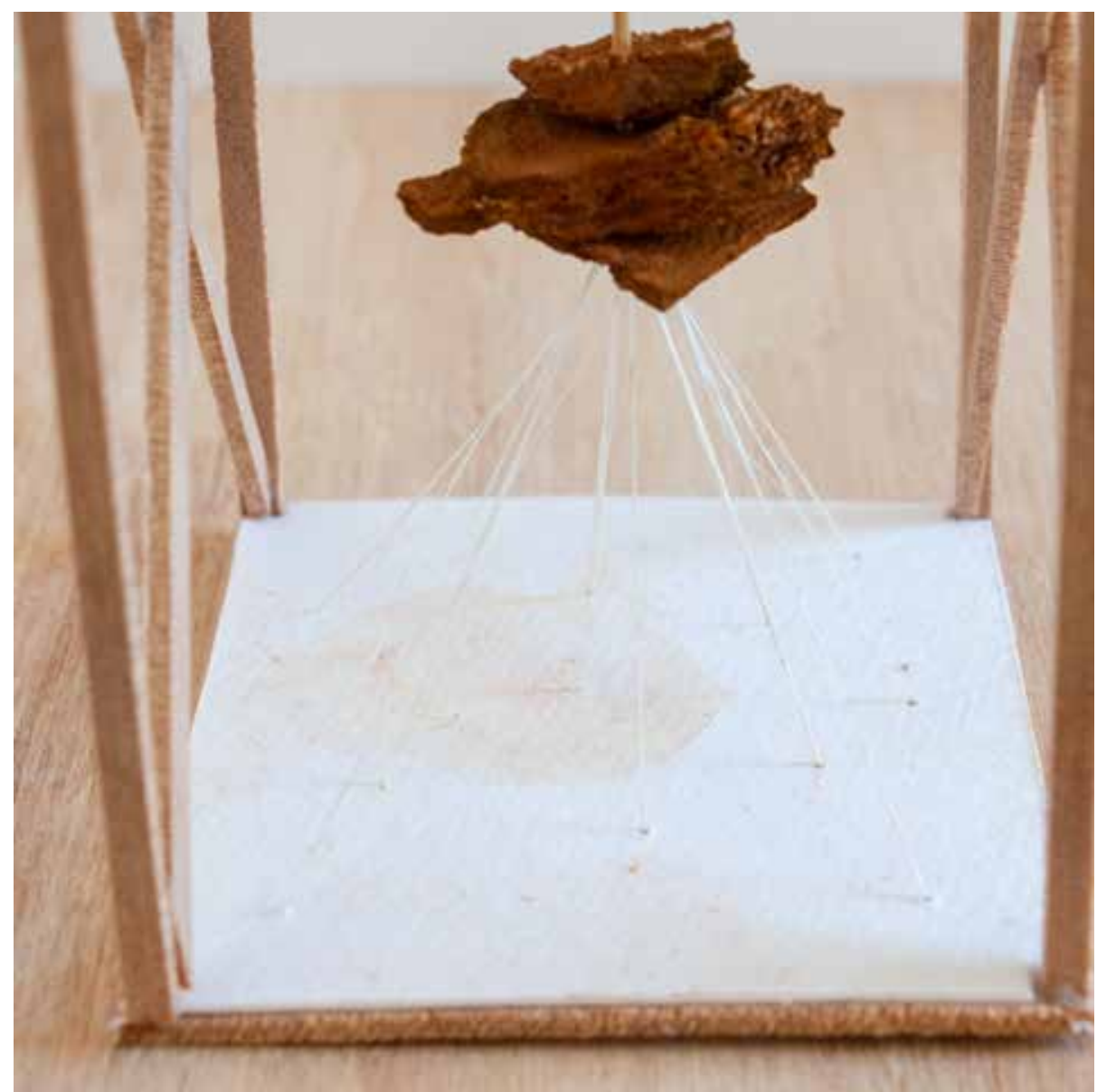

Left: Pigment gradually acculumates on paper, following muka threads

Over the next few days, the 'tank' was repeatedly refilled each time it ran dry. The accumulation of pigment was slow, but even during the process, the materials were reacting. The water ran down the muka in beads initially, and then as a slow flow once the threads were saturated. The ochre turned from a bright yellow to a deep orange. Eventually, the paper began to form light plots of pigment where it built up over time. It was a temporal process with uncertain outcomes, which allowed the materials to behave somewhat naturally. 

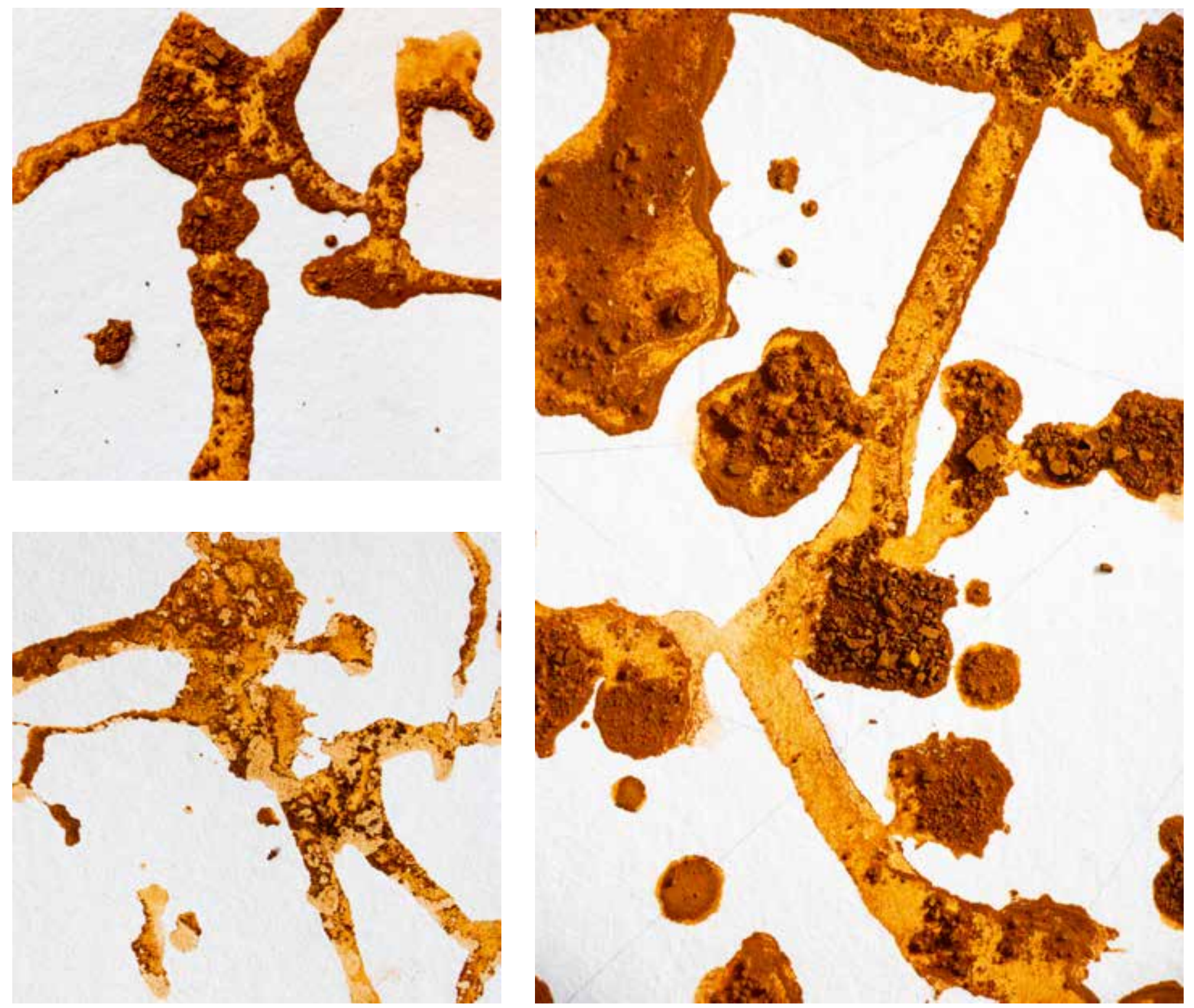

\subsection{OCHRE - DRAWING}

The final exploration returned to the ochre, ground into a rough pigment. Where initially the ochre was treated much like paint, the 'water tower' exploration encouraged a more mechanical approach to experimentation with the material. Large amounts of wet pigment were splattered on the page, allowed to run and dried with hot air. The results were photographed to highlight the thick threedimensionality of the result. 

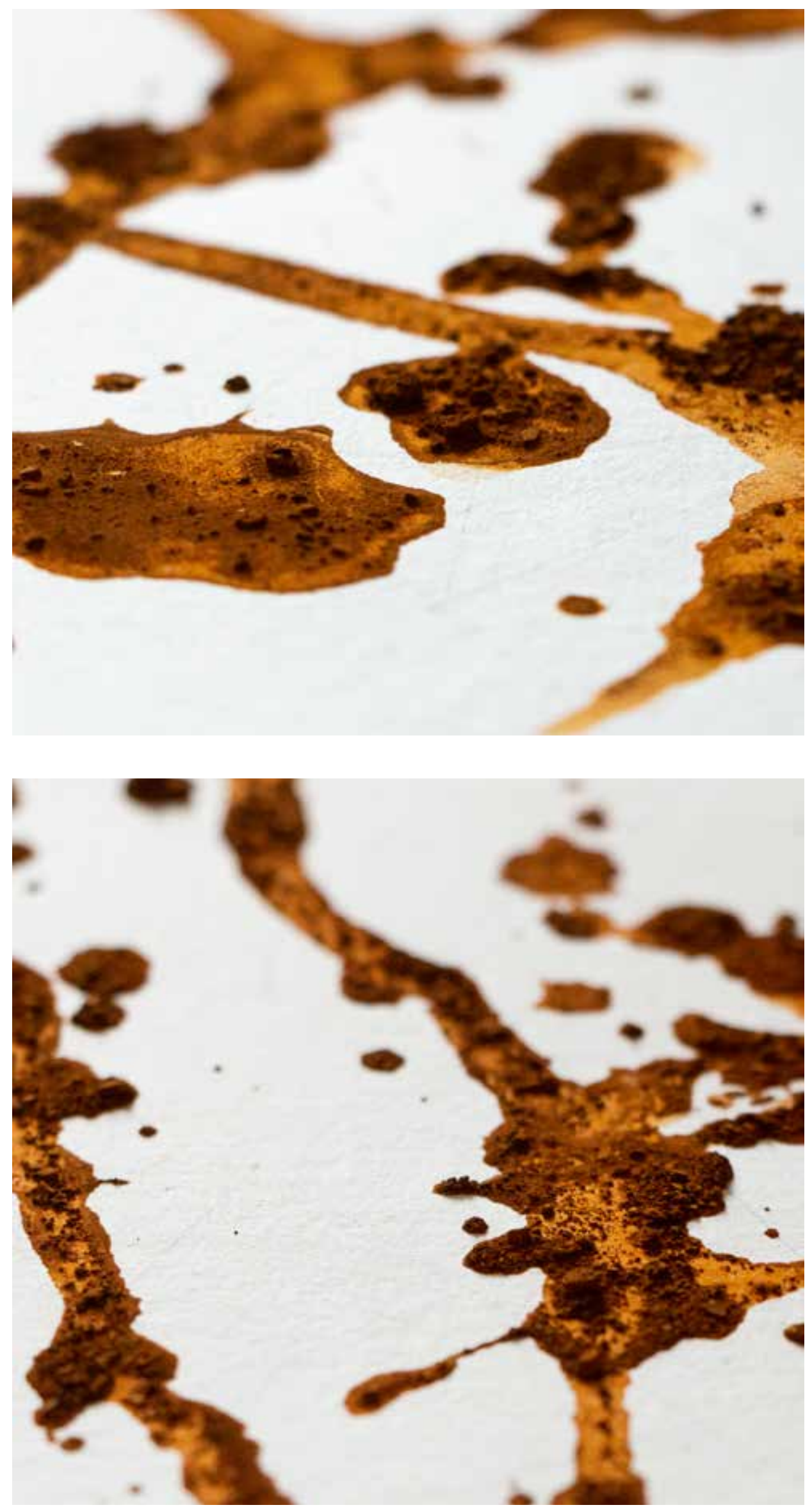

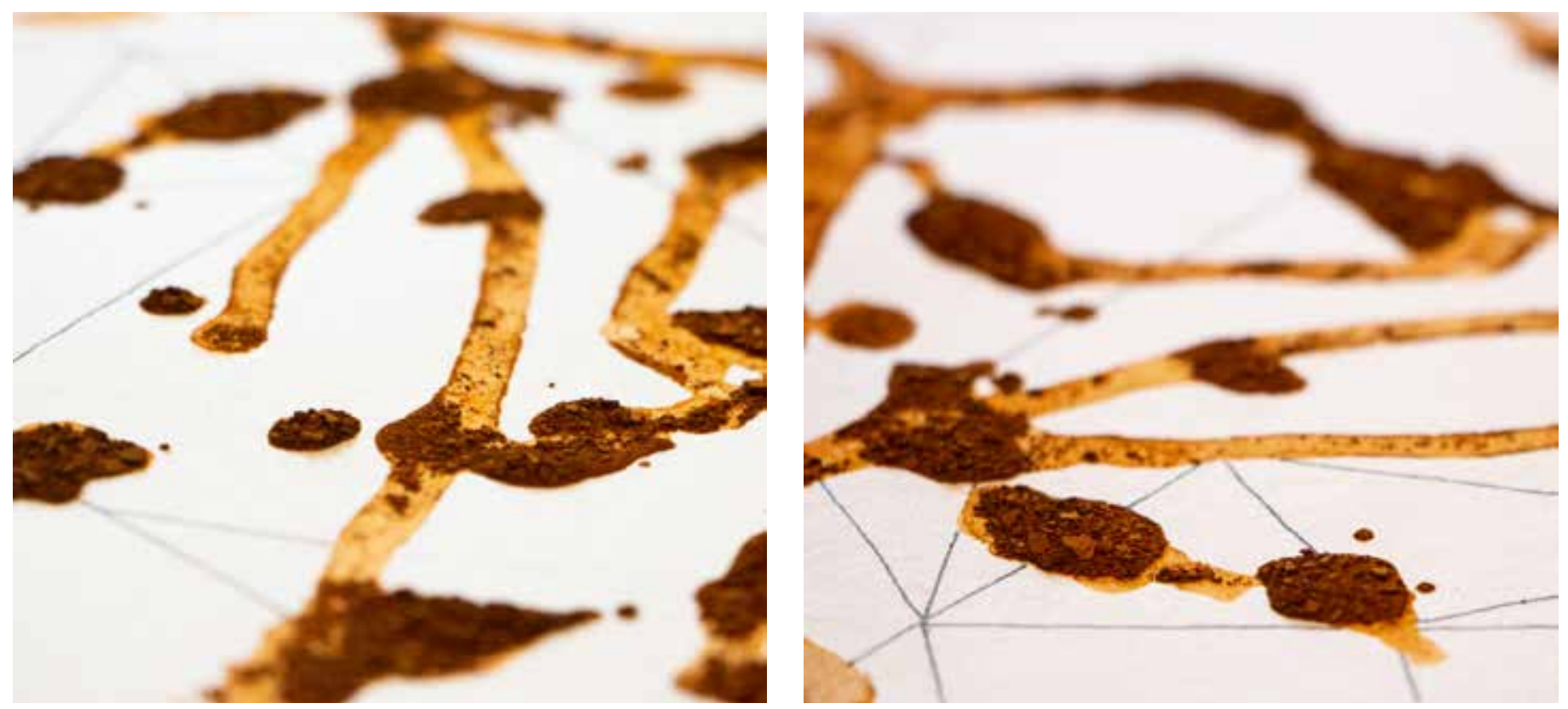

From there, a light under-drawing of geometric lines was set up on the page in order to emphasise the organic forms created by the roughly-ground ochre. The geometric lines were elaborated on with pen, to draw connections between the material and the negative space. Once dry, the loosest groups of dry pigment were knocked off. The areas in which pigment was removed went from being the deepest colour to the lightest, and created an inverted effect. 

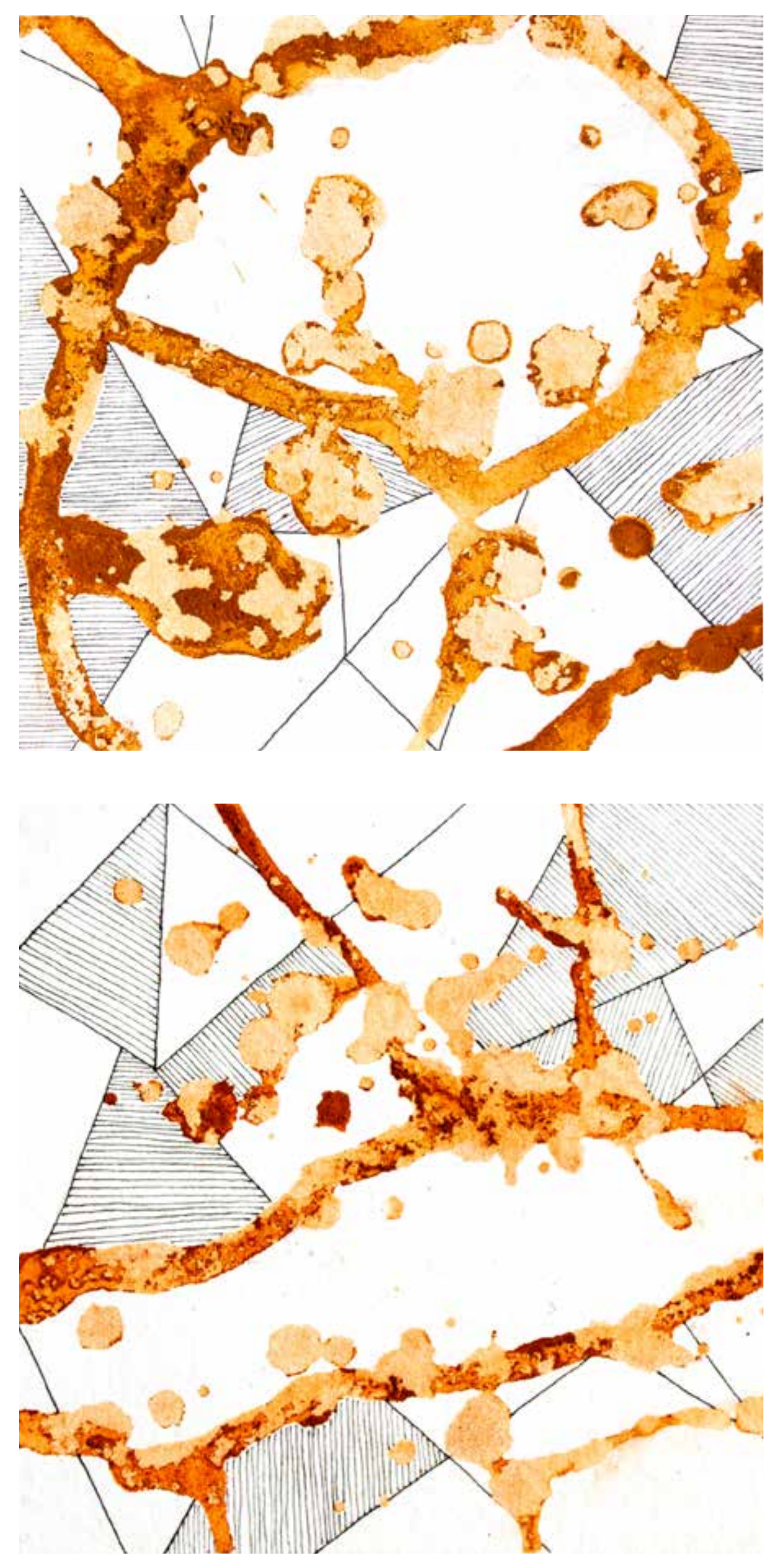


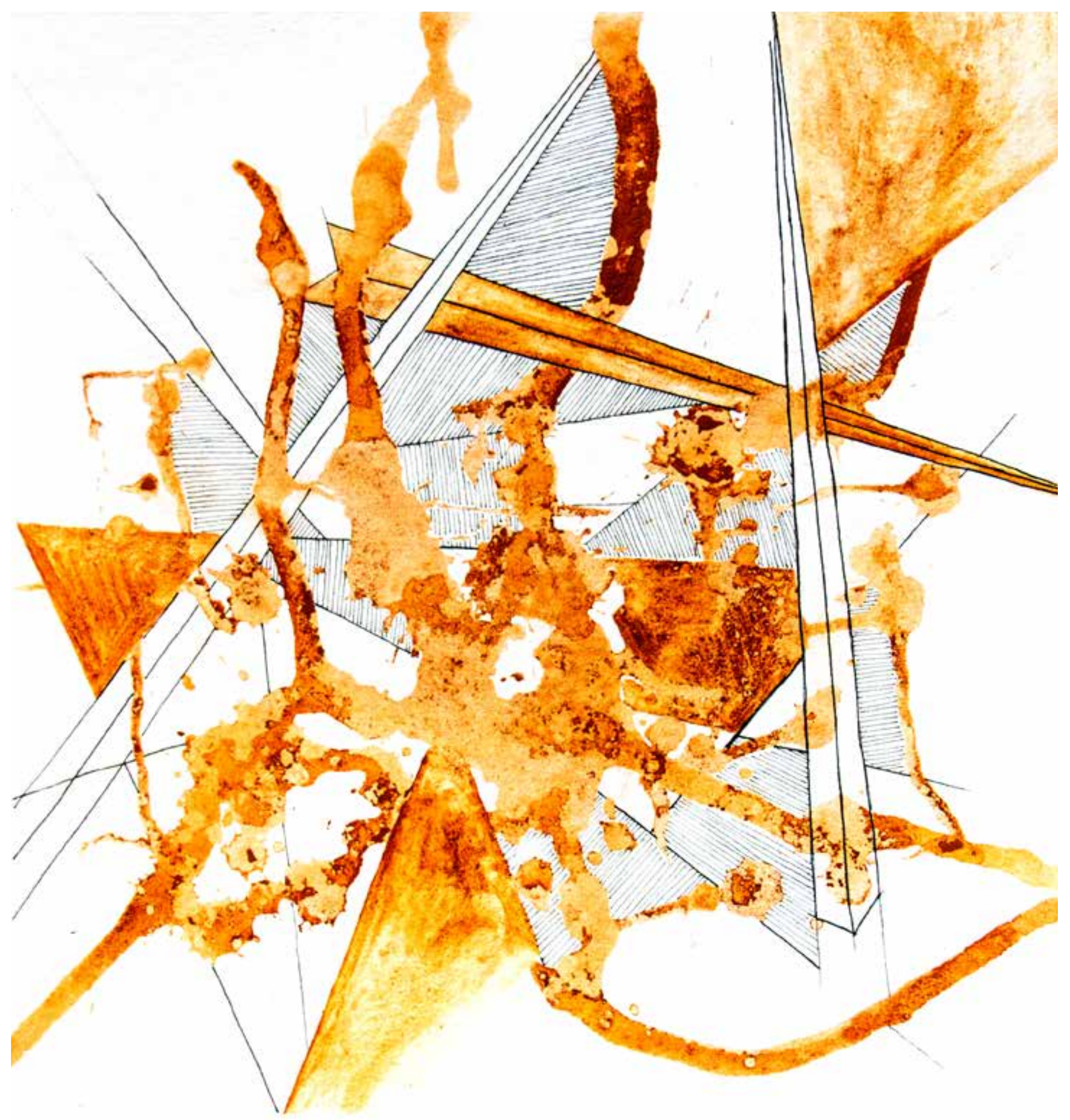




\subsection{MATERIALS AS PROCESS; MATERIALS AS THERAPY?}

The purpose of these exercises was to engage with materials as process, but they also revealed how different ways of engaging with materials in architectural design could provide therapeutic benefit. Traditionally, materials have been experienced as static, tectonic components in the finished architectural object. Deeper engagement with materials has been suggested as a way of producing design that is "more sustainable, more expressive, and healthier on a psychological level" (Petrović \& Perkins, 2016). Engaging with materials through art therapy has also been shown to have positive benefits in occupational therapies (Fancourt, 2017), and sensory experiences have been shown to induce both positive and negative states in adults (Bailliard, 2015). Haptic stimulation has also been shown to decrease the bodily effects of stress (Kelling et al., 2016). Through free, creative engagement, the exercises unpacked the multi-layered sensory opportunities offered by natural materials and explored the process of production as an affective therapeutic encounter (Foley, 2015).

The selection of materials was largely influenced by their relationship to place and identity. As exemplified by the research into clay, natural materials have a strong relationship to place, and are formed through an interconnected range of human and nonhuman factors. In Aotearoa New Zealand, these human factors include cultural use and significance. Place has been seen to be closely entwined with individual and social identity (Mahar, 1981); two factors which contemporary Māori and Pacific models of wellbeing suggest are fundamental contributors to mental wellness (2.1.2). Place also plays an important role in people's experiences of therapeutic landscapes (Bell et al., 2014). Understanding materials and interacting with them on a more relational, deeper level may help to inform architectural design that emphasises place identity and cultural connection in a supportive therapeutic way.

As found through these exercises, materials have their own temporal qualities and inherent agency. The final exercise began to explore the architectural possibilities of this through upsetting the hierarchy of form and material. Architectural elements were suggested through the drawing of post-and-beam like lines. These formal lines are disrupted by the activity of splattering, and serve primarily to emphasise the agency and affective qualities of the material itself. This exercise suggests that working with a relational, experiential approach to a materials can offer new ways of designing affective space, an idea explored more in the following sections. 


\section{SPATIAL DRAWINGS}

From materials to atmosphere

1. THERAPEUTIC ATMOSPHERES

2. DRAWINGS

3. REFLECTION 


\subsection{THERAPEUTIC ATMOSPHERES}

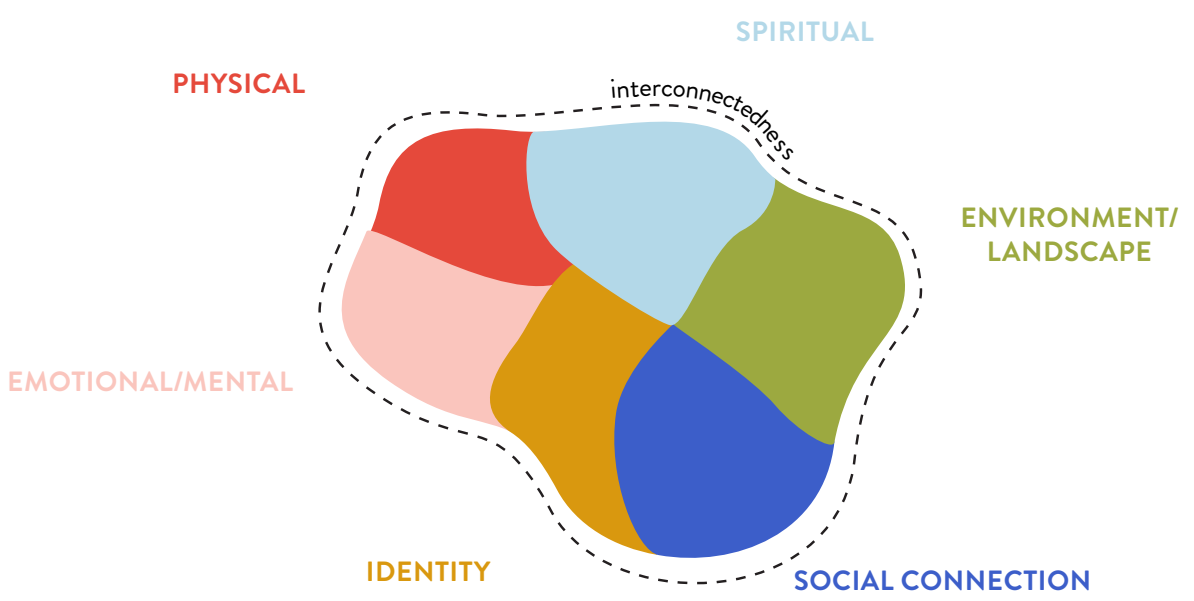

The reflexive design exercises proved insightful for the design of a therapeutic third place through a more relational materiality. This approach offered the potential to enhance the sensory and affective experience of individuals within a shared community space. To extend this approach into spatial design, the decision was made to begin by focusing on small, human-scale moments, rather than overarching programme or structure. These were developed through concept sketches for interior moments in a built third place within the community.

As well as the materials research, the concepts explored in the following sketches were informed by the wellbeing principles identified in Chapter 2 (2.1). The challenge of articulating these principles through design - especially the overall "interconnectedness," or interrelatedness, between each principle - was addressed by looking to the idea of multiplicity. Multiplicity is core component in defining "atmosphere" in NRT and related subjects, separate from most other nuance (Anderson, 2009). It goes hand in hand with the "movement" of affects and relations described by Thrift (2004) and others (Lorimer, 2008; Massumi, 2002; McCormack, 2008), in that it is essentially many things (human and nonhuman) acting at once on and with each other. This confluence produces an ambiguity which is open to interpretation; an affective atmosphere. The following sketches attempt to visualise a "therapeutic atmosphere" based on a multiplicity of potential sensory stimulants, activities, and levels of sociability and interaction. 


\section{MOMENTS}

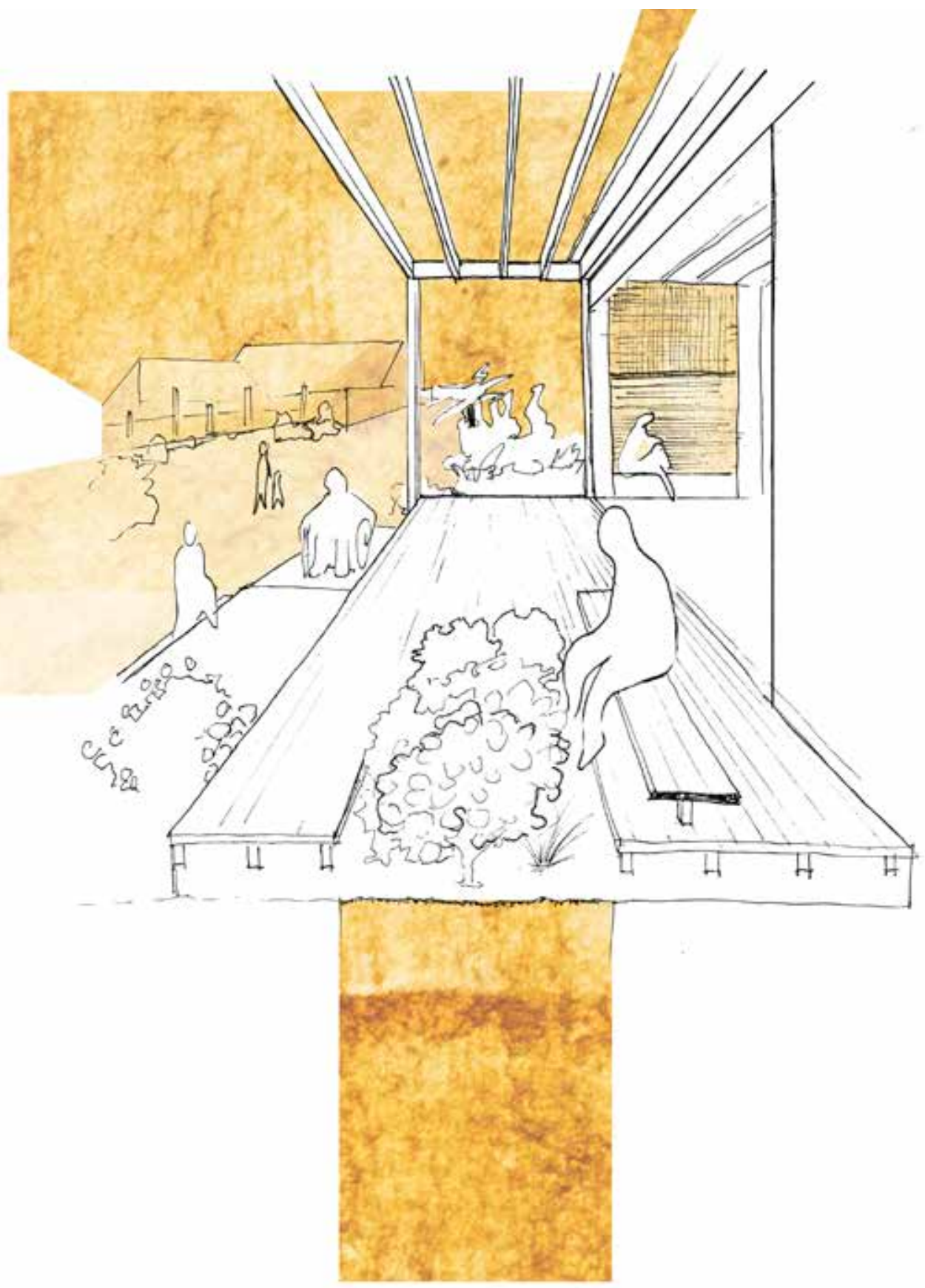

\section{Transition}

Explores the relationship between indoor and outdoor, with exterior environment shown in ochre.
Sensory: Fluctuations in natural environment (wet,dry, hot, cold); Touching plants

Activity: Enter/exit. Watch/Observe. Talk; Sit; Smoke; Think

Social: Chance encounters, sitting together, waving/light acknowledgement 


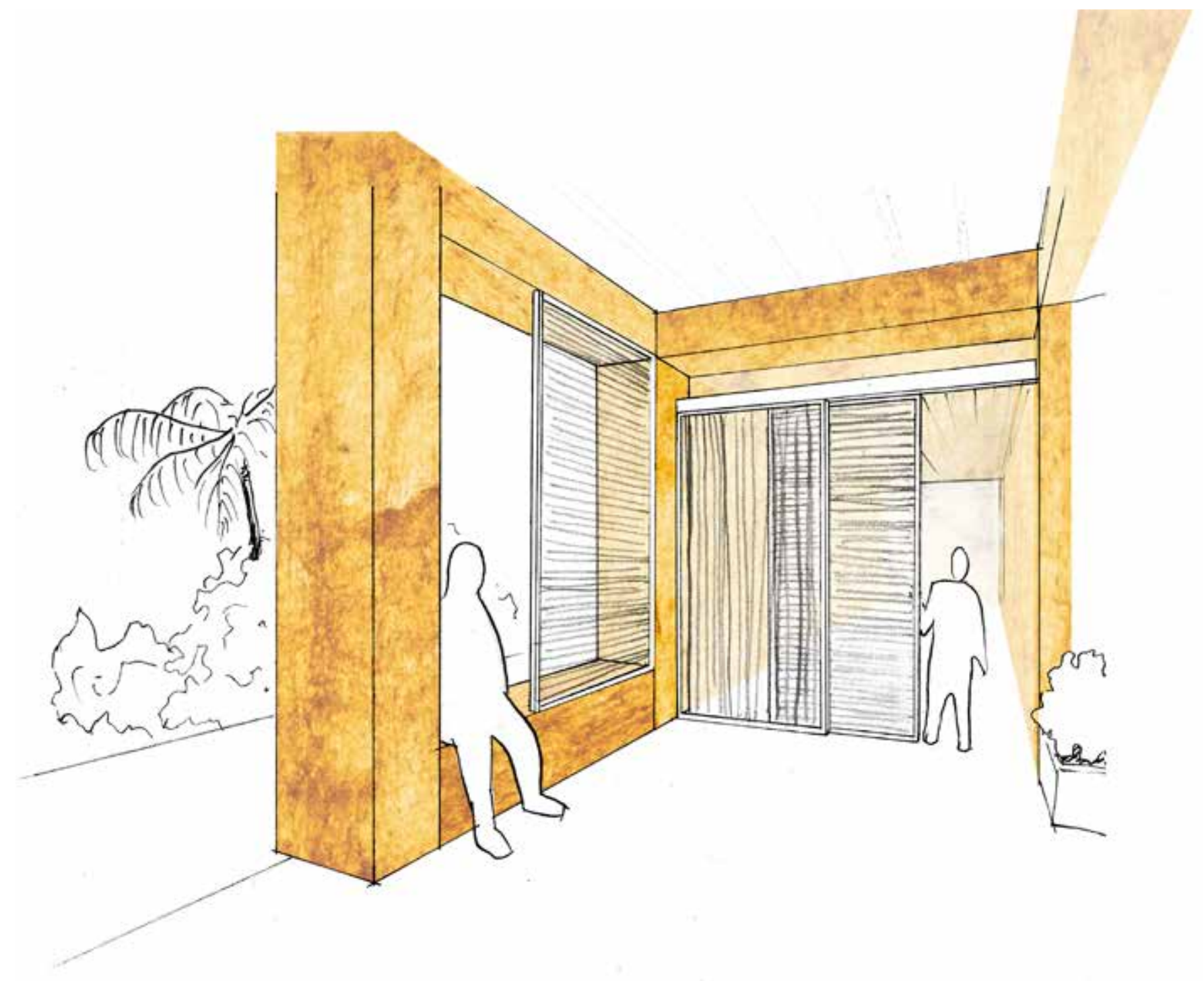

\section{Nook}

Transitions and opportunities in spatial layout to allow for choice and autonomy, using materials to separate space.
Sensory: Partition materials; sound; temperature; views/sightlines

Activity: $\quad$ Sit / Think OR Engage/Participate

Social: Options for a spectrum of social engagement; group/solo 


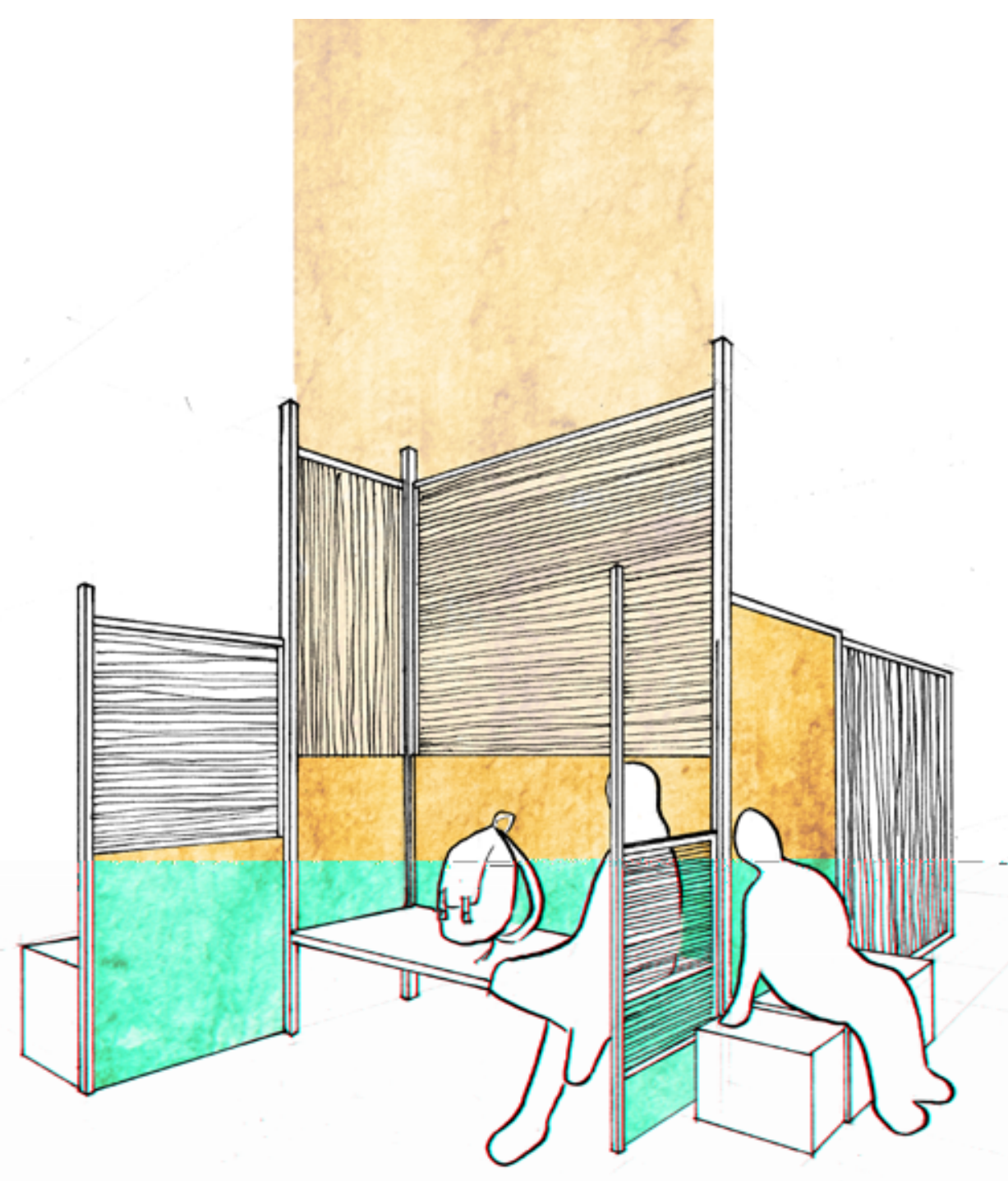

\section{Opacity}

Explores opacity and materials as a means for modulating interaction with others.

Potentially moveable/interactive
Sensory: Seating materials (hard/soft); moving partitions; enclosure

Activity: $\quad$ Sit; study; talk; counsel; read

Social: Solo activity; share experiences with flexible privacy settings; move furniture into groups 


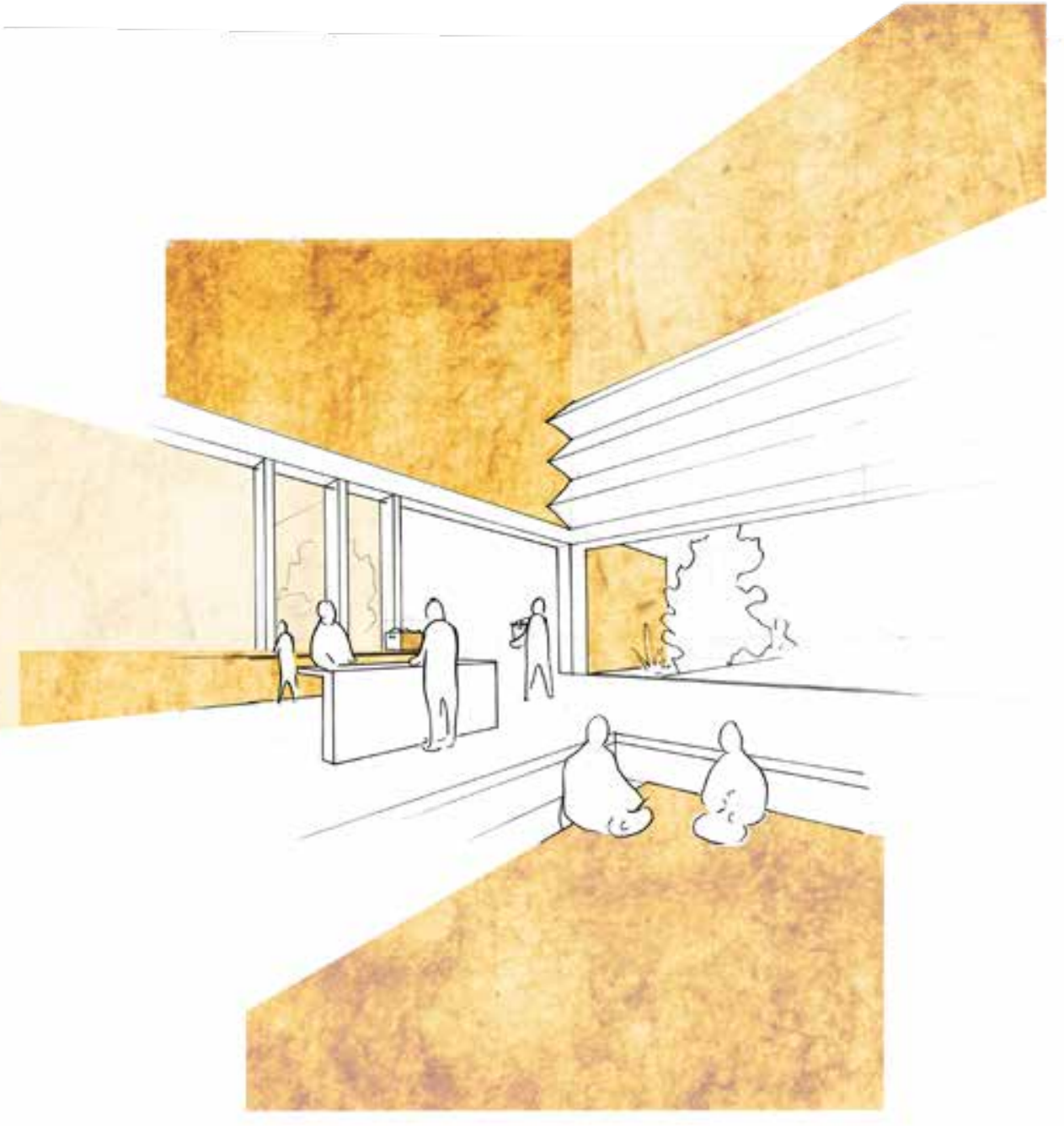

\section{Commensality}

Concept for an open kitchen space which is domestic but open to the public. Space for shared meals and community food distribution.
Sensory: Taste/smell/sound. Light effects, touch of surfaces, food items

Cook, eat, organise, "help out," learn,

Activity: share, converse

Classes, group cooking sessions, food

Social: collection and distribution, volunteering, teaching 


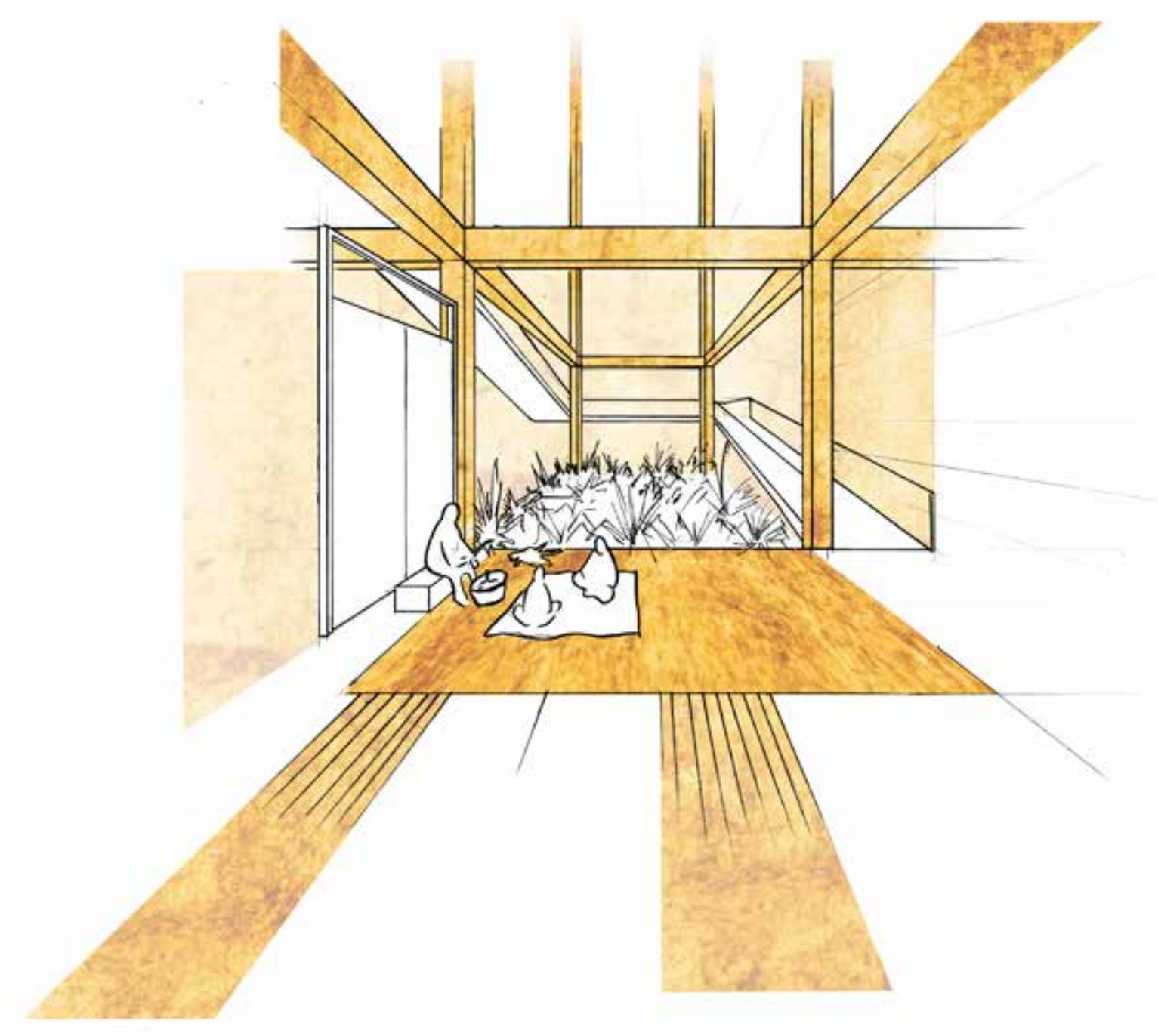

\section{Whenua}

An atrium space based around the

experience of harvesting and weaving

with harakeke, with the idea of "whiria te

tangata" / weaving people together
Sensory: Light, Touch (plants, dirt, floor), Smell, Sound

Activity: Akoranga/classes, learn, weave, teach, harvest, play, work, talk, share

Social: $\quad$ Sharing of knowledge, activity-based socialising. Visible, open. 


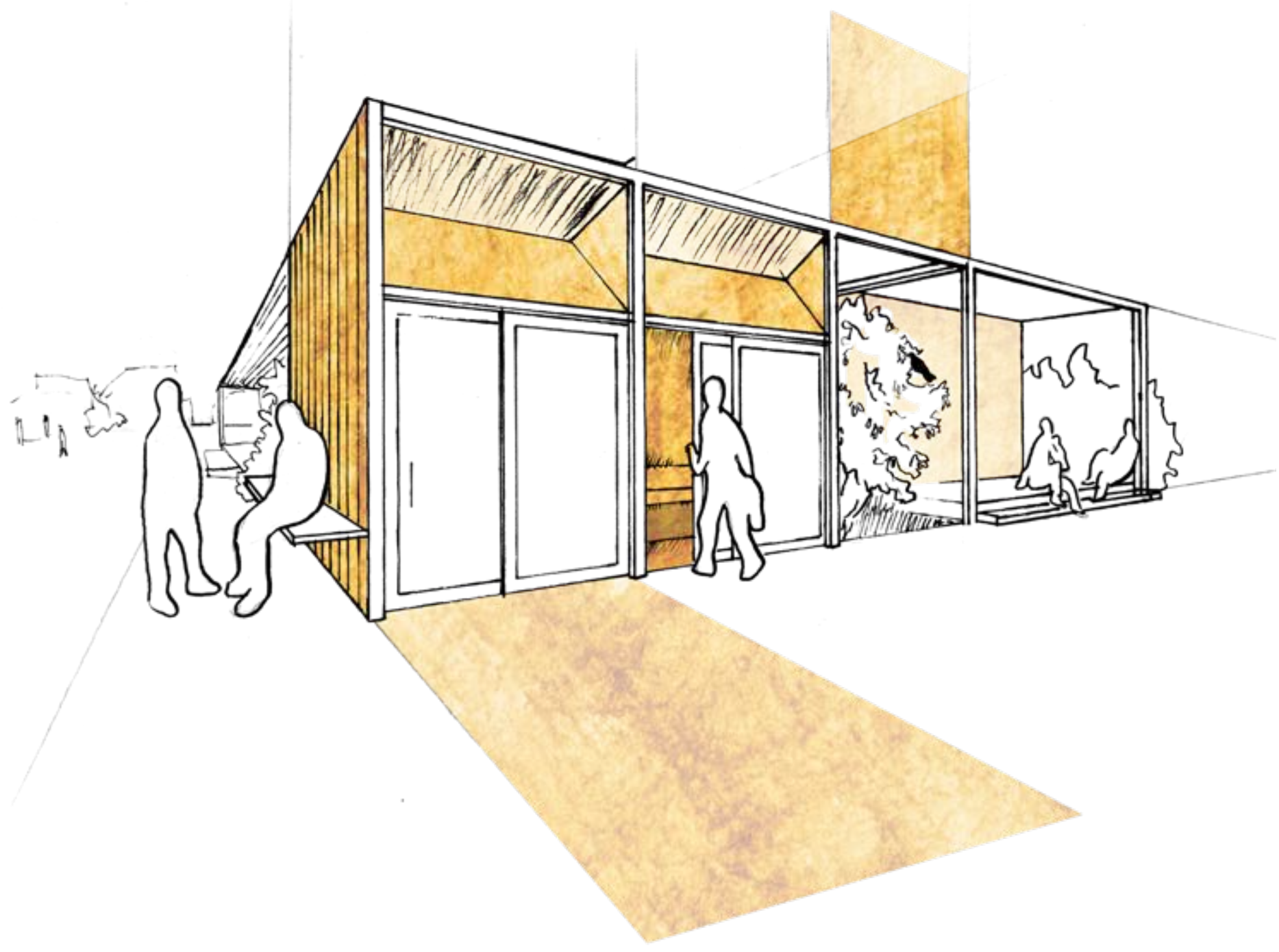

\section{Shelter}

This sketch questions accepted use

of/behaviour in public spaces with affordances for emergency sleeping shelters, benches, covered places to rest. It is suggested that safe use of the space (not excluding the potential for drug-taking activity) can be encouraged by considering the placement of this kind of amenity in relation to other spaces, and providing oversight and outreach.
Sensory: Touch - materials of bed, seats; Light, views, sightlines, enclosure/exposure; sound (people, birds, urban noise)

Activity: Sleep, sit, "be" in private; adaptable. Potentially provide a space to use drugs in a safe environment, with opportunities for outreach and addiction support.

Social: $\quad$ Sitting, "loitering" in public space allows opportunities for chance encounters. Conversely, sleeping shelters allow for privacy. 


\subsection{REFLECTION}

The generation of these sketches offered a lot of opportunity to imagine and image situations from a human-centred perspective. The benefit of the multiplicity approach in working toward describing "therapeutic atmospheres" was that it encouraged different ways of thinking about space, with emphasis on activity, sensory and social potentials. Upon reflection, the different combinations of these potentials imbued each scene with a range of values from the wellbeing models. Moment 5 is an example of this. While most directly speaking to the concept of whenua, or engagement with the natural environment, this space equally addresses the sensory and social aspects of this 'third space,' and suggest a range of activities to activate the therapeutic affective experience described in Chapter 2.

The difficulty and limit of these sketches is that site has been largely deemphasised in order to focus on establishing a way of spatialising the therapeutic third place. In order to move forward, introducing a site as a testing ground for these concepts adds the important layer of complexity and messiness, where the "flow of everyday life" [2.2.3] is situated. The next section combines the information gained from the reflexive design exercises and these spatial drawings with the experience and analysis of site, producing sited spatial drawings for a third place in the Taita Shopping Centre. 
Designing for mental wellbeing in suburban public space

\subsection{APPROACH TO SITE}

7.2 SITED SPATIAL DRAWINGS

7.2 TOWARD A THERAPEUTIC JOURNEY 


\subsection{APPROACH TO SITE}
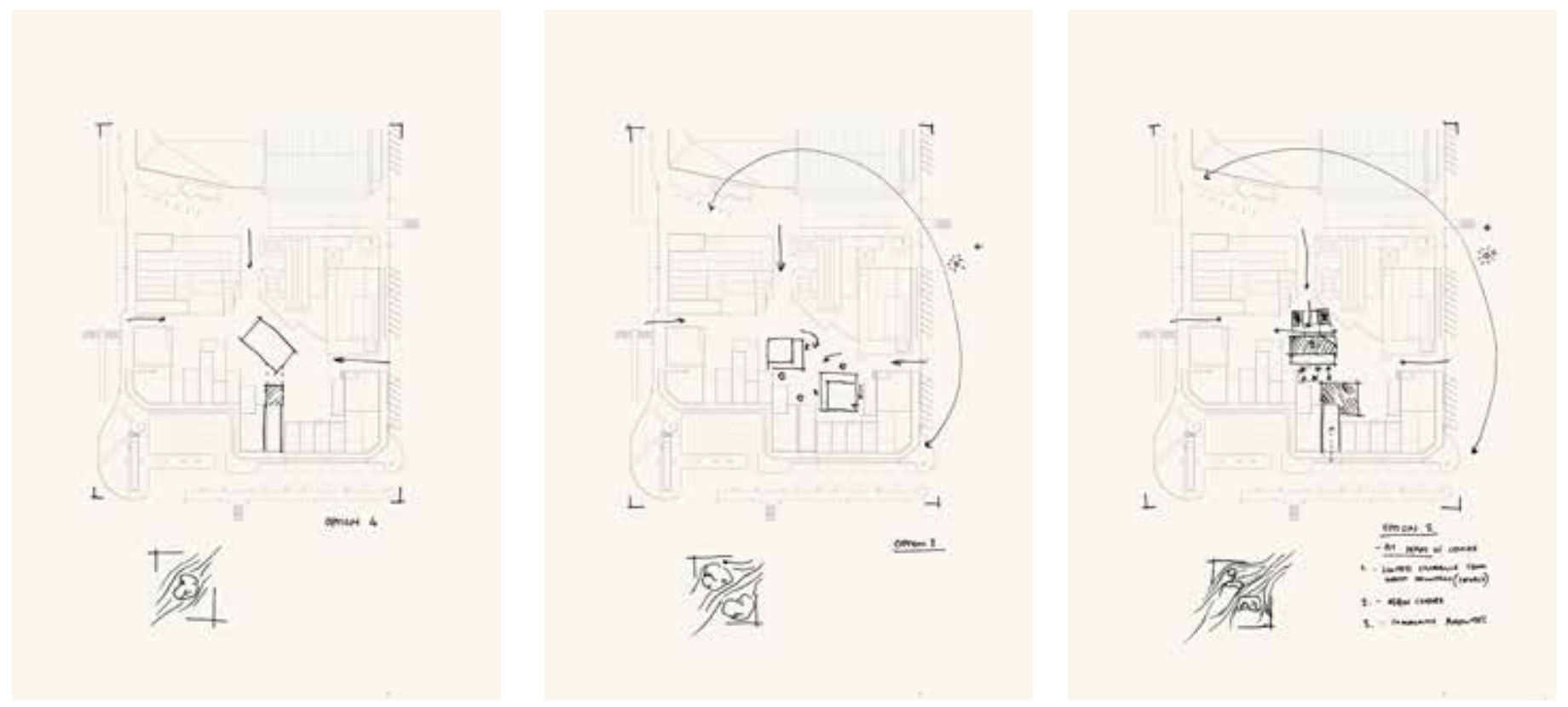

In previous stages, the work was developed from a human-scale, interior perspective; designing "therapeutic atmospheres" for moments within a looselyimagined building. Coming from an architectural perspective, and with the amount of open space located behind the existing medical centre, the idea of designing a building as a third place appeared to be the natural conclusion to the research. However, initial attempts at planning this building in relation to Taita Shopping Centre were stalled by a lack of coherence between concept drawings and the understanding of site gained in Chapter 4. The problem of existing historical mental health architecture is that it has uneccessarily isolated people from the community, so developing a typology which caters to a full community is important. An inability to resolve this problem through a contained building suggested that a change in approach was needed. The first stages of design looked at 'bringing the outside in:' using therapeutic landscape principles to incorporate natural elements into interior space through their affective properties. An inverse approach involves 'bringing the inside out:' working to reimagine the spatial qualities and multiplicities of the "therapeutic atmospheres" conceptualised in Chapter 6 in relation to the exterior, public space of the suburban shopping centre. 

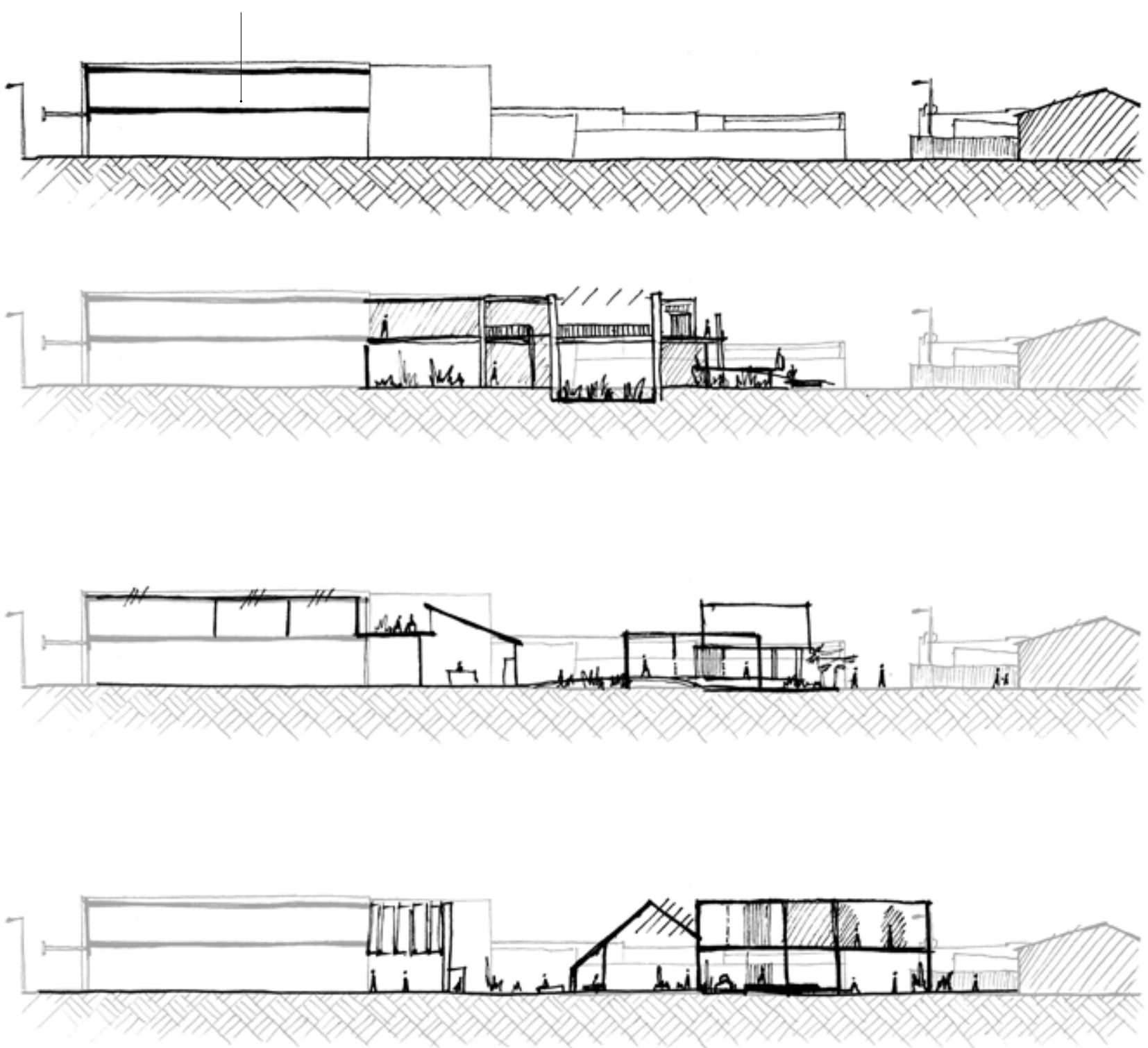

\section{Site Sections:}

Initial site sections (taken through medical centre, looking south) looked at how the existing medical centre could be extended and integrated into the interior of the site. 

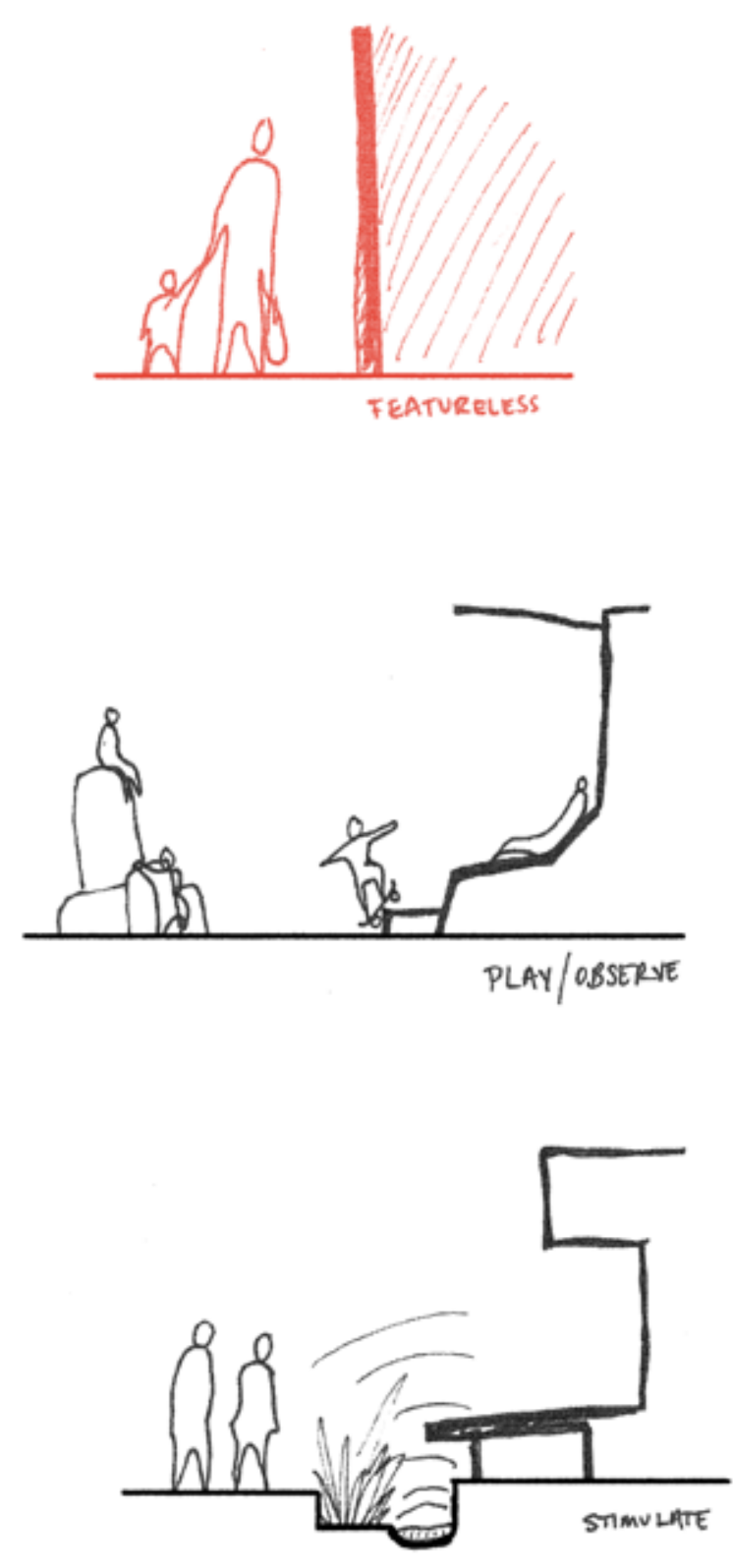
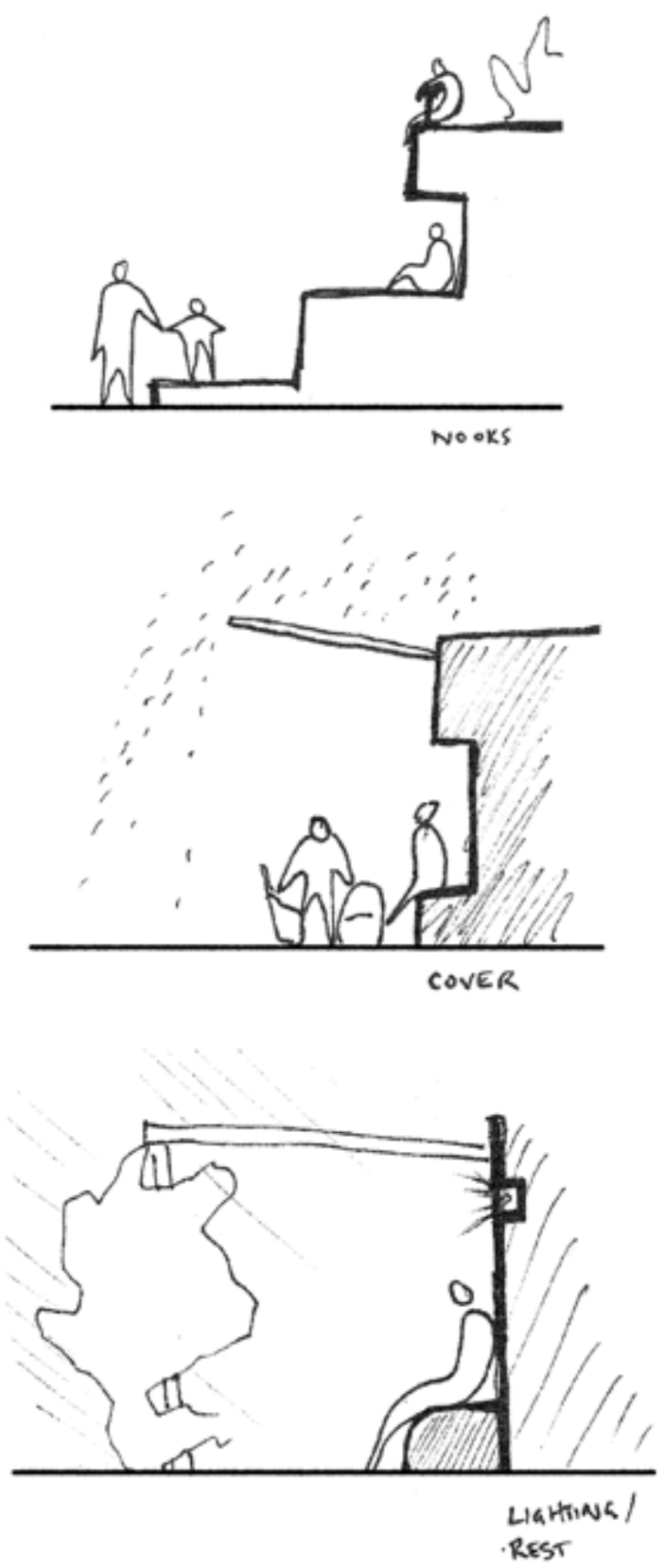

\section{Above:}

Edge encounters offering human-scale alternatives to the blank, featureless walls which currently dominate the site. These interfaces can be used to allow people to engage with the architecture and site, and create affective moments in a variety of ways. 

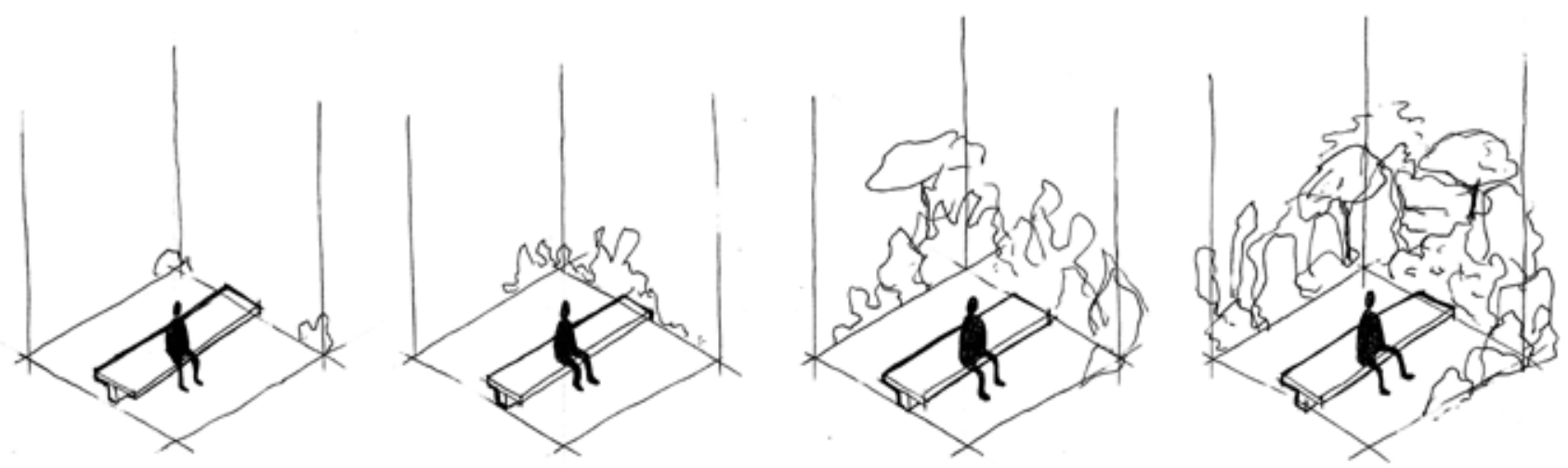

"Garofn Tims"

\subsection{SITED SPATIAL DRAWINGS}

This change in approach first required building an understanding of how "therapeutic atmospheres" could be imagined in outdoor public space. The language of site in respect to landscape (the physical, outdoor environment) and gardens is contained within different parameters than the interior, or built environment (Thrift, 2009). So-called "garden time," the acceptance and expectation of dynamic change and growth over an indefinite period of time, is an inherent aspect of spatial understanding and atmosphere in this setting, which is capable of producing less predictable kinds of potential effects and uses, separate from programmatic intent. The multiplicities outlined in Chapter 6 are still relevant, but augmented by environmental factors such as changes in weather, weathering of materials, and the different expectations of behaviour and patterns of use in public space. The following sketches explore the spatial possibilities found in this added complexity. 


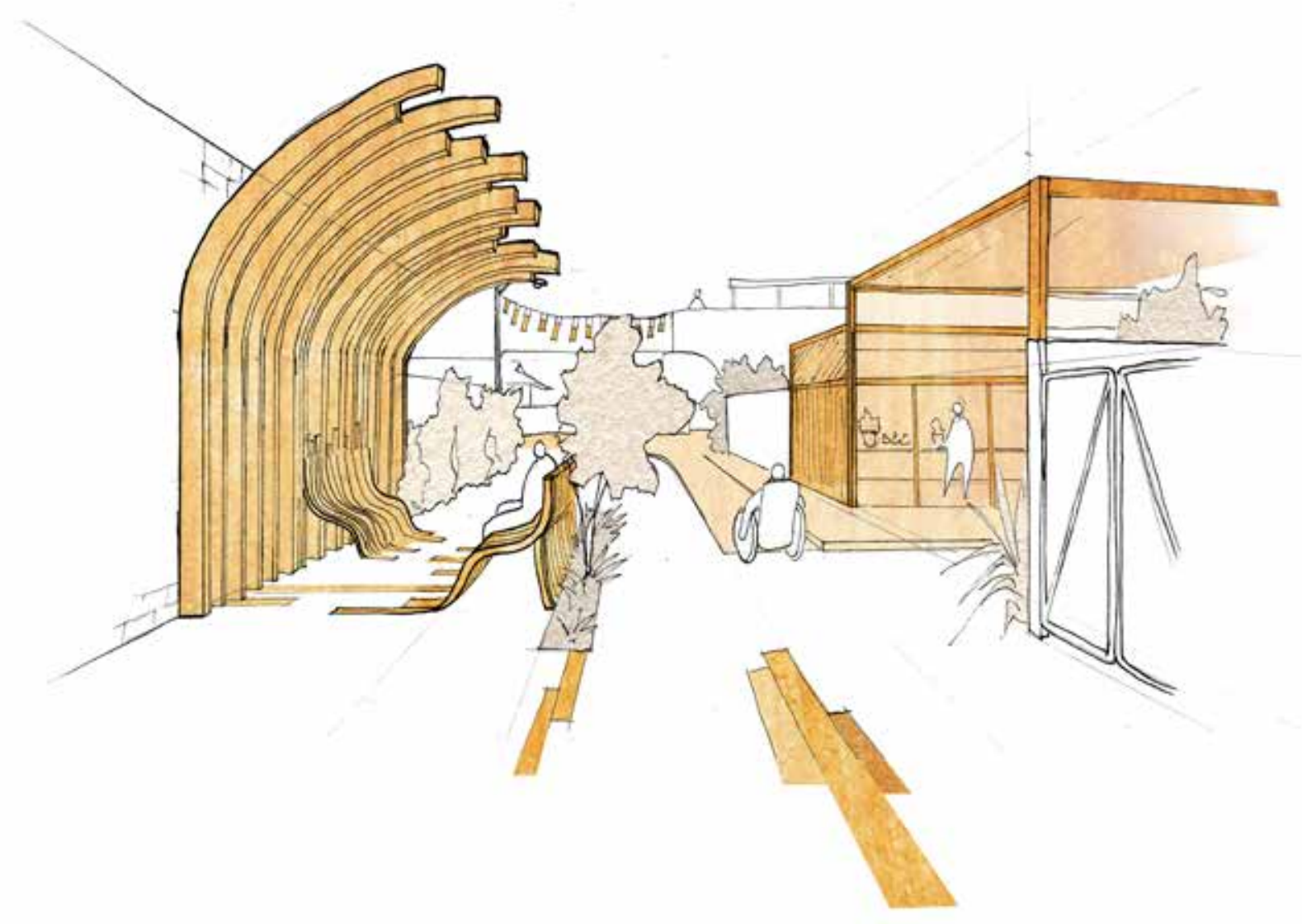

\section{Lanes}

A concept imagining the lanes which provide entry to the space as multisensory public space. A range of "options" along the way propose different kinds of therapeutic experience.
Sensory:

Activity:

Social:

Environment: Open, exposed contrast with moments of enclosure; planting to create shelter/spatial separation 


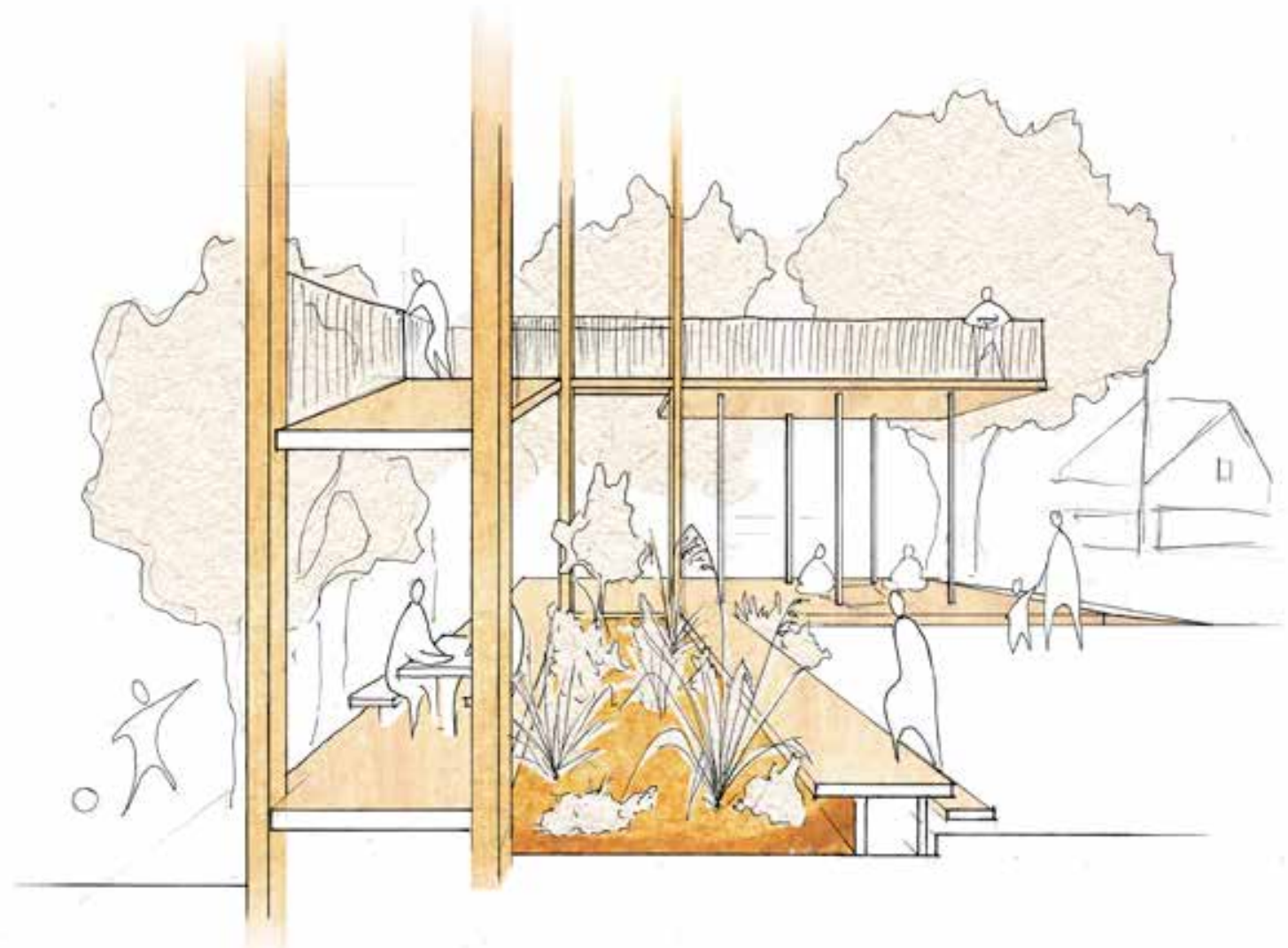

\section{Levels}

Increasing engagement with the

landscape by creating levels on which to

view and engage with the surrounding

environment and activities
Sensory: $\quad$ Viewing, watching, touching, physical exertion - climbing, descending

Activity: $\quad$ Exploring, wandering, exercising, resting, playing

Social: Wander alone, watch other groups, participate in group activity

Environment: Levels create semi-enclosed space/ shelter, different relationships to planting/ground 


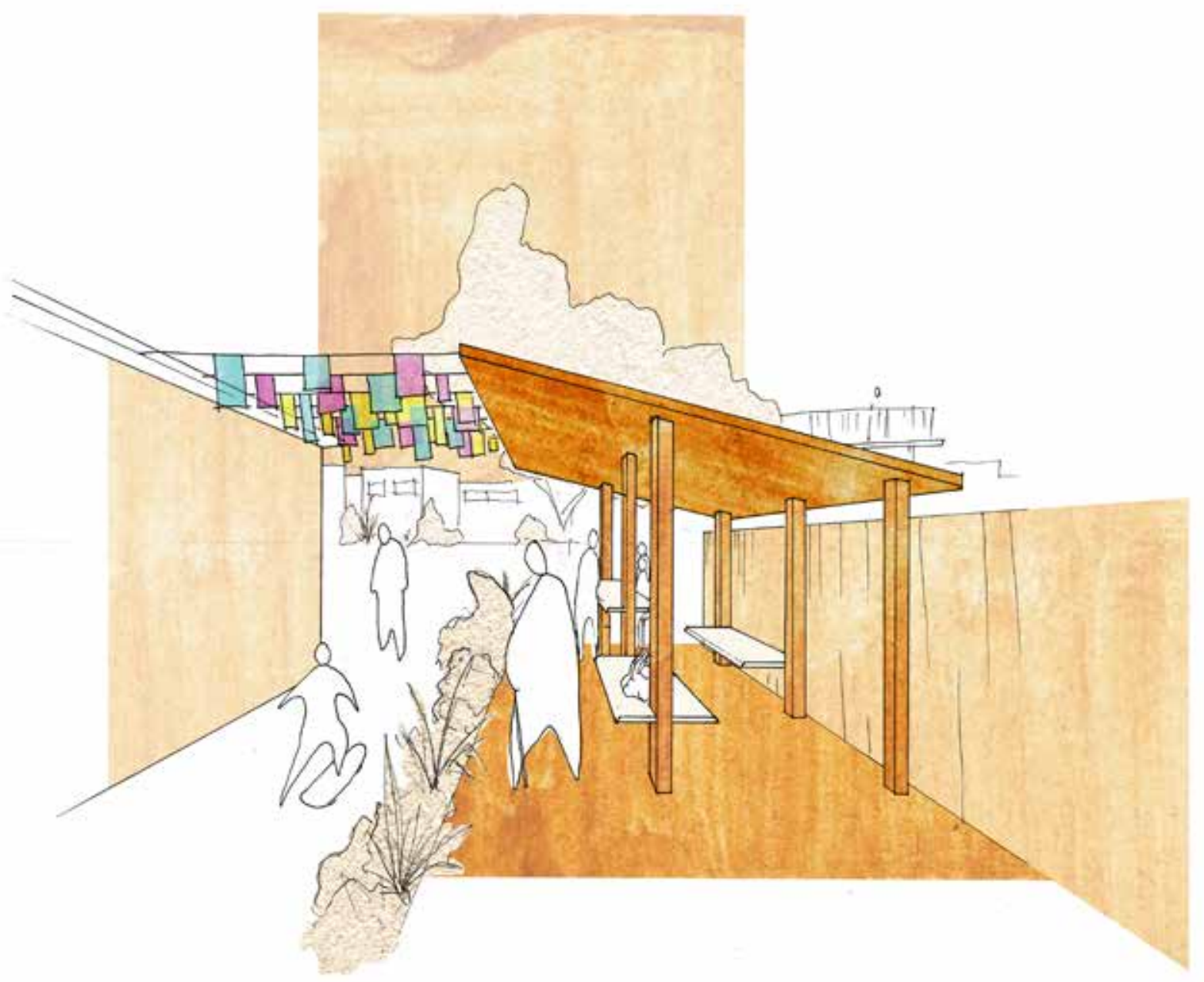

3. Stalls

Places adjacent to main pathways which allow options for stepping out of main flow. Potentially places to host weekend/ night markets, family events, informal meetings/ counselling sessions.
Sensory: $\quad$ Light, sound, sights, smells from food markets

Activity: $\quad$ Meetings, resting, playing board games, markets, small group classes

Social: $\quad$ Flexible levels of sociability, high possibility of chance interactions

Environment: Changes in spatial use during day/ night; weekend/weekday. Protection from rain/sun 


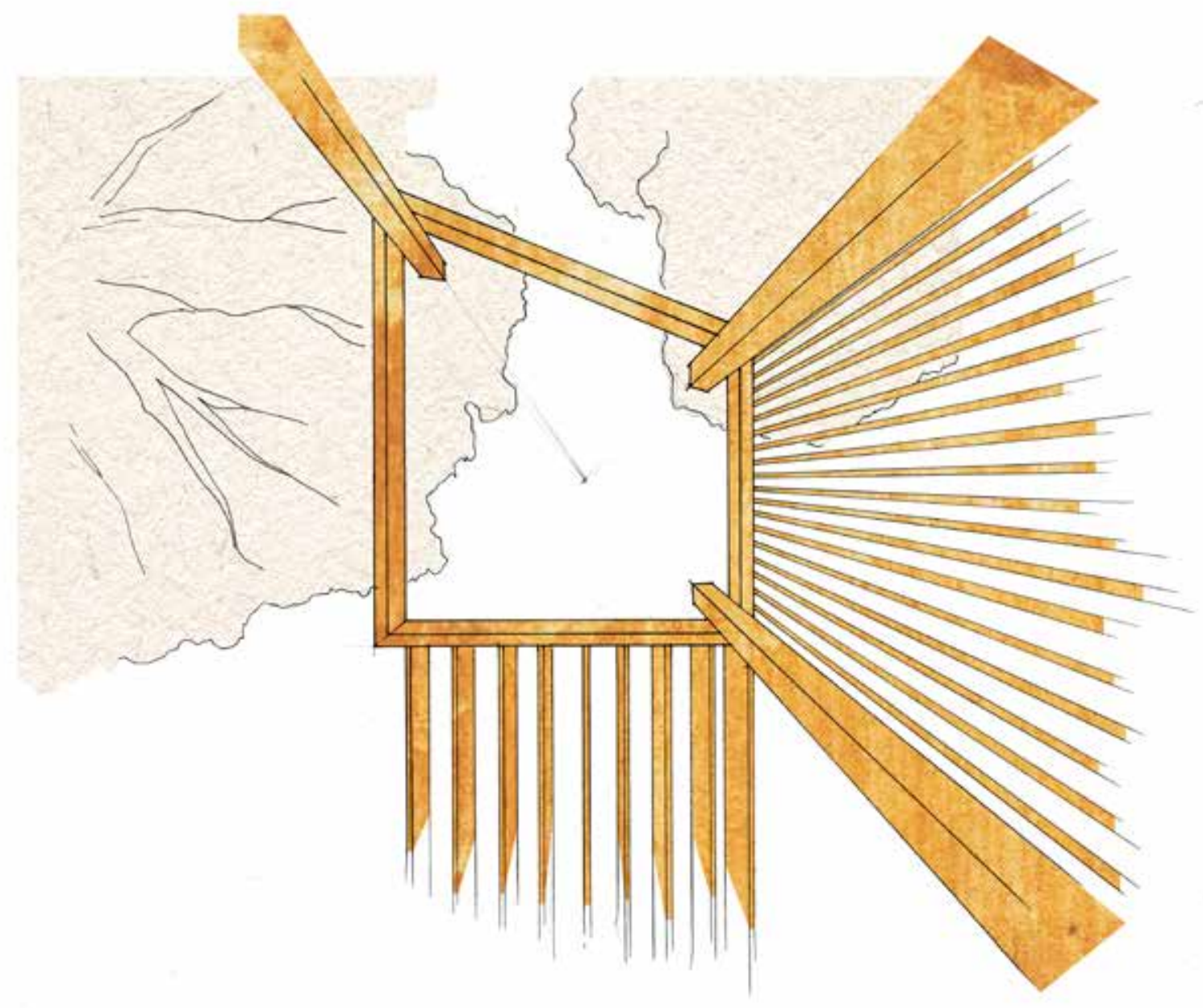

\section{Views}

Structures to frame views and create opportunities for private introspection and respite
Sensory:

Activity:

Social:

Environment: High attunement to weather conditions / time of day and year 


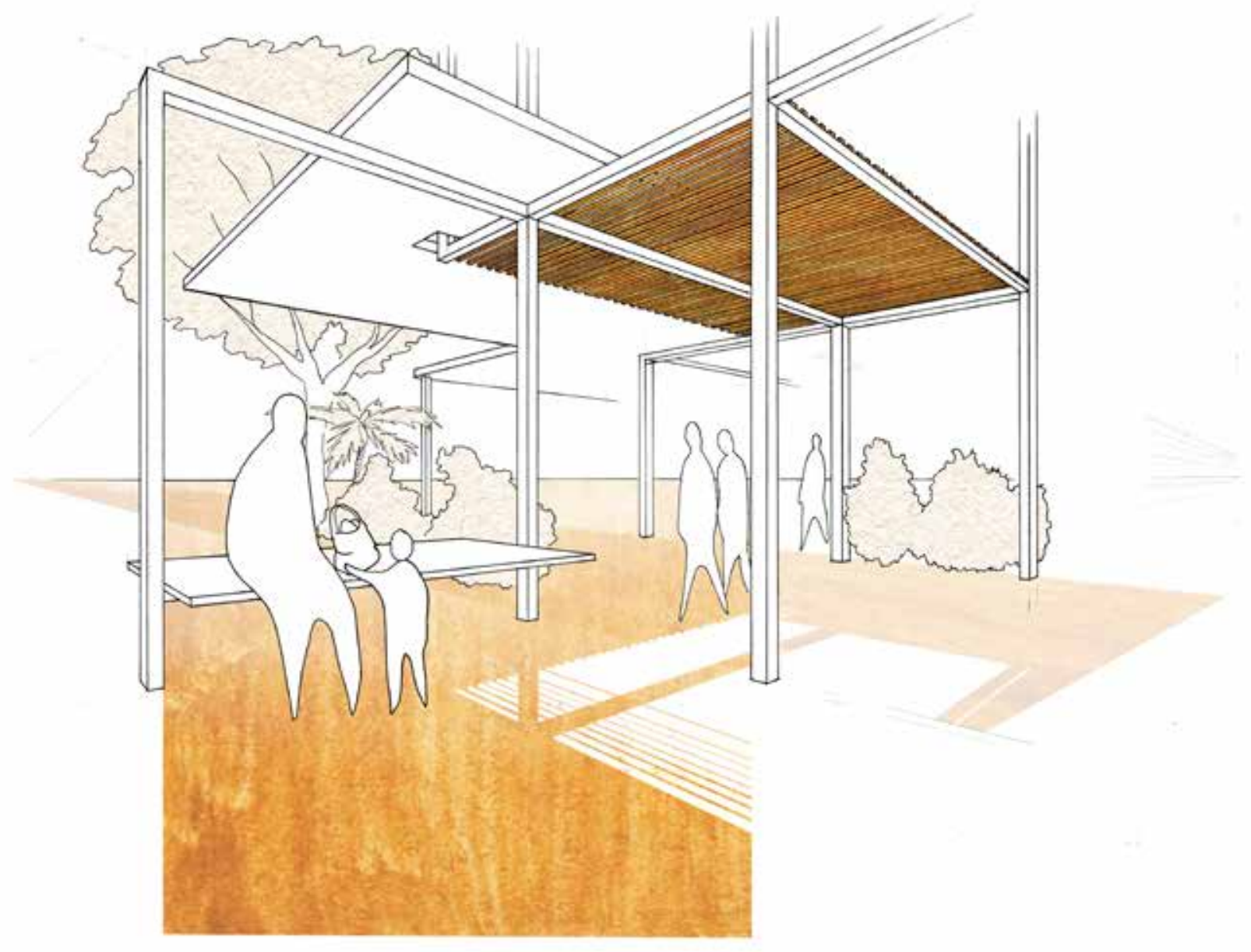

\section{Shelter}

Structure to divide large space, defining certain areas for different activities. Hard and porous roof to protect from rain and provide shade without closing off from natural world.
Sensory: Touch - wind/rain/sun. Sight. Enclosure

Activity: $\quad$ Flexible - defined by structural spaces

Social: $\quad$ Smaller spaces provide options for individuals, larger for groups

Environment: Structure can be used to guide a certain relationship with the environment at different moments in space and time. 


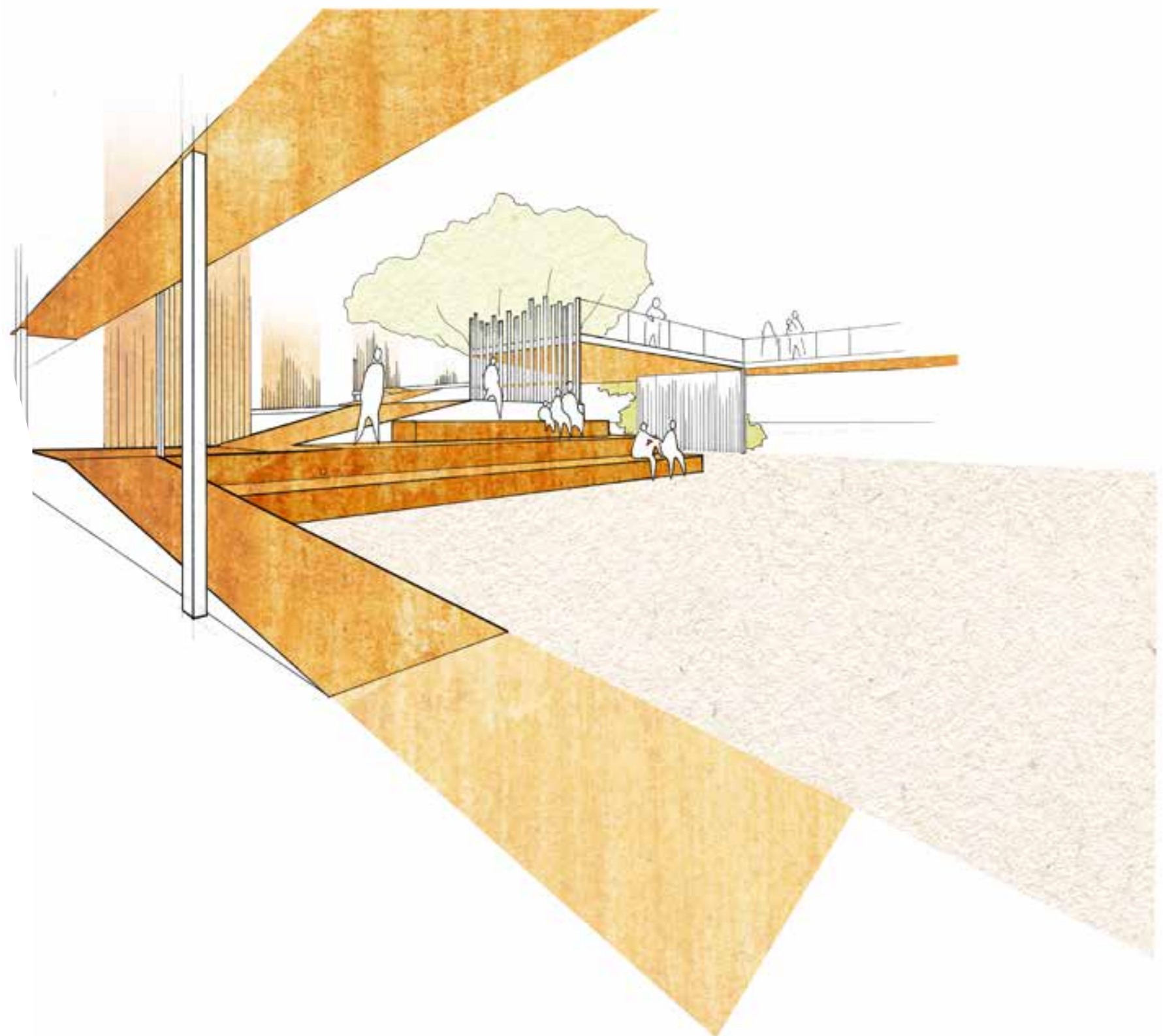

\section{Community Space}

Open areas for activities such as sports, performance, open play, with connections to rest of site.
Sensory:

Activity:

Social:
Sound, views, touch (grass/ground, seating materials)

Watch, perform, talk, meet, celebrate, cultural performance, public meetings

Highly social - opportunities for "whiria te tangata" - "weaving together" of community.

Environment: Community and natural rhythms working in conjunction with each other 


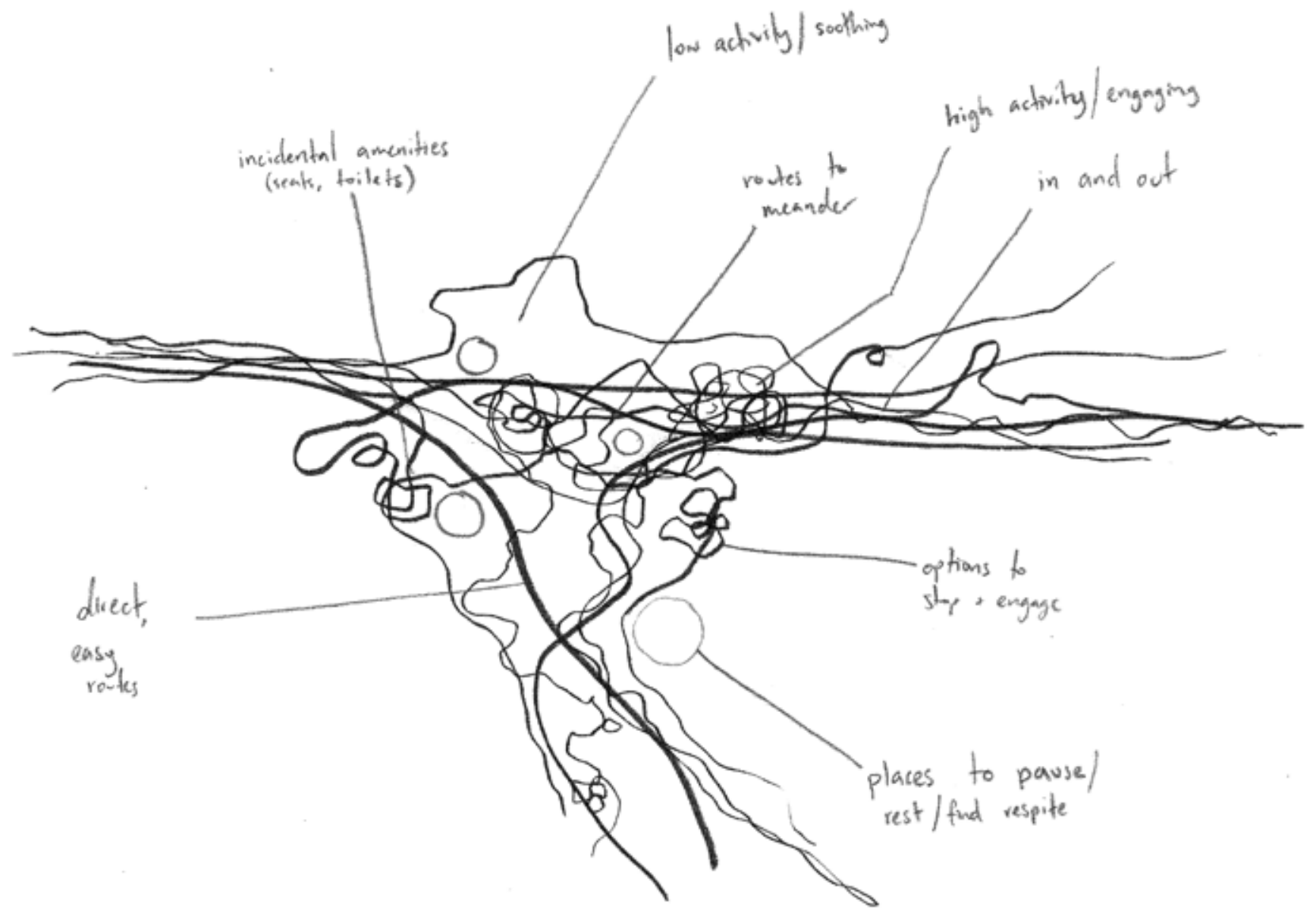

\subsection{REFLECTION}

Adding environmental factors to the mulipilicity approach explored in Chapter 6 prompted a different kind of spatial understanding, based more directly on the experience of site. Designing for general public use with a focus on mental health means providing a range of options that suit different experiential and sensory needs. Some people may want to use the space as a site for group activities, while others may want to find a quiet place to rest there; some may seek positive distraction (Emami et al., 2018), while others may be overwhelmed by too much of a certain stimulus (Bailliard, 2015). The drawings explore how architectural intervention in conjunction with environmental and community factors can be used to generate different kinds of public space which can facilitate a range of options for moments in public space that cater for a diverse range of preferences and needs. The sketches suggest that "therapeutic atmospheres" could be considered as parts of a "therapeutic journey" through the site, with different options to suit different kinds of desirable affective experience.

\section{A new approach:}

Working "outside-in," the above sketch shows potential ways of journeying through the assemblage of public space, with opportunities for affective therapeutic experiences. 


\section{THERAPEUTIC \\ JOURNEY}

Designing for a range of therapeutic space preferences

\subsection{WAYS TO JOURNEY}

\subsubsection{Accessibility}

\subsubsection{Ramp Development \\ 8.1.3 Walkway Structure}

8.2 DESIGN PROPOSAL FOR A THIRD PLACE IN TAITA SHOPPING CENTRE 
This content is unavailable. Please consult the figure list for further

details: https:/slate.com/human-interest/2015/03/madlove-a-designer-asylum-fromjames-leadbitter-the-vacuum-cleaner-is-a-mental-health-space-designed-by-patientsin-the-u-k.html

FIG 8.1: THE STAIRCASE TO NOWHERE from Madlove : A Designer Asylum

A "multifunctional object that offers the opportunity to retreat from the activity below while still remaining part of the action" Image and text: (Hoehandel, 2015) 


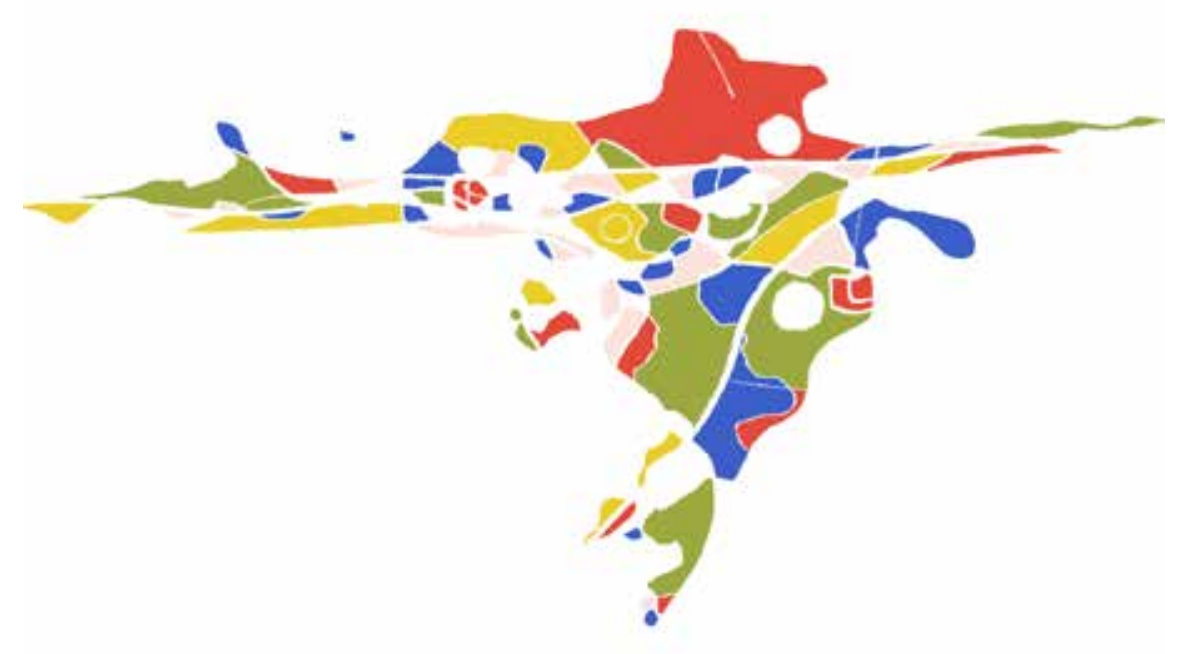

\subsection{WAYS TO JOURNEY}

A journey can take many different forms. In order to plan a therapeutic spatial journey through the site, consideration of pathways and the experience of moving through a landscape was needed. The sited spatial design sketches explored a range of different "therapeutic moments" that could be accessed through this journey, and suggested different ways of connecting them; but further development was needed to understand how the experience of walking through site could generate opportunities for architectural intervention. In order to do this, several ways of journeying through the site were iterated through isometric drawing, then assessed based on the following criteria derived from the sited spatial designs, research into therapeutic landscapes, and precedents:

- The journey must be accessible to all levels of physical ability

- The journey must maximise opportunities for therapeutic encounters, creating moments along the way which emphasise interaction with nature, sensory experiences and social activities

- These therapeutic encounters must be optional: where there are spaces that allow for high levels of stimulus and activity, there must be quieter places which allow for retreat and contemplation (see example, right).

Images in this chapter are all author's own (2019), unless otherwise specified. 
1.

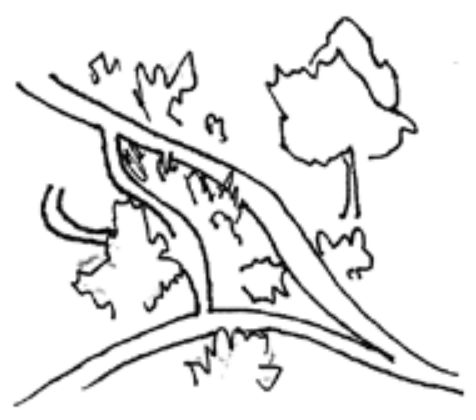

3.

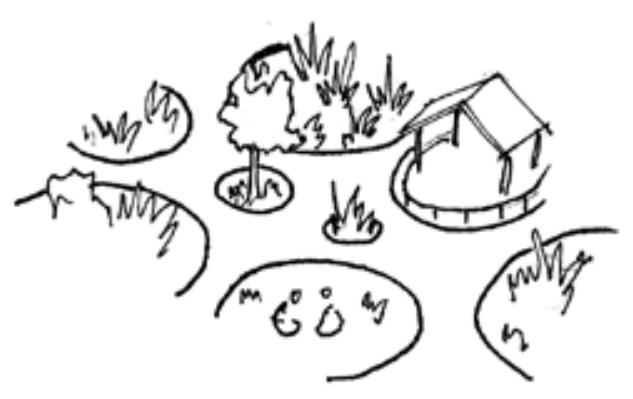

5.

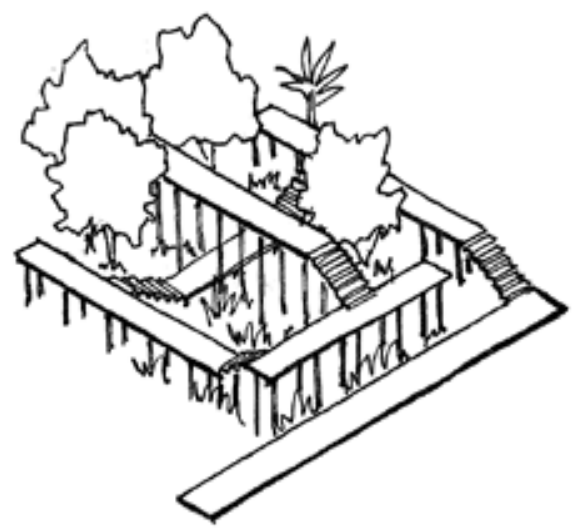

7.

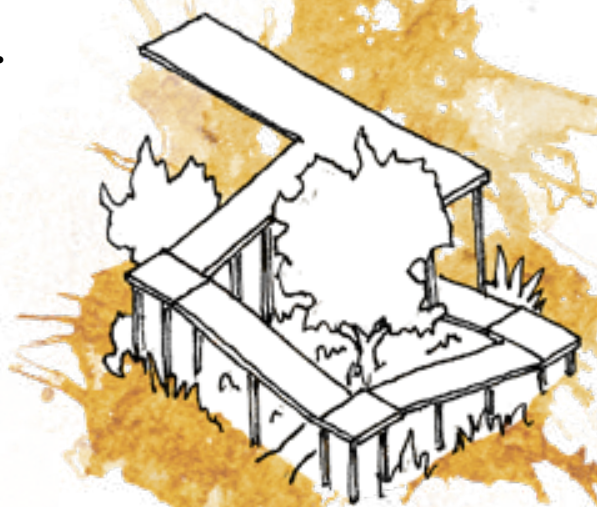

2.

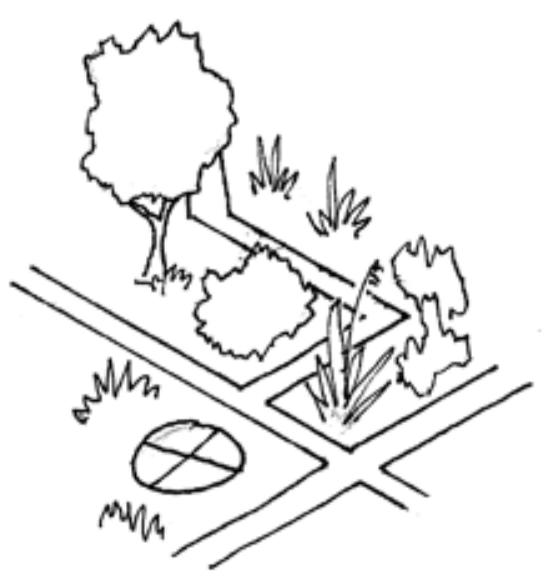

4.

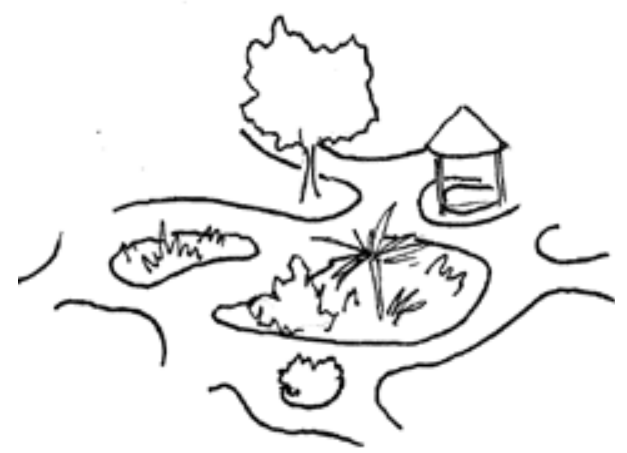

6.

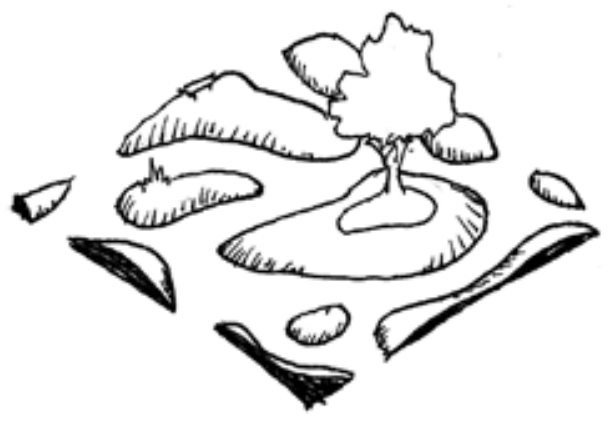

8.

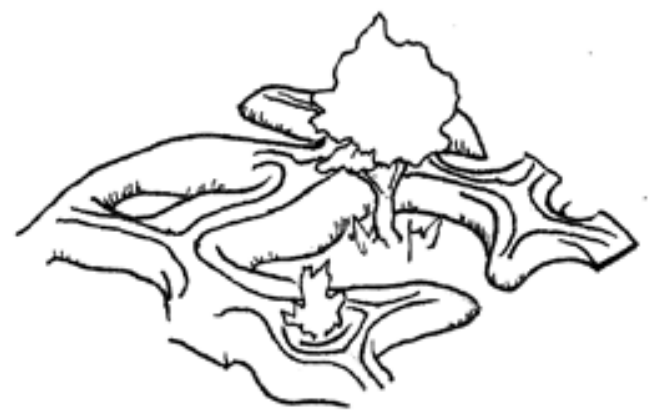

134 


\section{Opposite:}

1. Pathway through flat ground based on organic lines.

2. Pathway through flat ground based on geometric lines.

3. Boardwalk/raised pathway with cutouts for green space

4. As above, with more organic cutouts

5. Raised walkways at different levels, with stairway connections

6. Flat pathway with raised areas of landscaping

7. Raised walkways at different levels, with ramp connections

8. Landscaped walkways with depressions for encounters/green space

\section{ANALYSIS:}

As indicated through the drawings, the intersections of pathways can create a range of different spaces in which therapeutic moments could be set. The drawings explore how these moments could relate to the overall journey, whether on an equal plane $(1,2)$, a lightly separated plane $(3,4)$, or a highly separated plane (5-6). While the first few options are the most physically accessible, moments 5 and 6 provide the most opportunity for creating optional therapeutic spatial experiences. Moment 5 recalls the "staircase to nowhere" designed by the Madlove precedent (see Fig 8.1), which was intended to allow "space to retreat while remaining part of the action" (Hoehandel, 2015), by providing physical distance, but retaining sight connections. Raised walkways also create semi-enclosed space beneath them which can be utilised, unlike solid spatial separations $(6,8)$. However, as an important criteria of this space is that is should be accessible to all people, regardless of physical ability, the ramp version of this option (7) was selected as the most appropriate choice of journey to develop. 


\subsubsection{ACCESSIBLITY}

An essential element of designing for wellbeing, whether it be specifically mental/emotional or other, is accessibility. Wanting to create different spaces and opportunities for interventions on the site through levels means providing accessible paths for all people. In this exercise, accessibility guidelines ${ }^{*}$ for ramps and inclines were used as a guide to investigate the kinds of spaces that could be created by ramps on site. These sections are diagrammatic, and as such, handrails and other accessibility requirements are not included.
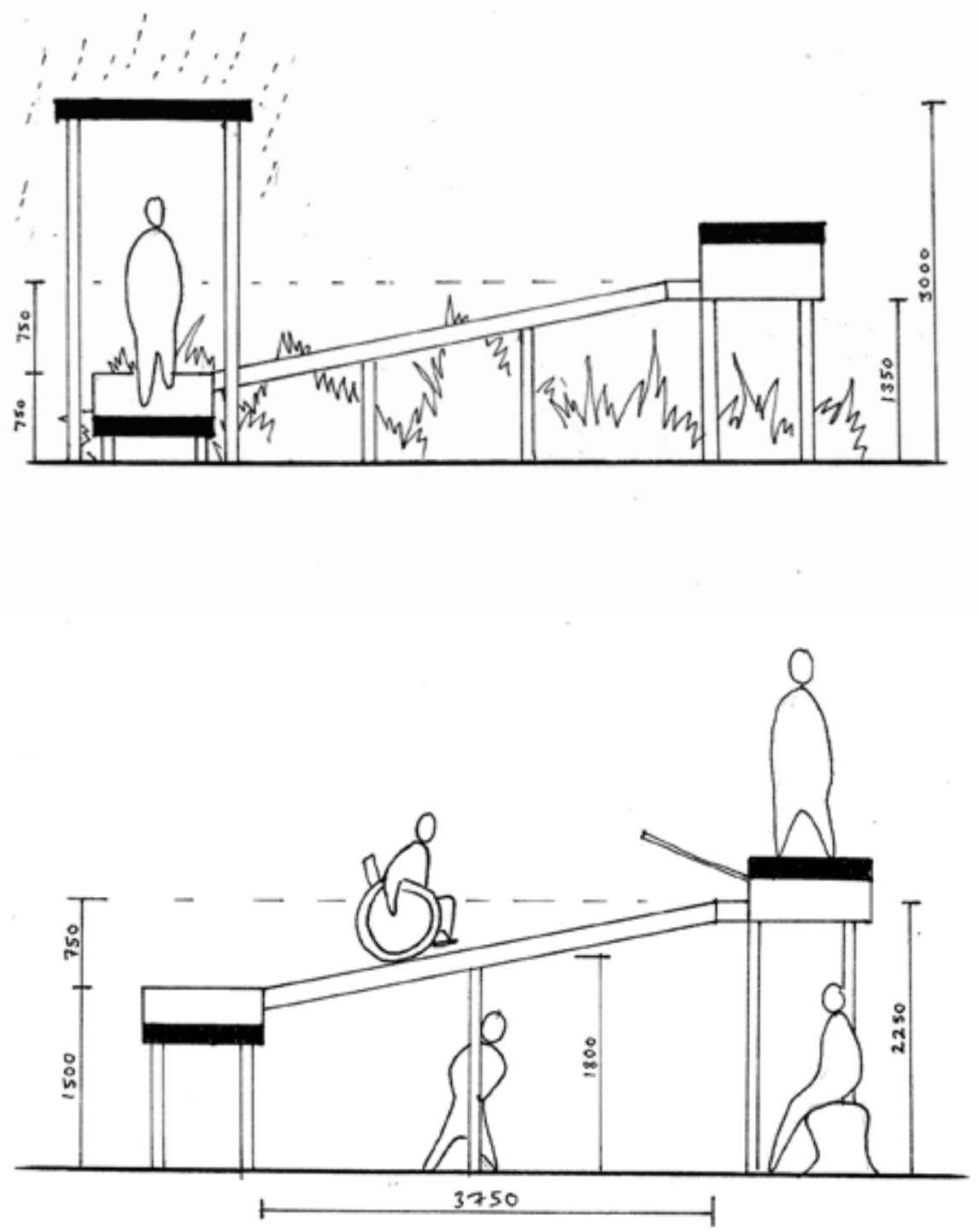

\section{SECTION 2-2}

Between the $1500 \mathrm{~mm}$ and $2250 \mathrm{~mm}$ space, habitable space begins to form, especially for children, or people using wheelchairs. The opportunity here is to provide access routes/journeys solely for these two user groups, who are often an afterthought in both design and discussions of mental wellbeing. While 2250 is a low ceiling height, it does provide an intimate kind of architectural space that could be suitable for rest/respite areas.

*Accessibility guidelines taken from NZ:3604. 


\subsubsection{RAMP DEVELOPMENT}

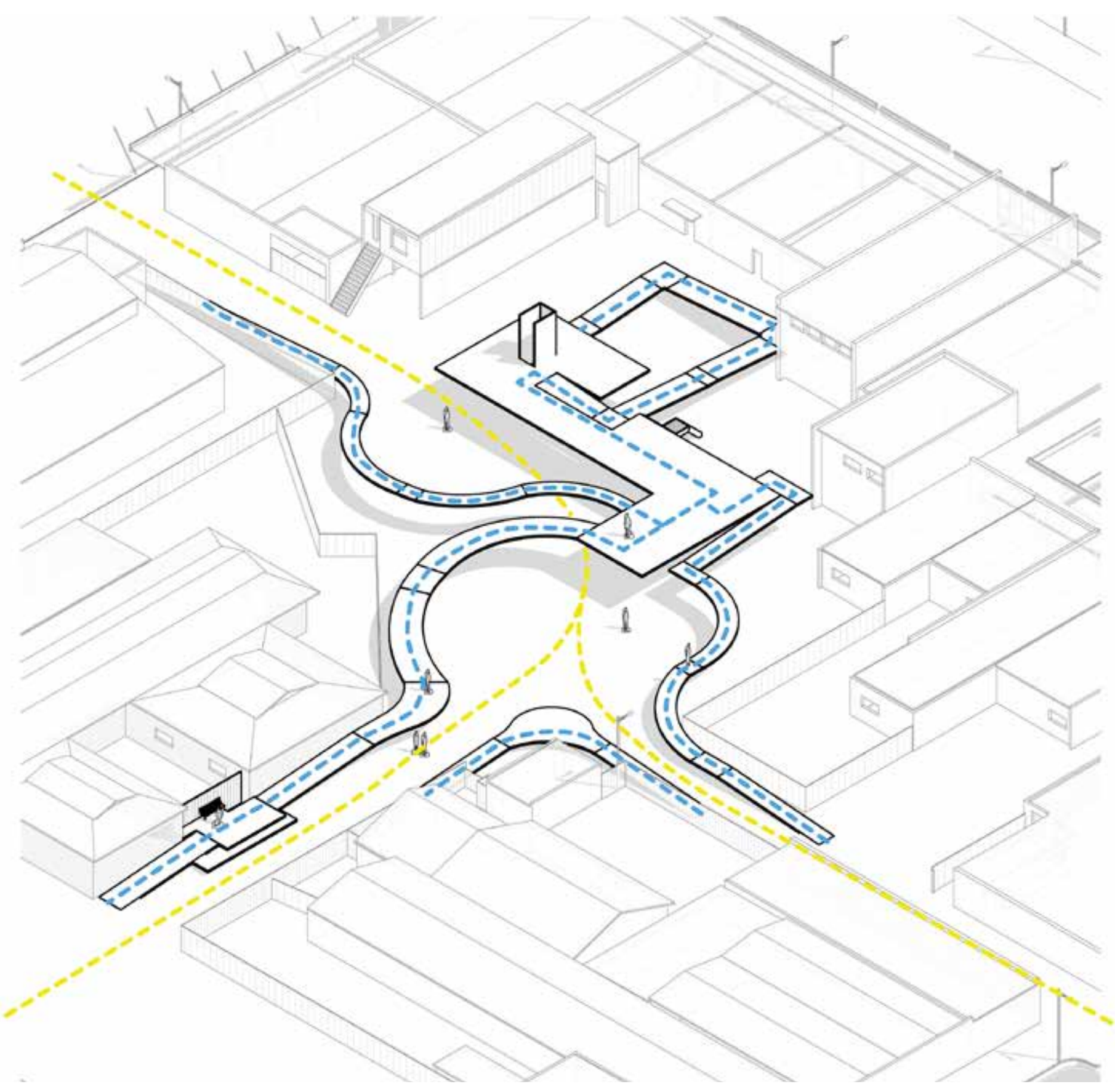

The ramps were set out on site according to pre-existing and potential pathways.

Above: Circular ramps were initially In line with the emphasis on accessibility, they were set out in a way that still allowed for an un-interrupted ground level journey through the site, making the used in an attempt to bridge the space, while also creating clear walkways underneath. potential physical exertion of the raised journeys completely optional. Initially, as shown above, this was negotiated through the use of circular ramps (above). Research into Universal Design, however, highlighted that was not an accessible option for people using wheelchairs. 


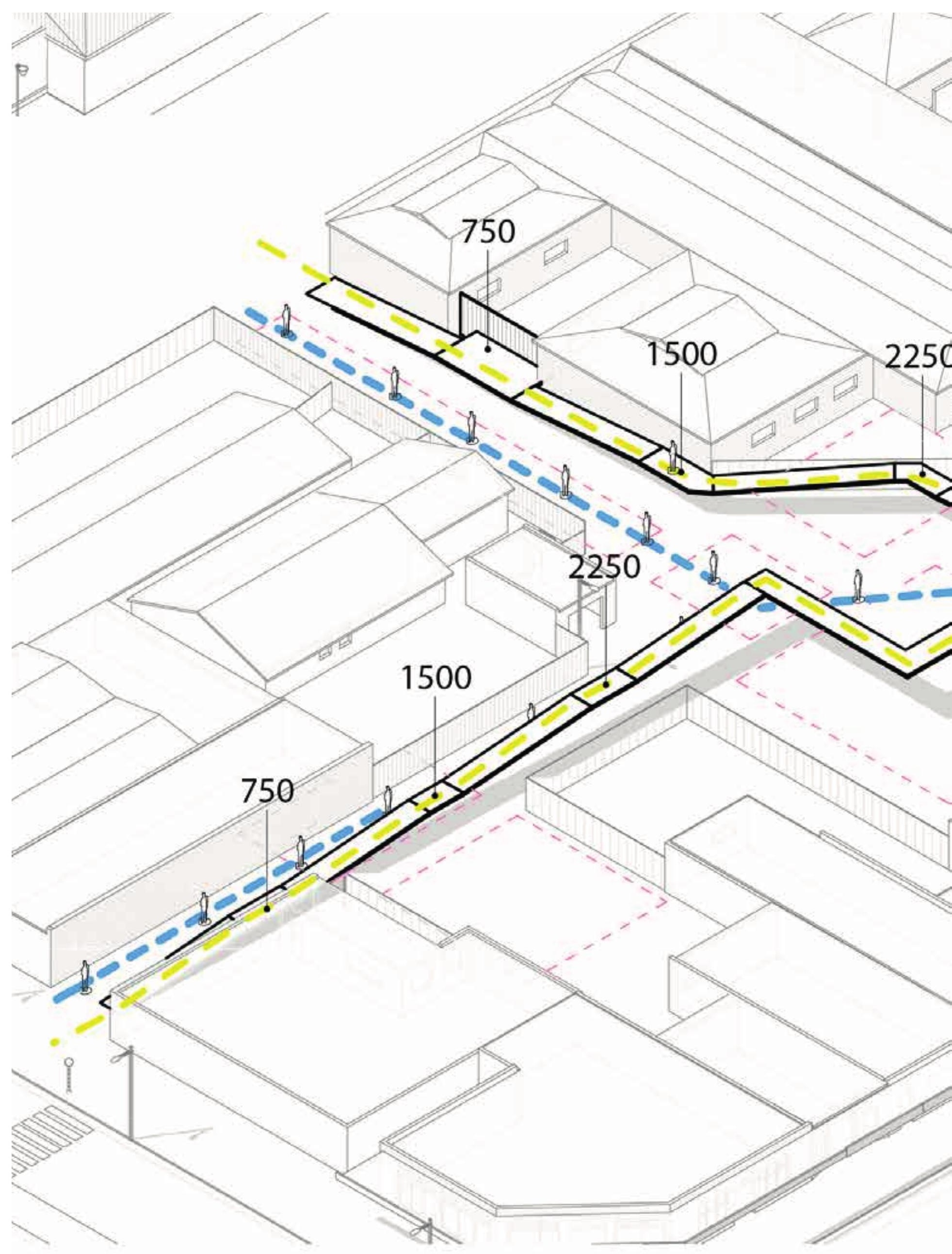




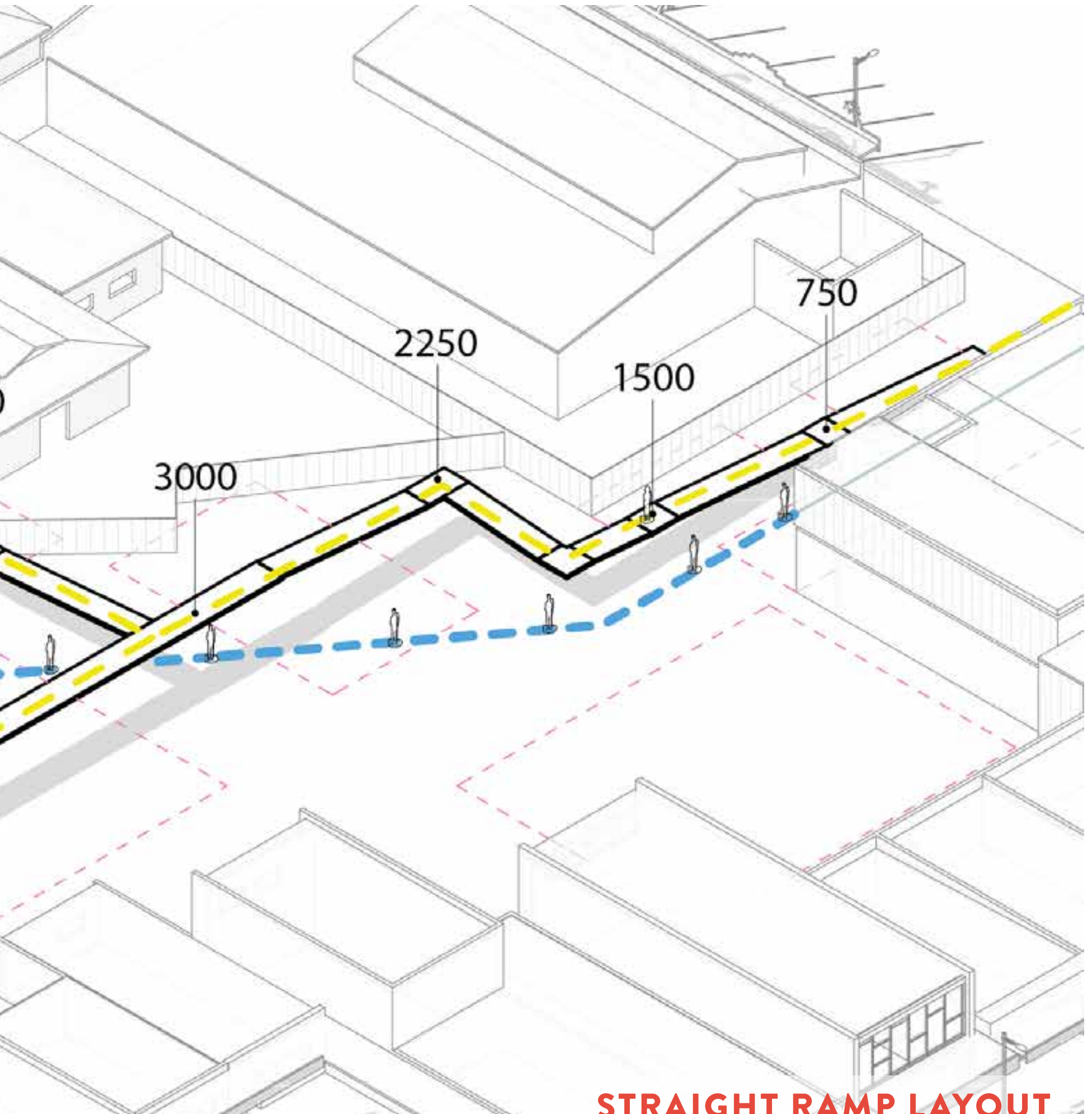

STRAIGHT RAMP LAYOUT

Following universal design principles, circular ramp layouts were reworked into a straight layout, following the most direct pathways possible. Primary ground level paths through the site are shown in blue, while secondary raised journeys are shown in yellow. Numbers indicate top-of-ramp height from ground, and red squares suggest possible sites for interventions. 


\subsubsection{WALKWAY STRUCTURE}

The following investigation explores how interactions with different kinds of structure at ground level can form and guide therapeutic place experiences.

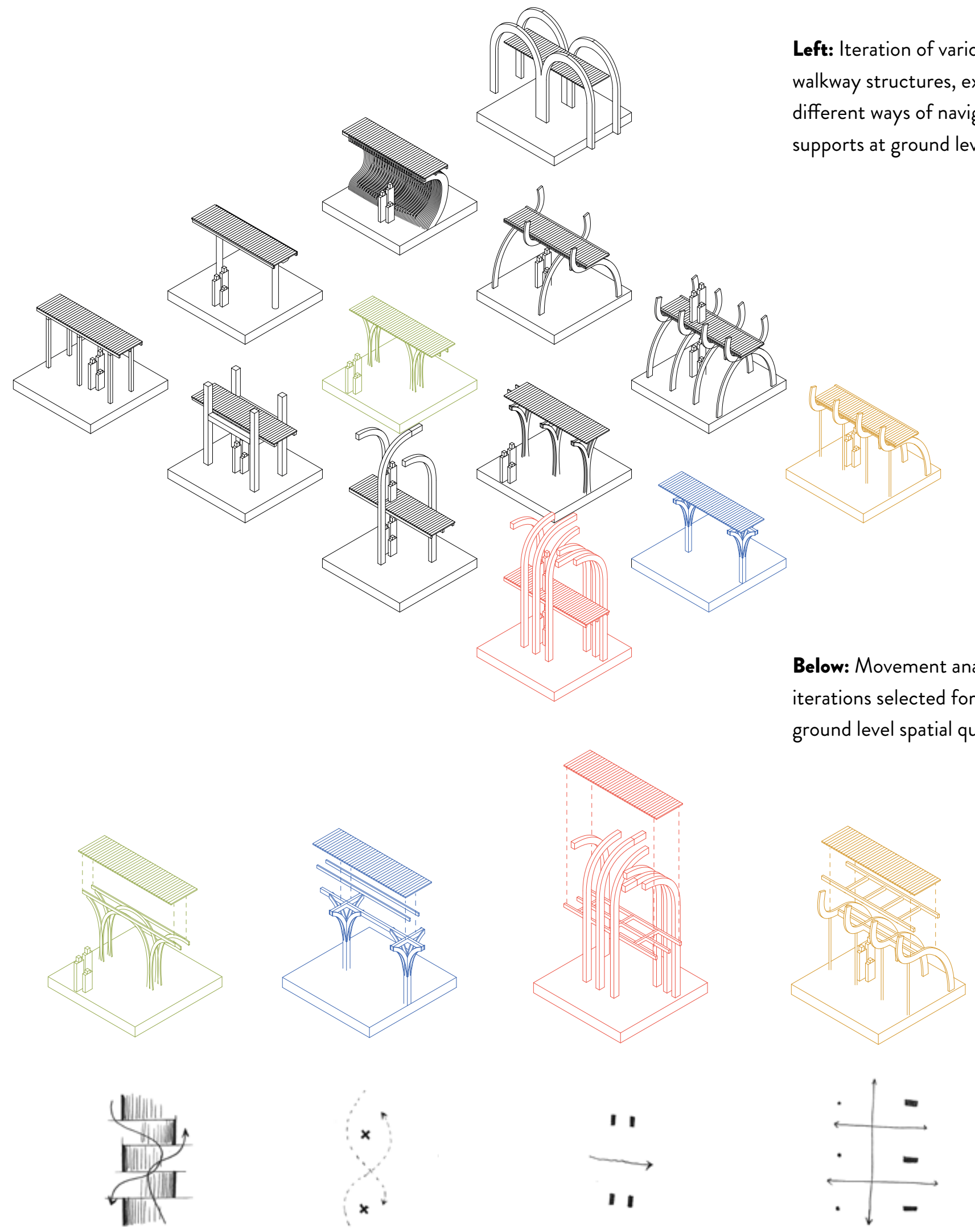




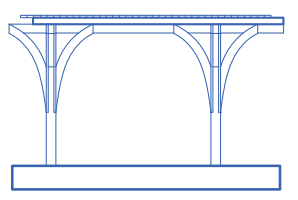

\section{Tree Supports}

Single Posts allow less

clutter at ground level

1.

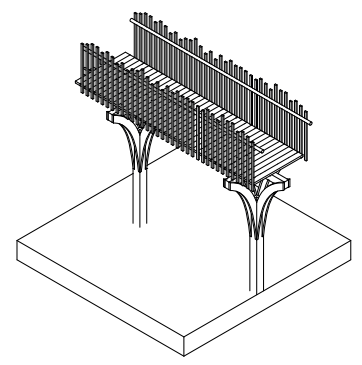

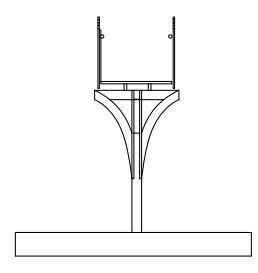
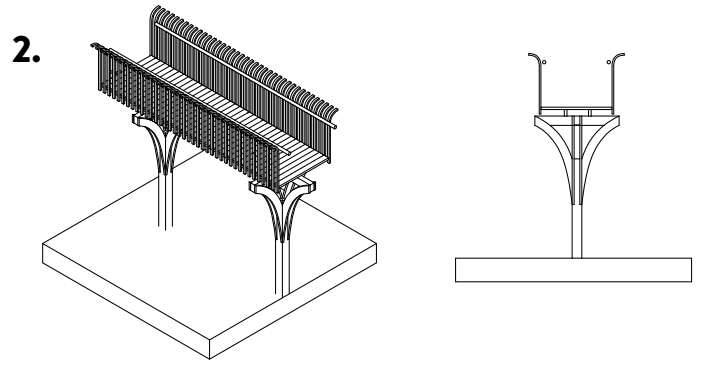

\section{Railing Development}

1. Uneven railing posts $(100 \mathrm{~mm}$ c.) create an profile from ground

2. Curved railing posts could encourage leaning behaviour, to view activity/natural elements below
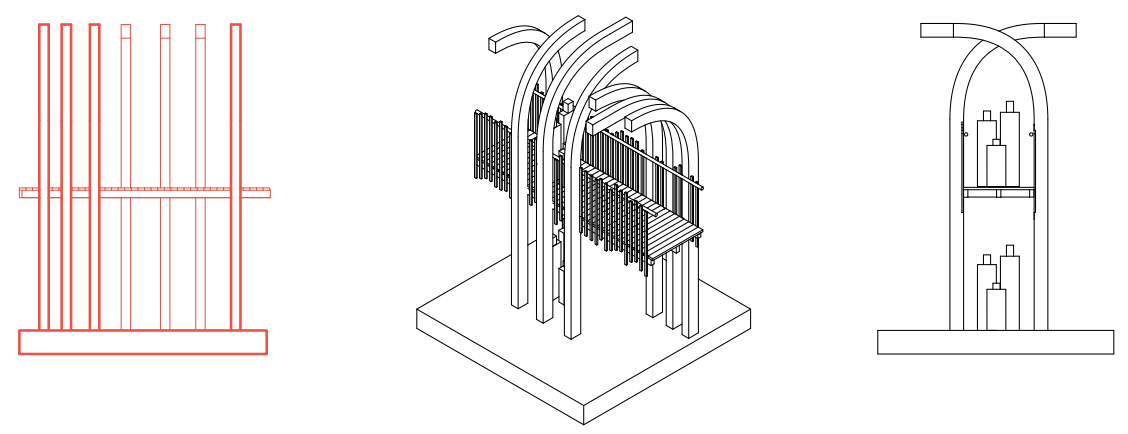

Arch Structure: Can direct movement/views on ground level, and provide shelter above.
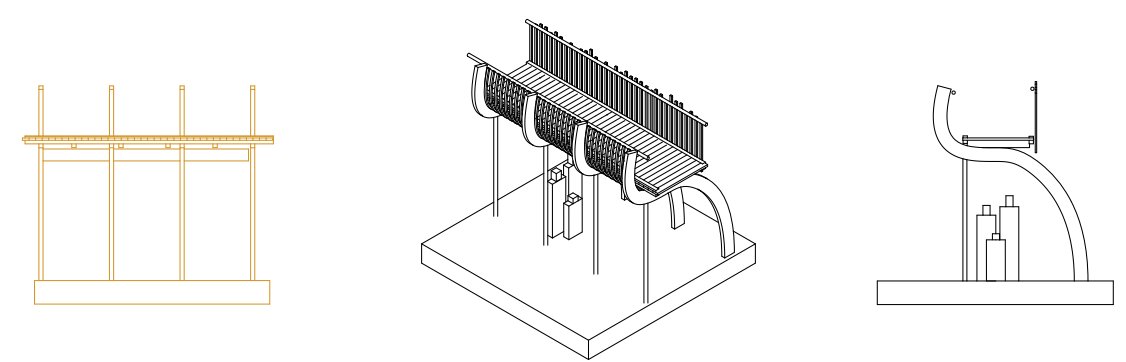

\section{Asymmetrical Arch}

Structure: Maximises space below ramp, with steel supports if neccessary. 


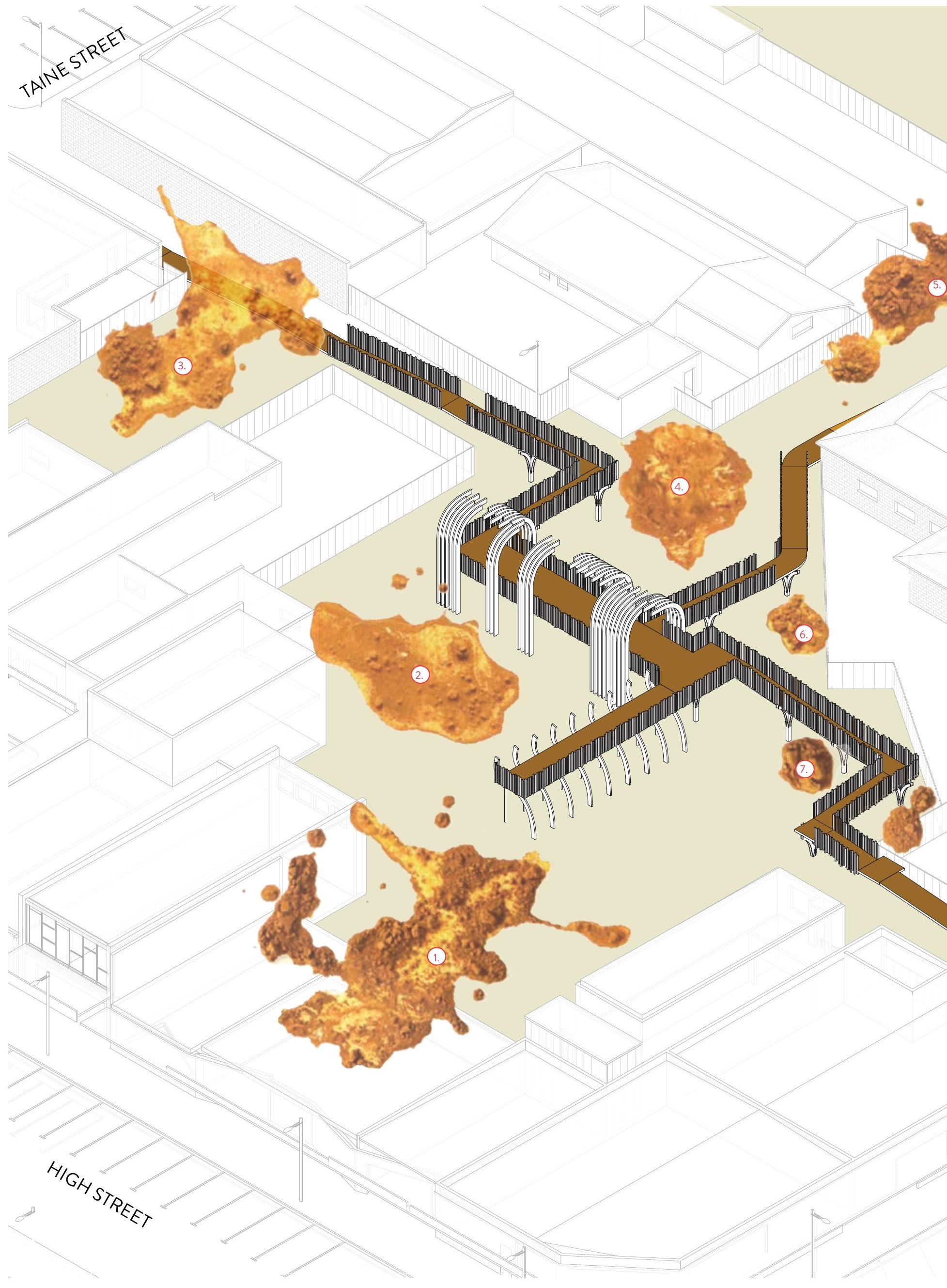




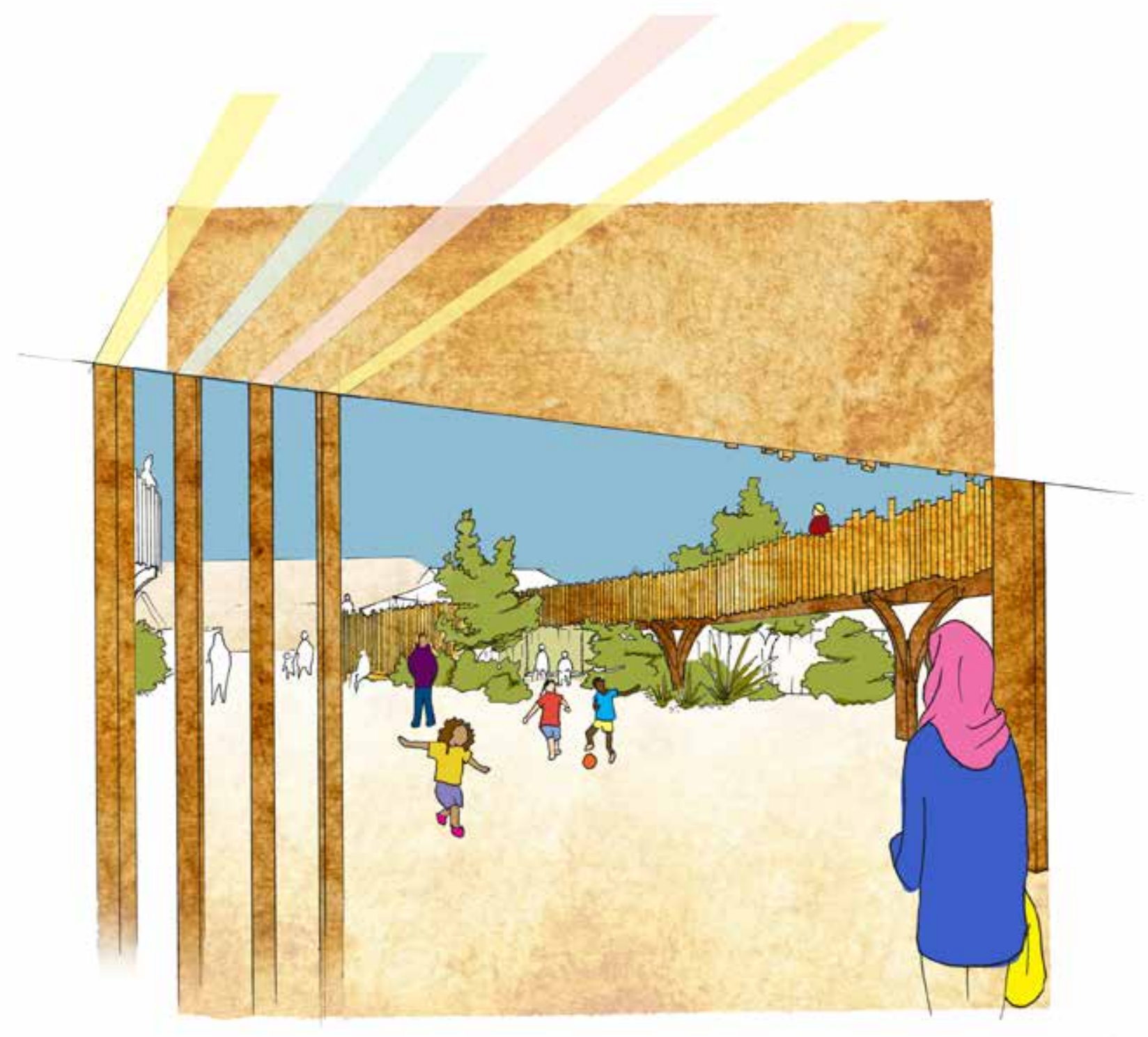

\section{EXPERIENCE OF STRUCTURE}

Wooden glulam structure can blend into natural elements on site, while framing different kinds of social and community experiences. Options for lighting to be integrated into it allow for safe use of site at night. 


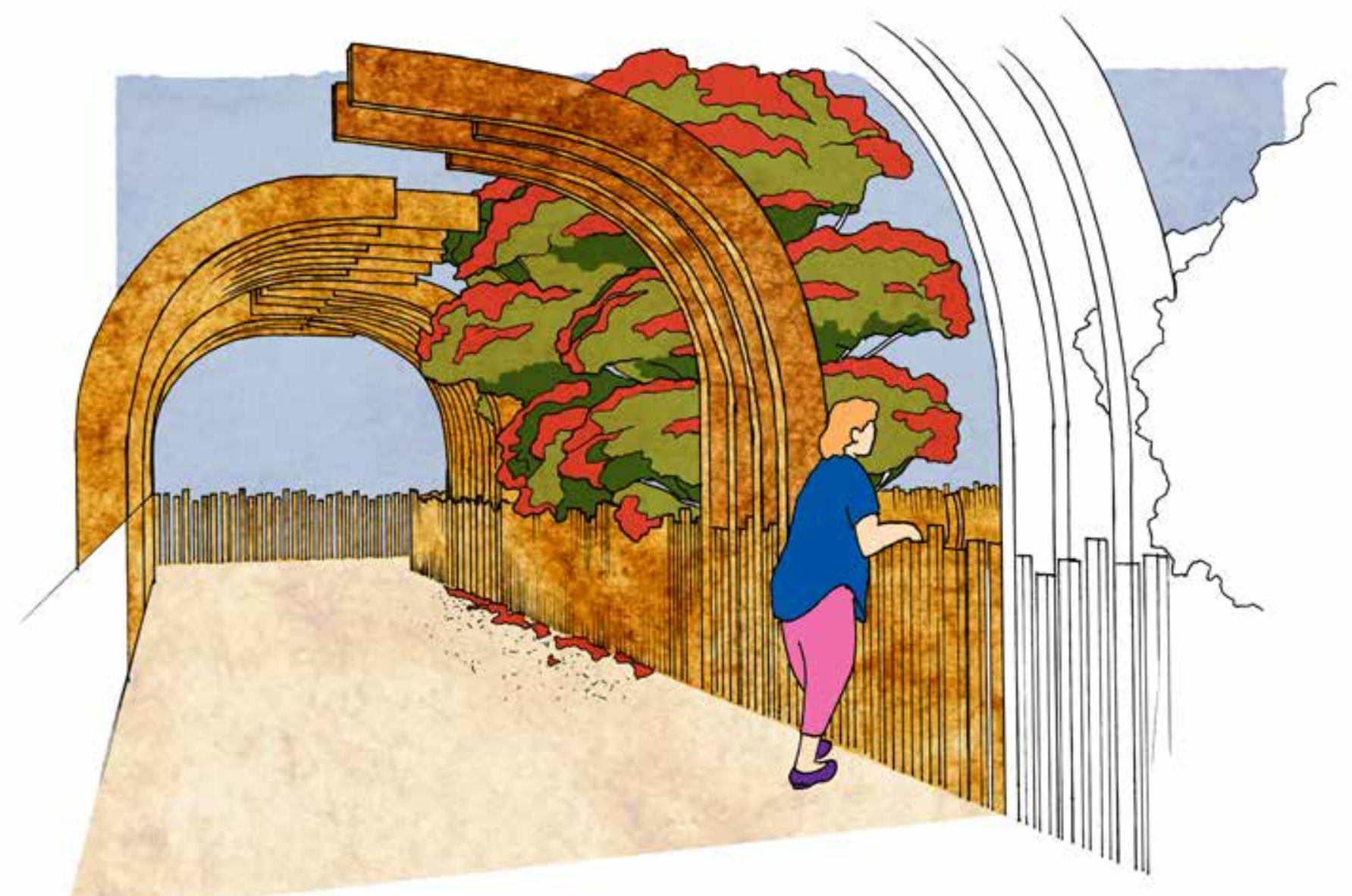




\section{Tocker St Entrance; 2. Taine St Entrance; 3. Walter Nash Entrance}

\section{Sensory play area, for children and adults}

A more private area where both children and adults are encouraged to explore their relationship to the land through touching, moulding and interacting with clay, sand and water. An accessible ramp leads to an ochrewater installation where people can touch and see the temporal qualities of these materials.

\section{Non-gendered public toilet (accessible, change amenities)}

To provide a lockable, familiar space to "get away," as well as providing amenity.

\section{Rest areas along walkways}

To encourage a slower journey through the space

\section{Pockets of retreat}

Where noise is minimised and nature is emphasised

\section{Lower areas under walkways}

Utilised for interventions for people in wheelchairs, children, two user groups often ignored in design

\section{Community food centre / Emergency sleeping cosies}

Building on existing community efforts, the centre celebrates these groups and also provides space for learning, sharing and growing food on a rooftop garden. Attached is are lockable emergency sleeping cubicles for people to sleep near the safety and oversight of the community centre and new mental health centre.

\section{Harakeke garden}

Allows for a deeper immersion in natural space, with an accessible walkway around providing views for wheelchair users.

\section{Harakeke preparation and weaving area}

Based on the therapeutic and cultural benefits of working with harakeke, this space is for the "weaving together" of people and landscape.

\section{New community mental health centre}

Formal oversight is provided through repurposing the existing medical centre. Serves as a "base of operations" and also provides direct mental health services, such as counselling and respite.

\section{Outdoor seating (sheltered space underneath)}

With sheltered nooks underneath in which to rest, or play games.

\section{4, 15. Youth centre}

Re-oriented toward interior square, with stage for cultural performances, public meetings, etc.

\section{Existing residential space retained,}

For safety and wider use of space. Further residential spaces to be encouraged. 


\subsection{DESIGN PROPOSAL FOR A THIRD SPACE IN}

\section{TAITA SHOPPING CENTRE}




\section{Playful nooks}

Smaller spaces under structure provides seating and options for children and wheelchair users.

\section{Quiet Areas}

Low-sensory areas adjacent to main flow, for retreat and privacy
Support Network

Space supported by organisations and volunteer groups who can coordinate community initiatives, and provide a point of contact for people in distress.

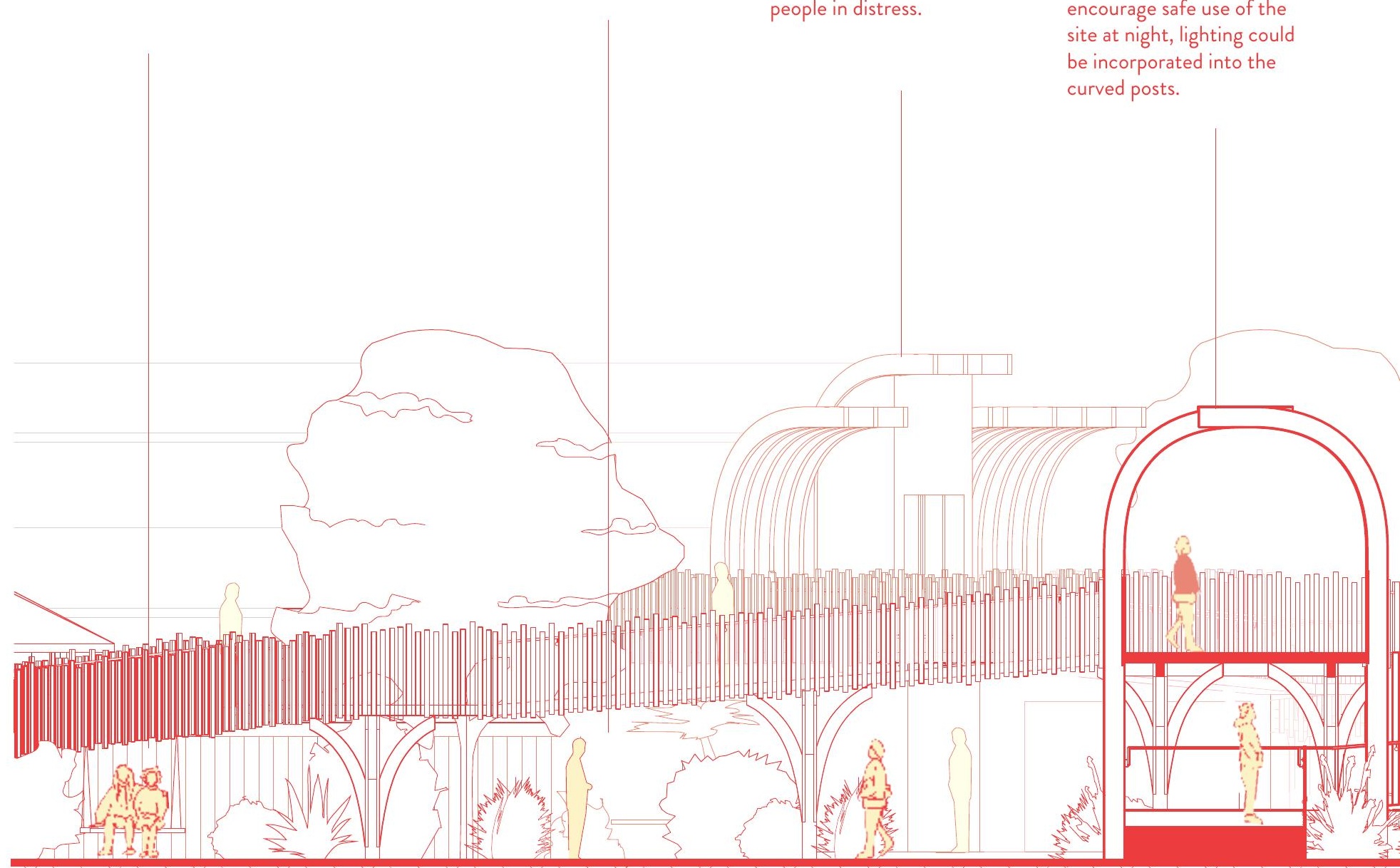


Accessible Levels

Levels provide an element of spatial separation, while maintaining a connection to activity below. Ramp cluster supports seating for an outdoor stage adjacent to youth centre.
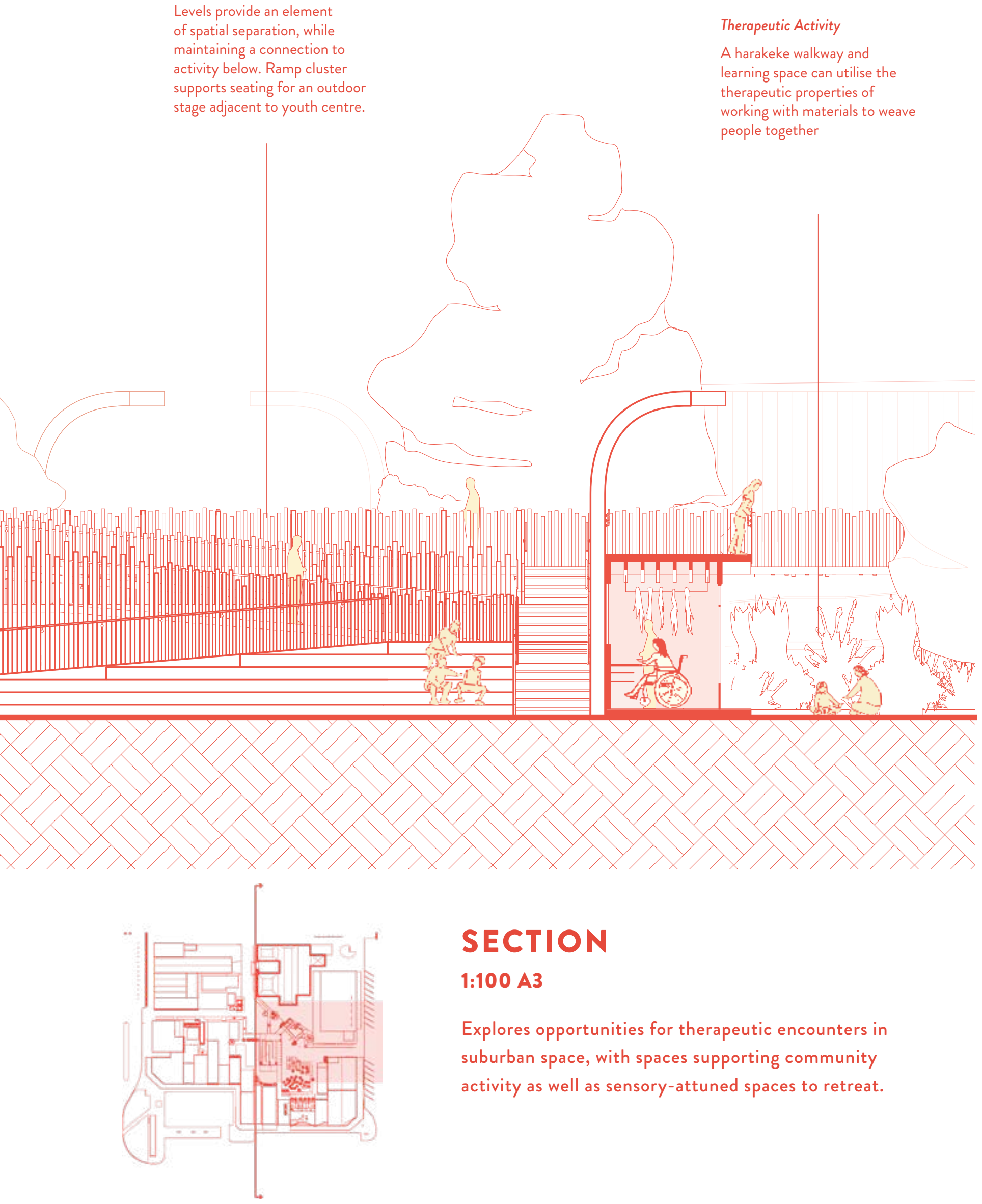

SECTION

\section{$1: 100$ A3}

Explores opportunities for therapeutic encounters in suburban space, with spaces supporting community activity as well as sensory-attuned spaces to retreat. 


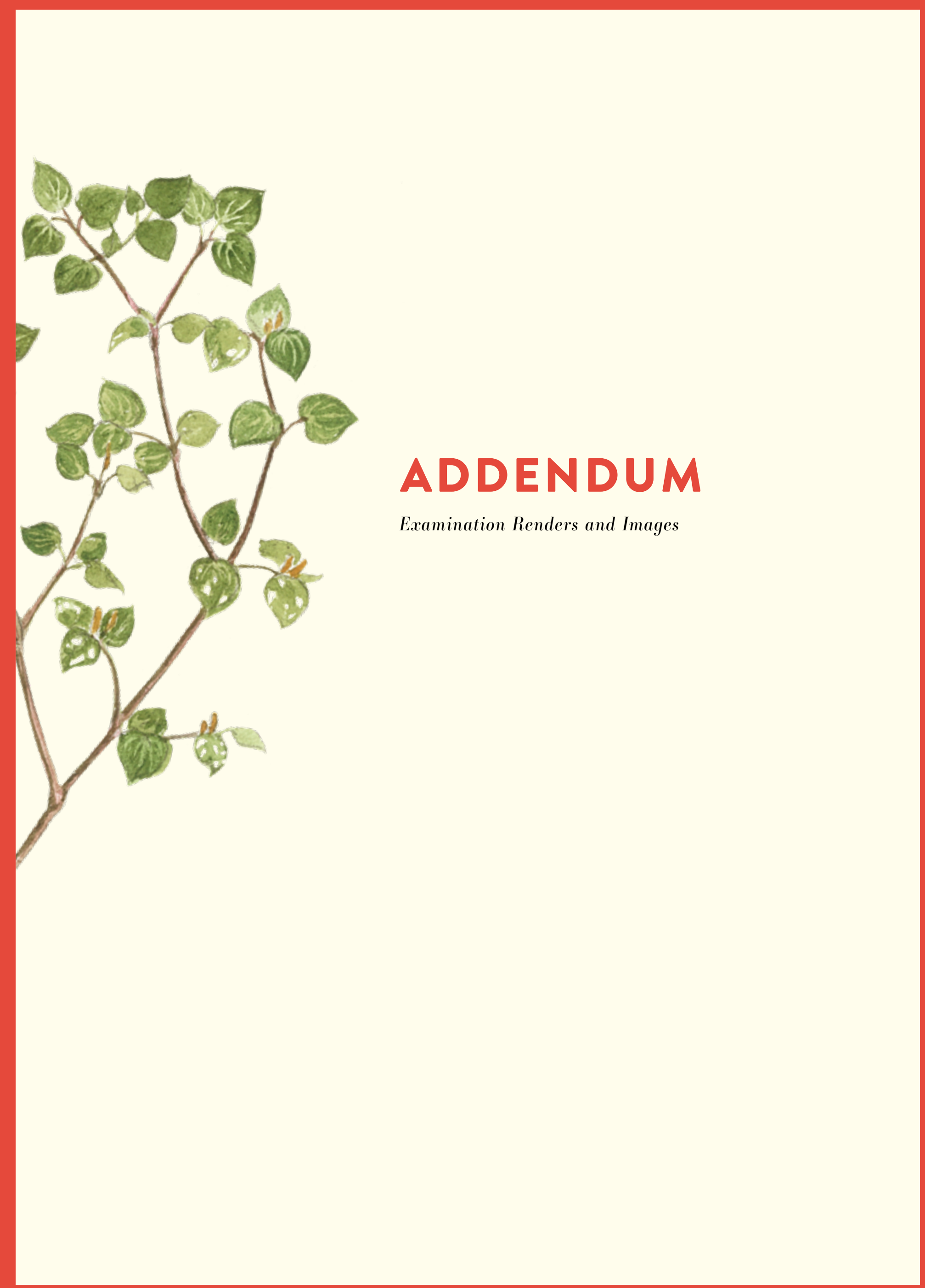




\section{DESIGNING WELLBEING (FOR EVERYONE)}

Spaces intended to support mental wellbeing in public areas should be fundamentally inclusive. The design builds on this principle by imagining architectural intervention as providing an accessible journey through the site; both on ground level, and a raised level which offers a different perspective and affective experience.

Underneath these ramps, pockets are created at various heights, which allow for a range of sensorial

installations that provide a range of potential affective encounters along the way.

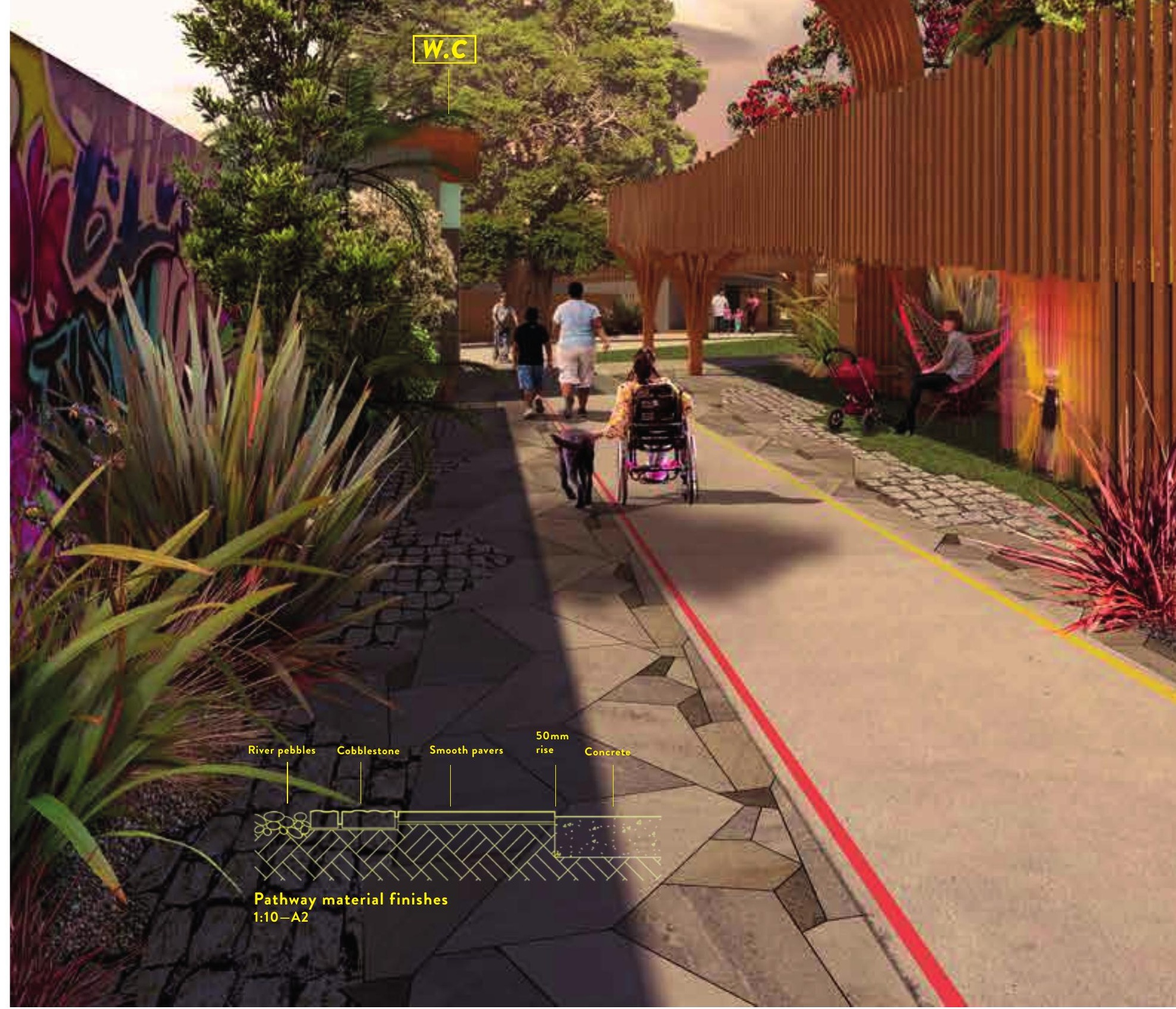




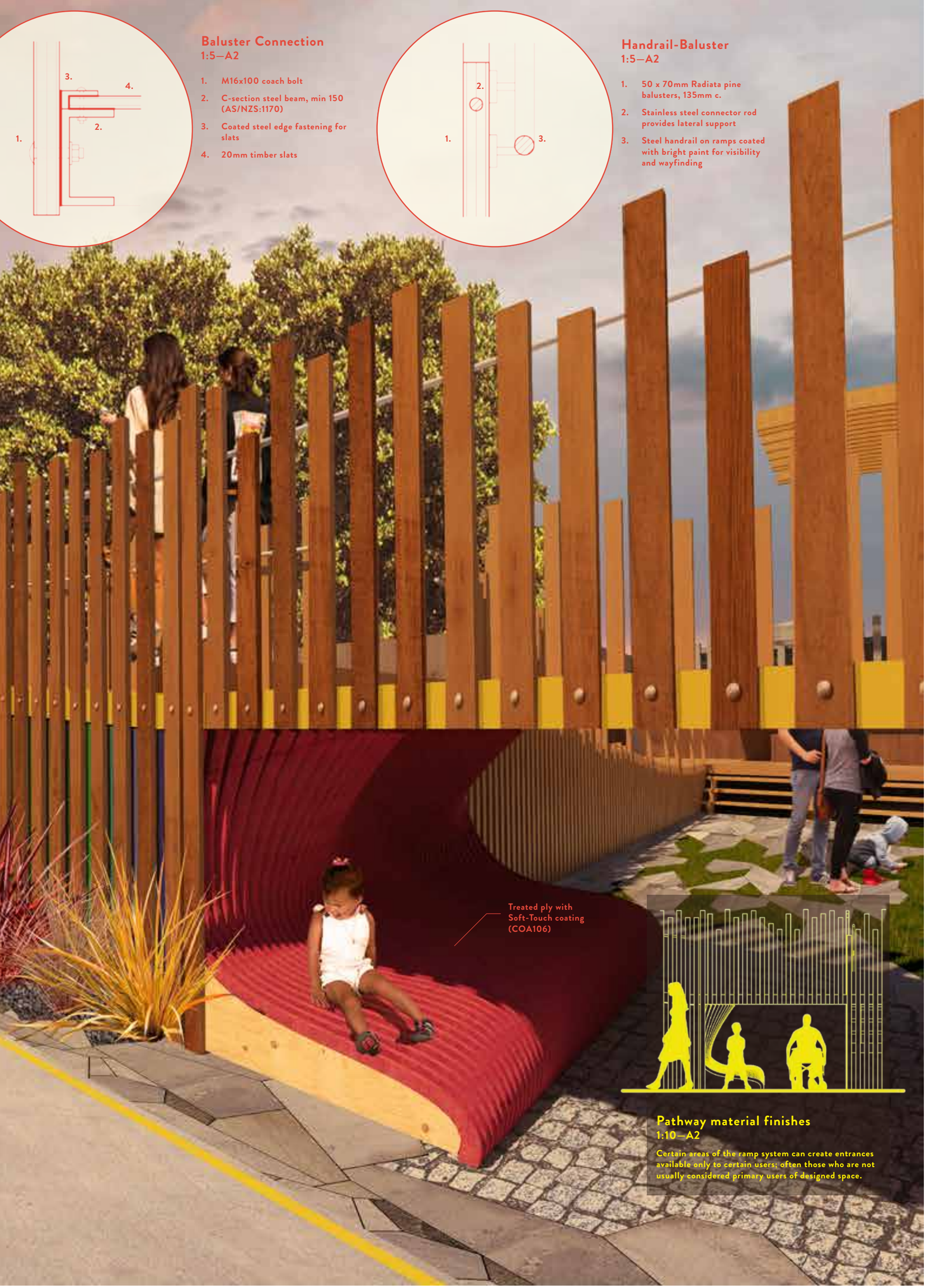




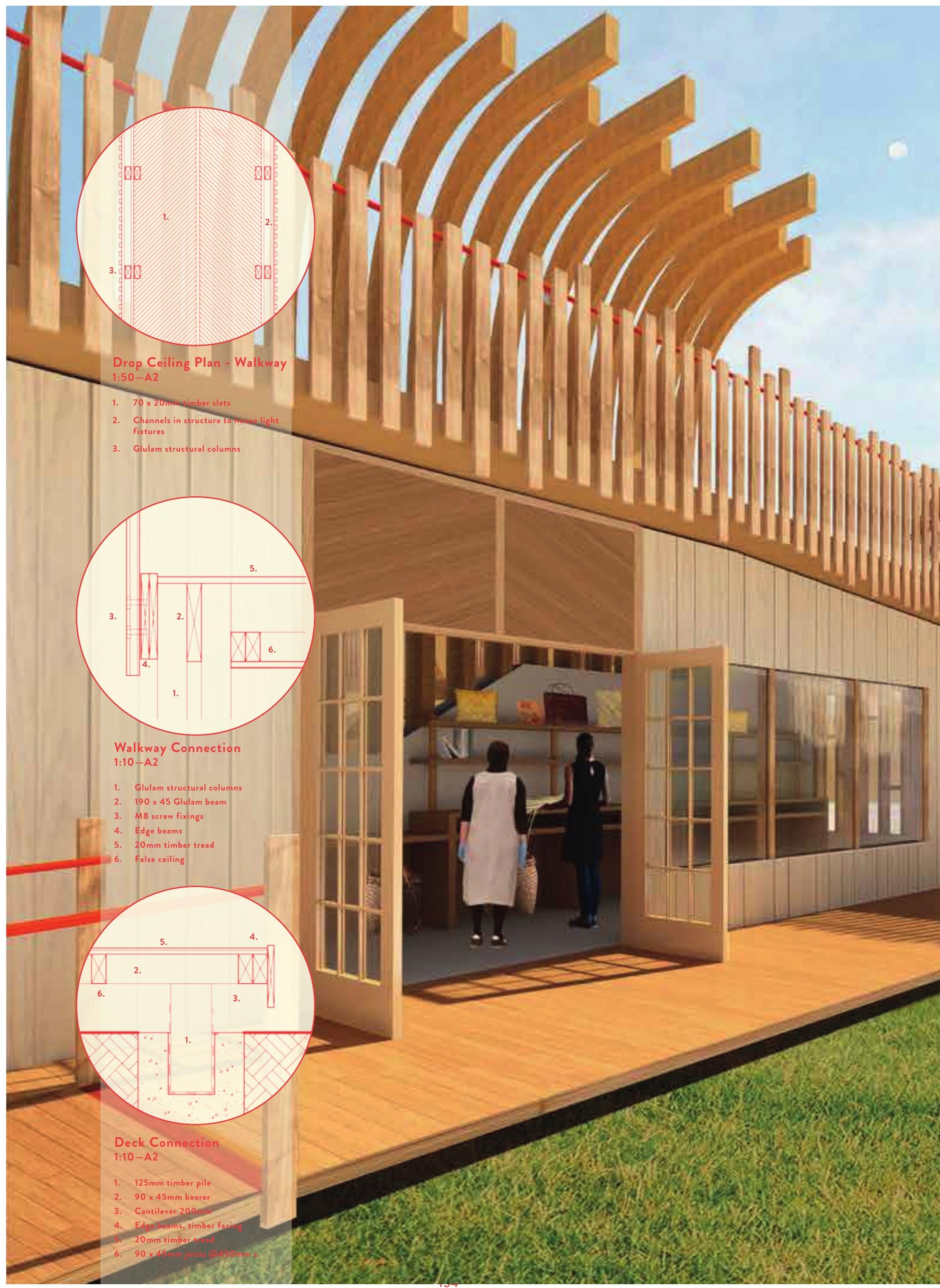




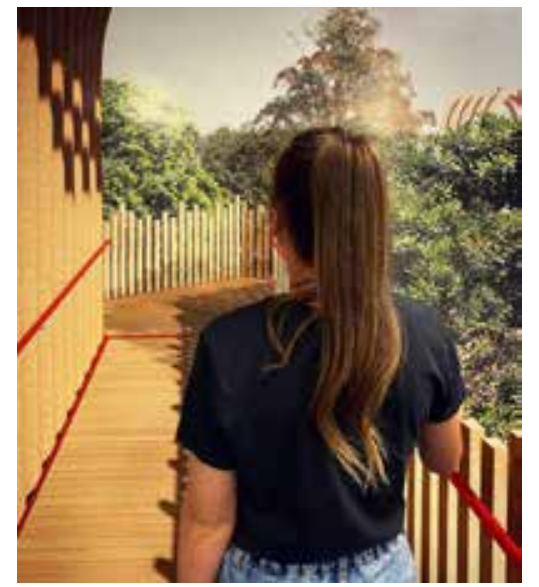

Fig 10.1 A student in front of large format image (Cawdron, 2020).
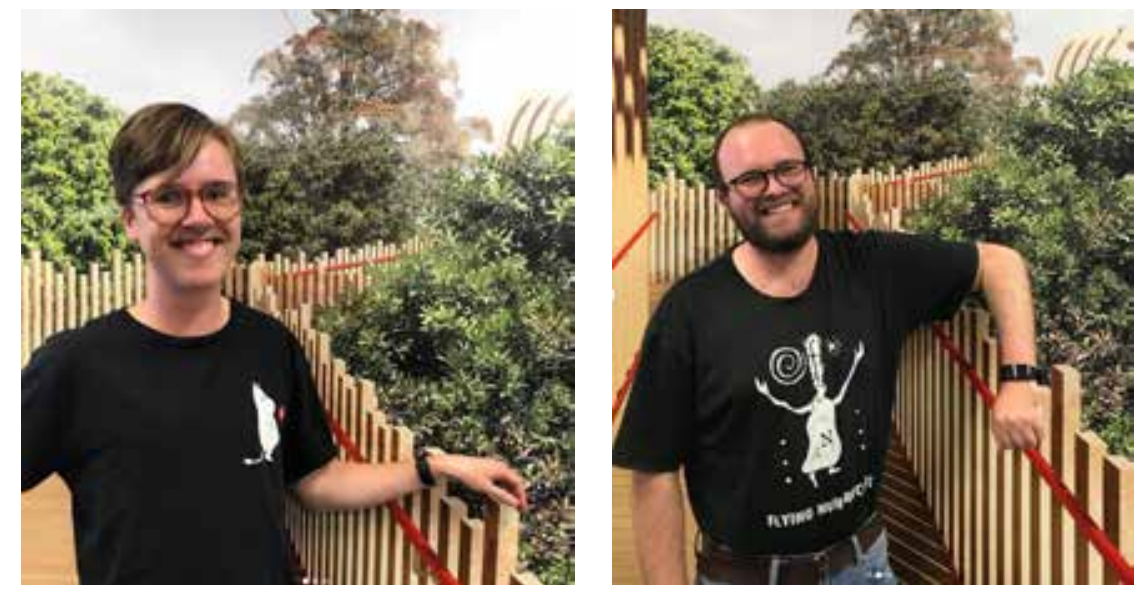

Figs 10.2, 10.3 Friends in front of large format image (Lennon, 2020).

Opposite: Render of walkway produced at 1:1 scale for examination 


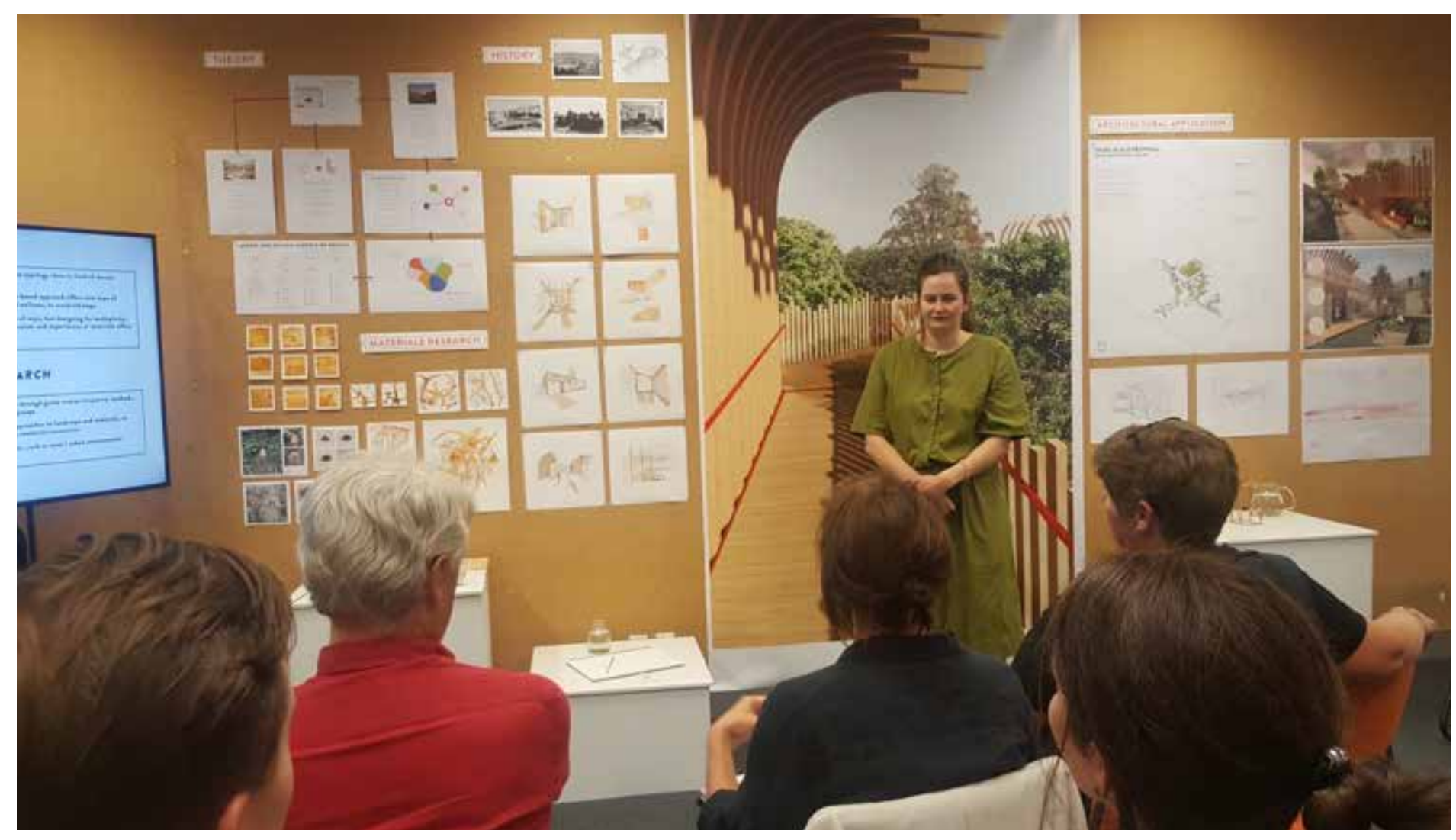

10.4: Image of examination

proceedings in front of review wall

layout (Fairbrother, 2020) 


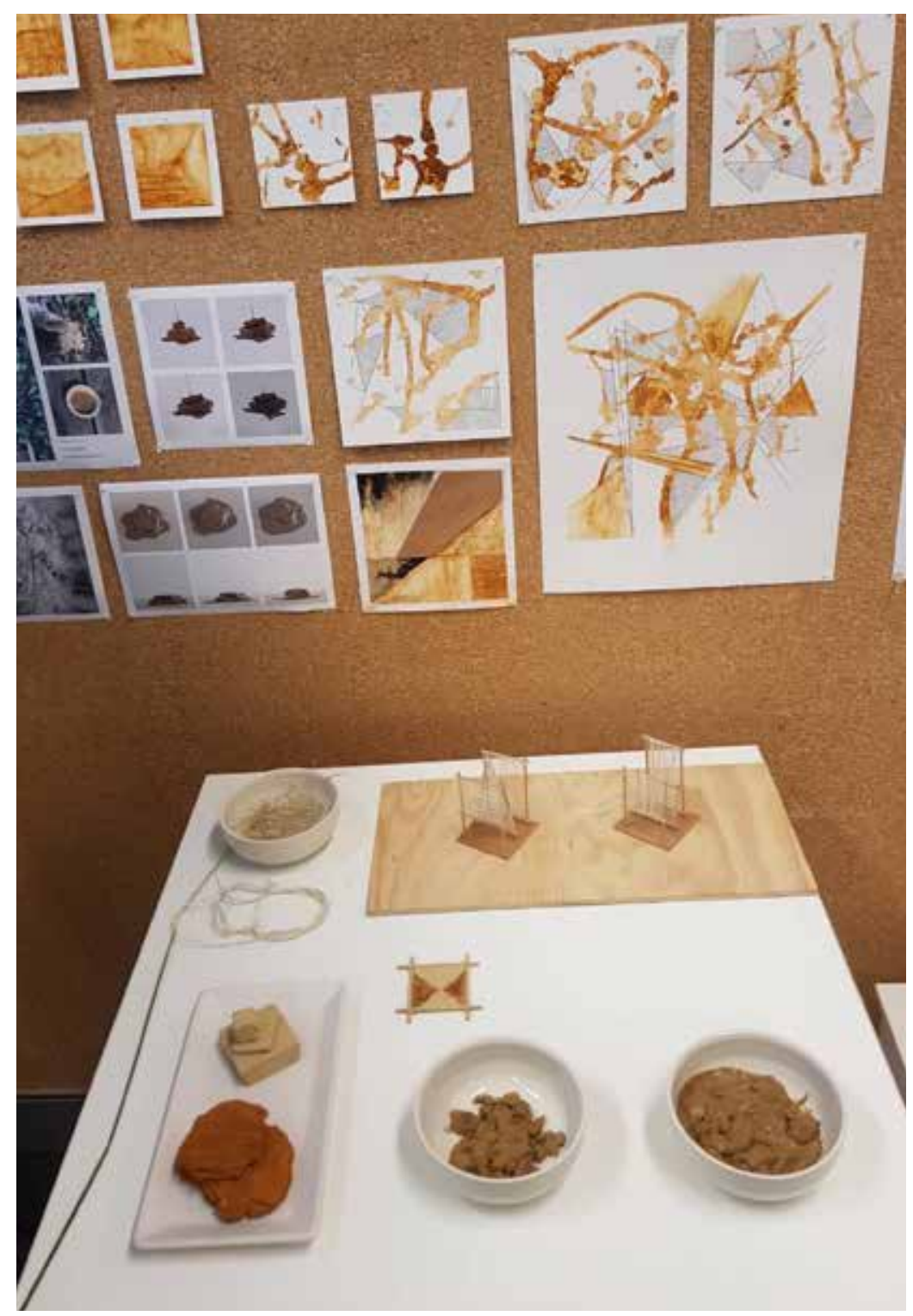

10.5: Image of examination display table (Author's own image, 2020) 


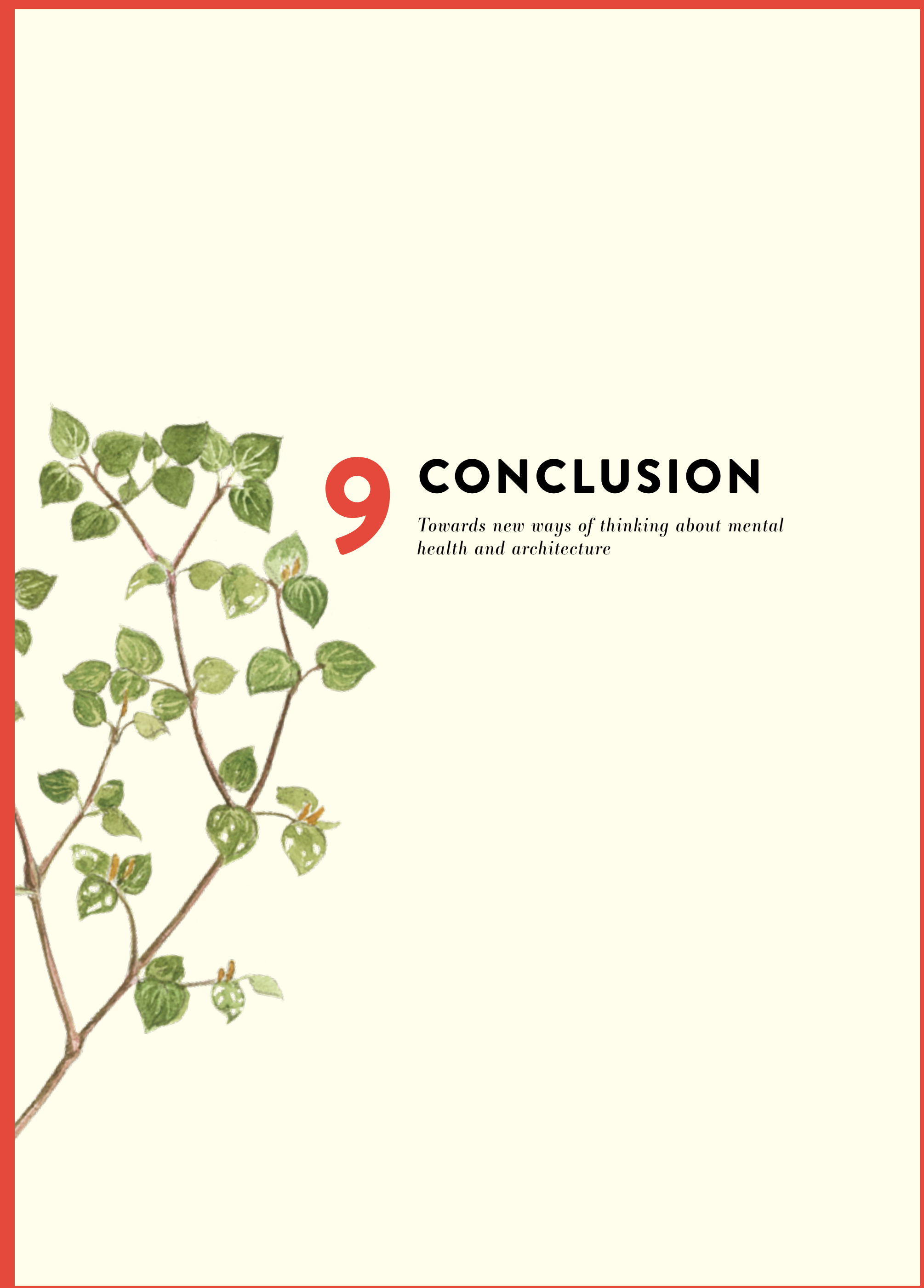




\section{SUMMARY}

The primary aim of this research project was to explore new ways that architecture can support mental health in New Zealand, based on the need for a 'paradigm shift' called for in He Ara Oranga, the report of the Government Inquiry into Mental Health and Addiction (2018). The supporting aims and objectives of this research were addressed through contextual and design-led research into typologies, materials, and spatial atmosphere.

Research into the history of mental health and architecture in Wellington established the problematic historical relationship between mental health and architecture, and suggested new architectural typologies are needed to support mental health in the community, on a non-institutional level. Research into current approaches to wellbeing supported this, with current themes and models of health focusing on the interconnectedness of multiple factors which can contribute to positive mental health outcomes, including increased social interconnectedness in the community. This focus on interconnectedness informed the theoretical research, which focused on understanding how spaces and places can support mental health from a relational perspective, incorporating social, cultural and sensory experiential factors. The values and concepts derived from this theoretical and contextual research, in combination with information gained from key precedents, were used to inform the design research.

The first stage of design research focused on exploring the therapeutic affective properties of materials, beyond their role as tectonic architectural elements, through a series of free creative exercises using locally sourced natural materials. The second stage of research involved the creation of a set of spatial drawings which explored "therapeutic atmospheres," using a multiplicity approach drawn from the contextual research and findings of the first stage of design research. The final stage of design research involved developing these "therapeutic atmospheres" in relation to a particular site, Taita Shopping Centre. The site was analysed from an experiential perspective, using photography as a way of recording these experiences, a method of site analysis which was necessary in order to gain an understanding of the "flows of everyday life" which add to the complexity of the "therapeutic atmosphere." This sited design exploration led to the development of a proposal for a third place for mental wellbeing in the community, illustrating the architectural potentials of a materials-based, relational approach to mental health architecture. 
Reseach into the history of mental health architecture in Wellington revealed that site is deeply important, both on an experiential and associations-based level. Previous architecture has been seen to "lock people away" out of sight and mind, so the positioning of a new kind of architecture should explore sites which are visible, integrated and have positive community associations. Theoretical research identified the "third place" as a positive direction for a new kind of architectural typology and site in the community. This research identified suburban shopping centres as one such possible site, for their location in the community, historical role in supporting social connection, and current state of under-utilisation. The applicability of the findings from this research could be investigated further by investigating other suburban sites (including a wider range of shopping centres), and/or through an analysis of both more rural and more urban sites. Photography is suggested as a method of site exploration, but other experience-based analysis methods could also be explored.

Initial design exploration involved a series of materials-based design exercises, exploring the therapeutic potentials of natural materials. This exploration took a process-centred approach and in doing so, uncovered therapeutic elements within the processes of production and materials themselves which could be utilised in developing a therapeutic architecture. It also emphasised the connection of materials to place and identity, two important elements identified by Māori health models as supporting wellness. The limitation of this research was its scope; the findings were mostly based on work produced by the author alone. In order to broaden this scope, participatory workshops are suggested, where a wider range of perspectives and methods could be explored as a therapeutic activity. Further research could also explore the materials-place-identity connection in more depth, particularly from a mātauranga Māori perspective.

The method of transferring the findings from theoretical and materials research into spatial design undertaken in this thesis was to use a "multiplicity" approach. This was a productive starting point, resulting in spatial drawings which addressed a range of values and findings from initial research in an interconnected way, including values from the models of wellness and the "everyday flows" suggested by NRT. The problem of designing affective experience is that it involves a complex range of dynamic factors operating in tandem. While the drawing process was successful in suggesting some of this complexity, it was also based on a necessarily reductive framework; further research could look at more immersive design approaches; for 
example, using virtual reality technologies, or designing small installations in situ. On balance, however, this research identified the multiplicity approach as a useful tool for transferring theoretical knowledge into spatial design.

Introducing insights from experience of the site into the spatial design process helped to add complexity to the multiplicity framework. Immediately, the focus of research shifted from a contained building, to a more publicly-accessible suburban space, due to the problems of trying to integrate a building for mental health into the community without it becoming stigmatised, segregated or over-medicalised. In order to create a more accessible, positive therapeutic community space, the research explored the design of a "therapeutic journey," a series of affective therapeutic interventions in suburban space which can cater to a range of space and sensory preferences, while appealing to the wider community as well. The design research looked at the therapeutic possibilities of journeying itself, and identified different levels as a way of creating spatial separation while maintaining a moderated form of social connection. This was explored through an accessible ramp structure which can guide the user through and around the space, exploring different kinds of therapeutic experience along the way.

The design proposal integrates a range of findings from the initial research: that a new architectural typology should emphasise interactions with materials and place, that it should provide space for activities that support the "weaving together" of the community, and that it should be as accessible as possible, allowing for a multitude of sensory and social options. This proposal uses the ramp framework as a way of connecting a range of therapeutic interventions, building on the existing use of space (such as volunteer food distribution) by the community. The proposal is highly conceptual, but it articulates a range of different ways that architecture can support mental wellbeing outside of conventional institutions. If taken further, the next steps should be a comprehensive, participatory community consultation process. The materials explorations explored in this research project could serve as an accessible base for people who are not intimately familiar with the complex theory around space, place and culture; it could be a starting point for a discussion about how and why to build a new kind of architectural space that supports a holistic and community-minded approach to mental wellbeing.

This research suggests that architecture has a role to play in supporting a cultural shift in our approach to mental health. By designing more visible, community-based architecture that supports therapeutic experiences outside of the medical and justice system, space can be created for a new range of therapeutic experiences, for the many people suffering from mental illness and distress that are not currently cared for by our mental health system. In order for architecture to support positive, community-based mental health outcomes for tāngata whaiora (people seeking

wellness), design should be based on a relational understanding of space and place, 
factoring in a range of different experiential and material qualities, activities, and options to produce therapeutic affective encounters. While architecture is just one factor in supporting better mental health outcomes, designing places that support community, social and therapeutic networks, outside of institutions, can create space to support a 'paradigm shift' in our mental health system. 


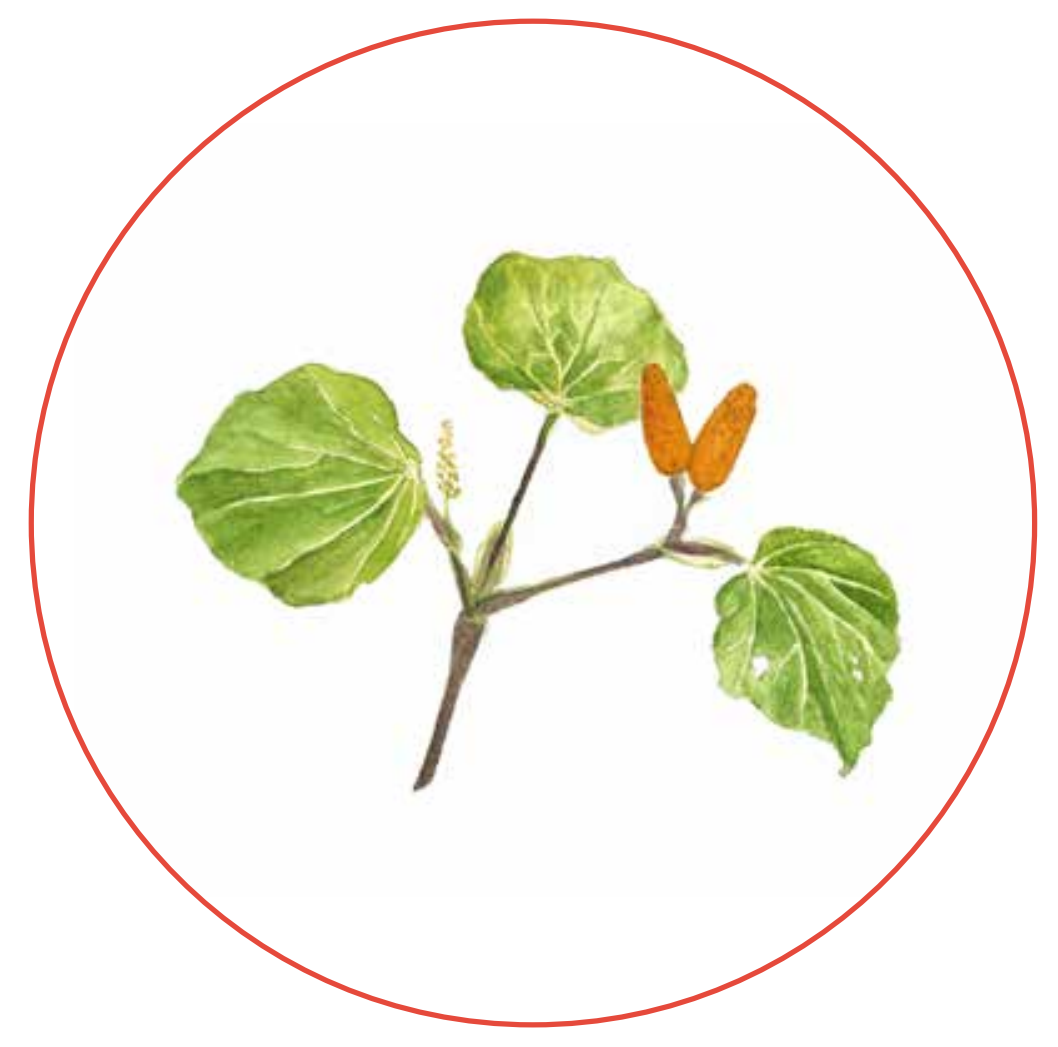




\section{IMAGE LIST}

(Images not listed are author's own, 2019/2020)

\subsection{The Terrace Gaol, on the current site of Te Aro School.}

Crown Studios Ltd: Negatives and prints. (1927). Terrace Gaol, Wellington (Ref: 1/1-032512-F). Alexander Turnbull Library, Wellington, New Zealand./records/22887211. https://natlib. govt.nz/records/22887211 Reproduced with permission.

\section{$1.2 \quad$ Karori, c.1870}

Karori Historical Society: Photographs. (1870). 372 and 378 Karori Road, ca 1870; home of Stephen Lancaster (Ref: PAColl-5277-1-09.). Alexander Turnbull Library, Wellington, New Zealand. /records/23181211. https://natlib.govt.nz/records/23181211. Reproduced with permission

\subsection{Karori Lunatic Asylum}

Author's image based on: Williams, W. H. (1987). Out of mind, out of sight: The story of Porirua Hospital. The Hospital.

\section{$1.4 \quad$ Mount View Asylum}

Cyclopedia Company Limited. (1897). The Mount View Lunatic Asylum. The Cyclopedia Company Limited; New Zealand Electronic Text Collection, Victoria University of Wellington. http:// nzetc.victoria.ac.nz/tm/scholarly/tei-Cyc01Cycl-t1-body-d4-d20-d9.html Reproduced with permission

\subsection{Porirua Lunatic Asylum, c. 1910}

Unknown Photographer. (1910). Porirua psychiatric hospital (Ref: 1/2-057708-F). Alexander Turnbull Library, Wellington, New Zealand. /records/22909317. https://natlib.govt.nz/ records/22909317 Reproduced with permission

\subsection{Inpatient rooms at Te Whare o Matairangi, Wellington Hospital}

Tso, M., \& Holl, M. (Photographer). (2018, December 18). Lack of beds forces mental health patients to sleep in lounge. Stuff. https://www.stuff.co.nz/national/health/108892642/ lack-of-beds-forces-mental-health-patients-to-sleep-in-lounge

\subsection{Installation produced for a Madlove exhibition}

What is Madlove? (n.d.). Madlove. Retrieved January 21, 2020, from http://www.madlove.org.uk/ 


\subsection{A sketch produced at a Madlove community workshop}

Hohenadel, K. (2015, March 19). This Is What a Psychiatric Ward Designed by Patients Looks Like. Slate Magazine. https://slate.com/human-interest/2015/03/madlove-a-designer-asylumfrom-james-leadbitter-the-vacuum-cleaner-is-a-mental-health-space-designed-bypatients-in-the-u-k.html

\subsection{Maggie's Centre, Edinburgh}

Richard Murphy Architects: Maggie's Cancer Caring Centre, Edinburgh. (n.d.). Retrieved January 22, 2020, from http://www.richardmurphyarchitects.com/viewltem.php?id=2452

\subsection{Our Future Foyle Concept Drawing}

Our Future Foyle. (2018). The Project. Our Future Foyle.Retrieved January 22, 2020, from http:// www.futurefoyle.org/bio

\subsection{The Staircase to Nowhere}

Hohenadel, K. (2015, March 19). This Is What a Psychiatric Ward Designed by Patients Looks Like. Slate Magazine. Retrieved January 21, 2020, from: https://slate.com/humaninterest/2015/03/madlove-a-designer-asylum-from-james-leadbitter-the-vacuumcleaner-is-a-mental-health-space-designed-by-patients-in-the-u-k.html

\subsection{A student in front of large format image}

Cawdron, M. [@melissa_cawdron] (2020, Feb 17). Somehow I went to uni this morning and ended up in @tobefairbrother 's thesis....! How cool is this 1:1 render! Literally... [Photograph] Instagram. https://www.instagram.com/p/B8qLZq2IMPtNRLTgI_4kP6qUe5W7wtDNsv-3Y00/ Reproduced with permission

\section{2/3 Friends in front of large format image}

Lennon, O. [@oxinboots] (2020, Feb 18). Wow I can't believe Kezia built a whole real building for her architecture masters!! Stunning!!. [Photographs] Instagram. https://www.instagram.com/p/ B8sQK8Apfg7/ Reproduced with permission.

\subsection{Image of examination proceedings in front of review wall layout}

Fairbrother, P. (2020). Image of examination proceedings for Kezia Fairbrother [Photograph]. Used with permission. 


\section{REFERENCES}

A Madlove Take Over. (n.d.). The Vacuum Cleaner. Retrieved January 21, 2020, from http://www. thevacuumcleaner.co.uk/madlove-take-over/

Adlam, J., Gill, I., Glackin, S. N., Kelly, B. D., Scanlon, C., \& Mac Suibhne, S. (2013). Perspectives on Erving Goffman's "Asylums" fifty years on. Medicine, Health Care, and Philosophy; Dordrecht, 16(3), 605-613. http://dx.doi.org.helicon.vuw.ac.nz/10.1007/s11019-0129410-z

An inclusive design approach to improving community wellbeing: A case study of architectural interventions in Derry/Londonderry. (2019). In M. Jones, L. Rice, \& F. Meraz, Designing for Health \& Wellbeing: Home, City, Society (pp. 205-218). Vernon Press.

Anderson, B. (2009). Affective atmospheres. Emotion, Space and Society, 2(2), 77-81. https://doi. org/10.1016/j.emospa.2009.08.005

Andrews, G. J., Chen, S., \& Myers, S. (2014). The 'taking place' of health and wellbeing: Towards non-representational theory. Social Science \& Medicine, 108, 210-222. https://doi. org/10.1016/j.socscimed.2014.02.037

Atkinson, S. (2013). Beyond Components of Wellbeing: The Effects of Relational and Situated Assemblage. Topoi, 32(2), 137-144. https://doi.org/10.1007/s11245-013-9164-0

Bailliard, A. L. (2015). Habits of the Sensory System and Mental Health: Understanding Sensory Dissonance. The American Journal of Occupational Therapy; Bethesda, 69(4), 1-8.

Bell, S. L., Foley, R., Houghton, F., Maddrell, A., \& Williams, A. M. (2018). From therapeutic landscapes to healthy spaces, places and practices: A scoping review. Social Science \& Medicine, 196, 123-130. https://doi.org/10.1016/j.socscimed.2017.11.035

Bell, S. L., Phoenix, C., Lovell, R., \& Wheeler, B. W. (2014). Green space, health and wellbeing: Making space for individual agency. Health \& Place, 30, 287-292. https://doi. org/10.1016/j.healthplace.2014.10.005

Bell, S. L., Westley, M., Lovell, R., \& Wheeler, B. W. (2018). Everyday green space and experienced well-being: The significance of wildlife encounters. Landscape Research, 43(1), 8-19. https://doi.org/10.1080/01426397.2016.1267721

Bohnen, N., Houx, P., Nicolson, N., \& Jolles, J. (1990). Cortisol reactivity and cognitive performance in a continuous mental task paradigm. Biological Psychology, 31(2), 107-116. https://doi.org/10.1016/0301-0511(90)90011-K

Brunton, W. (n.d.). Mental health services - Lunatic asylums, 1840s to 1900s [Web page]. Te Ara - the Encyclopedia of New Zealand. Retrieved December 2, 2019, from https://teara.govt.nz/ en/mental-health-services/page-2 
Brunton, W. (2003). The Origins of Deinstitutionalisation in New Zealand. Health and History, 5(2), 75-103. JSTOR. https://doi.org/10.2307/40111454

Brunton, W. (2005). The place of public inquiries in shaping New Zealand's national mental health policy 1858-1996. Australia \& New Zealand Health Policy, 2(24). https://natlib-primo. hosted.exlibrisgroup.com/primo-explore/search?query=any,contains, 995012683602837 \&tab=innz\&search_scope $=I N N Z \&$ vid $=N L N Z \&$ offset $=0$

Bryder, L., \& Dow, D. A. (2001). Introduction: Maori Health History, Past, Present and Future. Health and History, 3(1), 3-12.

Burch, J., \& Hughes, B. (1998). Karori Lunatic Asylum 1854-1873. Stockade, 31, 4-8.

Burge, R. (2016). Callan Park in Transition. In D. Kritsotaki, V. Long, \& M. Smith (Eds.), Deinstitutionalisation and After: Post-War Psychiatry in the Western World (pp. 267-287). Springer International Publishing. https://doi.org/10.1007/978-3-319-45360-6_13

Burls, A. (2007). People and green spaces: Promoting public health and mental well-being through ecotherapy. Journal of Public Mental Health; Brighton, 6(3), 24-39. http://dx.doi. org/10.1108/17465729200700018

Butler, C. H. (1999). Afterimage: Drawing through process. Museum of Contemporary Art.

Butterfield, A., \& Martin, D. (2016). Affective sanctuaries: Understanding Maggie's as therapeutic landscapes. Landscape Research, 41(6), 695-706. https://doi.org/10.1080/01426397.201 6.1197386

Chief Coroner Releases Provisional Annual Suicide Figures. (2018). Coronial Services of New Zealand. https://coronialservices.justice.govt.nz/suicide/annual-suicide-statistics-since-2011/

Childs, C. W., Wells, N., \& Downes, C. J. (1986). Kokowai Springs, Mount Egmont, New Zealand: Chemistry and mineralogy of the ochre (ferrihydrite) deposit and analysis of the waters. Journal of the Royal Society of New Zealand, 16(1), 85-99. https://doi.org/10.1080/030367 58.1986 .10426958

Chrysikou, E. (2014). Architecture for psychiatric environments and therapeutic spaces. IOS Press.

Citizens of Wellington, Awake! Awake! To the Editor. (1896, October 13). Evening Post. Papers Past, https://paperspast.natlib.govt.nz/newspapers/EP18961013.2.13.

Coleborne, C. (2003). Preserving the Institutional Past and Histories of Psychiatry: Writing about Tokanui Hospital, New Zealand, 1950s-1990s. Health and History, 5(2), 104-122. JSTOR. https://doi.org/10.2307/40111455 
Coleborne, C. (2012). Patient journeys: Stories of mental health care from Tokanui to mental health services, 1930s to the 1980s. Half Court Press Ltd. https://researchcommons.waikato.ac.nz/ handle/10289/6899

Coleborne, C. (2020). The Asylum and Its Afterlife. In C. Coleborne (Ed.), Why Talk About Madness? Bringing History into the Conversation (pp. 29-40). Springer International Publishing. https://doi.org/10.1007/978-3-030-21096-0_3

Collins, J., Avey, S., \& Lekkas, P. (2016). Lost landscapes of healing: The decline of therapeutic mental health landscapes. Landscape Research, 41(6), 664-677. https://doi.org/10.1080/0 1426397.2016.1197192

Connellan, K., Gaardboe, M., Riggs, D., Due, C., Reinschmidt, A., \& Mustillo, L. (2013). Stressed Spaces: Mental Health and Architecture. HERD: Health Environments Research \& Design Journal, 6(4), 127-168. https://doi.org/10.1177/193758671300600408

Conradson, D. (2005). Landscape, care and the relational self: Therapeutic encounters in rural England. Health and Place, 11(4), 337-348. Scopus. https://doi.org/10.1016/j. healthplace.2005.02.004

Cook, F. (2017, October 11). Police systems overhauled to stop mentally ill people being locked up. NZ Herald. https://www.nzherald.co.nz/nz/news/article.cfm?c_id=1\&objectid=11931965

Donald Beasley Institute Inc. (2008). An examination of the outcome of the resettlement of residents from the Kimberley Centre. Ministry of Health. https:/www.health.govt.nz/publication/ examination-outcome-resettlement-residents-kimberley-centre

Dunkley, C. M. (2009). A therapeutic taskscape: Theorizing place-making, discipline and care at a camp for troubled youth. Health \& Place, 15(1), 88-96. https://doi.org/10.1016/j. healthplace.2008.02.006

Durie, M. (2011a). Indigenizing mental health services: New Zealand experience. Transcultural Psychiatry, 48(1-2), 24-36. https://doi.org/10.1177/1363461510383182

Durie, M. (2011b). Indigenizing mental health services: New Zealand experience. Transcultural Psychiatry, 48(1-2), 24-36. https://doi.org/10.1177/1363461510383182

Durie, M. (2018). Te Taiao: Māori Mental Health in Twenty-First Century Environments. In T. K. R. Kingi, M. Durie, H. Elder, R. Tapsell, M. Lawrence, \& S. Bennett (Eds.), Maea te toi ora: Māori health transformations. Huia Publishers.

Durie, M. H. (1985). A Maori perspective of health. Social Science \& Medicine, 20(5), 483-486. https://doi.org/10.1016/0277-9536(85)90363-6

Eisen, S. L., Ulrich, R. S., Shepley, M. M., Varni, J. W., \& Sherman, S. (2008). The stressreducing effects of art in pediatric health care: Art preferences of healthy children and hospitalized children. Journal of Child Health Care, 12(3), 173-190. https://doi. org/10.1177/1367493508092507 
Emami, E., Amini, R., \& Motalebi, G. (2018). The effect of nature as positive distractibility on the Healing Process of Patients with cancer in therapeutic settings. Complementary Therapies in Clinical Practice, 32, 70-73. https://doi.org/10.1016/j.ctcp.2018.05.005

Fancourt, D. (2017). Arts in health: Designing and researching interventions (First edition.). University Press.

Fenton, Liz, \& Te Koutua, Te Wera. (2000). Four Māori kōrero about their experience of mental illness. Mental Health Commission.

Finlay, J., Franke, T., McKay, H., \& Sims-Gould, J. (2015). Therapeutic landscapes and wellbeing in later life: Impacts of blue and green spaces for older adults. Health \& Place, 34, 97-106. https://doi.org/10.1016/j.healthplace.2015.05.001

Foley, R. (2015). Swimming in Ireland: Immersions in therapeutic blue space. Health \& Place, 35, 218-225. https://doi.org/10.1016/j.healthplace.2014.09.015

Foley, R., \& Kistemann, T. (2015). Blue space geographies: Enabling health in place. Health \& Place, 35, 157-165. http://dx.doi.org/10.1016/j.healthplace.2015.07.003

Foliaki, S., New Zealand, \& Mental Health Commission. (2001). Pacific mental health services and workforce: Moving on the blueprint. http://www.moh.govt.nz/notebook/nbbooks.nsf/0/EA 9A9BEE5EE575CFCC256CFC00763FB2/\$file/Pacific\%20mental\%20health\%20 services.pdf

Gesler, W. M. (1992). Therapeutic landscapes: Medical issues in light of the new cultural geography. Social Science \& Medicine, 34(7), 735-746. https://doi.org/10.1016/02779536(92)90360-3

Gesler, W. M. (2009). Therapeutic Landscapes. In R. Kitchin \& N. Thrift (Eds.), International Encyclopedia of Human Geography (pp. 229-230). Elsevier. https://doi.org/10.1016/B978008044910-4.00351-5

Gibbs, H. S. (1960). Soils of Wellington. Department of Scientific and Industrial Research. http://bts. nzpcn.org.nz/bts_pdf/WBS46-1994-13-22-Soils-Wgtn.pdf

Glover, T. D., \& Parry, D. C. (2009). A third place in the everyday lives of people living with cancer: Functions of Gilda's Club of Greater Toronto. Health \& Place, 15(1), 97-106. https://doi. org/10.1016/j.healthplace.2008.02.007

Goffman, E. (1961). Asylums: Essays on the Social Situation of Mental Patients and Other Inmates. Anchor Books.

Gone, J. P. (2008). 'So I Can Be Like a Whiteman': The Cultural Psychology of Space and Place in American Indian Mental Health. Culture \& Psychology, 14(3), 369-399. https://doi. org/10.1177/1354067X08092639 
Hohenadel, K. (2015, March 19). This Is What a Psychiatric Ward Designed by Patients Looks Like.

Slate Magazine. https://slate.com/human-interest/2015/03/madlove-a-designer-asylumfrom-james-leadbitter-the-vacuum-cleaner-is-a-mental-health-space-designed-bypatients-in-the-u-k.html

Hu, F. (2016). Towards a non-intentional space. Vol.1, About Sou Fujimoto's architectural design for Mirrored Gardens. König Books.

INEBRIATE ASYLUMS. (1899, August 18). Star. Papers Past. https://natlib.govt.nz/ records $/ 14567261$

Jencks, C., \& Heathcote, E. (2010). The architecture of hope: Maggie's Cancer Caring Centres (1st Frances Lincoln ed.). Frances Lincoln.

Jiang, S., Powers, M., Allison, D., \& Vincent, E. (2017). Informing Healthcare Waiting Area Design Using Transparency Attributes: A Comparative Preference Study. HERD : Health Environments Research \& Design Journal; London, 10(4), 49-63. http://dx.doi. org/10.1177/1937586716675581

Jones, R. (2000). Diagnosis in traditional Maori healing: A contemporary urban clinic. Pacific Health Dialog, 7(1), 17-24.

Kang, Y., \& Kim, E. J. (2019). Differences of Restorative Effects While Viewing Urban Landscapes and Green Landscapes. Sustainability; Basel, 11(7). http://dx.doi.org/10.3390/su11072129

Kaplan, S. (1995). The restorative benefits of nature: Toward an integrative framework. Journal of Environmental Psychology, 15(3), 169-182. https://doi.org/10.1016/02724944(95)90001-2

Kearns, R. A. (1993). Place and Health: Towards a Reformed Medical Geography. The Professional Geographer, 45(2), 139-147. https://doi.org/10.1111/j.0033-0124.1993.00139.x

Kelling, C., Pitaro, D., \& Rantala, J. (2016). Good vibes: The impact of haptic patterns on stress levels. Proceedings of the 20th International Academic Mindtrek Conference, 130-136. https://doi.org/10.1145/2994310.2994368

Kingi, T. K. R., Durie, M., Elder, H., Tapsell, R., Lawrence, M., Bennett, S., \& EBSCOhost. (2018). Maea te toi ora: Māori health transformations. Huia Publishers.

Kritsotaki, D., Long, V., \& Smith, M. (2016). Deinstitutionalisation and After: Post-War Psychiatry in the Western World. Springer.

Kylén, M., Koch, L. V., Pessah-Rasmussen, H., Marcheschi, E., Ytterberg, C., Heylighen, A., \& Elf, M. (2019). The Importance of the Built Environment in Person-Centred Rehabilitation at Home: Study Protocol. International Journal of Environmental Research and Public Health; Basel, 16(13). http://dx.doi.org/10.3390/ijerph16132409

Lasch, C. (1996). The Revolt of the Elites and the Betrayal of Democracy. W. W. Norton \& Company. 
Long, C. G., Langford, V., Clay, R., Craig, L., \& Hollin, C. R. (2011). Architectural change and the effects on the perceptions of the ward environment in a medium secure unit for women. The British Journal of Forensic Practice, 13(3), 205-212. https://doi. org/10.1108/14636641111157850

Lorimer, H. (2008). Cultural geography: Non-representational conditions and concerns. Progress in Human Geography, 32(4), 551-559. https://doi.org/10.1177/0309132507086882

Love, C. (2004). Extensions on Te Wheke. https://repository.openpolytechnic.ac.nz/handle/11072/182 Lunatics Act 1882 (46 VICT 1882 No34). (1882). New Zealand Government. http://www.nzlii.org/nz/ legis/hist_act/la188246v1882n34189/

MacDonald, N. (2018, February 3). A growing emergency: Why are cops looking after mental health patients in crisis? Stuff. https://www.stuff.co.nz/national/health/99735922/a-growingemergency-why-are-cops-looking-after-mental-health-patients-in-crisis

Mahar, C. A.-C. (1981). Place and Identity. In Reinventing Practice in a Disenchanted World: Bourdieu and Urban Poverty in Oaxaca, Mexico. University of Texas Press. http://ebookcentral. proquest.com/lib/vuw/detail.action?docl D=3443478

Marcus, C. C. (2013). Therapeutic landscapes an evidence-based approach to designing healing gardens and restorative outdoor spaces (1st ed). SI: Wiley. http://portal.igpublish.com/iglibrary/ search/WILEYB0016664.html

Markus, T. A. (1993). Buildings \& power: Freedom and control in the origin of modern building types. Routledge.

Mason, K. H. (1988). Report of the Committee of Inquiry Into Procedures Used In Certain Psychiatric Hospitals In Relation To Admission, Discharge Or Release On Leave Of Certain Classes Of Patients (WM 35 REP 1988). Ministry of Health; Ministry of Health Online Cataloge.

Massumi, B. (2002). Parables for the Virtual: Movement, Affect, Sensation. Duke University Press.

Mawer, C. (2018). Community decision-making and privatised spaces: A case study of suburban shopping malls in the Wellington Region. Victoria University of Wellington.

McCormack, D. P. (2008). Geographies for Moving Bodies: Thinking, Dancing, Spaces. Geography Compass, 2(6), 1822-1836. https://doi.org/10.1111/j.1749-8198.2008.00159.x

Mclaughlan, R. (2012). FAREWELL TO THE BAD OLD DAYS: ARCHITECTURE'S CURTAIN CALL ON THE MYTHS OF MENTAL HEALTH CARE. Traditional Dwellings and Settlements Review, 24(1), 36-36. JSTOR.

McLaughlan, R. (2014). One dose of Architecture, taken daily: Building for Mental Health in New Zealand. Victoria University of Wellington.

Methven, P. (2011). The Terrace Gaol: A short history of Wellington's prisons, 1840-1927. Steele Roberts. 
Milne, J. D. G., \& Northey, R. D. (1975). Soils of the Wellington urban area: N.Z. Soil Survey Reports (NZ Soil Survey Report No. 34). Department of Scientific and Industrial Research. doi:10.7931/DL1-SSR-34

Montgomery, S. E., \& Miller, J. (2011). The Third Place: The Library as Collaborative and Community Space in a Time of Fiscal Restraint. College \& Undergraduate Libraries, 18(2-3), 228-238. https://doi.org/10.1080/10691316.2011.577683

Morris, R. (1968). Anti Form. Artforum, 6(8), 33-35.

Nancy Swarbrick. (n.d.). Flax and flax working-Industry changes: 1930s-2000s. Te Ara - The Encyclopedia of New Zealand. Retrieved January 23, 2020, from http://www.TeAra.govt. nz/en/flax-and-flax-working/page-5 (accessed 25 August, 2019)

New Zealand Government. (2018). He Ara Oranga: Report of the Government Inquiry into Mental Health and Addiction. https://mentalhealth.inquiry.govt.nz/inquiry-report/he-ara-oranga/

New Zealand Mental Health Commission. (2007). Te haererenga mo te whakaoranga 1996-200: The journey of recovery for the New Zealand mental health sector. Ministry of Health. https:// www.moh.govt.nz/notebook/nbbooks.nsf/0/12912EA93B0B85EFCC2573C9006884 $5 \mathrm{D}$

NiaNia, W., Bush, A., \& Epston, D. (2019). Huarahi Oranga: An introduction to Māori concepts informing a Māori healing and psychiatry partnership. Australasian Psychiatry, 27(4), 334-336. https://doi.org/10.1177/1039856219828191

Oakley Browne, M. A., Wells, J. E., \& Scott, K. M. (2006). Te Rau Hinengaro: The New Zealand Mental Health Survey. Ministry of Health. https://www.health.govt.nz/publication/te-rauhinengaro-new-zealand-mental-health-survey

O'Brien, A. J., \& Kydd, R. (2013). Compulsory Community Care in New Zealand Mental Health Legislation 1846-1992. SAGE Open, 3(2), 2158244013490175. https://doi. org/10.1177/2158244013490175

Oldenburg, R., \& Brissett, D. (1982). The third place. Qualitative Sociology, 5(4), 265-284. https:// doi.org/10.1007/BF00986754

Our Future Foyle. (2018). The Project. Our Future Foyle. http://www.futurefoyle.org/bio

Parr, H. (1997). Mental Health, Public Space, and the City: Questions of Individual and Collective Access. Environment and Planning D: Society and Space, 15(4), 435-454. https://doi. org/10.1068/d150435

Pearce, M. (2015). Art in the Age of Emergence. Cambridge Scholars Publishing.

Peters, T., \& Verderber, S. (2017). Territories of Engagement in the Design of Ecohumanist Healthcare Environments. HERD: Health Environments Research \& Design Journal, 10(2), 104-123. https://doi.org/10.1177/1937586716668635 
Petrović, E., \& Perkins, N. (2016). Materials in Furniture Design: Towards a new conceptual framework. li International Journal of Interior Architecture + Spatial Design, 4: Material Vocabularies, 56-63.

Pleasant, A., Scanlon, M. M., \& Pereira-Leon, M. (2013). Literature review: Environmental design and research on the human health effects of open spaces in urban areas. Human Ecology Review, 20(1), 36.

Puketapu-Hetet, E. (1989). Maori weaving. Pitman.

Rich, C. R., Oetgen, W. J., Mcentee, C. W., Day, T. D., \& Clancy, C. M. (2011). Administrator as Architect: A Primer of Evidence-Based Design. The Journal of Health Administration Education; Arlington, 28(4), n/a.

Richard Murphy Architects: Maggie's Cancer Caring Centre, Edinburgh. (n.d.). Retrieved January 22, 2020, from http://www.richardmurphyarchitects.com/viewltem.php?id=2452

Rollings, K. A., Wells, N. M., Evans, G. W., Bednarz, A., \& Yang, Y. (2017). Housing and neighborhood physical quality: Children's mental health and motivation. Journal of Environmental Psychology, 50, 17-23. https://doi.org/10.1016/j.jenvp.2017.01.004

Russell, L. (2006). Oho mauri: Cultural identity, wellbeing, and Tāngata Whai Ora/Motuhake [Ph.D., Massey University]. https://www.researchgate.net/publication/322929951_Oho_mauri_ Cultural_identity_wellbeing_and_Tangata_Whai_OraMotuhake

Saitelbach, J. (2016). Therapeutic streetscapes: A new bell street designed to accommodate those on the autism spectrum [Master's, University of Washington]. https://search.proquest.com/ docview/1821347038/abstract/C6DD3C8760F46D5PQ/1

Sanders, D., Kydd, R., Morunga, E., \& Broadbent, E. (2011). Differences in Patients' Perceptions of Schizophrenia Between Māori and New Zealand Europeans. Australian \& New Zealand Journal of Psychiatry, 45(6), 483-488. https://doi.org/10.3109/00048674.2011.561479

Satariano, B. (2019). Blue therapeutic spaces on islands: Coastal landscapes and their impact on the health and wellbeing of people in Malta. Island Studies Journal; Charlottetown, 14(2), 245-260. http://dx.doi.org/10.24043/isj.100

Sherman-Bien, S. A., Malcarne, V. L., Roesch, S., Varni, J. W., \& Katz, E. R. (2011). Quantifying the Relationship among Hospital Design, Satisfaction, and Psychosocial Functioning in a Pediatric Hematology Oncology Inpatient Unit. HERD: Health Environments Research \& Design Journal, 4(4), 34-59. https://doi.org/10.1177/193758671100400404

Smyth, F. (2005). Medical geography: Therapeutic places, spaces and networks. Progress in Human Geography, 29(4), 488-495. https://doi.org/10.1191/0309132505ph562pr

Statistics NZ. (2013). 2013 Census QuickStats about a place. http://archive.stats.govt.nz/ Census/2013-census/profile-and-summary-reports/quickstats-about-a-place.aspx 
Sutton, D., \& Nicholson, E. (2011). Sensory modulation in acute mental health wards: A qualitative study of staff and service user perspectives / Resources. Te Pou o te Whakaaro Nui. https:// www.tepou.co.nz/resources/sensory-modulation-in-acute-mental-health-wards-aqualitative-study-of-staff-and-service-user-perspectives/289

Sweetman, L. E. (2017). Ngā waiata o Tāne Whakapiripiri (The music of Tāne Whakapiripiri):

Cultural expression, transformation, and healing in a Māori forensic psychiatric unit [Ph.D., New York University]. http://search.proquest.com/docview/1880347833/abstract/ E9FAB10CA65C44C9PQ/2

Taitimu, M., Read, J., \& Mclntosh, T. (2018). Ngā Whakāwhitinga (standing at the crossroads): How Māori understand what Western psychiatry calls "schizophrenia." Transcultural Psychiatry, 55(2), 153-177. https://doi.org/10.1177/1363461518757800

Taituha, G. (2014). He käkahu, he korowai, he kaitaka, he aha atu anō? The significance of the transmission of Māori knowledge relating to raranga and whatu muka in the survival of korowai in Ngāti Maniapoto in a contemporary context [Mastter of Arts]. Auckland University of Technology.

Te Haika. (n.d.). Contact Te Haika / MHAIDS. Mental Health, Addictions and Intellectual Disability Services. Retrieved January 22, 2020, from http://www.mhaids.health.nz/our-services/doyou-or-does-someone-you-know-need-help-now/

The Karori Lunatic Asylum. (1862, February 20). The Karori Lunatic Asylum. Ref: MSDL-2063. Alexander Turnbull Library, Wellington, New Zealand. /records/32261300

The Terrace Gaol. (1908, September 4). Evening Post.

Thrift, N. (2004). Intensities of Feeling: Towards a Spatial Politics of Affect. Geografiska Annaler: Series B, Human Geography, 86(1), 57-78. https://doi.org/10.1111/j.04353684.2004.00154.x

Thrift, N. J. (2008). Non-representational theory: Space, politics, affect. Routledge.

Ulrich, R. S. (1984). View through a window may influence recovery from surgery. Science (New York, N.Y.), 224(4647), 420-421. https://doi.org/10.1126/science.6143402

Ulrich, Roger S., Simons, R. F., Losito, B. D., Fiorito, E., Miles, M. A., \& Zelson, M. (1991). Stress recovery during exposure to natural and urban environments. Journal of Environmental Psychology, 11(3), 201-230. https://doi.org/10.1016/S0272-4944(05)80184-7

UNFIT CASE FOR THE GAOL. (1913, July 1). Clutha Leader. Alexander Turnbull Library, Wellington, New Zealand. /records/33983950

Velarde, M. D., Fry, G., \& Tveit, M. (2007). Health effects of viewing landscapes - Landscape types in environmental psychology. Urban Forestry \& Urban Greening, 6(4), 199-212. https://doi. org/10.1016/j.ufug.2007.07.001 
Verderber, S. (2014). Residential hospice environments: Evidence-based architectural and landscape design considerations. Journal of Palliative Care, 30(2), 69-82. https://doi. org/10.1177/082585971403000202

Viggers, H., Howden-Champman, P., Day, P., \& Pearce, J. (2008). Community Profile and Description of Place:Taita and Naenae. (p. 124) [A report prepared for Housing New Zealand Corporation]. He Kainga Oranga/University of Otago.

Wellington Lunatic Asylum. (1881, April 16). Star. https://paperspast.natlib.govt.nz/newspapers/ TS18810416.2.22

What is Madlove? (n.d.). Madlove. Retrieved January 21, 2020, from http://www.madlove.org.uk/

White, R. (2018, July 2). Every New Zealander needs a third place. The Spinoff. https://thespinoff. co.nz/society/02-07-2018/every-new-zealander-needs-a-third-place/

Williams, A. (2007). Therapeutic landscapes. Ashgate.

Williams, M. W., Haarhoff, B., \& Vertongen, R. (2017). Mental Health in Aotearoa New Zealand: Rising to the Challenge of the Fourth Wave? 46(2), 7.

Williams, W. H. (1987). Out of mind, out of sight: The story of Porirua Hospital. The Hospital.

Wilson, C., Bungay, H., Munn-Giddings, C., \& Boyce, M. (2016). Healthcare professionals' perceptions of the value and impact of the arts in healthcare settings: A critical review of the literature. International Journal of Nursing Studies, 56, 90-101. https://doi. org/10.1016/j.jijnurstu.2015.11.003

Wratten-Stone, A. (2016). Kaupapa Māori models of psychological therapy \& mental health services: A literature review (First edition.). Te Whānau o Waipareira.

Zagorska, A. (2019). Madlove: A designer asylum. In The Handbook of Community Mental Health and Space: Community and Clinical Applications. Routledge.

Zimmerman, M., Morgan, T. A., \& Stanton, K. (2018). The severity of psychiatric disorders. World Psychiatry, 17(3), 258-275. https://doi.org/10.1002/wps.20569 